\section{Bridging the Gap between Structure and Properties in Nano-Particle Filled Polymers}

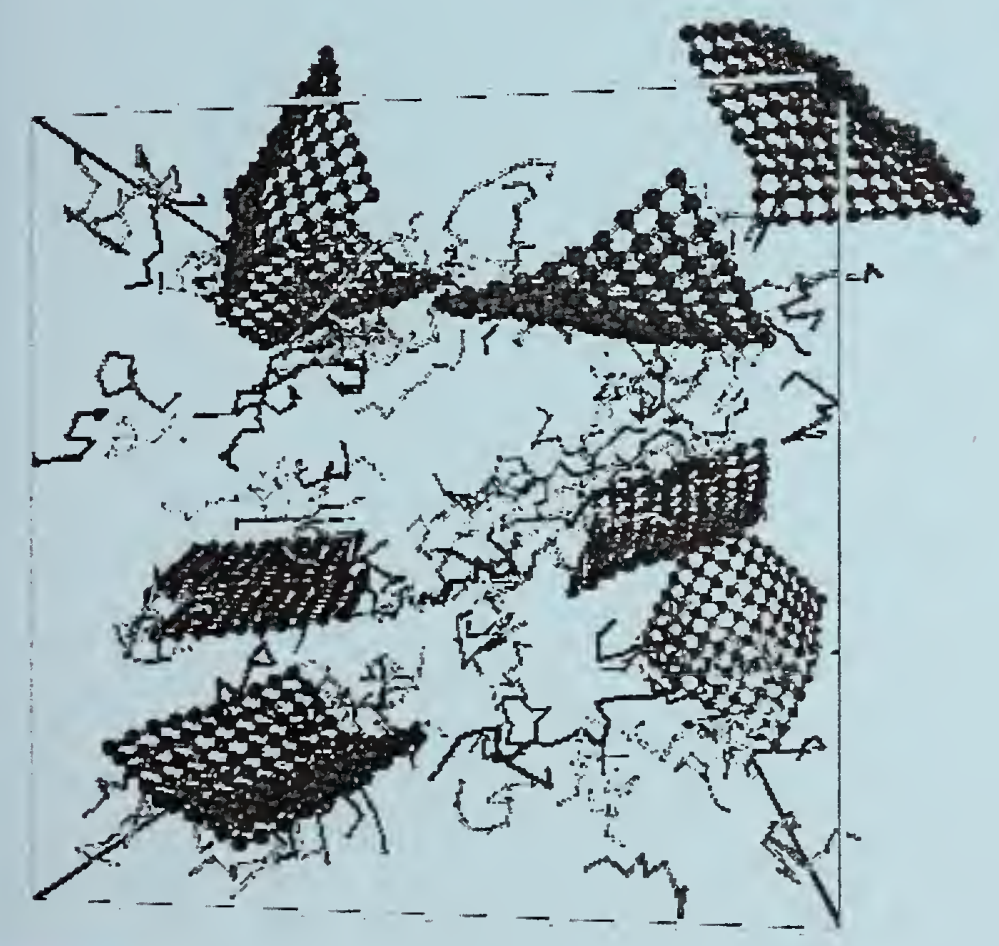

\section{Erik Hobbie Jack Douglas Francis Starr Charles Han}

U.S. DEPARTMENT OF COMMERCE Technology Administration National Institute of Standards and Technology

Gaithersburg, MD 20899-8910
$Q C$

100

.456

\#6893

2002

\section{NLT}

National Institute of Standards and Technology

Technology Administration

U.S. Department of Commerce 

Bridging the Gap between Structure and Properties in Nano-Particle Filled Polymers

\section{Erik Hobbie Jack Douglas Francis Starr Charles Han}

U.S. DEPARTMENT OF COMMERCE Technology Administration National Institute of Standards and Technology

Gaithersburg, MD 20899-8910

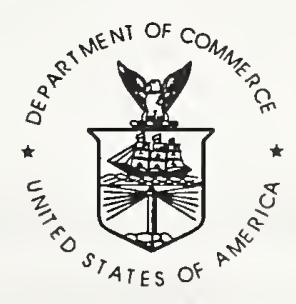

U.S. DEPARTMENT OF COMMERCE Donald L. Evans, Secretary

TECHNOLOGY ADMINISTRATION

Phillip J. Bond, Under Secretary for Technology

NATIONAL INSTITUTE OF STANDARDS AND TECHNOLOGY

Arden L. Bement, Jr., Director 


\title{
Bridging the Gap Between Structure and Properties in Nanoparticle-Filled Polymers
}

\author{
May 29-30, 2002
}

National Institute of Standards and Technology

Gaithersburg, MD

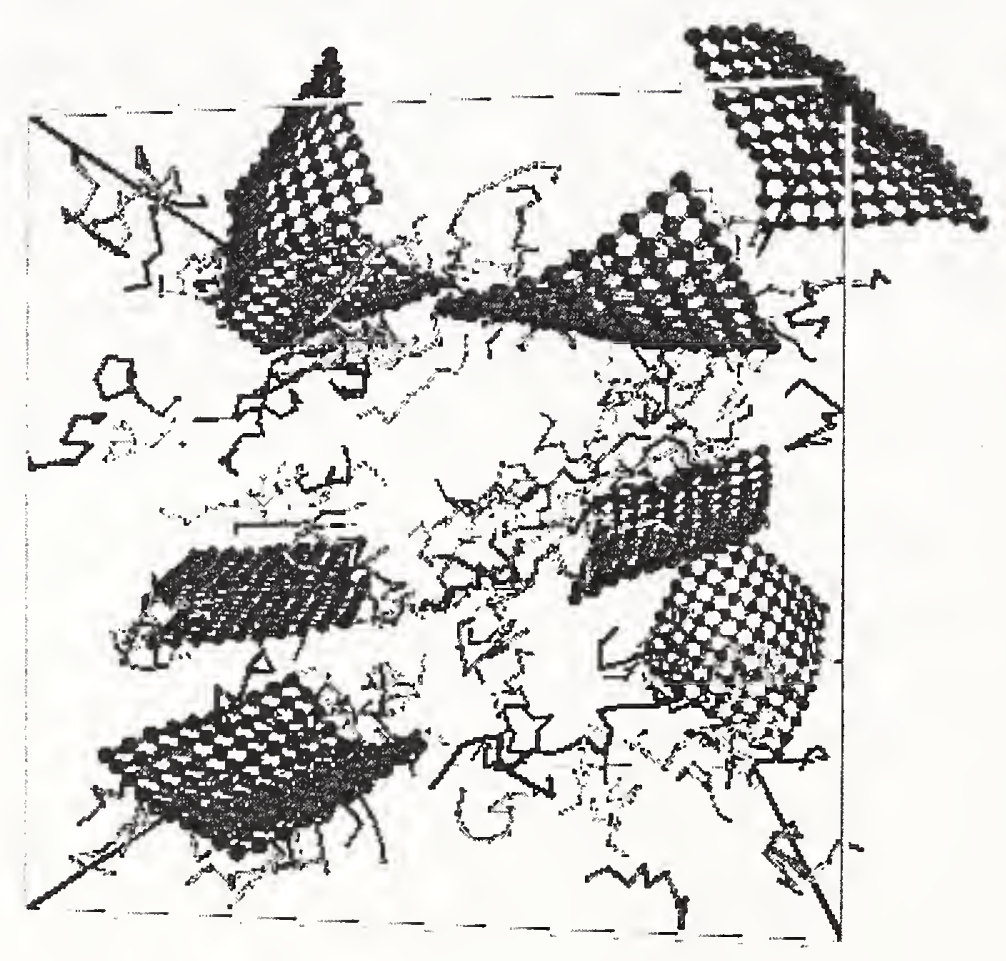

Organizers: Erik Hobbie

Jack Douglas

Francis Starr

Charles Han 


\section{Nanotechnology Workshop}

On May 29-30 of 2002, a workshop on polymer nanocomposites was held at NIST in Gaithersburg, Maryland. The workshop was entitled Bridging the Gap Between Structure and Properties in NanoparticleFilled Polymers and focused primarily on the interrelation between particle dispersion and the properties of polymers filled with clay and nanotube fillers. The purpose of the workshop was to identify research topics for NIST research and to initiate research collaboration with industrial and academic researchers in this important technological area. The workshop participants included a diverse mix of industrial, government and academic researchers.

This document reproduces the slides presented by the speakers of this workshop along with a few introductory remarks about each contribution. We would like to thank the contributors for providing the presentations that made the workshop a success.

1) Douglas Hunter, "The Effect of Extruder Processing on the Extent of Exfoliation in Clay-Polymer Nanocomposites"

2) Jeff Gilman, "Flame Retardant Polymer-Clay Nanocomposites"

3) Ramanan Krishnamoorti, "Melt Rheology of Polymer Nanocomposites"

4) Satish Kumar, "Processing, Structure, and Properties of NanoComposite Fibers and Films"

5) Alex Morgan, “Polypropylene Nanocomposites: Clay Organic Treatment Concentration Effects on Mechanical Properties, Flammability Properties and Clay Dispersion" 
6) Atsushi Takahara, "Structure and Mechanical Properties of Natural Inorganic Nanofiller / Polymer Hybrid"

7) R. A. Vaia, "Impact and Control of Ultrastructure (Meso) in Polymer Nanocomposites"

8) Francis W. Starr, "Probing Nanocomposite Structure and Properties Using Computer Simulations"

9) Juan J. de Pablo, "Molecular Simulation and Characterization of Ultrathin Films and Nanoscopic Polymeric Structures: Departures from Bulk Behavior"

10) Guoqiang Qian, "Applications of Plastic Nanocomposites"

11) Eric A. Grulke, 'Production, Dispersion and Applications of Multiwalled Carbon Nanotubes"

12) Ken McElrath and Tom Tiano, "Achieving Conductive Polycarbonate with Single Wall Carbon Nanotubes" 


\section{U.S. Government and Nanotechnology}

Nanotechnology holds the promise to dramatically change many aspects of the world in which we live. The range and scope of the potential economic and societal benefits from nanotechnologies is so staggering it has been called the "Next Industrial Revolution". Recognizing the large potential for nanotechnologies, the FY2001 Federal Budget included support for a major new initiative on nanotechnology. The National Nanotechnology Initiative (NNI) was established by the U.S. Government to promote longterm nanoscale research and development leading to potential breakthroughs in areas ranging from materials and manufacturing to biotechnology and agriculture to national security and Defense, and many others. The NNI creates a research infrastructure by coordinating activities such as fundamental research, Grand Challenges (which will be described later), and centers and networks of excellence, activities that are all potentially high payoff and broadly enabling. The NNI evolved from publications authored by the Interagency Working Group on Nanoscience, Engineering and Technology (IWGN), and is currently supported and monitored by the IWGN's successor, the Subcommittee on Nanoscale Science, Engineering, and Technology (NSET). In FY 2001, the total investment by the NSET agencies in nanotechnology was estimated to be $\$ 422$ million, of which NIST has invested approximately $\$ 13.5$ million.

The NNI exemplifies the government's critical role in promoting the development of new science and technology. For clarity's sake, we should first consider what types of things we define as nanotechnology. Ask any scientist, engineer, or layperson for a definition of nanotechnology, and you will most likely receive a very different answer. In many cases, it is 
considered hard to define; like good art, most people "know it when they see it" but have difficulty explaining it in general. Thus, we use the definition of nanotechnology given by the NSET:

Nanotechnology is defined as the ability to work at the atomic, molecular or macromolecular levels, in the length scale of approximately 1 $100 \mathrm{~nm}$ range, in order to create, manipulate and use structures, devices and systems that have novel properties and functions because of the small size. The novel and differentiating properties and functions are developed at a critical length scale of matter typically under $100 \mathrm{~nm}$. Nanotechnology includes integration of nanoscale structures into larger material components, systems and architectures that are used in most industries, health care systems, environment and national security. Within these larger scale devices, the control and construction of the devices remains at the nanoscale. In some particular cases, the critical length scale for novel properties and phenomena may be under Inm (e.g., manipulation of atoms at $\sim 0.1 \mathrm{~nm}$ ) or be larger than $100 \mathrm{~nm}$ (e.g., nanoparticle reinforced polymers have the unique feature at 200/300nm as a function of the local bridges or bonds between the nanoparticles and the polymer).

It is critical that the Federal government is involved at this stage in the development of nanotechnology, since "the necessary fundamental nanotechnology research and development is too broad, complex, expensive, long-term, and risky for industry to undertake." Industry is unable to fund or is under-funding critical areas of long-term fundamental research and development and is not developing the necessary nanoscience technologies needed to realize nanotechnology's potential.

In supporting the NNI, the participating agencies fund the NNI recommended $R \& D$ priorities as a function of their mission, contingent on 
available resources. The stated goals of the NSET involve developing a... ...coherent approach for funding the critical areas of nanoscience and engineering, establishing a balanced and flexible infrastructure, educating and training the necessary workforce, and promoting partnerships to ensure that these collective research activities provide a sound and balanced national research portfolio. By facilitating coordination and collaboration among agencies, the NNI will maximize the productivity and utility of the Federal government's investment in nanotechnology and avoid unnecessary duplication of efforts. 


\section{Nanotechnology and NIST Polymers Division}

Exfoliated clay and carbon nanotube materials can be considered to be two-dimensional polymeric materials, and the Polymers Division at NIST is in a good position to provide essential characterization information and to study the essential physics of this important class of materials, building on former work on conventional polymeric materials.

Similarly to high molecular weight blends, it is difficult to form stable dispersions of clay and nanotubes in polymer matrices. Dispersion is usually a matter of degree and this has a tremendous impact on the properties of polymeric materials filled with these additives. These materials raise many measurement challenges since the dimensions of these particles bridge molecular and colloidal particle scales so that characterization requires an array of techniques. Characterization is also made difficult by the complexity of the materials that depend on their source and processing history. It is clearly important to identify model systems allowing reproducible and meaningful measurement and measurement methods addressing more general questions (dispersion, interparticle interaction) and processes (phase separation, particle clustering). Simulation must play an important role in understanding these systems and the multi-scale physics involved. The workshop was intended to help focus these efforts. 


\section{Workshop Presentations}

1) Douglas Hunter, "The Effect of Extruder Processing on the Extent of Exfoliation in Clay-Polymer Nanocomposites" [PowerPoint] [PDF]

Dr. Hunter emphasized the importance of process conditions on the properties of exfoliated clay materials. Several screw extruders were investigated and the influence of residence time and position of the claypolymer extrudate was considered in relation to the extent of clay exfoliation. The processing history and screw geometry was shown to have a pronounced effect on the state of dispersion and a hierchical dispersion model was introduced to rationalize these results. The importance of combining chemical treatment with processing to achieve good dispersion was emphasized. High shear intensity was found to be not necessarily beneficial for dispersion, but long residence times in the extruder normally has a positive effect on the relative dispersion. One of the general philosophical questions raised by this talk is the need for a better understanding of the role of shear on mixing processes and clustering in colloidal systems. 


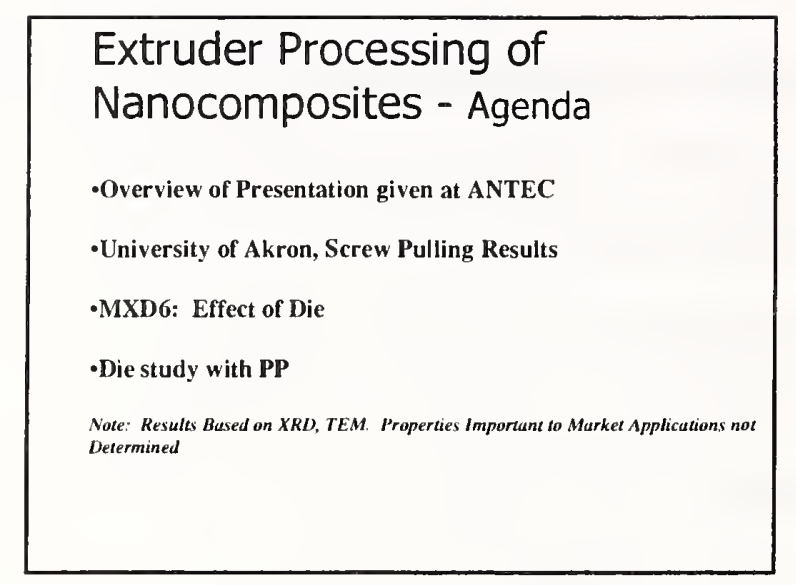

The Processing Challenge
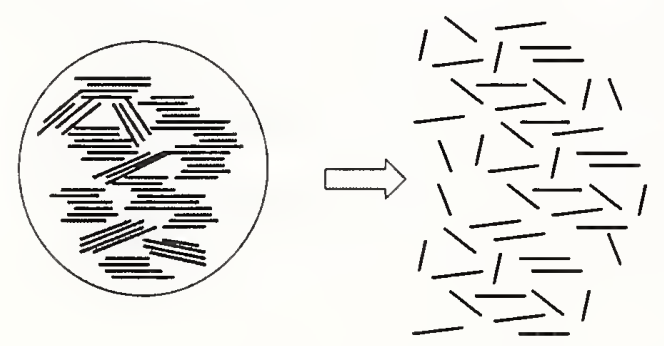

$8 \mu \mathrm{m}$ Particle
$>1$ Million Platelets
Processing Nanocomposites

Critical objectives of the presentation

- Process parameters as important as the choice of clay.

- Online monitoring of exfoliation can be deceptive - consideration needs to be given to the "die" effect.

\section{Nanocomposite Processing}

Antec

- Objective: establish the significance of processing.

- Multiple extruders and screw configurations.

- PA6 with Cloisite 15A, not exfoliate and Cloisite 30B, exfoliate.

\section{Single and Co Rotating Screws}

Killion Single Screw

20

Japan Steel Works Co Rotating Twin Screw

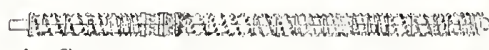
Low Shear

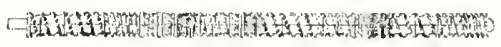
Medium Shaar
Leistritz Counter Rotating Intermeshing

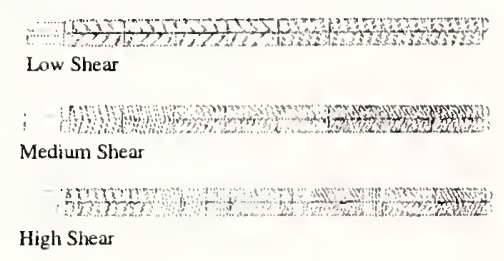



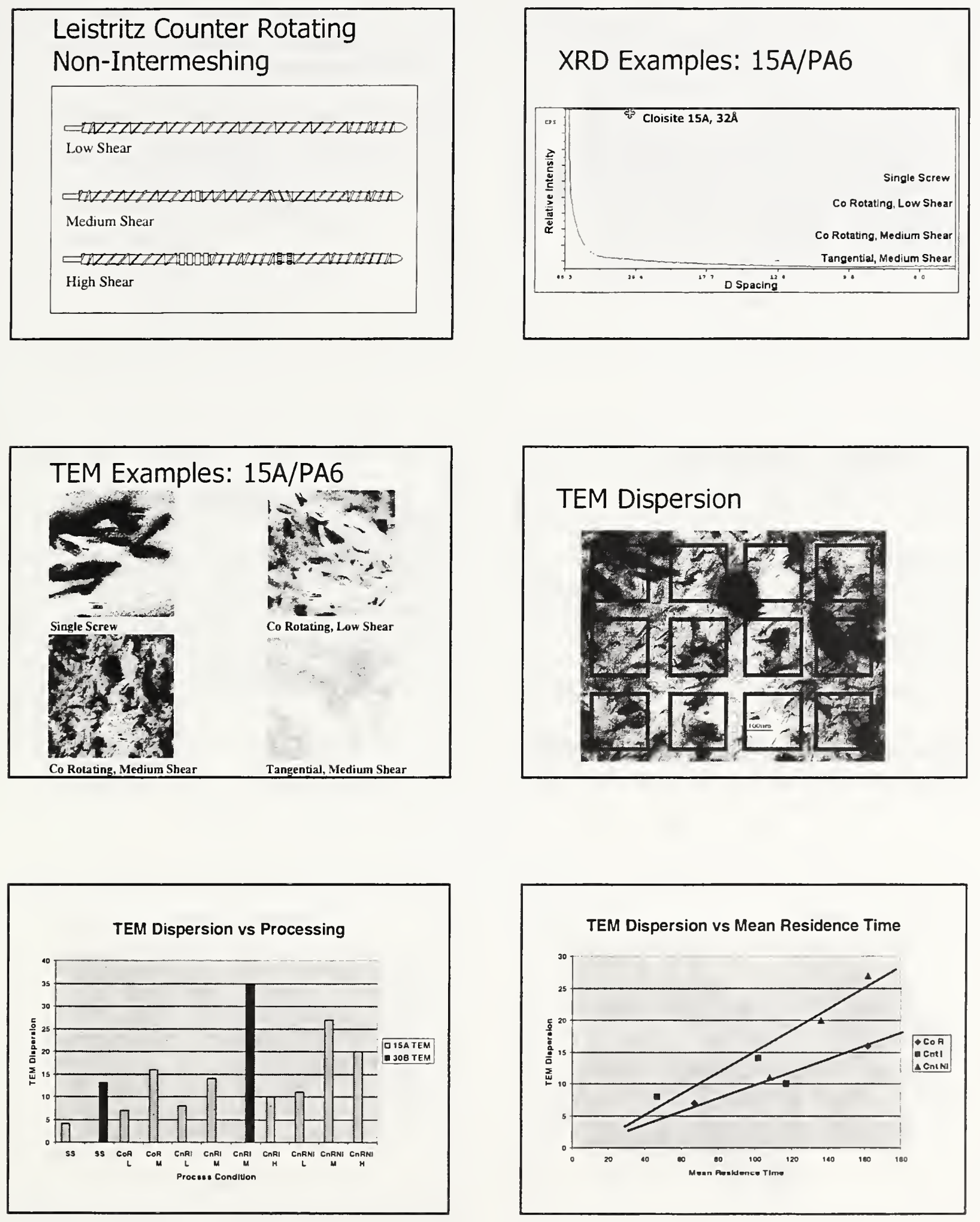


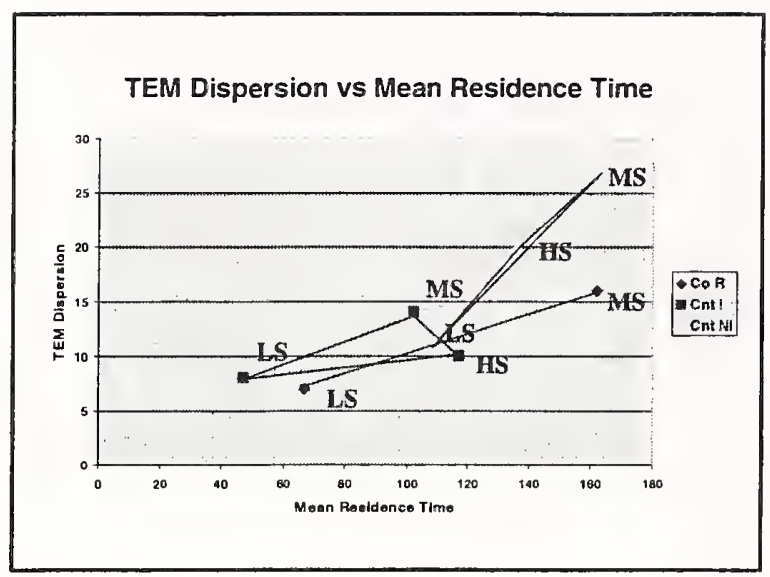

TEM Dispersion - Variance -

Mean Residence Time
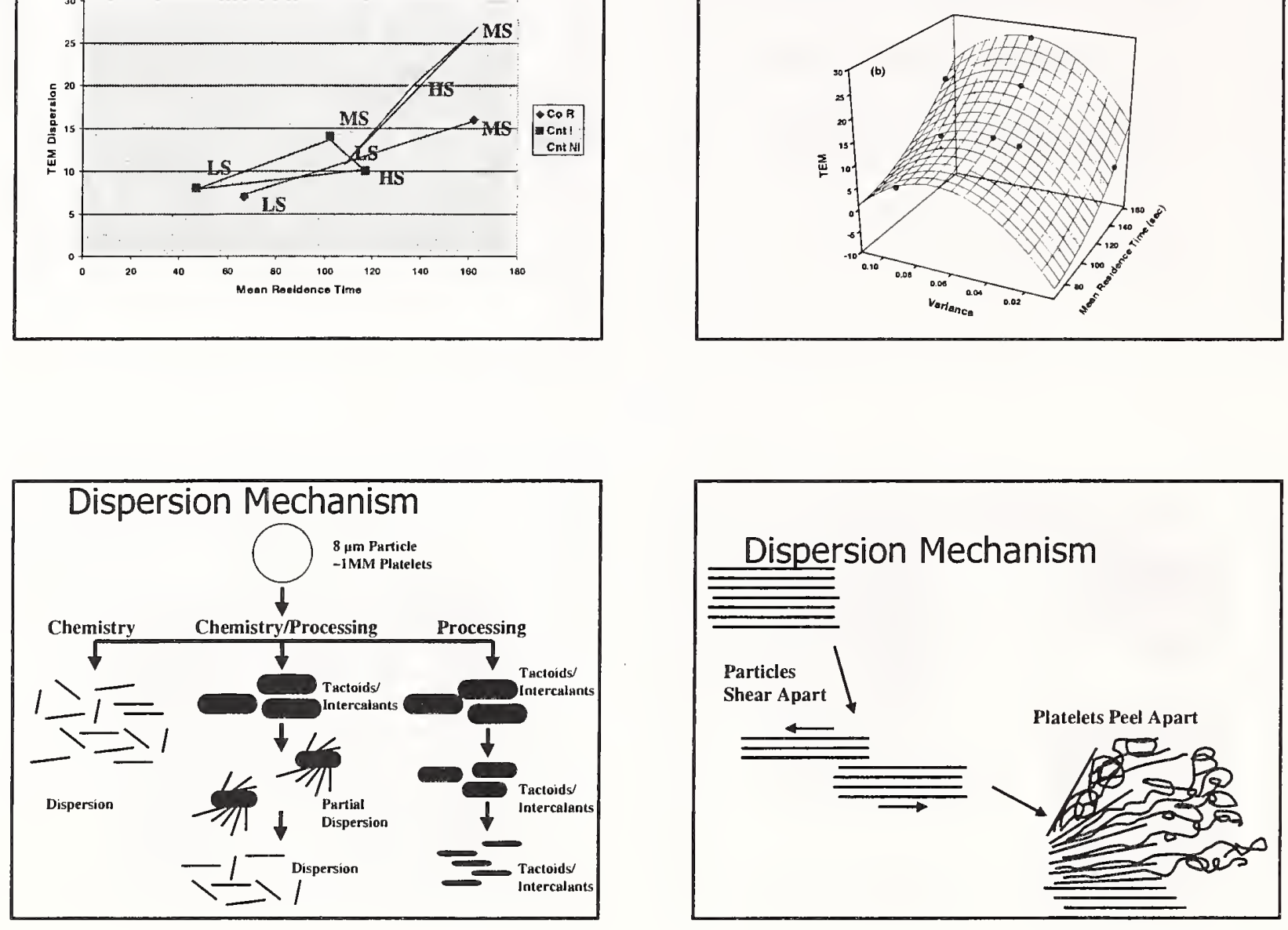

\section{Dispersion:}

Particles Shear Apart - Platelets Peel Apart
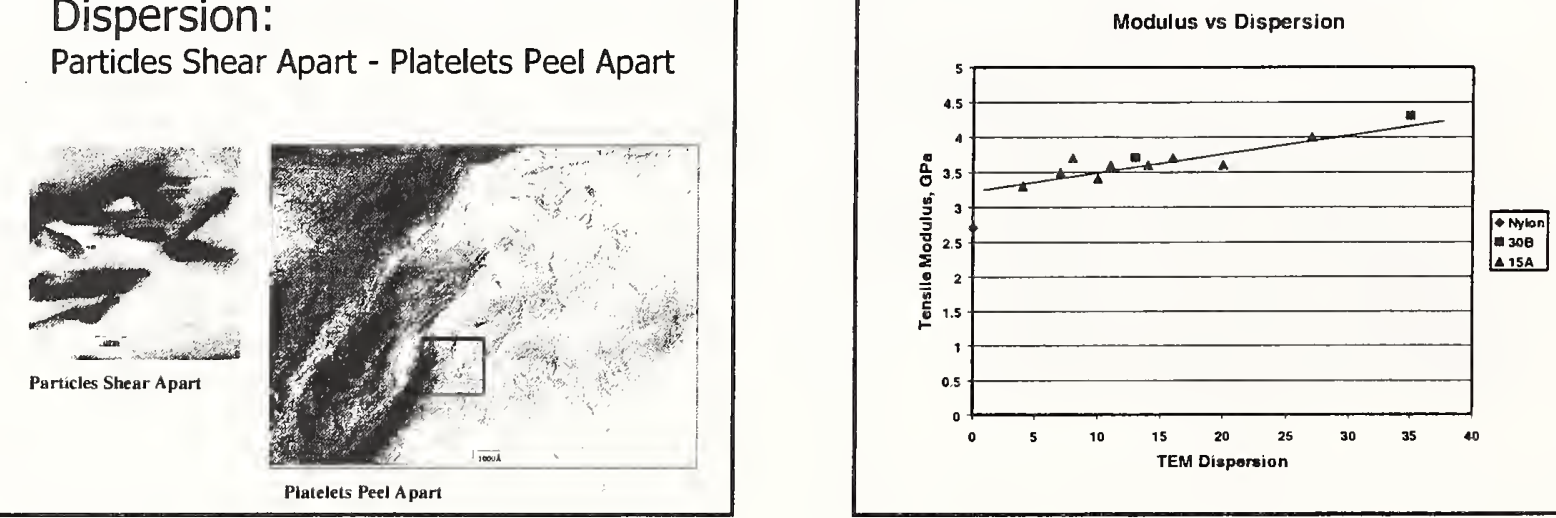


\section{Conclusions}

-To Optimize Dispersion: Clay Treatment \& Processing

-Longer Residence Time Important, Not only Variable

-Dispersion not Simply a Function of Shear Intensity

-Particles Shear Apart

-Platelets Peel Apart to Disperse

\section{Exfoliation not limited to extruder processing}

- Buss Kneader

- Brabender

- Banbury

- 2 Roll mill

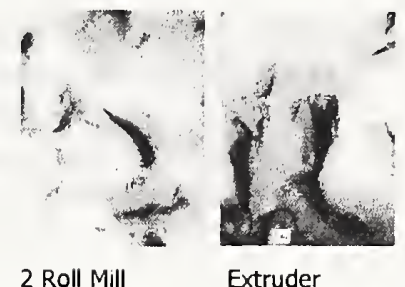

Extruder
Different Resin, JSW 5kg/hr/200rpm Alloy

Screw Pulling University of Akron

-Nanocomposites PA6/15A \& PP/MAPP/15A

-Vary Screw Design

-Vary Process Conditions

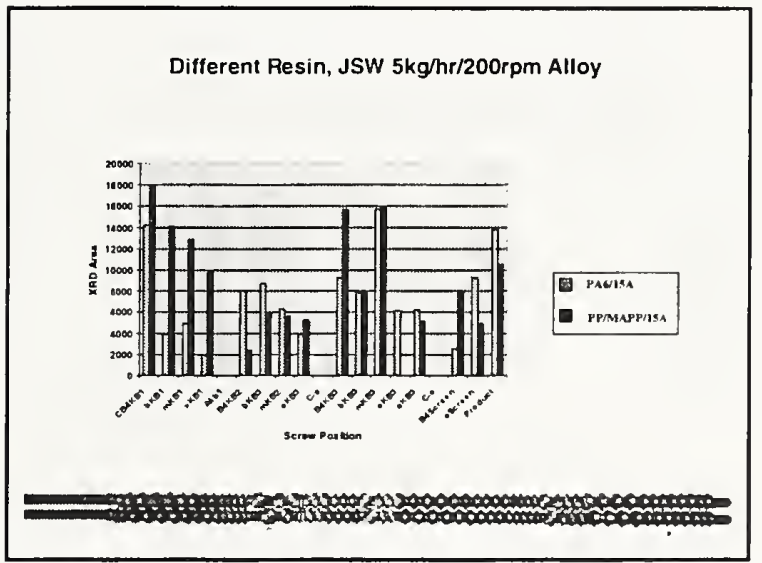

TEM Micrographs Pull Screw PA6-Cloisite 15A -JSW Alloy

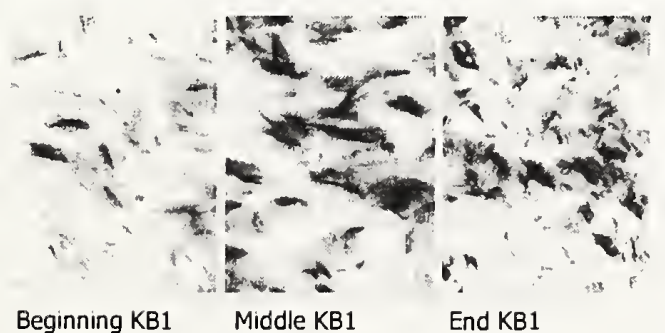

TEM Micrographs Pull Screw PA6-Cloisite 15A -JSW Alloy

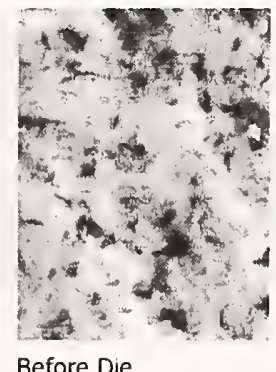

Before Die

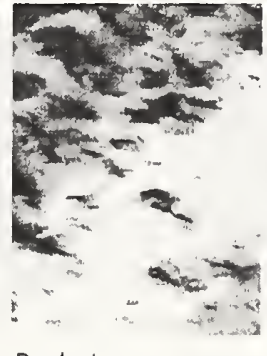

Product 


\section{Conclusions}

- Screw Design Important

- Process Conditions Important

- Possible to have the Optimum Design with Only Part of Screw

- What is the die effect?
Effect of Die: MXD6 Study

-Two Organoclays, Cloisites 30B and 93A

-Clay Fed Downstream

-Multi-Kneading Block Screw

-Past Experience, Screw Should Work

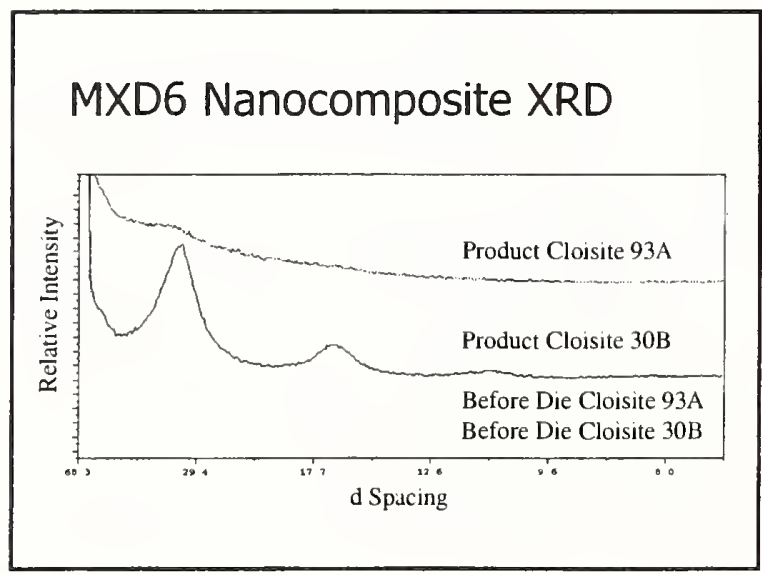

TEM MXD6 Nanocomposite

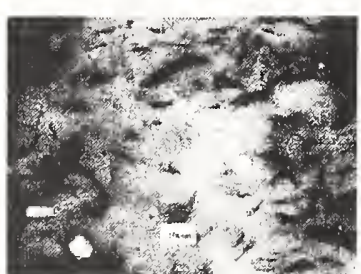

Cloisite 93A Before Die

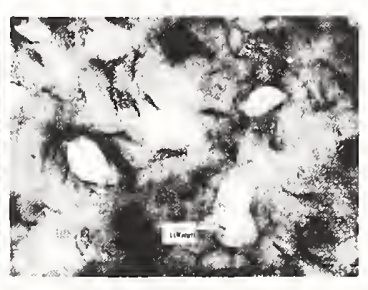

Cloisite 93A Product

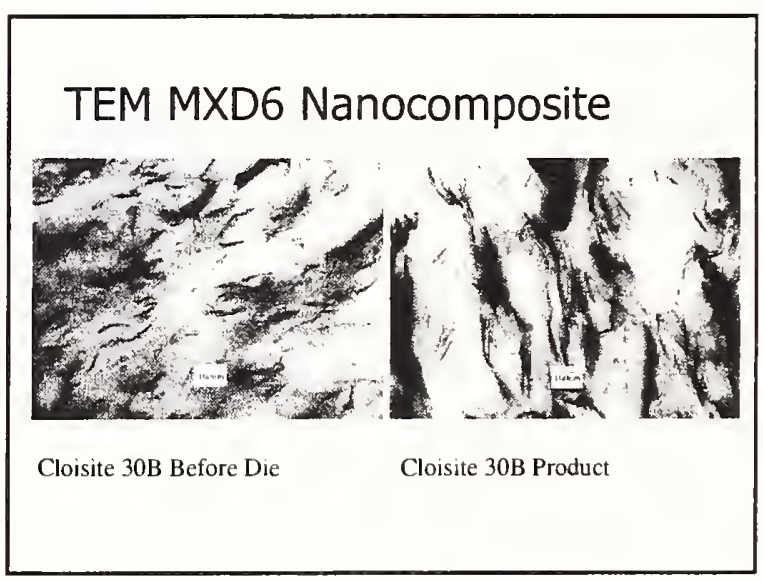

\section{Conclusions}

- Nanocomposite Sheared In Die

- Propose Results Controlled by Resin/Clay Treatment Compatibility

- Less Compatible Nanocomposite, Platelets Align - See in XRD and TEM

- Die Hole Size Problem?

- Possible Solution: Larger Die Hole 
Vary the Die Hole Diameter PP/MA-g-PP/Cloisite 20A

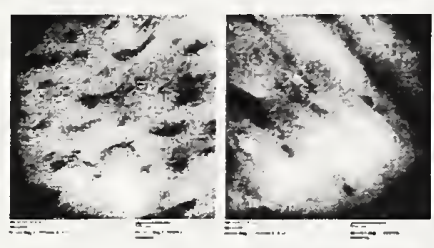

6 hole $1 \mathrm{~mm}$

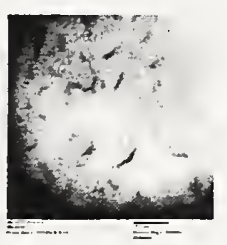

no die plate

\section{Extruder Monitoring Exfoliation}

- Assume slip stream to analysis tool

- Consider effect of shear in lines and analytical tool

- Platelet alignment during analysis alter results of the analysis 
2) Jeff Gilman, "Flame Retardant Polymer-Clay Nanocomposites" [PowerPoint] [PDF]

Dr. Gilman first stressed the human cost of home fires and the alternatives that exist for making flame retardent polymers. The challenge was indicated to be the development of environmentally friendly and economical approaches to reduce flammibility and the simultaneous improvement of the mechanical properties of the polymer-based materials. Clay nanocomposites were shown to be promising as fire suppressant agents due to the clay reinforcement of the char formed in the course of burning. Degradation issues of these materials under processing conditions were discussed and the advantages of combinatoric flammability tests were discussed in connection with optimizing and understanding the complex parameter space governing these complex materials. 

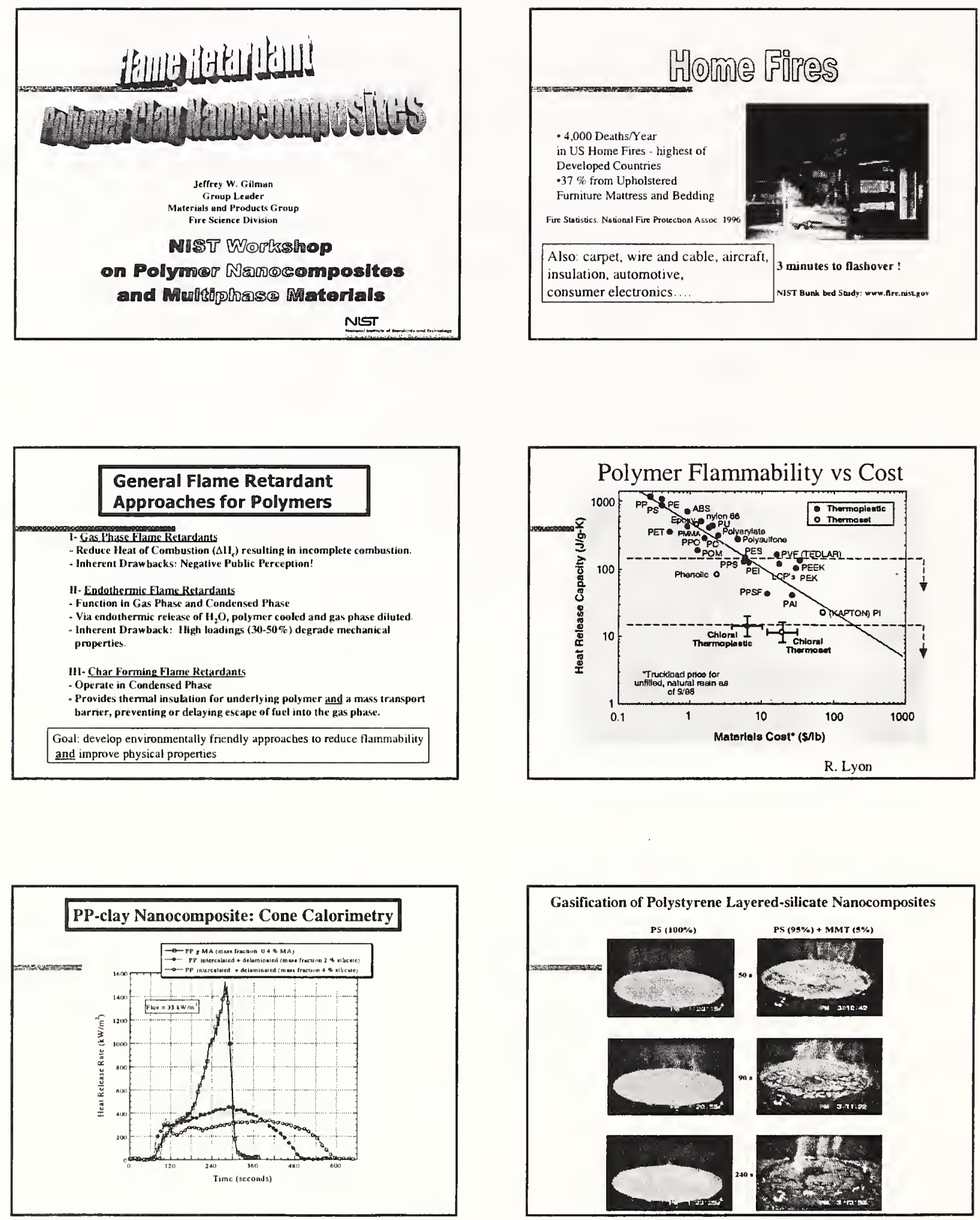

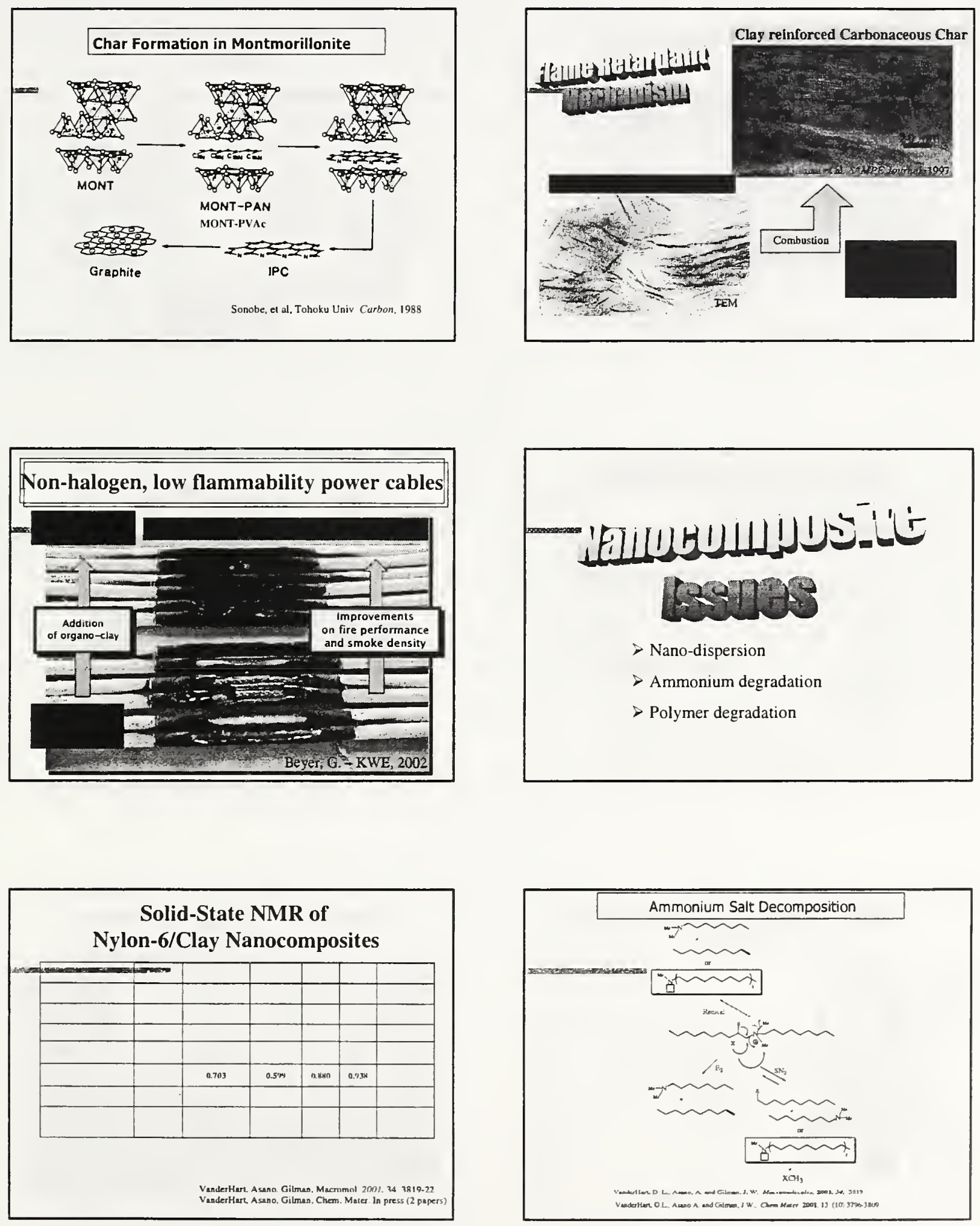

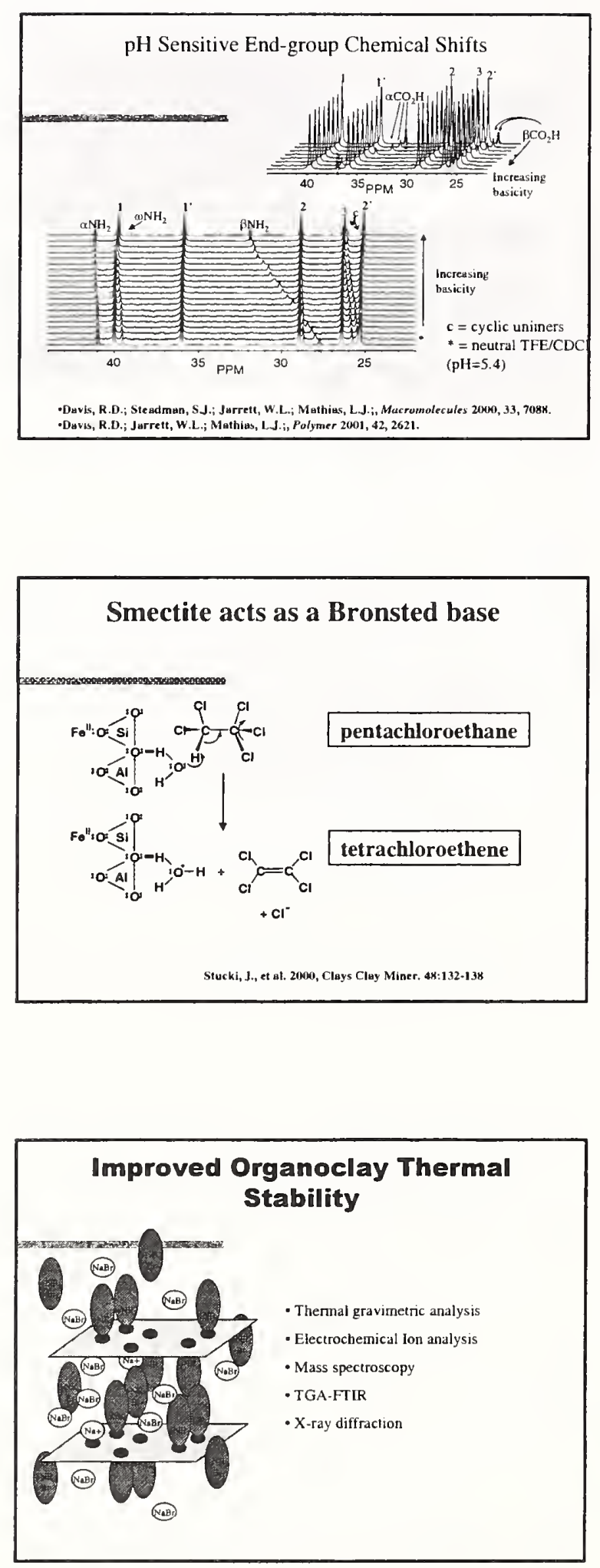

\begin{tabular}{|c|c|c|c|c|c|}
\hline \multicolumn{6}{|c|}{ Nylon 6 and Nylon 6/MMT } \\
\hline \multirow[t]{2}{*}{ Polyrner } & \multirow[t]{2}{*}{ M. (w/mole) } & \multirow{2}{*}{ 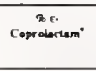 } & \multicolumn{3}{|c|}{ End-groups" } \\
\hline & & & Fomine & sated & $x_{\Delta} \Delta$ \\
\hline PA-6as recerved & $\begin{array}{c}13622 \pm \\
-1244 \\
-144\end{array}$ & 0.00 & 0.83 & 0.83 & 0.001 \\
\hline $\begin{array}{l}\text { PA-6injection } \\
\text { rmolded }\end{array}$ & $\begin{array}{l}12311 \pm \\
1489\end{array}$ & 0.92 & 0.92 & 0.92 & 0.00 \\
\hline $\begin{array}{l}\text { Nenoremposite } \\
\text { a recerived }\end{array}$ & $\underset{13672 \pm}{1544}$ & 0.19 & 0.83 & 0.83 & 0.60 \\
\hline $\begin{array}{l}\text { Numeramposite } \\
\text { injecrion malderd }\end{array}$ & $6321 \pm 334$ & 3.80 & 0.83 & 1.79 & 53.4 \\
\hline \multicolumn{6}{|c|}{-uncertainty $(20) \pm 0.1 \%$} \\
\hline \multicolumn{5}{|c|}{ What is the affect on properties? } & \\
\hline \multicolumn{6}{|c|}{ Duvis, R, Gilmun, J., Polym. Deg \& Slab, submutted } \\
\hline
\end{tabular}
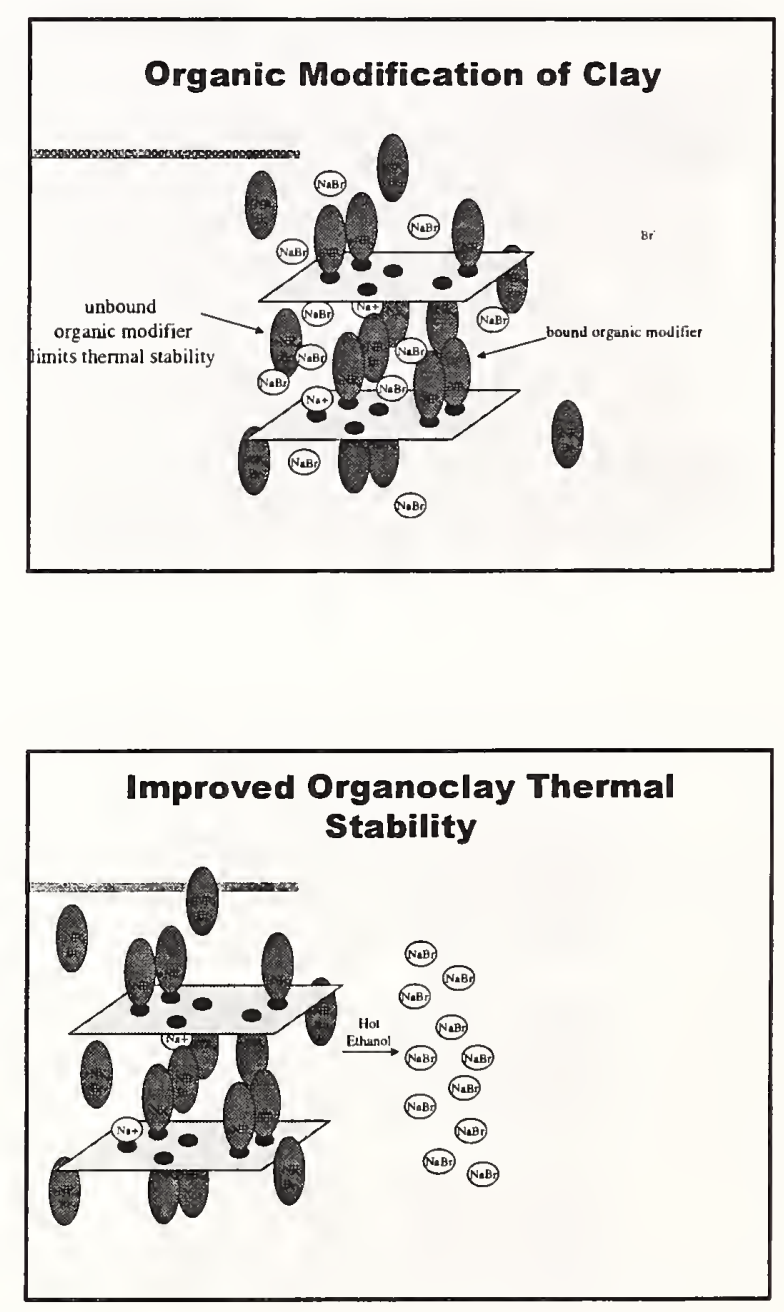

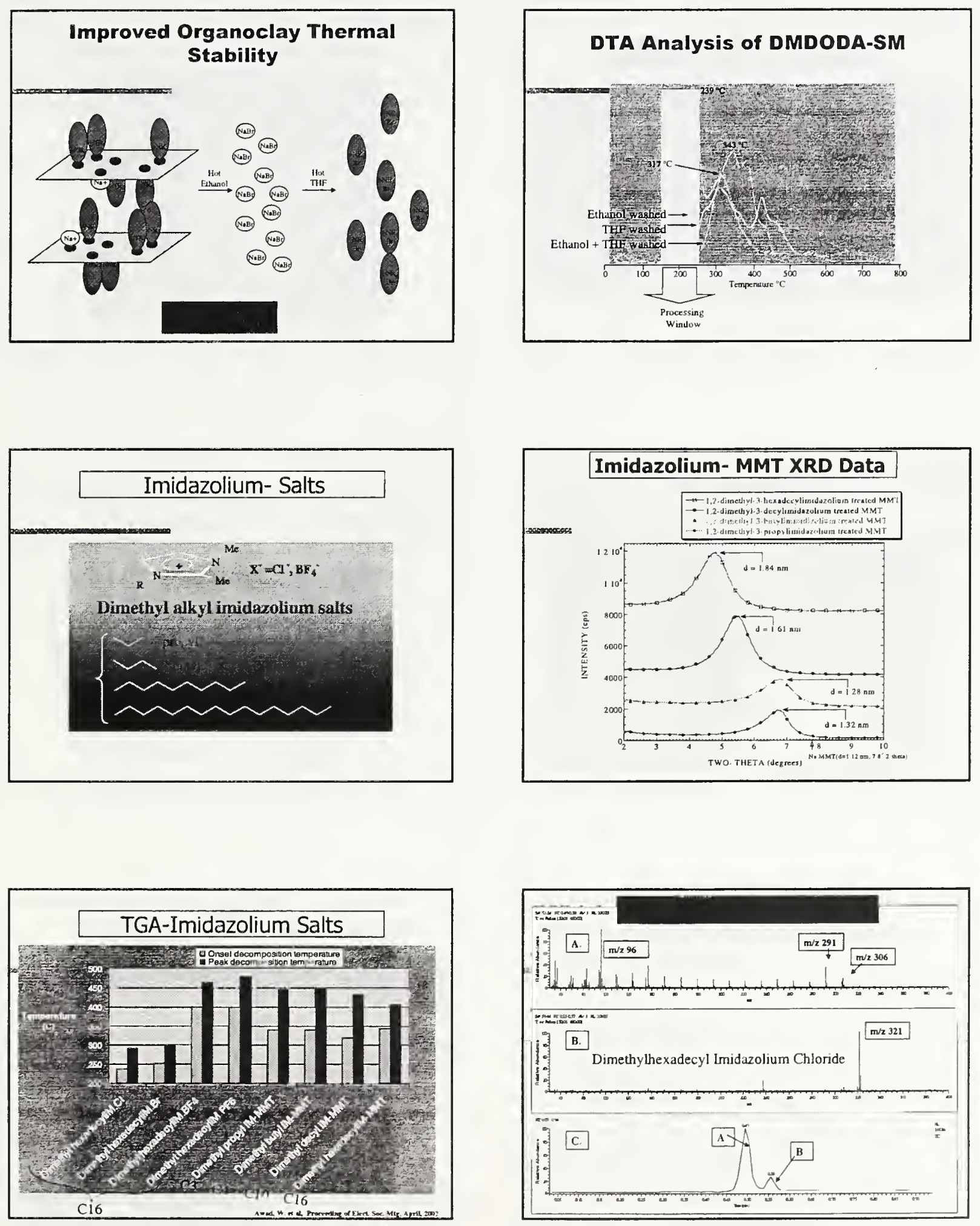


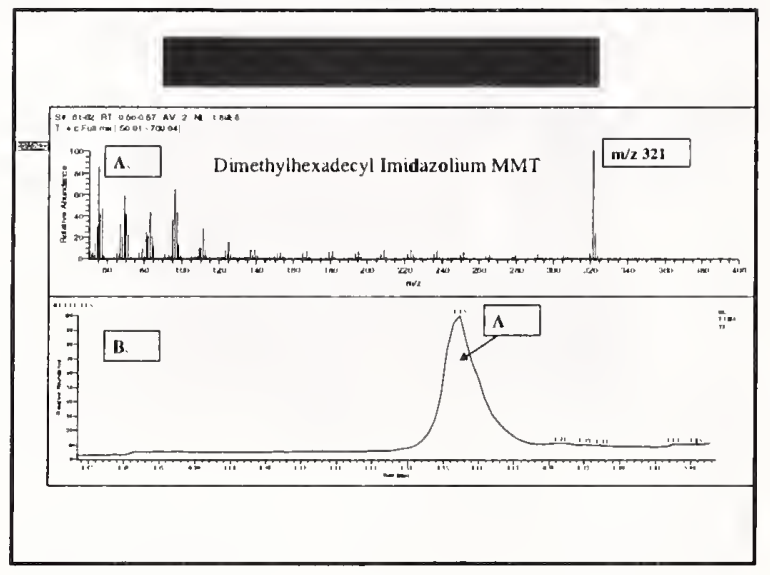

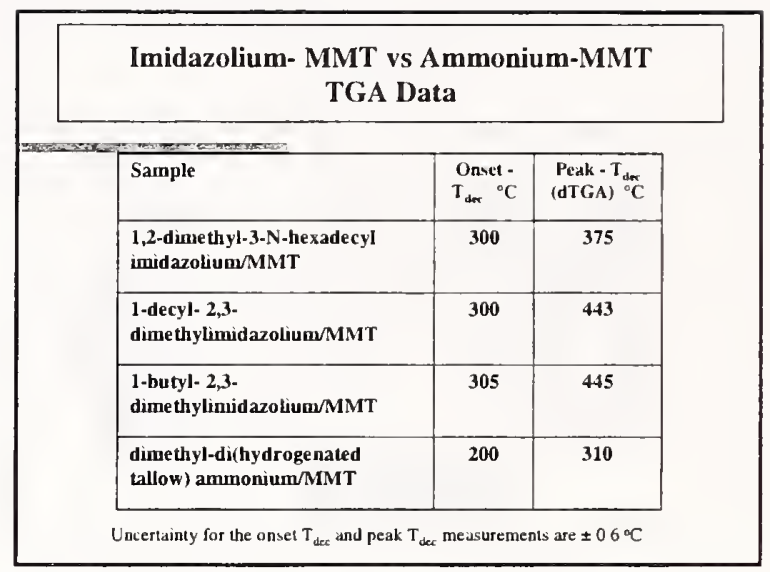
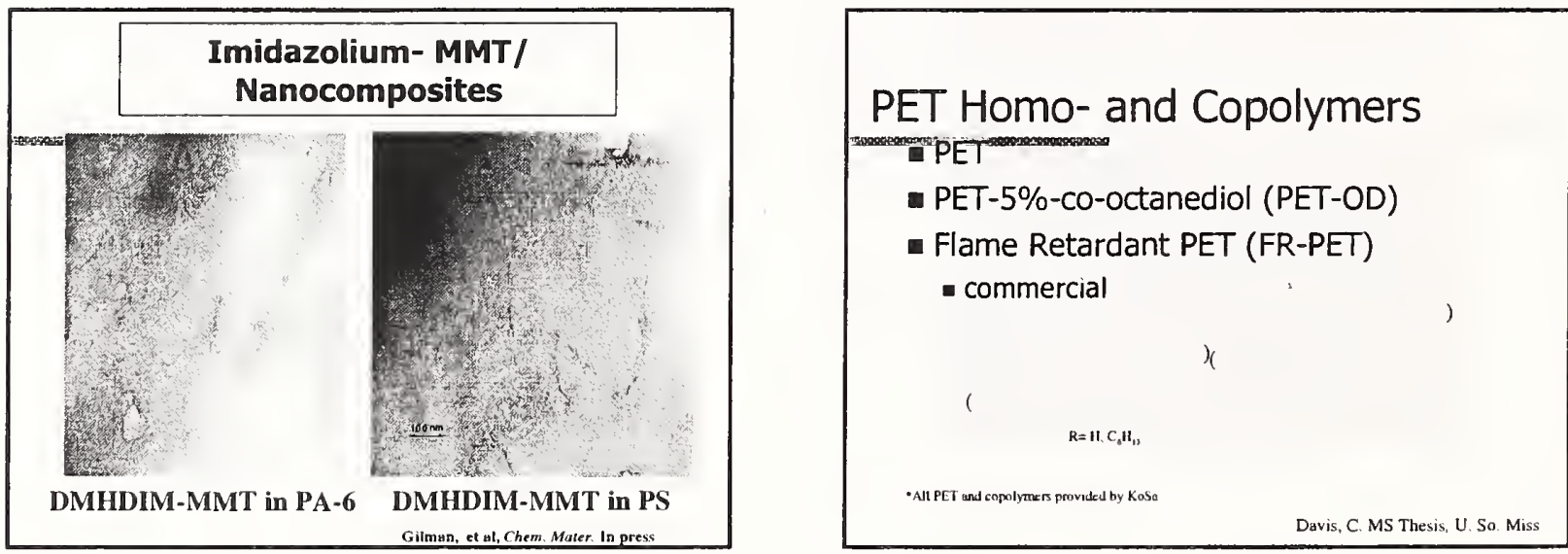

Effect of Varying Imidazolium Organic Modifier
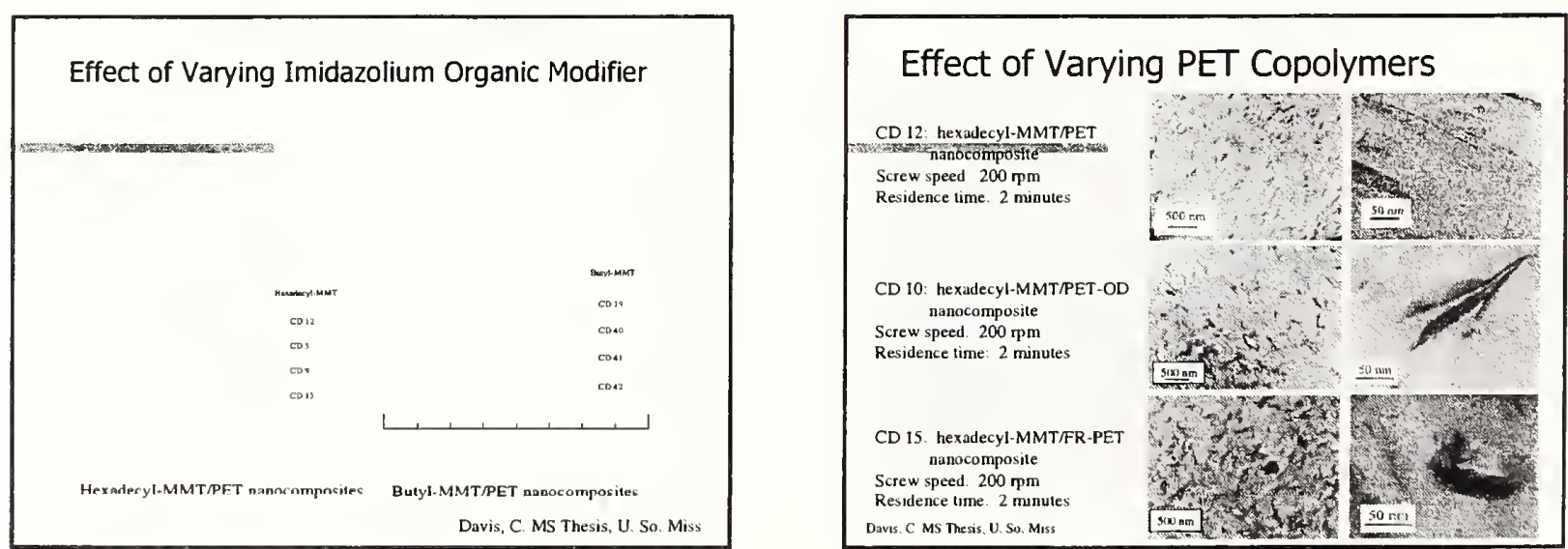


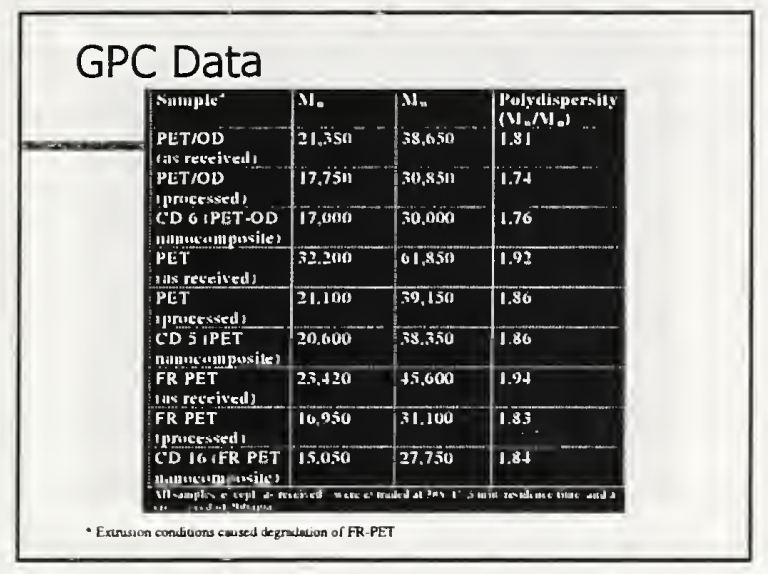

High-Throughput Methods: The Approach
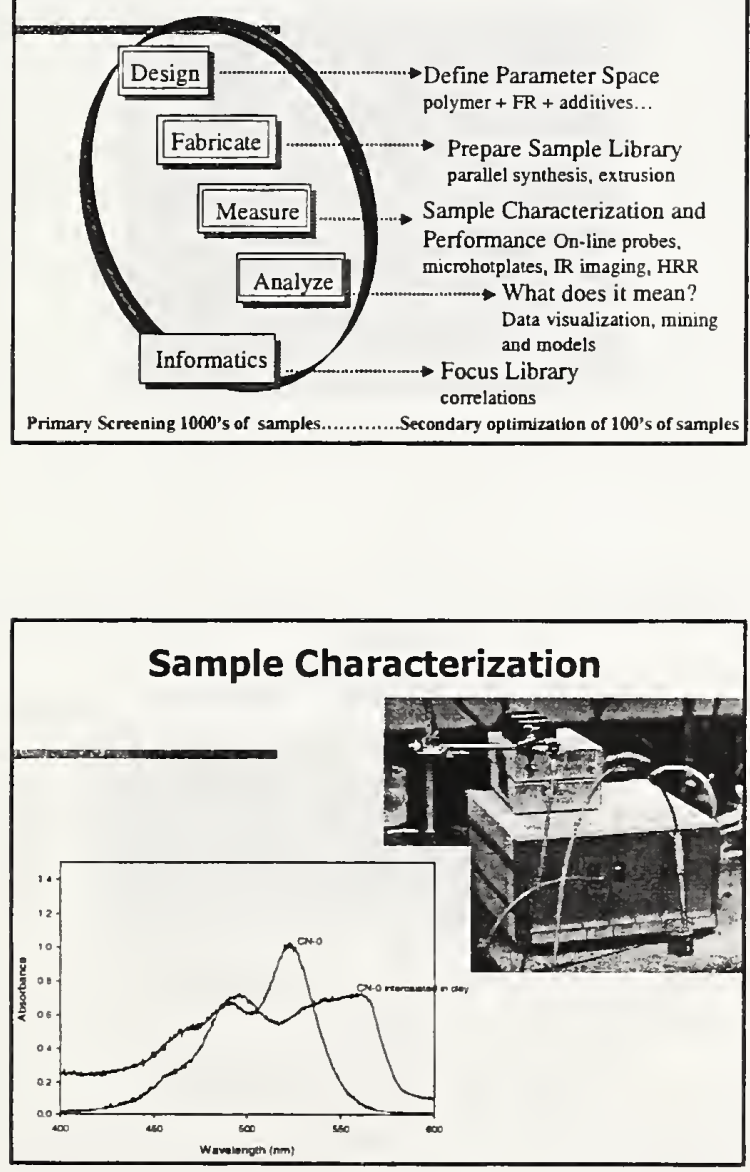

Parameter Space for Polymer Nanocomposites

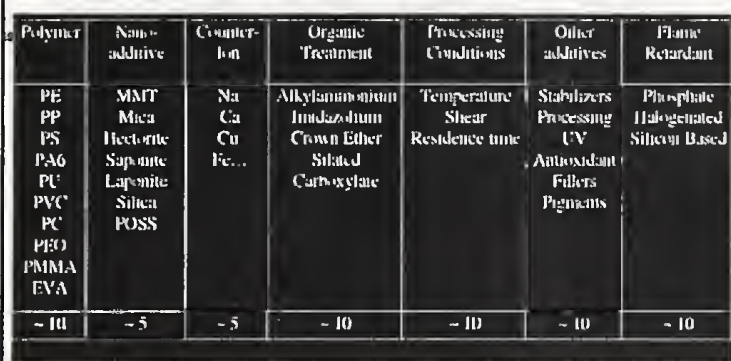

( $-10^{6}$ Experiments)

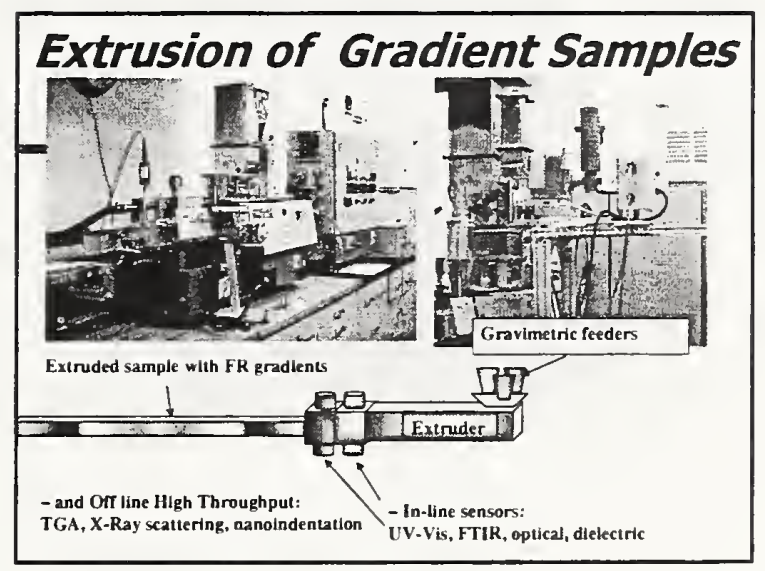

Fluoreneyl-benzimidazolium Layered Silicate.

- The fluoreneylbenzimidazolium LS (FBIM-LS) will be evaluated as an intercalated sensor for monitoring exfoliation.

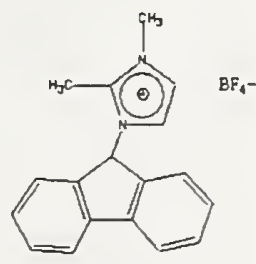



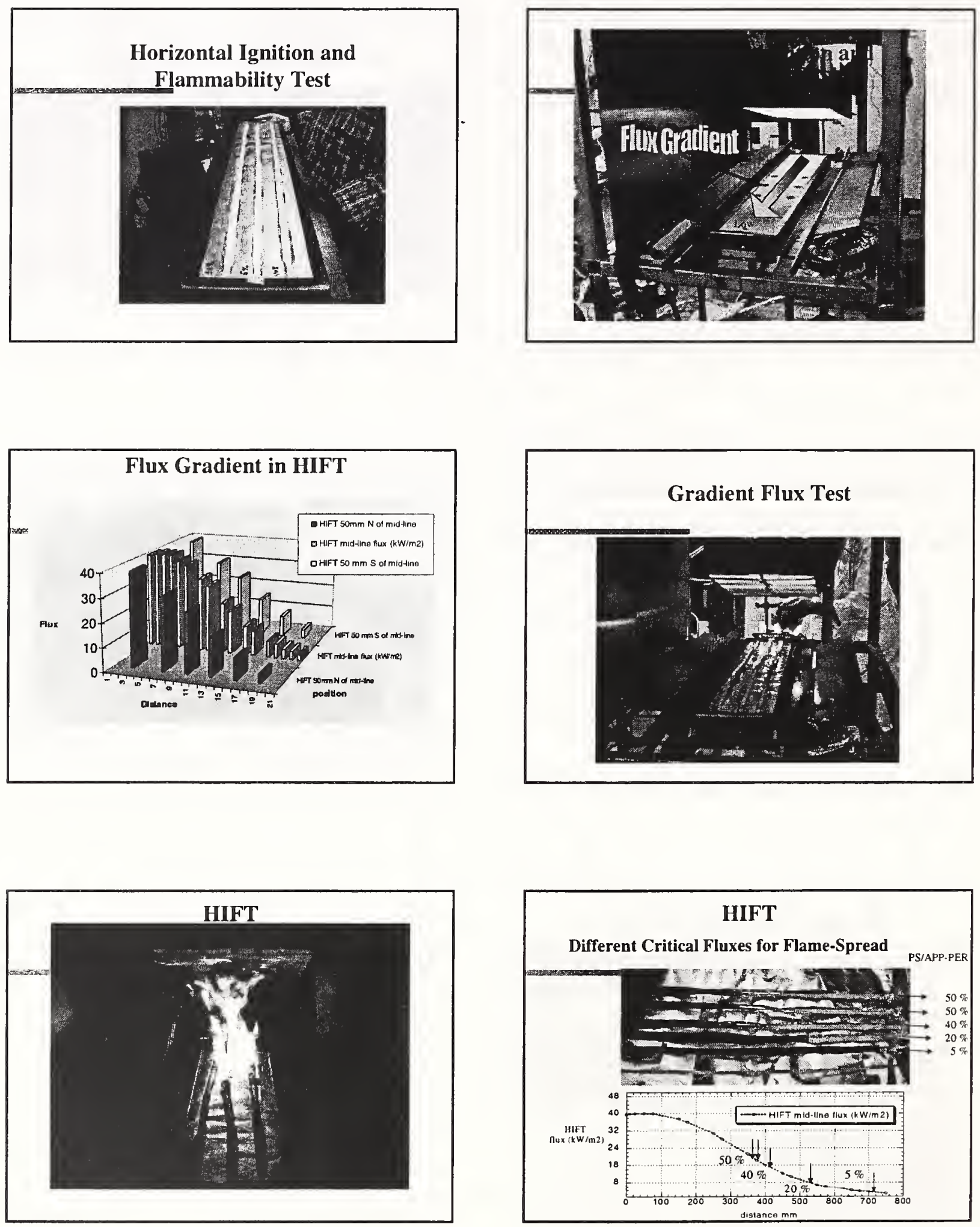

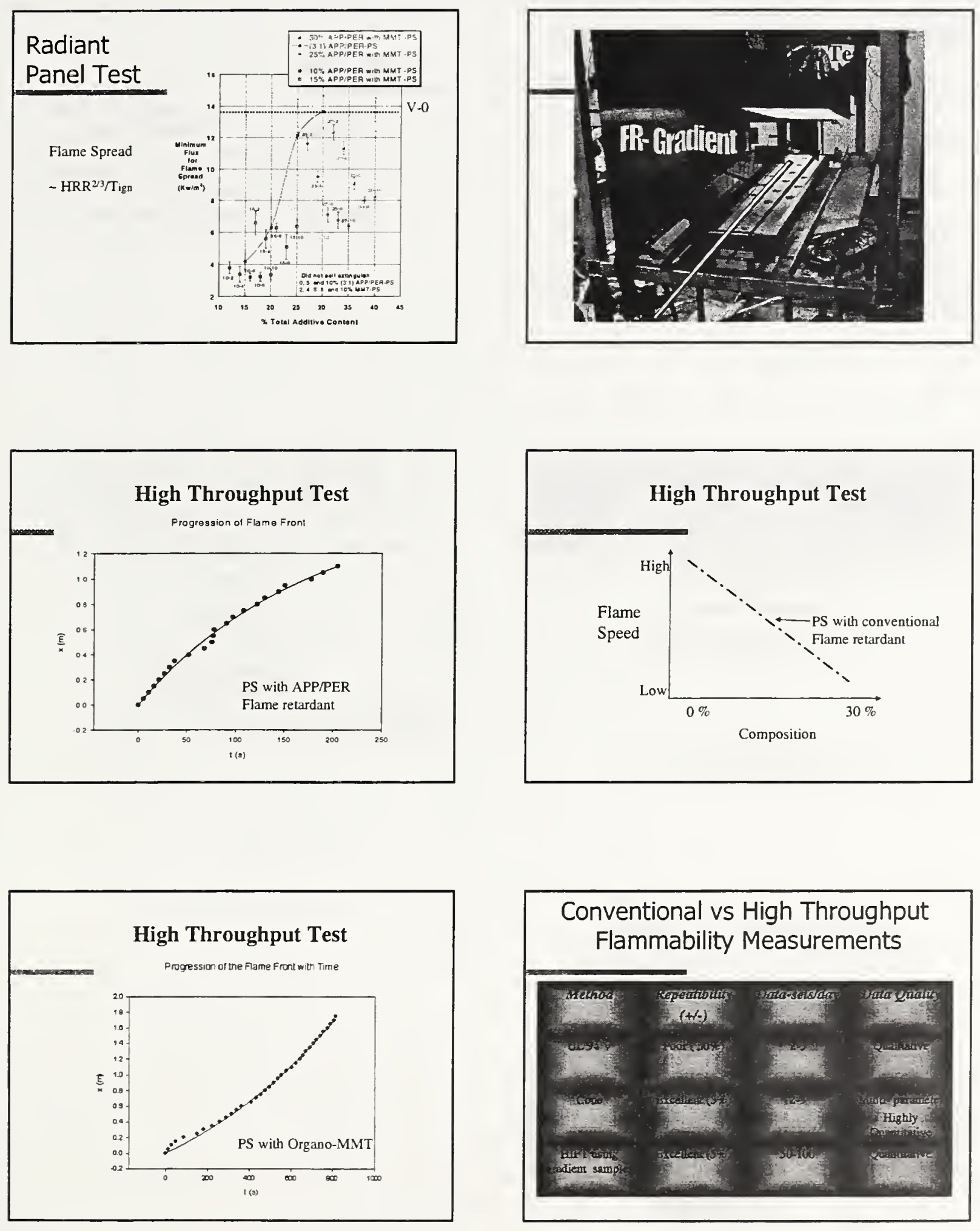

Conventional vs High Throughput Flammability Measurements

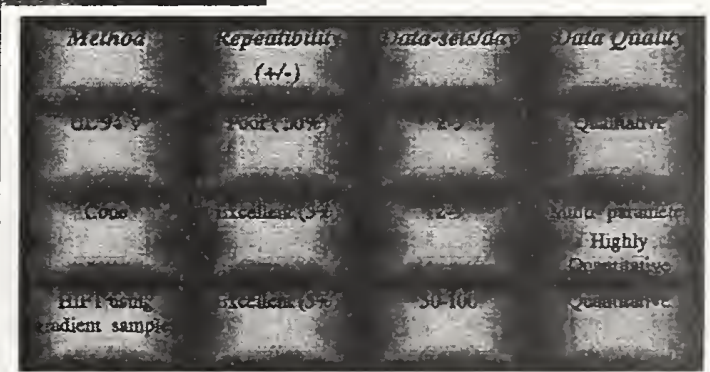



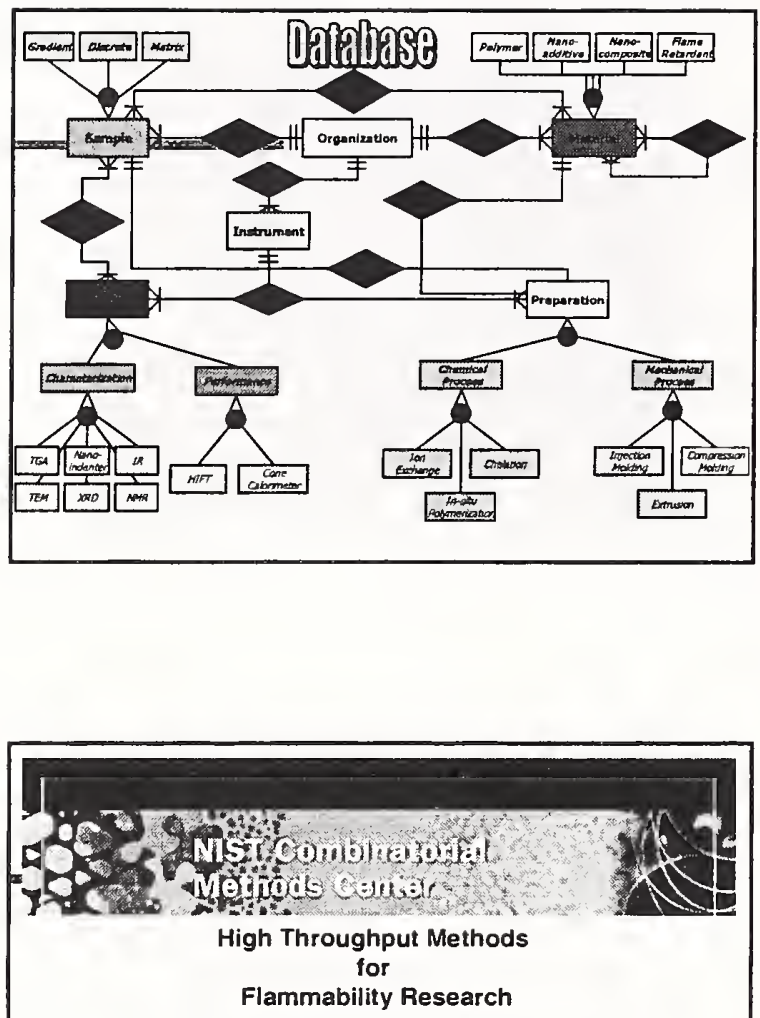

Focused Project Consortium

For information:

wwww.bfrl.nist.gov/focused_project

\section{Conclusions}

By combining nanotechnology with highthroughput experimentation, we can maximize the effect of additives and thereby provide industry with a powerful tool for the development of a new generation of high performance, low flammability materials.

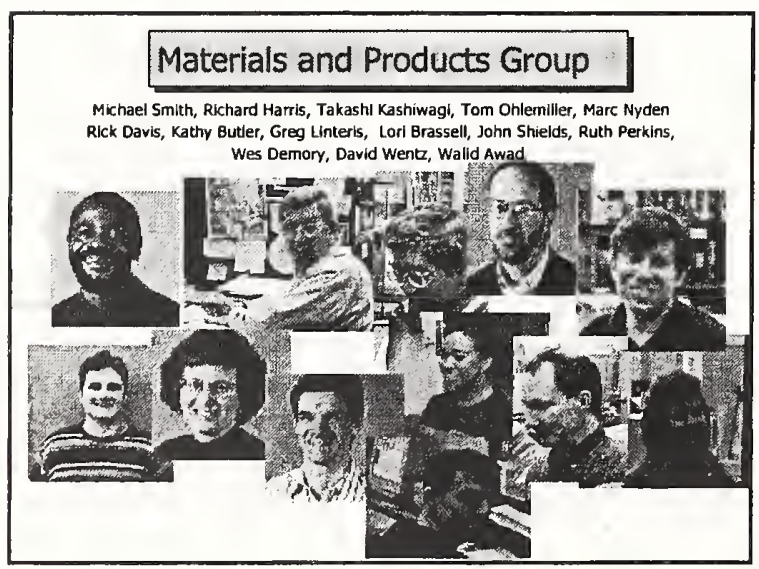


3) Ramanan Krishnamoorti, "Melt Rheology of Polymer Nanocomposites" [PowerPoint] [PDF]

(Talk presented by Charles Han due to family illness.)

This talk emphasized the effect of nanoparticles on the rheological properties of polymer melts. Melt measurements were contrasted for exfoliated (e.g., nylon-6) and intercalated clay-filled polymers. First, small amplitude linear dynamic measurements were considered for a clay-filled block copolymer system and gelation was observed with increasing filler concentration. This was attributed to the formation of a filler network structure, although scattering evidence is not yet available to support this hypothesis. Notably time-temperature superposition applied to the viscoelastic properties of these complex materials. Qualitatively similar behavior was found for intercalated and exfoliated clay-filled materials. Carbon nanotube (single wall) filled materials (polystyrene) were also considered and gelation (reinforcement) was similarly observed with increasing filler concentration-provided the nanotubes were functionalized to improve dispersion. At high concentration of clay, beyond the concentration of gelation, yield was observed and large amplitude oscillatory shear was shown to cause alignment followed by a slow recovery after the cessation of oscillation. An analogy to aging and rejuvenation effects in glass-forming liquids was discussed for these filled materials. 


\section{Melt Rheology of Polymer Nanocomposite}

\section{Ramanan Krishnamoorti}

Department of Chemical Engineering

University of Houston

\section{Introduction}

- Need to understand the effect of adding nanoparticles on the melt dynamics and processing.

- How does the dispersion of the nanoparticles affect the rheology of the composites?

- How does processing affect the dispersion (or equivalently rheology) and how does the system recover?

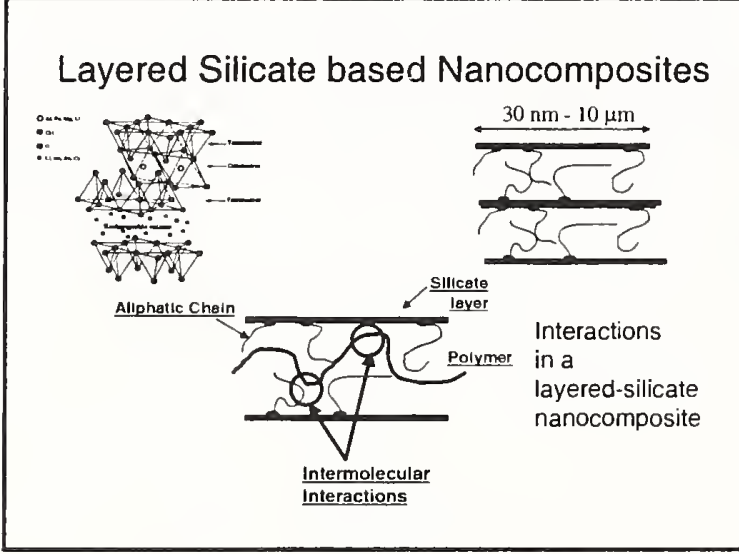

\section{Nanocomposites}

- Melt State Viscoelastic Measurements

- Exfoliated - Nylon 6 and Poly(E-caprolactone)

- Intercalated - Polystyrene, Polyisobutylene based random copolymers, Polystyrene - Polyisoprene Diblock Copolymers, polycarbonate.

- Layered Silicates - Organically Modified

- Montmorillonite (Natural Occurring)

- Synthetic including Laponite, Fluorohectorite and Fluoromicas

\section{Nanocomposite Classification}

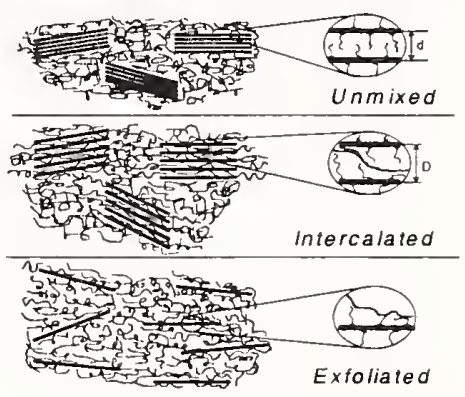

\section{Quiescent State Characterization of Nanocomposites}

- Linear Dynamic Viscoelastic properties

- Oscillatory Strain (small amplitude) 

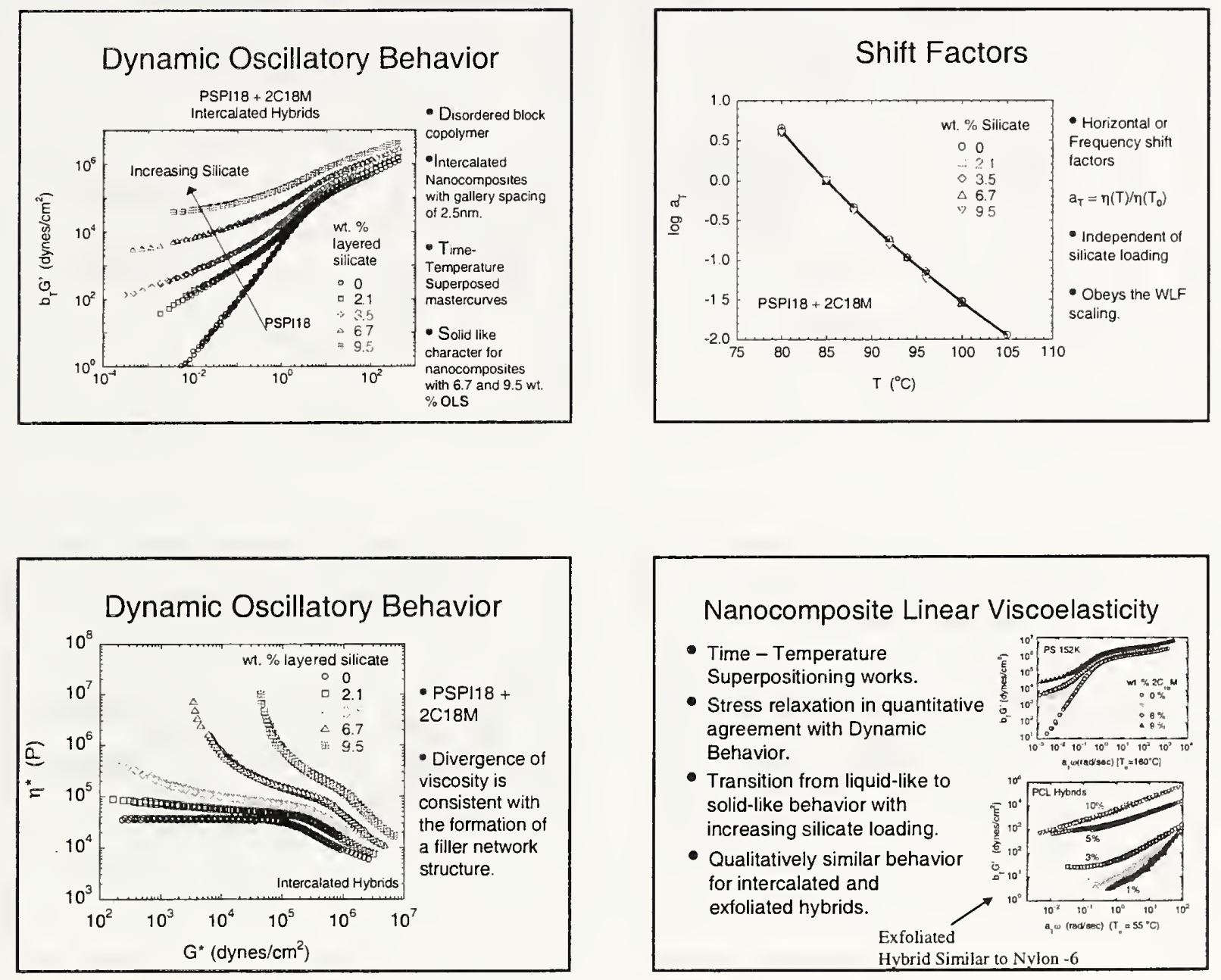

\section{Nanocomposite Linear Viscoelasticity}

- Time-Temperature Superpositioning works.

- Stress relaxation in quantitative agreement with Dynamic Behavior.

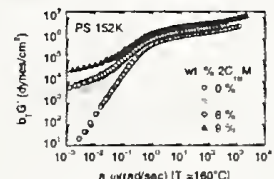

- Transition from liquid-like to solid-like behavior with increasing silicate loading.

- Qualitatively similar behavior for intercalated and exfoliated hybrids.

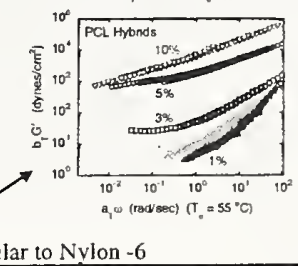

Hybrid Similar to Nylon -6

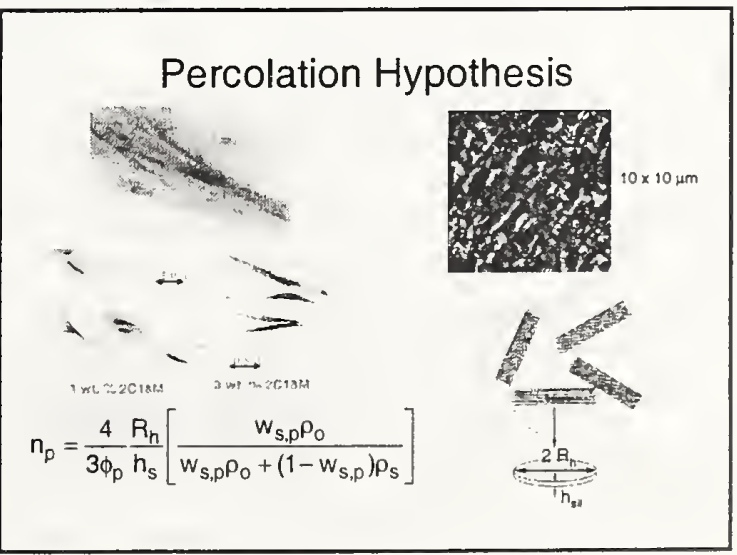



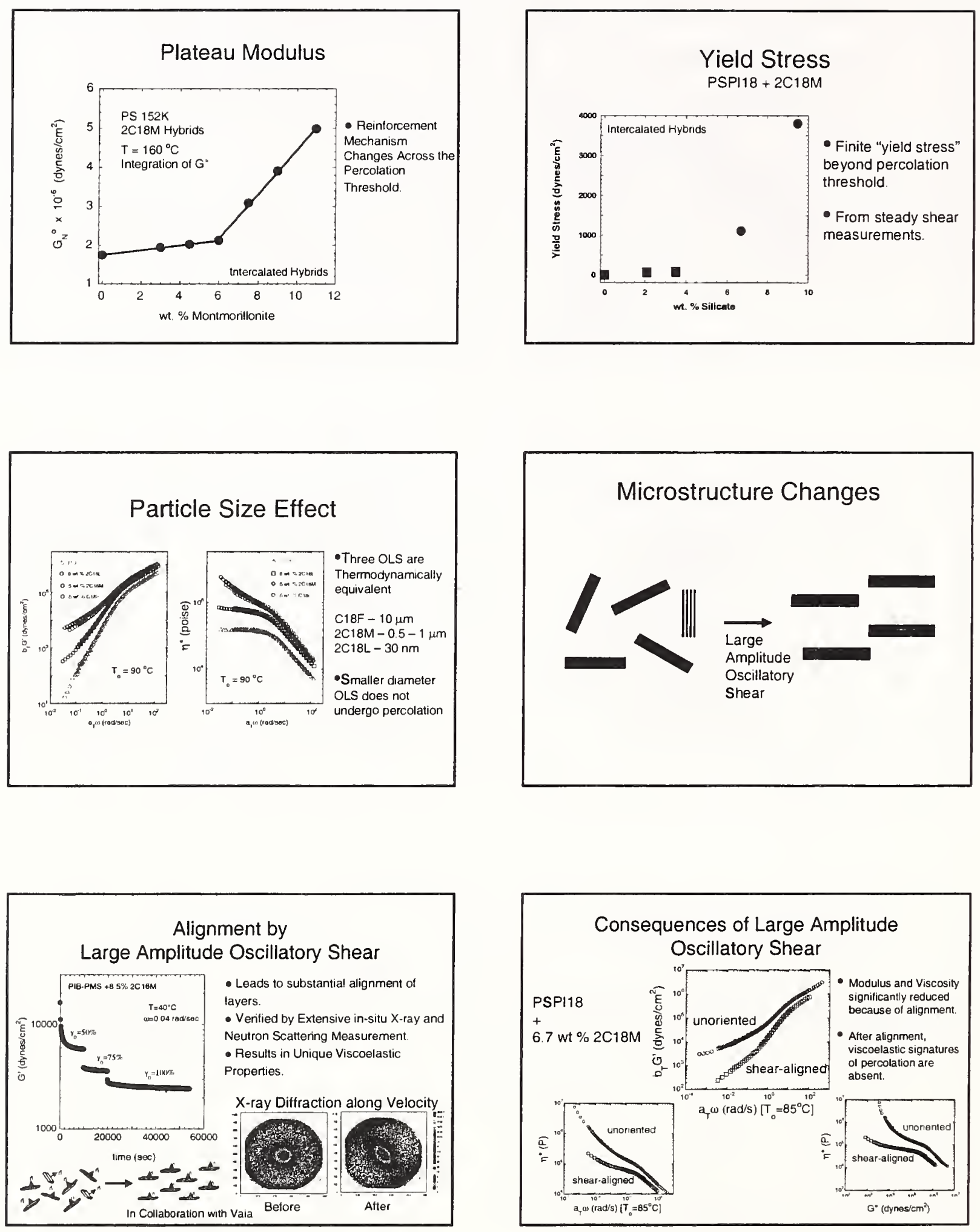

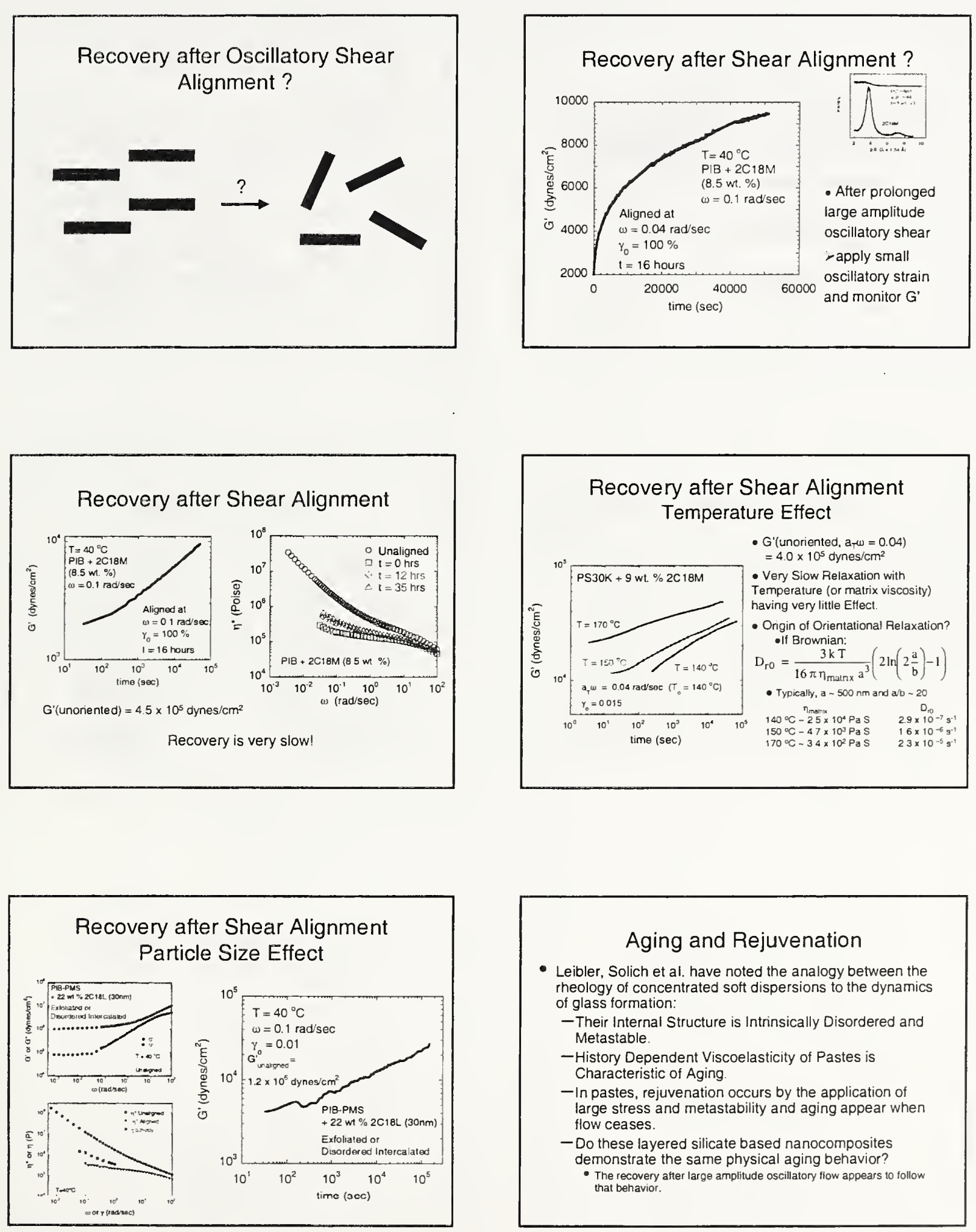

\section{Aging and Rejuvenation}

- Leibler, Solich et al. have noted the analogy between the rheology of concentrated soft dispersions to the dynamics of glass formation:

-Their Internal Structure is Intrinsically Disordered and Metastable

- History Dependent Viscoelasticity of Pastes is Characteristic of Aging.

- In pastes, rejuvenation occurs by the application of large stress and metastability and aging appear when flow ceases.

-Do these layered silicate based nanocomposites demonstrate the same physical aging behavior?

- The recovery ather large amplitude oscillatory flow appears 10 follow that behavior. 

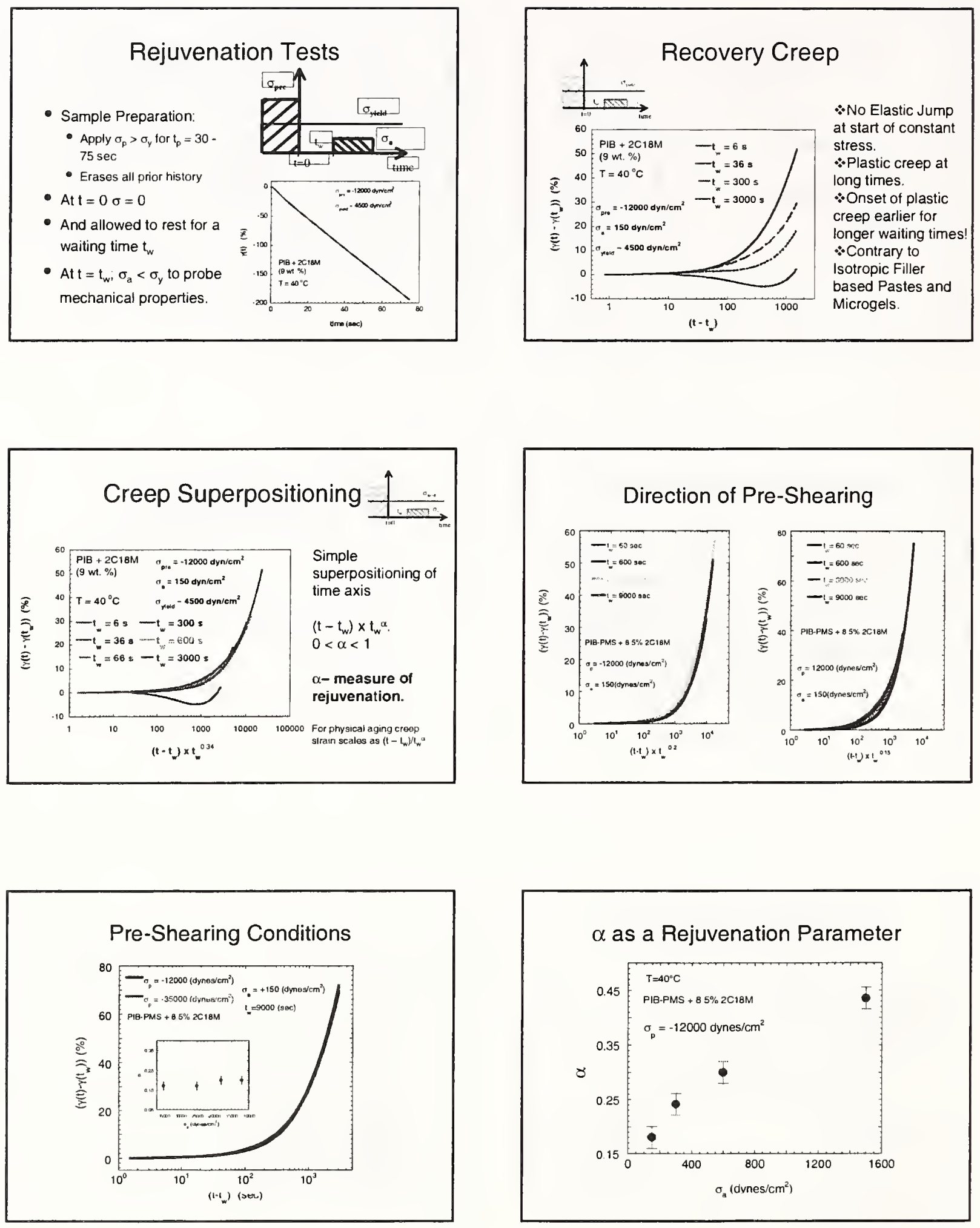


\section{Hypothesis for Unique Creep Recovery}

- Large Constant Stress (\& Steady Shear) do not lead to exclusively parallel orientation (layer normals in velocity gradient direction).

- Most Likely Scenario - Mixed Parallel + perpendicular orientation.(Preliminary scattering measurements support this hypothesis); Other possible hypothesis Disaggregation and Reaggregation

- The perpendicular aligned layers are unstable and disorient rapidly in the absence of flow.

\section{Conclusions}

- Linear Viscoelasticity Sensitive to Mesoscale Structure

- Recovery from Oscillatory Alignment appears to follow Physical Aging Like Kinetics.

- Recovery from Large Constant Stress - Unique and illustrative of the anisotropic layers influence on orientation.

- No Dependence on Pre - Shear Magnitude and Direction.

- Simple scaling of $t_{w}$ allows for superpositioning of creep data

- $\alpha$ appears to be a powerful parameter to capture the rejuvenation of the nanocomposites.

\section{Acknowledgements}

- Koray Yurekli

- Jiaxiang Ren

- Dr. Adriana Silva

- Cynthia Mitchell

- Barbara Casanueva

- Hsien Wang

- Mun Fu Tse

- Jay Dias
Financial Support

- American Chemical Society (PRF)

- Texas Coordinating Board for Higher Education(ATP)

- Welch Foundation

- NIST

- arl

- ExxonMobil Chemical Company 
4) Satish Kumar, "Processing, Structure, and Properties of Nano

Composite Fibers and Films" [PowerPoint not available] [PDF]

Dr. Kumar spent some time reviewing the field of nanocomposites as viewed from the perspective of a composite engineer. The geometrical structure of both single and multi-walled materials was reviewed and some measurements on melt-spinning these filler particles in polymer matrices were described. Some impressive improvements in compressive strength and tensile modulus of filled polypropylene and PMMA fibers were noted. Other notable observations include the observation of length changes in the single wall tubes upon blending and fiber spinning and the influence of the tubes on the size and rate of growth of polypropylene spherulites. It was also shown that highly conducting films could be formed from solutions of single wall nanotubes dispersed in Oleum. 


\section{Processing, Structure, and Properties of Nano Composite Fibers and Films}

\section{Satish Kumar}

School of Textile and Fiber Engineering

Georgia Institute of Technology, Atlanta GA 30332

satish.kumar@textiles.gatech.edu

\section{Nano Composites - Reinforcements}

\section{- SWNT}

- Diameter $\sim 1 \mathrm{~nm}$, From Rice University, HiPCO process

- MWNT or Carbon Nano Fibers

- (Diameter 50-200 nm. Applied Sciences Inc., OH)

\section{Nano Composites - Matrix Systems}

\section{- Insitu Polymerization}

- PBO and PBZT

\section{- Melt Blending}

- PP

- PET

- PMMA

\section{Carbon Nanotubes - Historical Perspective}

- Flexible Polymer - such as Polyethylene (1930s). High modulus PE fiber commercialized in 1980 s.

- Rigid Polymers - such as PBZT and PBO (1980s). Zylon fiber commercialized in 1998.

- Carbon Nanotubes - 1990s. By compariosn, synthesis, purification, and processing of these tubes is in its infancy.

$$
[\eta]=K^{3}
$$

Flexible polymer Semi-flexible polymer Rigid polymer SWNT

\section{$-\left[\mathrm{CH}_{2}-\mathrm{CH}_{2}\right]$}
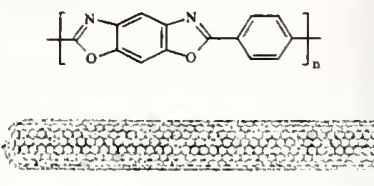

\section{MWNT}

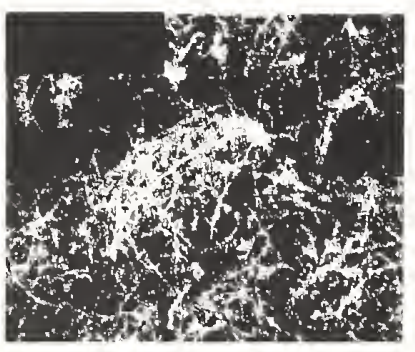

PR-21-PS

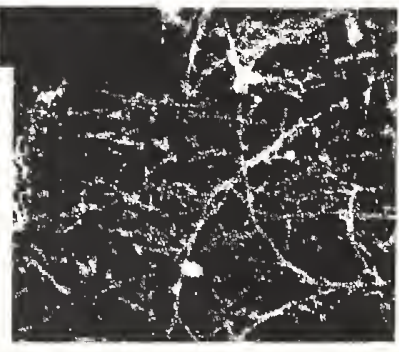

PR-24-PS

\section{MWNT}

TEM image of the wall of a carbon nanotube grown by ASl's Pyrografrm-III process.

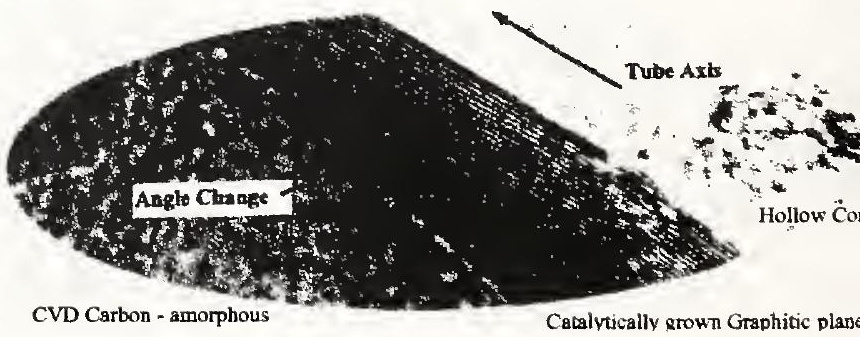

Photograph from Applied Sciences inc. 


\section{MWNT}

\begin{tabular}{|c|c|c|c|}
\hline MWNT & Processing method & $\begin{array}{c}\text { Oxygen content } \\
(\mathbf{w t} \%)\end{array}$ & $\begin{array}{c}\text { Sulfur content } \\
(\mathrm{wr} \%)\end{array}$ \\
\hline PR-21-PS & Pyrolytically stripped & 1.2 & 0.3 \\
\hline PR-24-PS & Pyrolytically stripped & 0.6 & 0.4 \\
\hline PR-24-HT & Graphitized at 3000 ${ }^{\circ} \mathrm{C}$ & 0.3 & 0.0 \\
\hline PR-24-AG & As Grown Fiber & 2.2 & 0.5 \\
\hline PR-24-PPO & $\begin{array}{c}\text { Post processing } \\
\text { oxidation of PR-24-AG }\end{array}$ & 2.1 & 0.4 \\
\hline PR-24-ISO & $\begin{array}{c}\text { In situ oxidation of } \\
\text { PR-24-AG }\end{array}$ & 2.2 & 1.1 \\
\hline
\end{tabular}

CNFs were provided by Applied Sciences, Inc. (Cedarville, Ohio)

\section{Raman Spectra of MWNT}

\begin{tabular}{|l|c|}
\hline CNF & $\begin{array}{c}\text { Raman intensity } \\
\text { ratio of } D \text { to G } \\
\text { band }\end{array}$ \\
\hline PR.24HT & 0.7 \\
\hline PR.24PS & 1.6 \\
\hline PR-21-PS & 3.1 \\
\hline PR-24AG & 1.5 \\
\hline PR-24PPO & 1.6 \\
\hline PR.24ISO & 1.8 \\
\hline
\end{tabular}

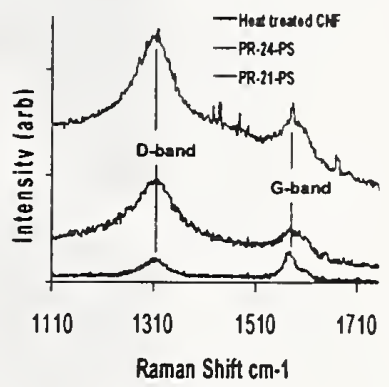

\section{Melt Blending and Fiber Processing}

PET melt blended with $5 \mathrm{wt} \%$ carbon nano fibers
- Dry Mixing

- Ball Milling

- Hand Mixing

- Melt Compounding

- Haake Twin-screw extruder

TW-100

Haake mixer

PP and PMMA melt blended at $240^{\circ} \mathrm{C}$
- Spinning

$-290^{\circ} \mathrm{C}, 250 \mu \mathrm{m}$ spinneret

- Drawing

$-120^{\circ} \mathrm{C}$, draw ratio $4 \mathrm{X}$ or $6 \mathrm{X}$

- Heat treatment

$-150^{\circ} \mathrm{C}$ at constant length

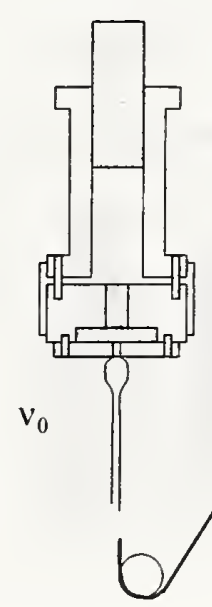

Melt spinning set up

PP/ MWNT Composite Fiber

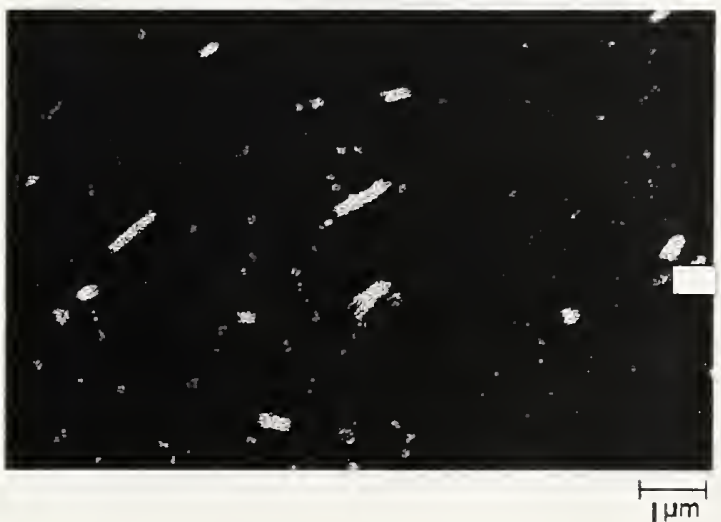

\section{PET/MWNT Composite Fibers}

Ium

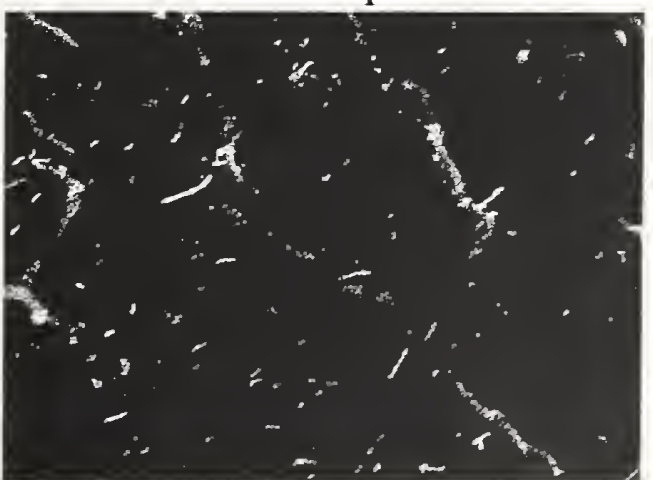




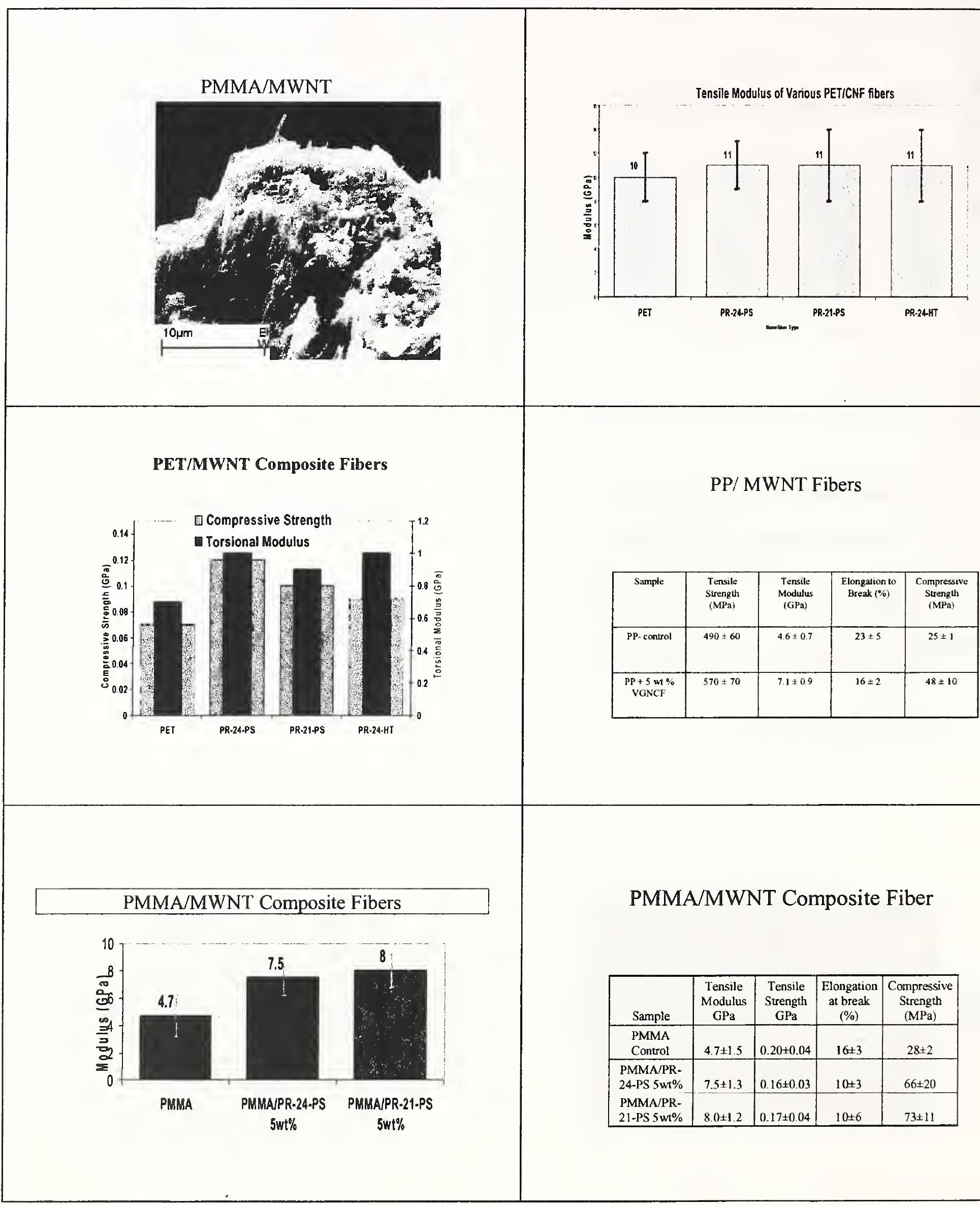


Thermal stability of PMMA/MWNT Composites

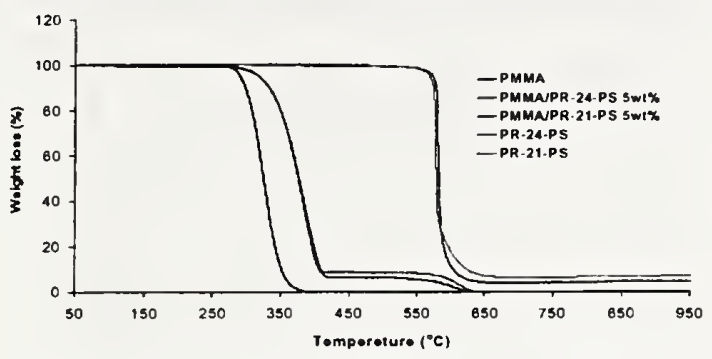

\begin{tabular}{|l|c|c|c|}
\hline & PMMA & $\begin{array}{c}\text { PMMA/PR-24.PS } \\
5 m \%\end{array}$ & $\begin{array}{c}\text { PMMA/PR-21.PS } \\
5 w 1 \%\end{array}$ \\
\hline $\begin{array}{l}5 \% \text { weight loss } \\
\text { temperature }\left({ }^{\circ} \mathrm{C}\right)\end{array}$ & 289 & 318 & 315 \\
\hline
\end{tabular}

Shrinkage Behavior - PMMA/MWNT Fibers

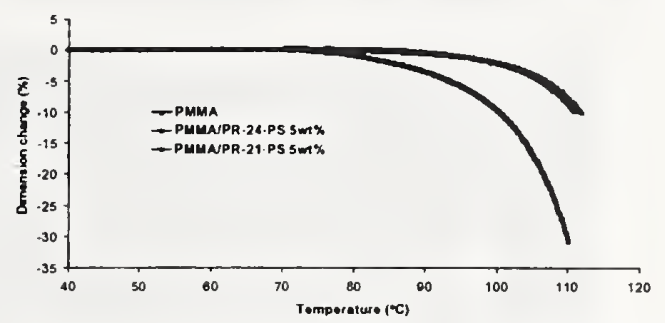

\begin{tabular}{|l|c|c|c|}
\hline & PMMA & $\begin{array}{c}\text { PMMA/PR-24-PS } \\
5 w \%\end{array}$ & $\begin{array}{c}\text { PMMA/PR-21-PS } \\
5 w t \%\end{array}$ \\
\hline Temp at $0.5 \%$ shnnkage $\left({ }^{\circ} \mathrm{C}\right)$ & $\mathbf{7 8}$ & 88 & 92 \\
\hline Shrunkage at $100^{\circ} \mathrm{C}$ & $\mathbf{9 . 0}$ & 2.4 & 2.0 \\
\hline
\end{tabular}

MWNT Length Reduction During Melt Blending and Fiber Spinning

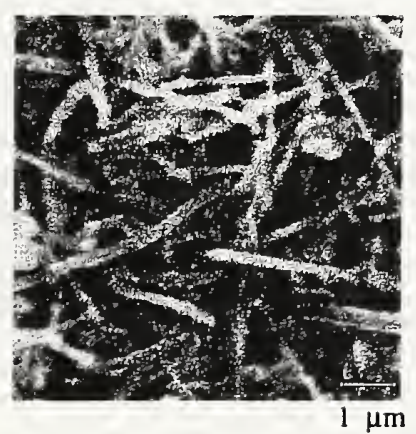

Fiber Tensile Modulus - PET/CNF Composite

Modified Cox model:

$\beta=\frac{l}{d} \sqrt{\frac{E_{m}}{(1+v) E_{f} \times \ln (\pi / 4 V)}}$

$E_{c}=(1-V) E_{m}+q\left(1-\frac{\tanh \beta}{\beta}\right) E_{f}$

l: nano nber length

d: nano nber dlameter

$V$ : volume fraetion

$E_{\text {z }}$; matrlx modulus

v: Polsson's ratto

$E_{f}$ : axlal tensile modulus

q: orlentation factor

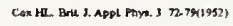

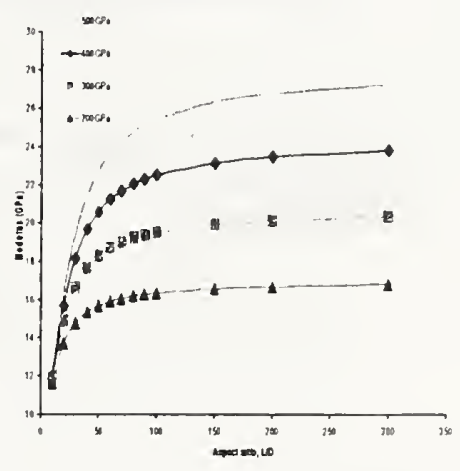

PET/MWNT Composite Fiber WAXD

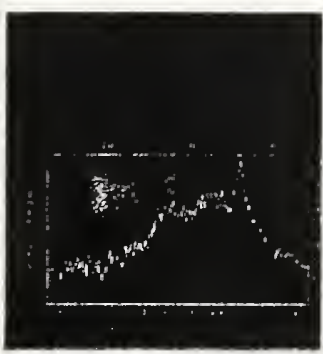

\section{Optical Microscopy-PP/SWNT Melt}
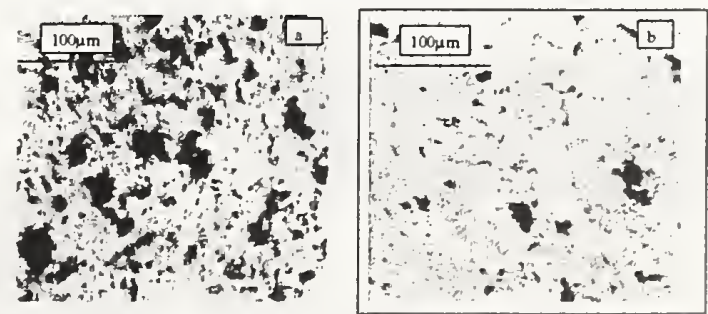

PP/SWNT Composite (a) before fNtration and (b) after nitration 


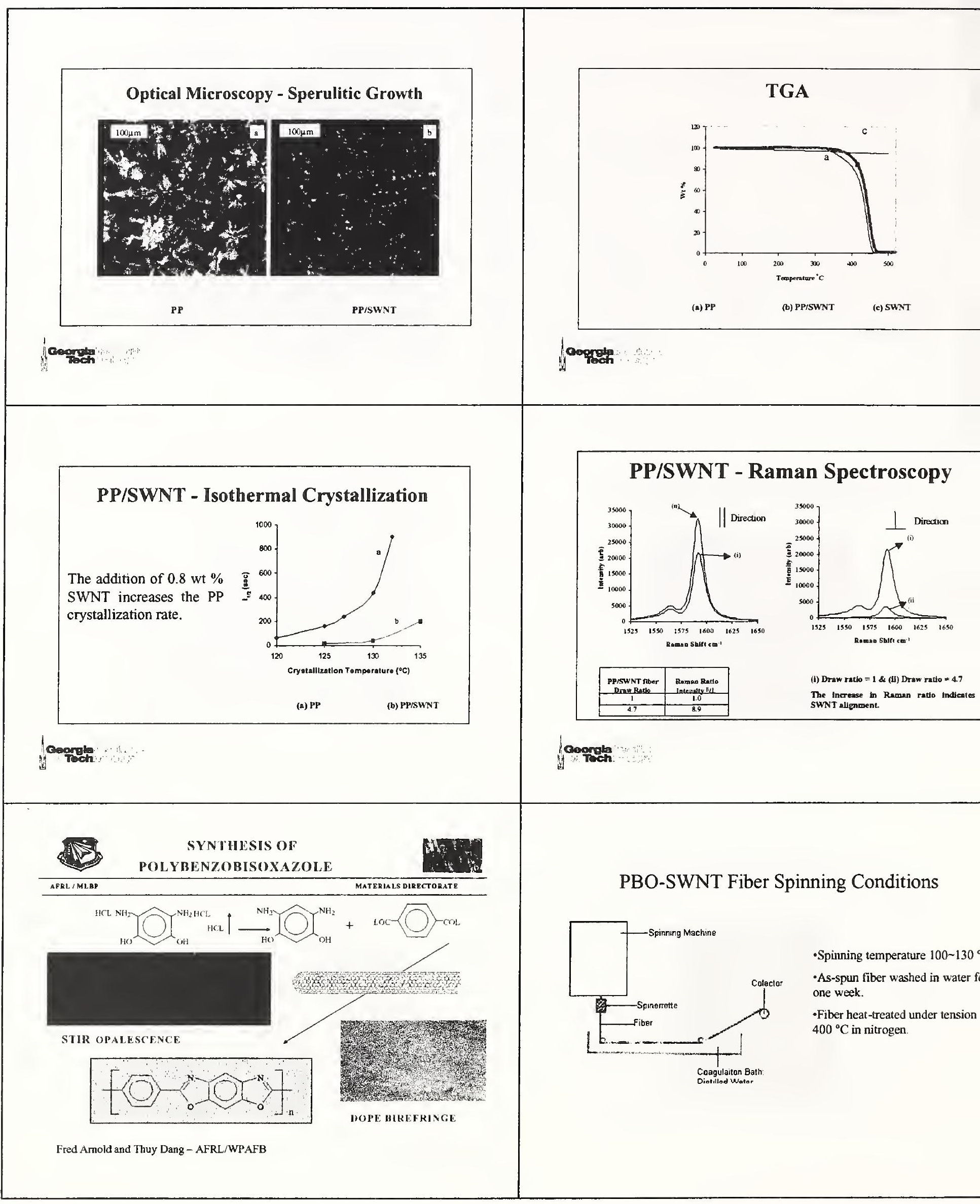


PBO/SWNT Fiber Mechanical Properties

\begin{tabular}{|l|l|l|l|}
\hline & E (GPa) & $\mathcal{E}(\%)$ & $\sigma_{t}$ (GPa) \\
\hline PBO HT & 138 & 2.0 & 2.6 \\
\hline $\begin{array}{l}\text { PBO/SWNTHT } \\
(95 / 5)\end{array}$ & 156 & 2.3 & 3.2 \\
\hline $\begin{array}{l}\text { PBO/SWNTHT } \\
(\mathbf{9 0 / 1 0 )}\end{array}$ & 167 & 2.8 & 4.2 \\
\hline
\end{tabular}

PBO/SWNT - Thermal Shrinkage

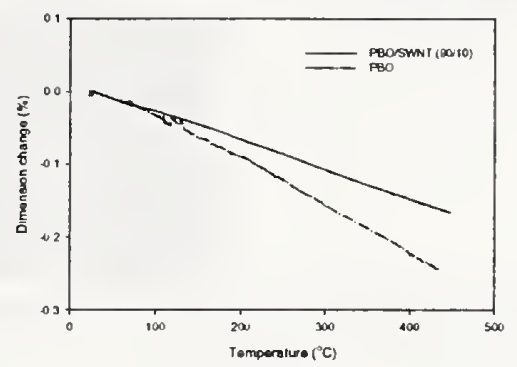

$\mathrm{PBO} / \mathrm{SWNT}$ Creep Behavior at $400^{\circ} \mathrm{C}$

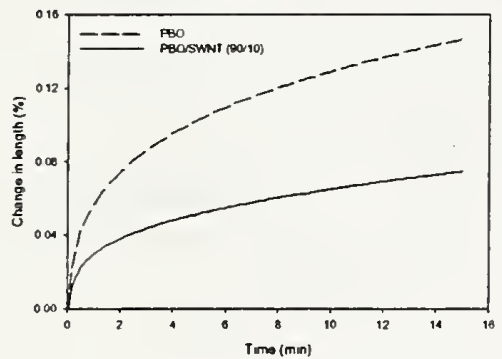

Raman Spectroscopy

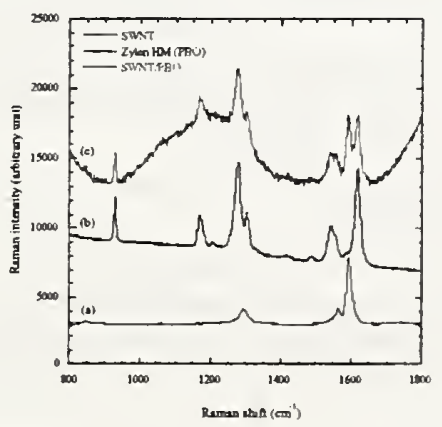

Cheol Park - NASA Langley

\section{PBO and PBO/SWNT Fibers} Fracture Behavior

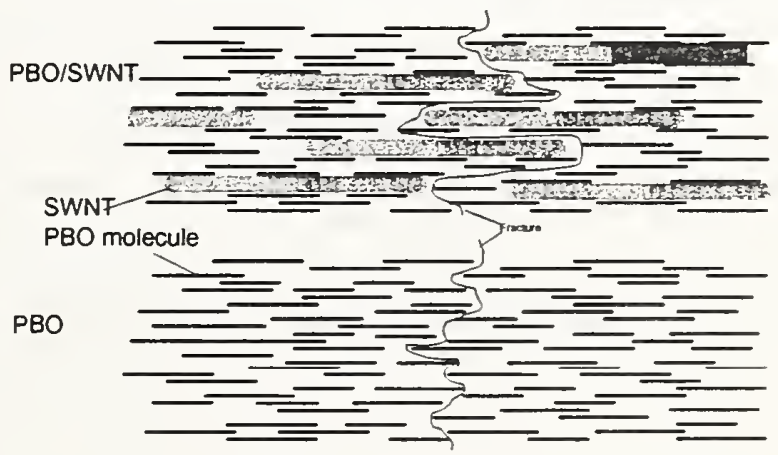




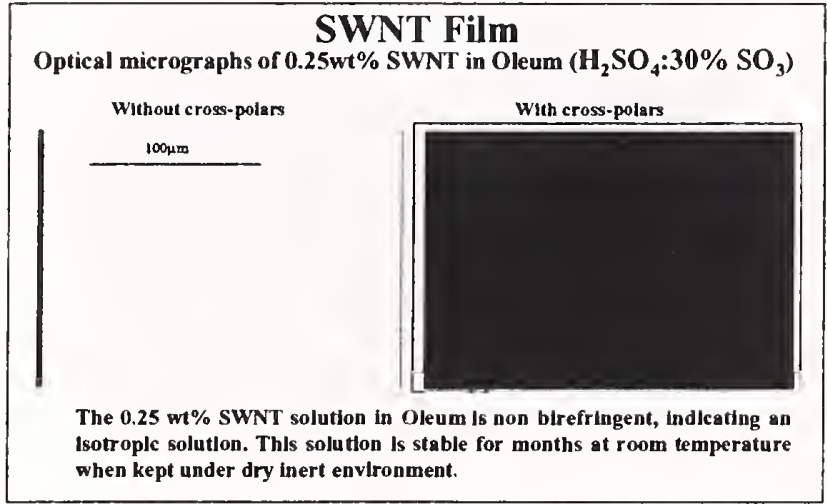

looggen

\section{SWNT Film}

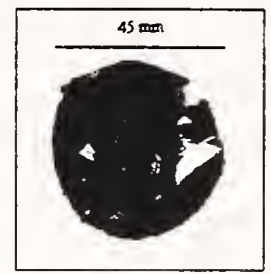

Goorga
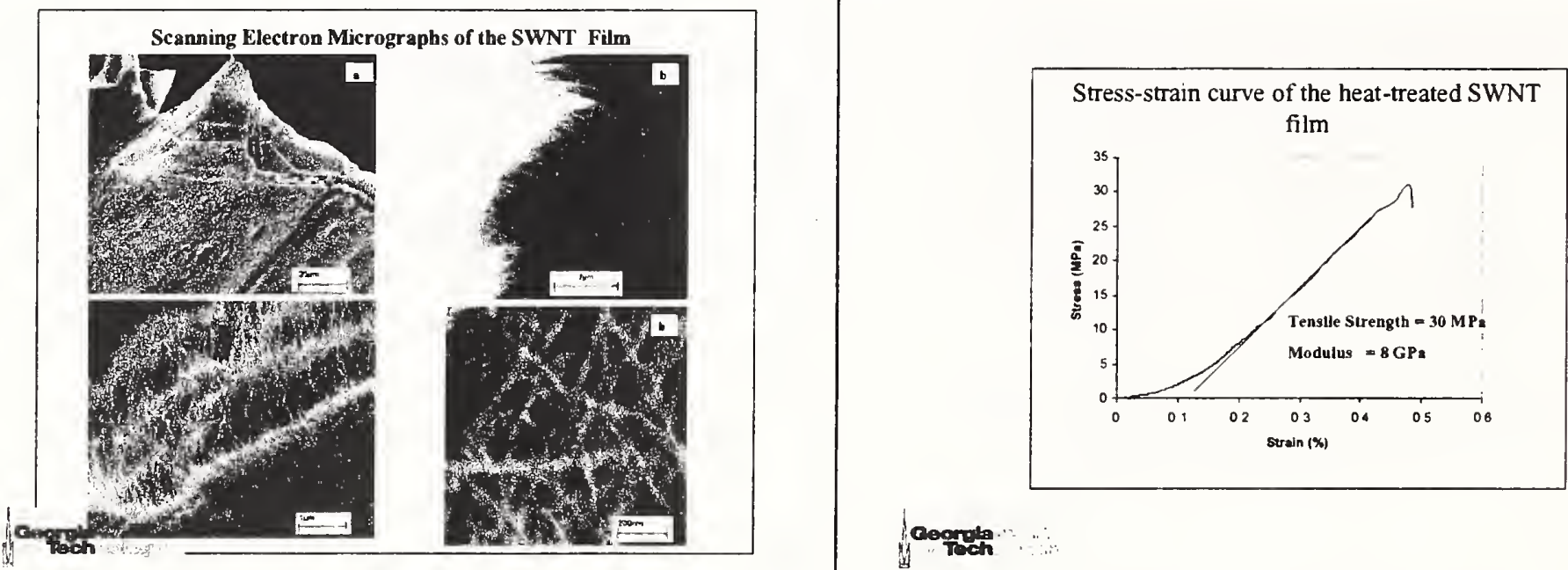

\section{Summary}

- Polymer/nanotube composite fibers can be spun using the typical polymer spinning equipment /conditions.

- $\quad$ MWNT exhibit good dispersion in PET, PP, and PMMA. PP and PMMA appears to have good interaction with MWNTs.

- High tensile strength fibers can be processed from PBO/SWNT.

- $\quad$ SWNT act as nucleating agent for PP.

- The electrical conductivity through the thlckness $=1.1 \times 10^{-2} \mathrm{~S} / \mathrm{m}$. (HP4192A LF Impedance analyzer)

- SWNT films with in plane DC electrical conductivity of the order of $10^{5} \mathrm{~S} / \mathrm{m}$ have been processed from isotropic solutions in oleum. 


\section{Acknowledgements}

- Funding

- AFOSR, ONR, NSF, KoSa, and CNI

- MWNT - Applied Sciences Inc.

- SWNT work is being done in collaboration with Professor Smalley's group at Rice University and Air force Research Laboratory (Fred Arnold, Thuy Dang, and Richard Vaia).

- Cheol Park - NASA

- Hongming Ma, Jijun Zeng, Harit Doshi, Byung Min, T. V. Sreekumar, Arup R. Bhattacharyya, Xiefei Zhang. 
5) Alex Morgan, "Polypropylene Nanocomposites: Clay Organic Treatment Concentration Effects on Mechanical Properties, Flammability Properties and Clay Dispersion" [PowerPoint] [PDF]

Dr. Morgan summarized some of the efforts at Dow at exploiting clayfilled thermoset and thermoplastic nanocomposites. These materials show major improvements in mechanical properties, gas barrier properties, thermal stability and flame retardancy and the factors influencing these property changes were summarized- synthesis method, extent of dispersion, clay type and organic treatment, polymer matrix type. The presentation emphasized the complexity of understanding and controlling the properties of these complex materials. Particular emphasis was given to property changes that accompany the variation in the amount of organic modifier in the material. The presentation covered a wide range of experimental methodologies (x-ray diffraction, transmission electron microscopy, thermal gravimetric analysis, mechanical property testing, Flammability property testing, NMR, Atomic force microscopy, neutron scattering calorimetry and optical microscopy) since no single method allows for the characterization of these multi-scale materials. The extensive efforts in characterizing these materials are an important factor in slowing the development of these materials and the need for faster and additional validation methodologies for characterization emphasized, especially methods relating to the characterization of polymer-clay and polymer-organic interactions that important for dispersion stability. 
Polypropylene Nanocomposites:

Clay Organic Treatment Concentration

Effects on Mechanical Properties,

Flammability Properties and Clay Dispersion

Alex Morgan

Inorganic Materials

Corporate R\&D

The Dow Chemical Company $05 / 29 / 02$
Current Polymer Nanocomposite Technology

- Polymer Natocomposites are composed a polymeric material (thernosel or thermoplastic) and a re-enforcing nanoscale material

- The most commonly studied re-entorcing nanoscale materials are layered materials, or clays

- Polymer-clay nanocomposites show major inprovements in nuechanical properies, gas burrier properties, thermal stability. and llane retardancy

- Muny faclors affect the polymer-clay nanocomposite properties

- Synthoss methow

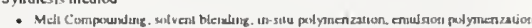

- Pulymer nanocumparsite misphulugy

- Clay lype and elay organic treasmen

- Layerad clay aspecit nues, structure

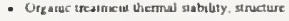

- Polymer masrix

- Cry sallsraly. molocular weight. polymer chenusury

- Understunding property improvenent due to polymer-clay nanocomposite properties very complex
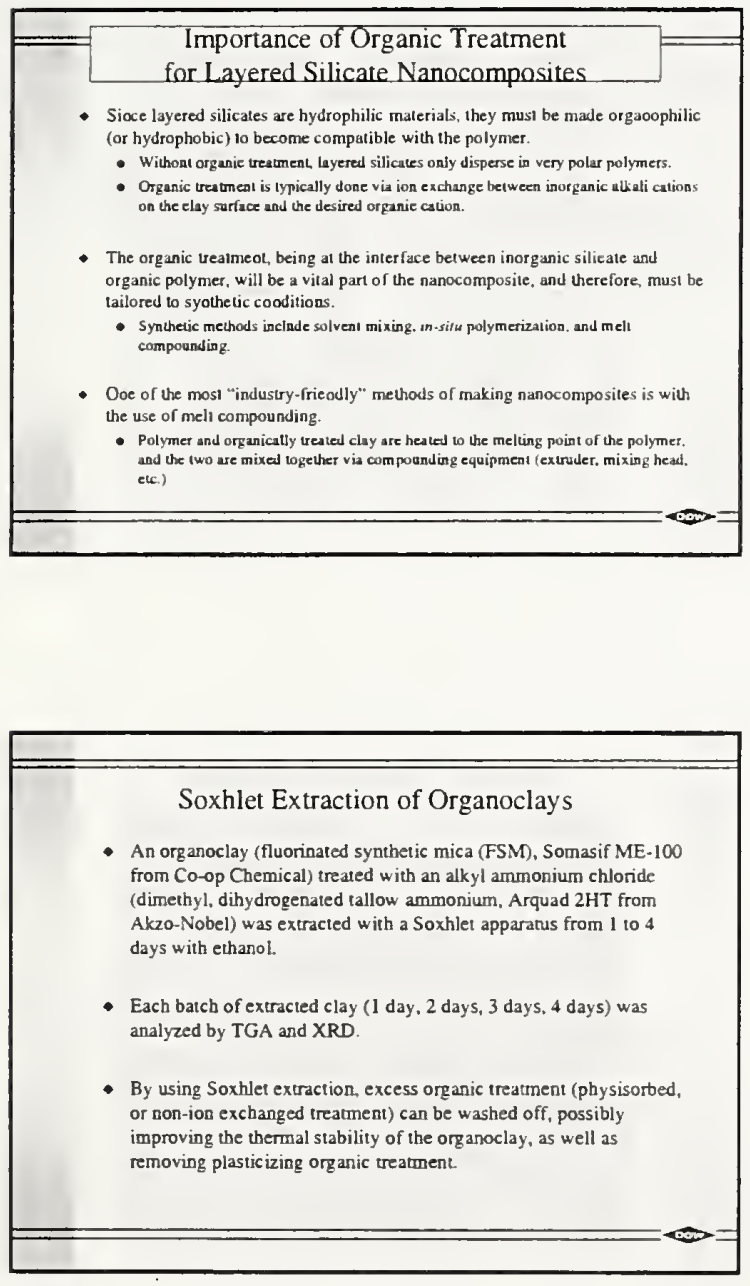
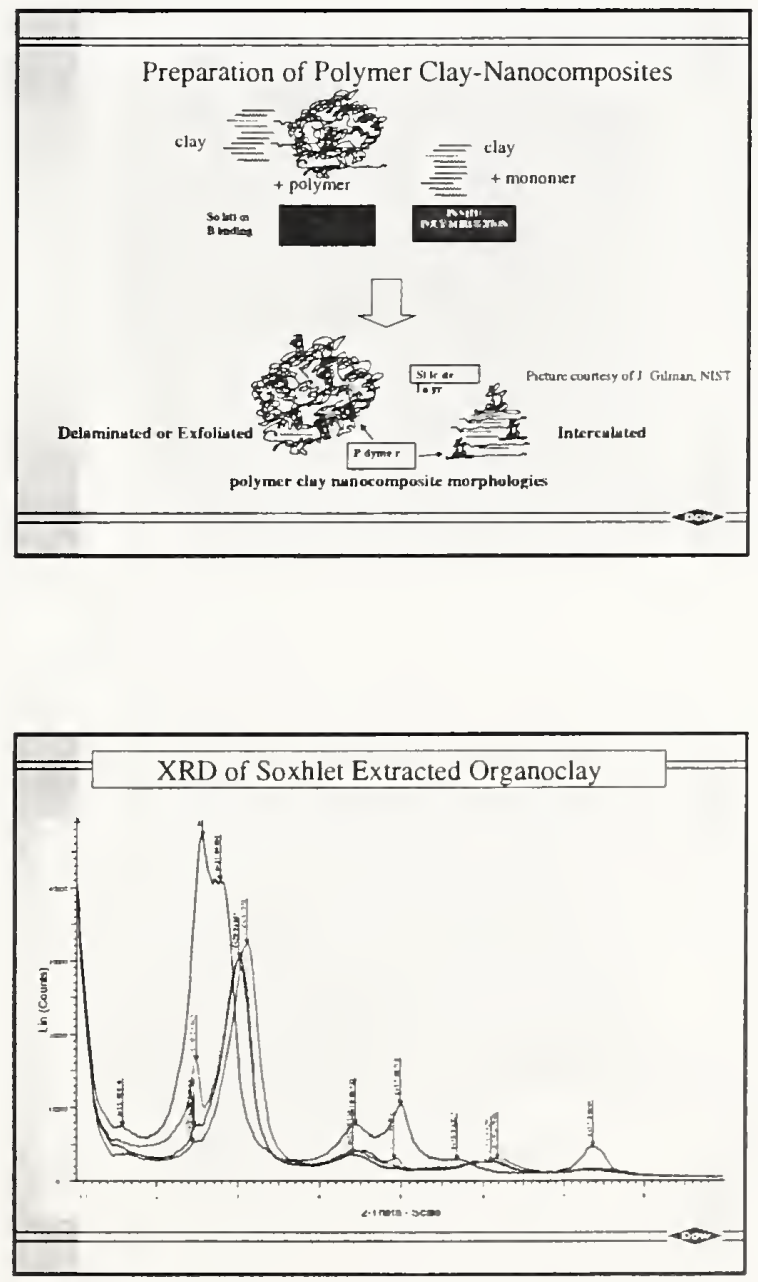


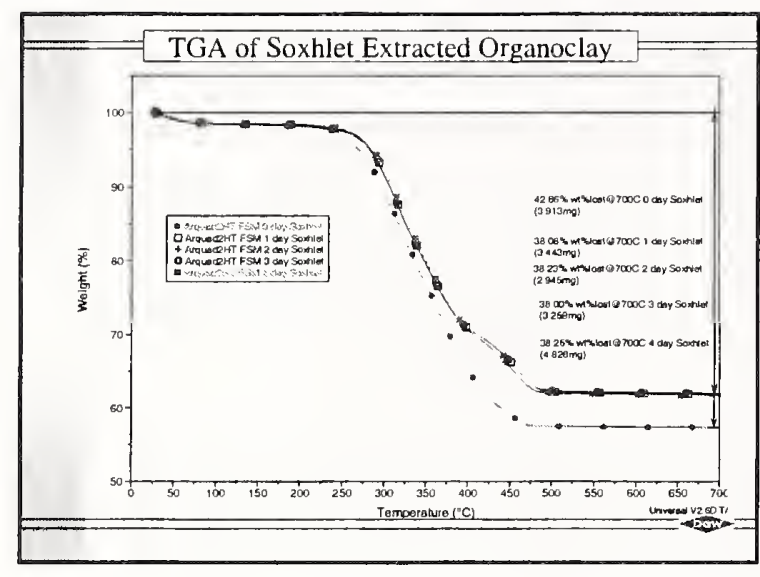

$\mathrm{XRD}, \mathrm{TGA}$ data for Extracted Clays

- Soxhlet extraction of organoclays removes excess (physisorbed) organic treatment from the clay surface

- TGA data shows that after I day, all excess organic treatment is removed. Additionil extraction removes no more treatment (TGA data unchanged)

- XRD data changes. Main d-spacing (100) peak drops with 1 day extraction time, and then another peak appears with increasing extraction time (organic treatment re-arrangement?)
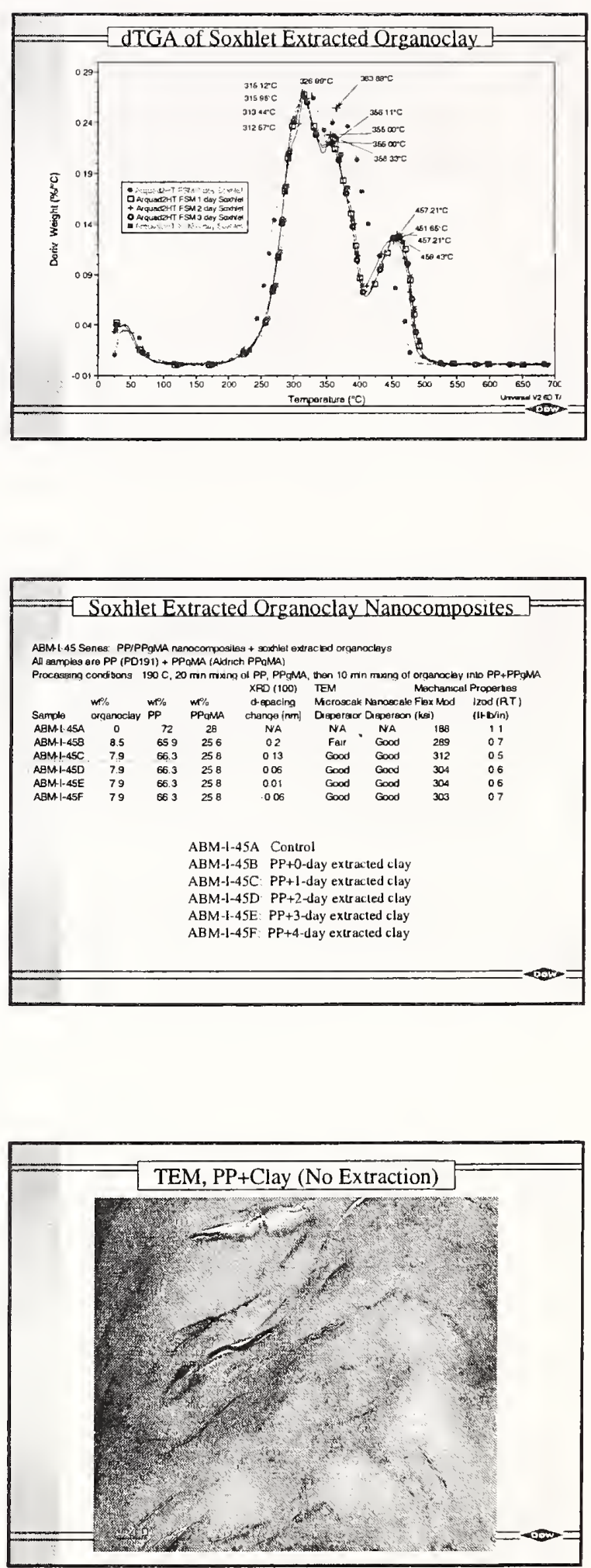

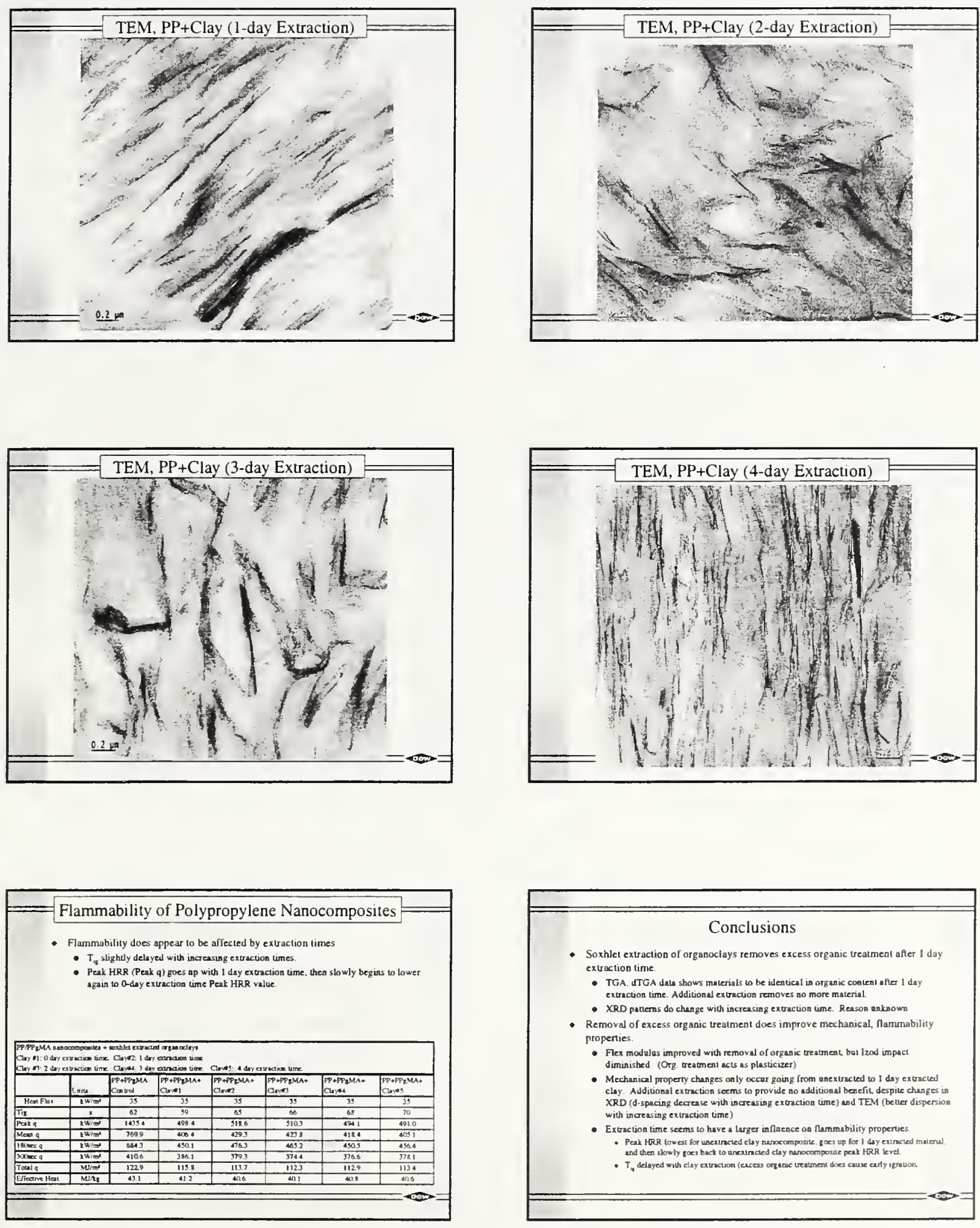

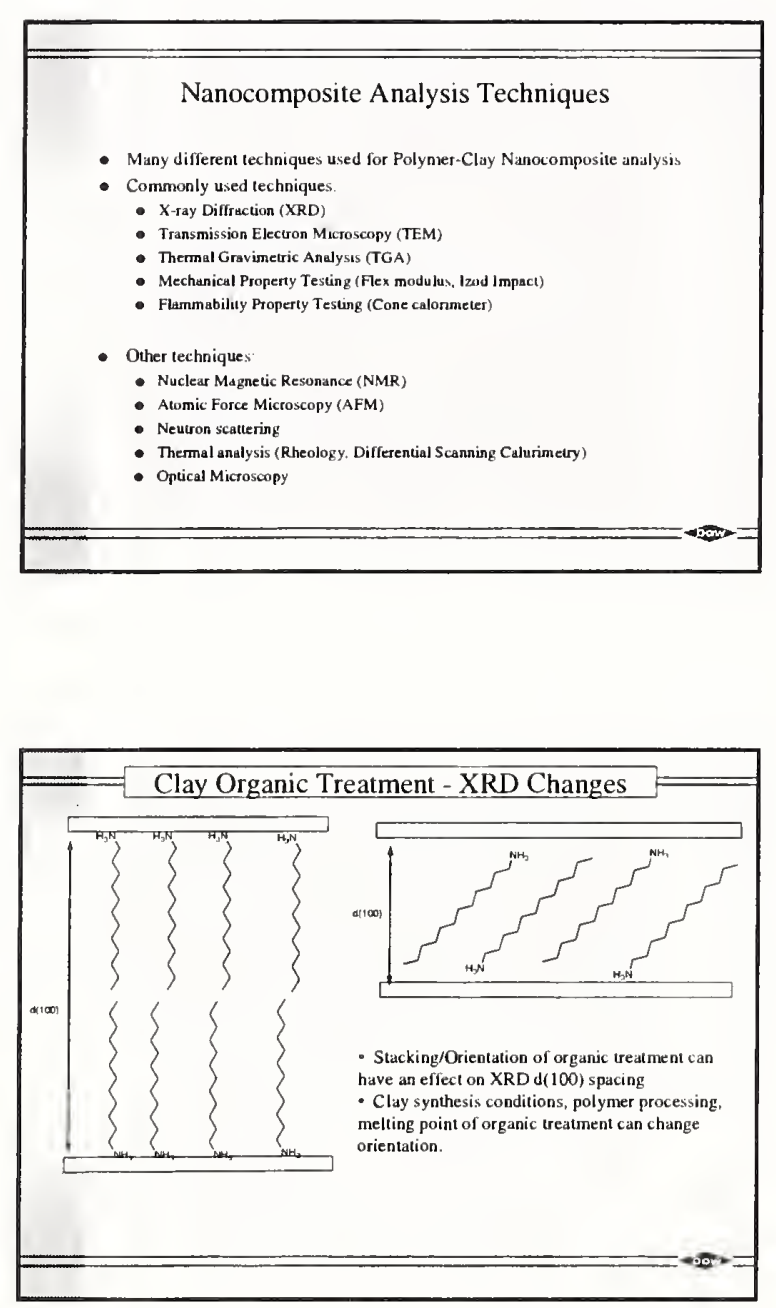

Nanocomposite Analysis Techniques: Property Testing

- Current property tests follow ASTM or other standards.

- Tests determıne property of materials, but do not indicate why propenties were oblained

- Example: Flex Modulus Measurement. Shows what flex modulus of propery is, but does not indicate why stilfiness of nanocomposite has improved.

- Exceptions:

- Cone Calorimeter: Measures additional parameters, such as heat release rate and mass loss rate, thus suggesting some polymer nanocomposite properties.

- Drawback Must rely upon other techniques to confirm nanocomposite dispersion. Technique measures flammability, but cannol explain why amproved flammability was obained on its own.

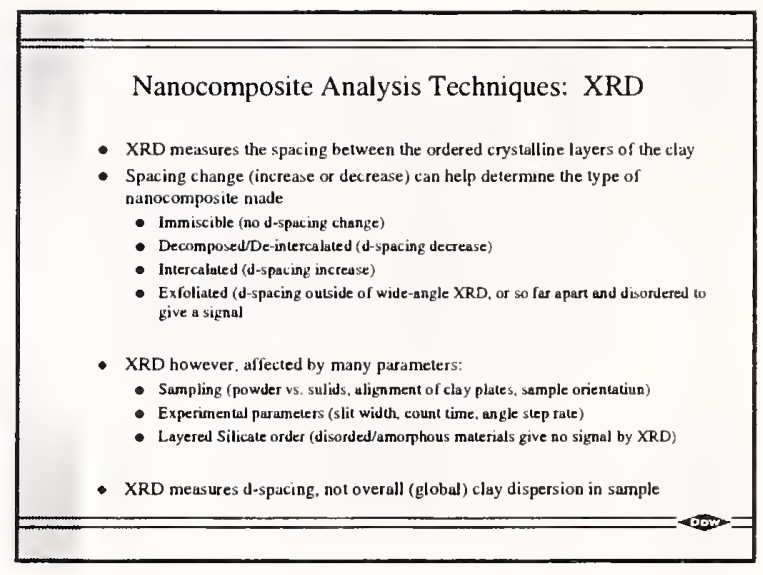

Nanocomposite Analysis Techniques: TEM

- TEM measures the overall clay dispersion in the sample

- Clay dispersion and structure observed under the microscope can determine the nature of a clay nanocomposite.

- Immiscible (Usually large clay tactoids. ngdispersed clay particles)

- Intercalated (Clay layers in ordered stacks can be observed)

- Exfoliated (Single clay layers can be observel)

- Can delemine global macroscale dispersion as well as nanoscale dispersiun/structure

- TEM has limitations and drawback

- Sampling (heterogeneous samples will give false results)

- Labor intensive analysis. expensive analy yical instrument

- Cannot measure d-spacing of clay, therefore. cannot easidy determine difference

between intercalaled clay nanocomposite and well-dispersed immiscible nanocomposite

- TEM measures overall clay dispersion, but should be combined with XRD data 


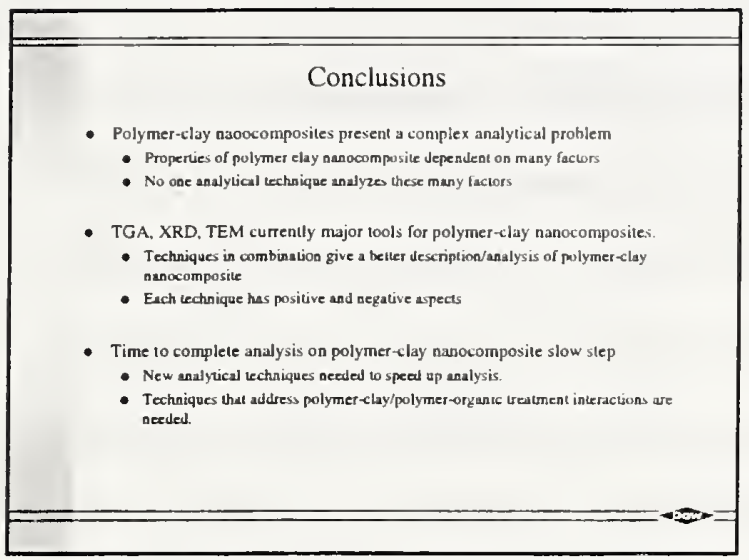

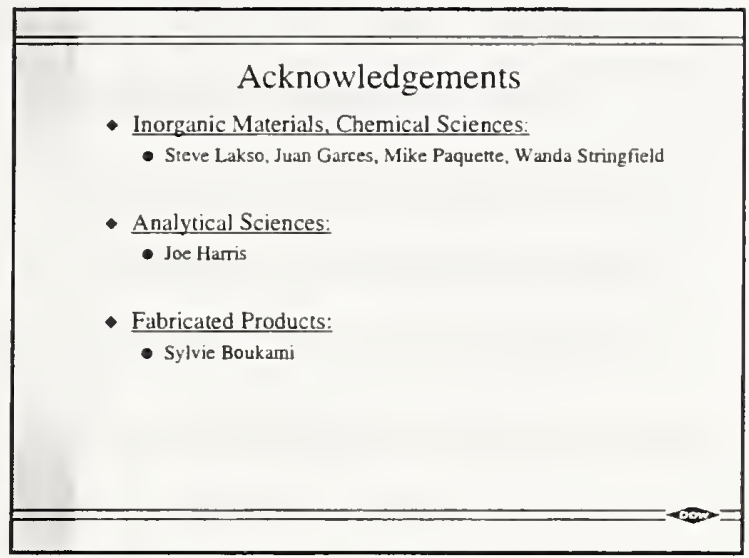


6) Atsushi Takahara, "Structure and Mechanical Properties of Natural Inorganic Nanofiller / Polymer Hybrids" [PowerPoint] [PDF]

Dr. Takahara discussed a novel inorganic counterpart to carbon nanotubes that should be useful in dispersing nanotubes in polymer polar matrices without the need of surfactant additives. This type of nanotube ('imogolite') has an aluminum silicate composition and has molecular dimensions comparable to single wall carbon nanotubes, and naturally occurs in certain volcanic ashes found near Kyushu University. The environmentally friendly nature of this nanofiller and advantages for chemical functionalization were emphasized. After the extraction of the imogolite from volcanic ash was discussed, the properties were characterized by a variety of techniques (TEM, AFM, wide angle x-ray diffraction) and a tendency towards gel formation was observed. The functionalization of the imogolite was characterized though the adhesive force with an AFM cantilever tip and it was shown that the functionalized imogolite could be dispersed in an organic solvent (hexane). Films of PVA and PMMA and imogolite were prepared and the viscoelastic properties were characterized. Modified imogolite was also dispersed in PMMA and formed fibrous network of gelling nanotubes within the polymer matrix. Notably the transparency of the PMMA was not sacrificed for these nanotube additives. This could be important for applications where carbon nanotubes have a negative impact on appearance because of the characteristic black color of the filled polymers. Finally, clay-filled polymer (nylon) composites and the fatigue and mechanical properties of these materials were considered. The resulting materials are excellent in comparison to glass-fiber reinforced nylon. 


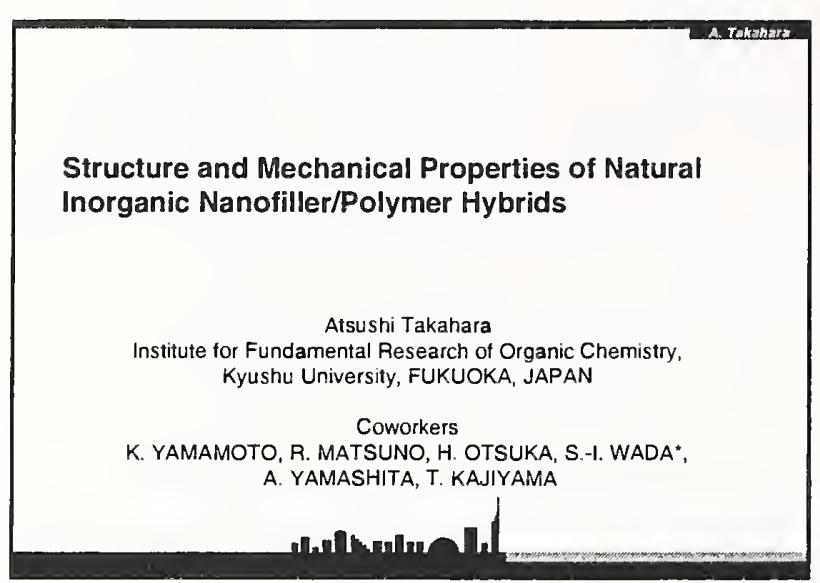

Content
-Characterization of natural nanofiber "Imogolite"
-Surface modification of natural nanofiber "Imogolite"
Chem. Lett., 1162(2001)
oPreparation of novel polymer nanohybrid from
natural nanofiber "Imogolite"
J. Adhesion, (2002).
ofatigue behavior of nylon clay hybrid based on
dynamic viscoelastic measurement during the fatigue
process
Composite Interfaces, 6, 247(1999).

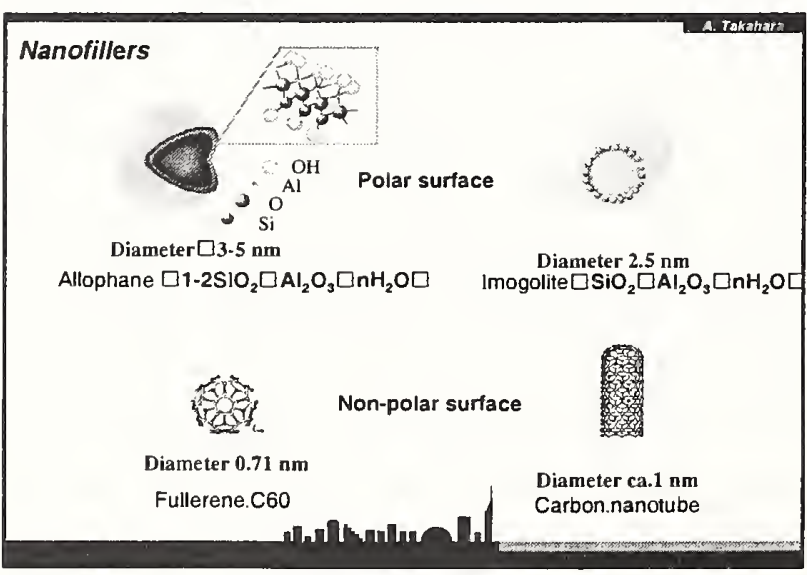

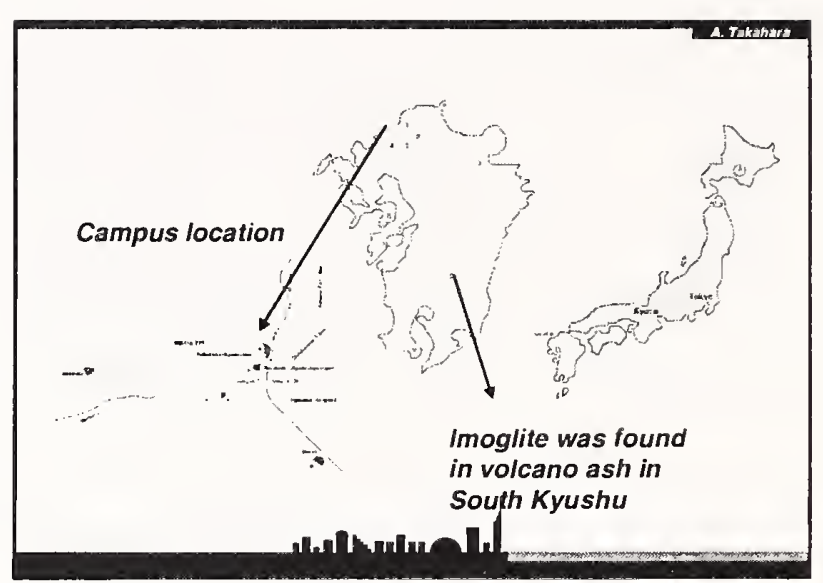

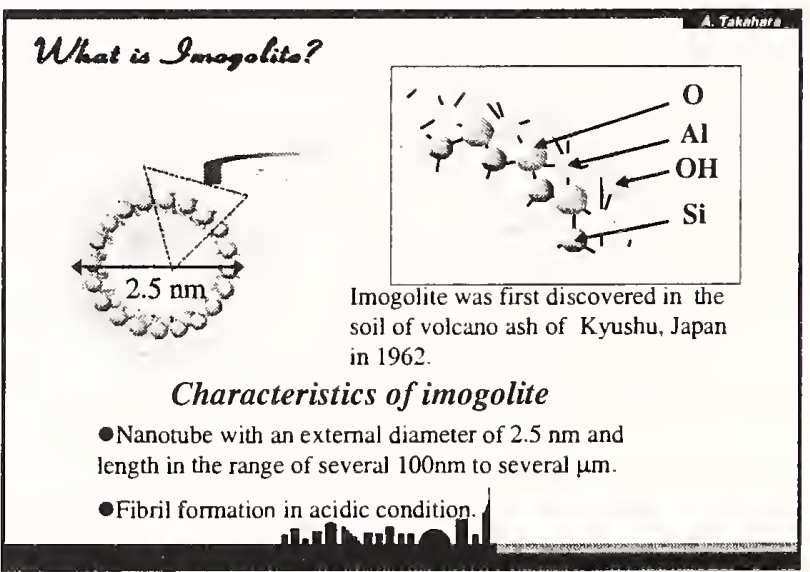

\begin{tabular}{l}
\hline Panofiller \\
$\begin{array}{l}\text { Extremely high aspect ratio of inogolite } \\
\text {-Imogolite forms space filling gel at the concentration of } 0.2 \mathrm{wt} \% \\
\text {-Improve mechanical, thermal,flame - retardant, barrier properties }\end{array}$ \\
\hline $\begin{array}{l}\text { Chemical modification of Al-OH group of the external surface of imogolite } \\
\text {-Control interaction between imogolite and matrix poiymer }\end{array}$ \\
$\begin{array}{l}\text { Imogolite retain water in soil } \\
\text { •Environmentally benign nanocomposite "Green Nanohybrid" can be realized. }\end{array}$ \\
$\begin{array}{l}\text { Purpose } \\
\text { Prepare novel (natural nanofiller /inorganic) nanohybrids }\end{array}$ \\
\hline
\end{tabular}



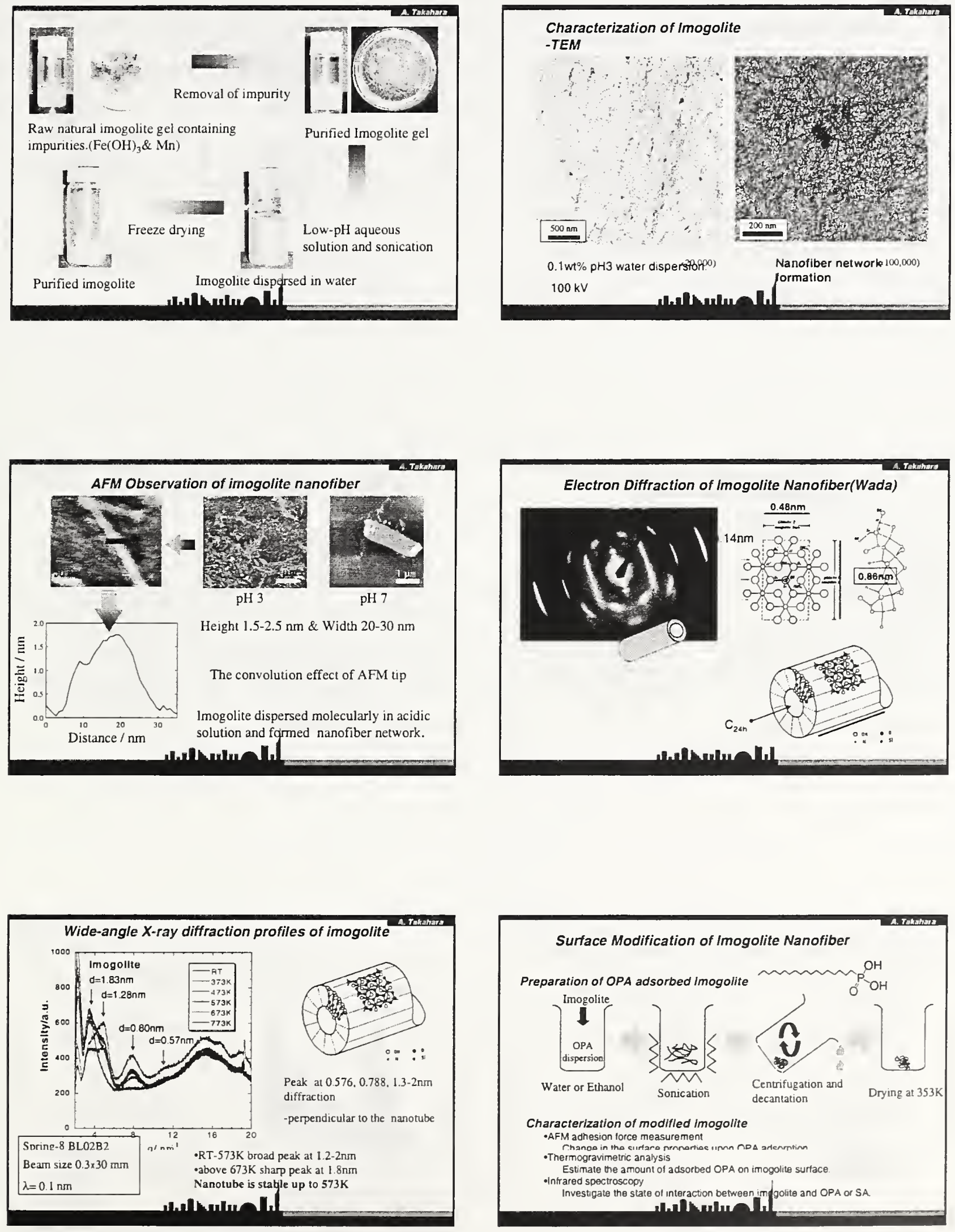

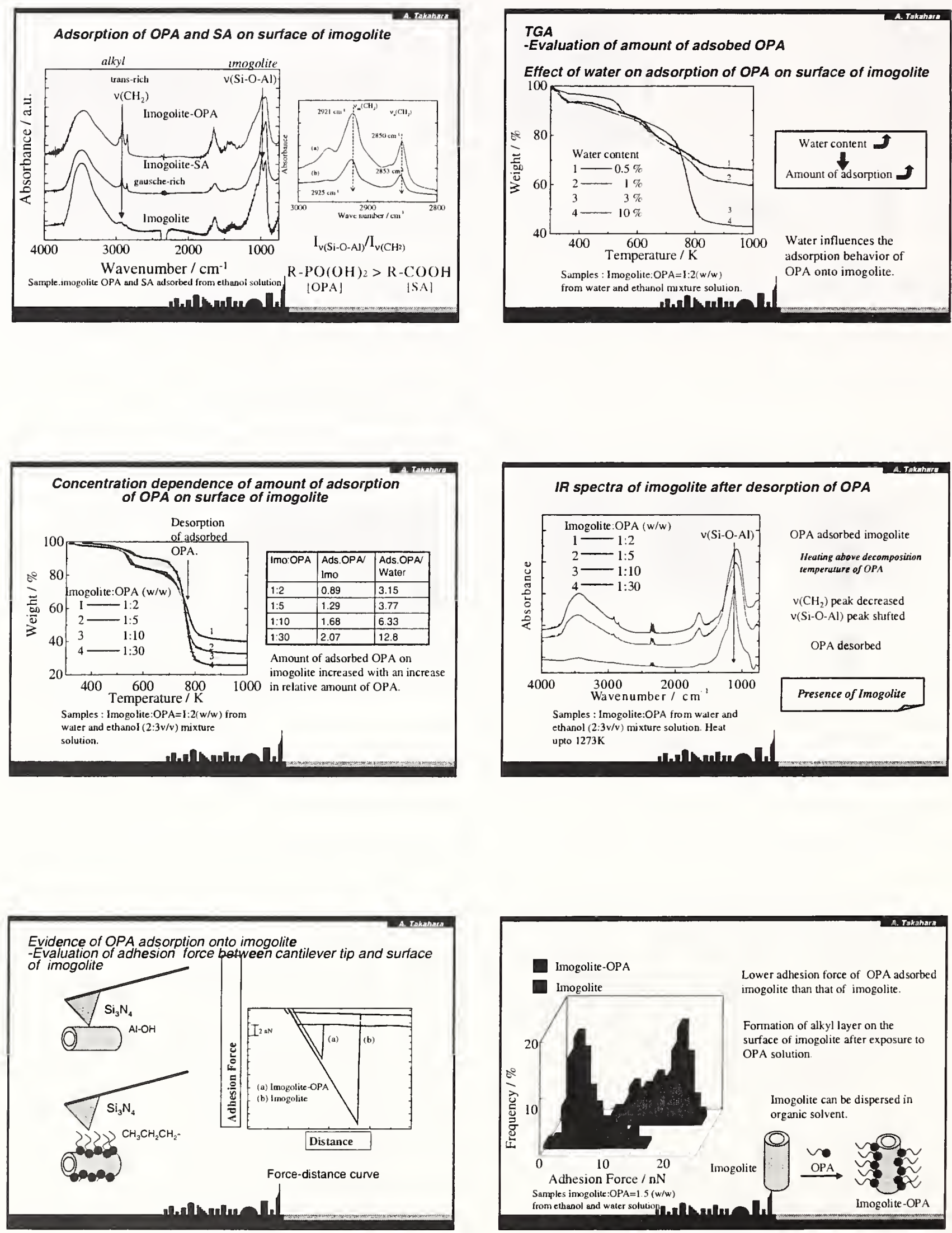


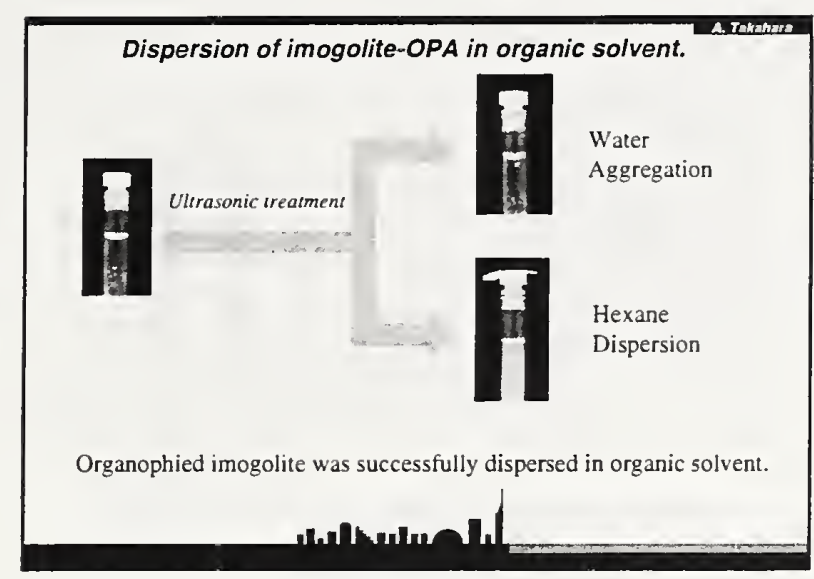

Influence of amount of imogolite on mechanical properties of (PVAVimogolite) nanohybrid

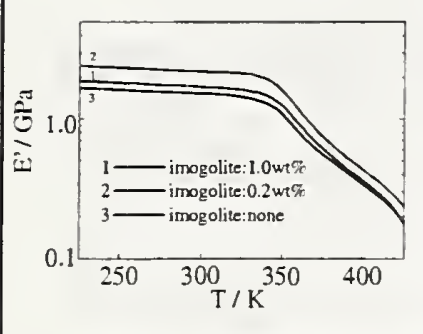

Addition and dispersion of $0.2 w 1 \%$ imogolite in PVA matrix

$E^{\prime}$ of (PVA/imogolite) film

Effective reinforcement was achieved by imogolite nanofiber

Further addition of imogolite ( 1 wit reduced E' because of the aggregation of imogolite.

Control of interfacial structure berween imogolite and PVA can avoid the

Samples were annealed at $393 \mathrm{~K}$ for $2 \mathrm{~h}$ aggregation of imogolite in PVA matrix

i.nivilun

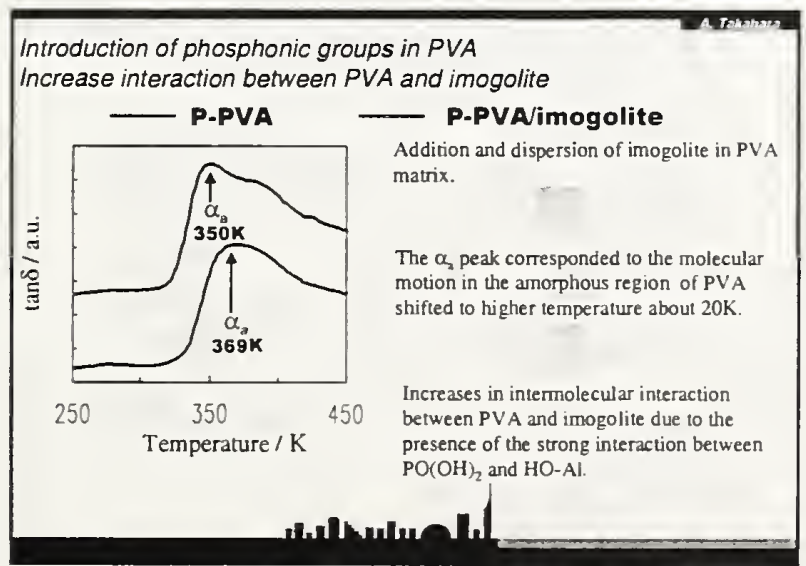

Preparation of (PVA imogolite) hybrid fitm

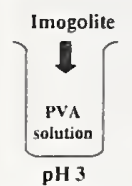

Aqueous solution

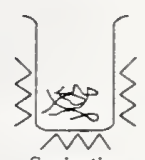

Sonication

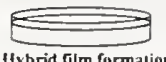

Itybrid film formation Anneal at $353 \mathrm{~K}$ for $2 \mathrm{~h}$ through evaporation of waler
Poly (vinyl alcohol) (PVA)

$\mathrm{DP}=630$, Degree of saponification $=98.3 \%$

Characterization of (PVAVImogolite) hybrid flim

Temperature dependence of dynamic viscoelasticlty

\section{nimingal}

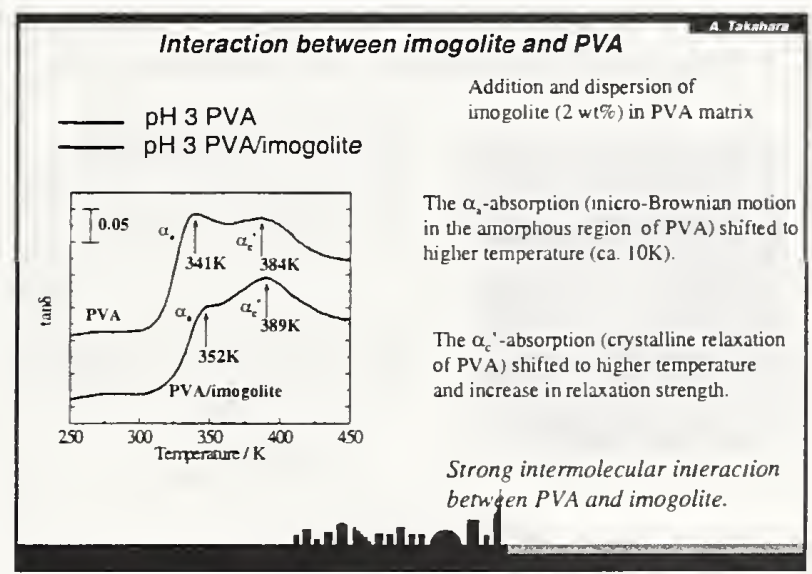

Preparation of (Imogolite/PMMA) nanohybrids

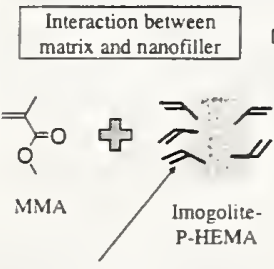

(2-hydroxyethyl)

methacrylphosphoric ester

$\mathrm{O}_{\mathrm{OH}}^{\text {(P-HEMA) }}$
Improve mechanical properties of interfate

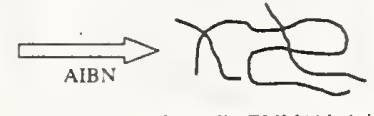

(Imogolite/PMMA) hybrid

Polymerization condition

Monomer : Initiator $=100.1,50: 1$

$$
343 \mathrm{~K} .6 \mathrm{~h}
$$

Characteristics of PMMA

100:1. $M_{n}=203 \mathrm{k}, M_{n} / M_{n}=1.86$

50. 1. $M_{n}=97 \mathrm{k}, M_{-} / M_{n}=2.31$

Intuln 

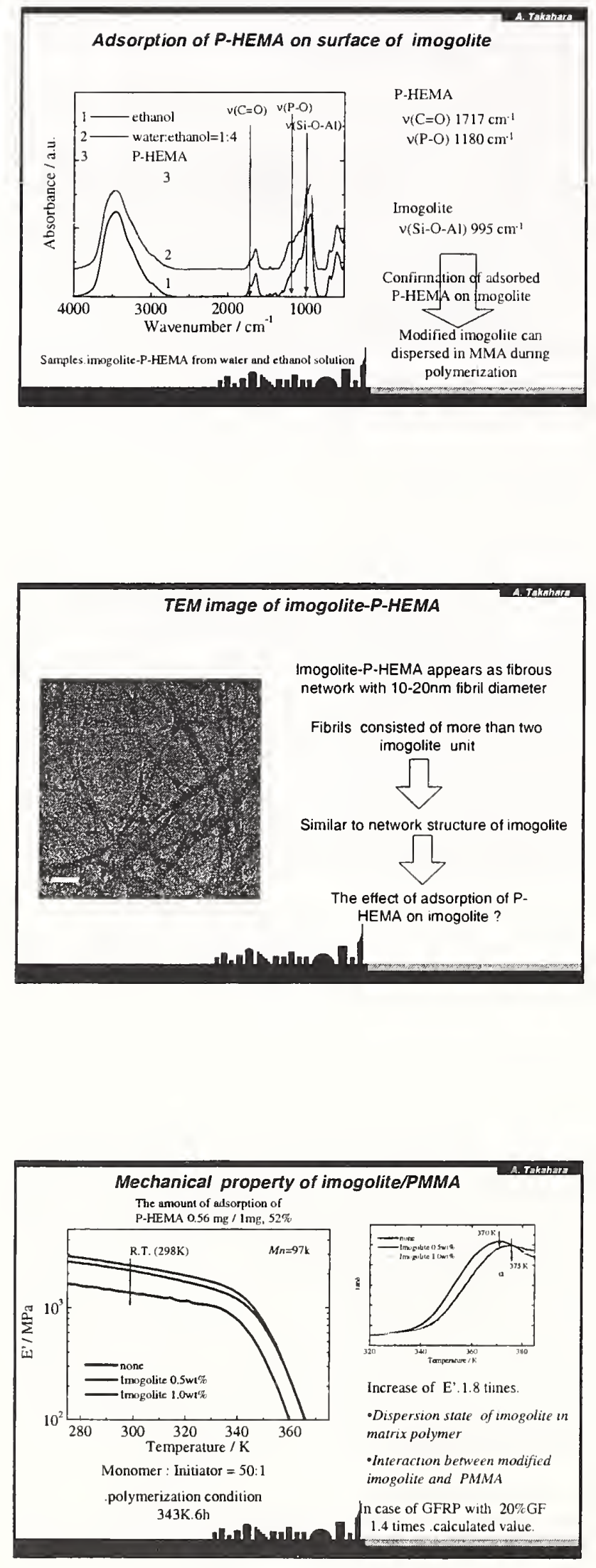
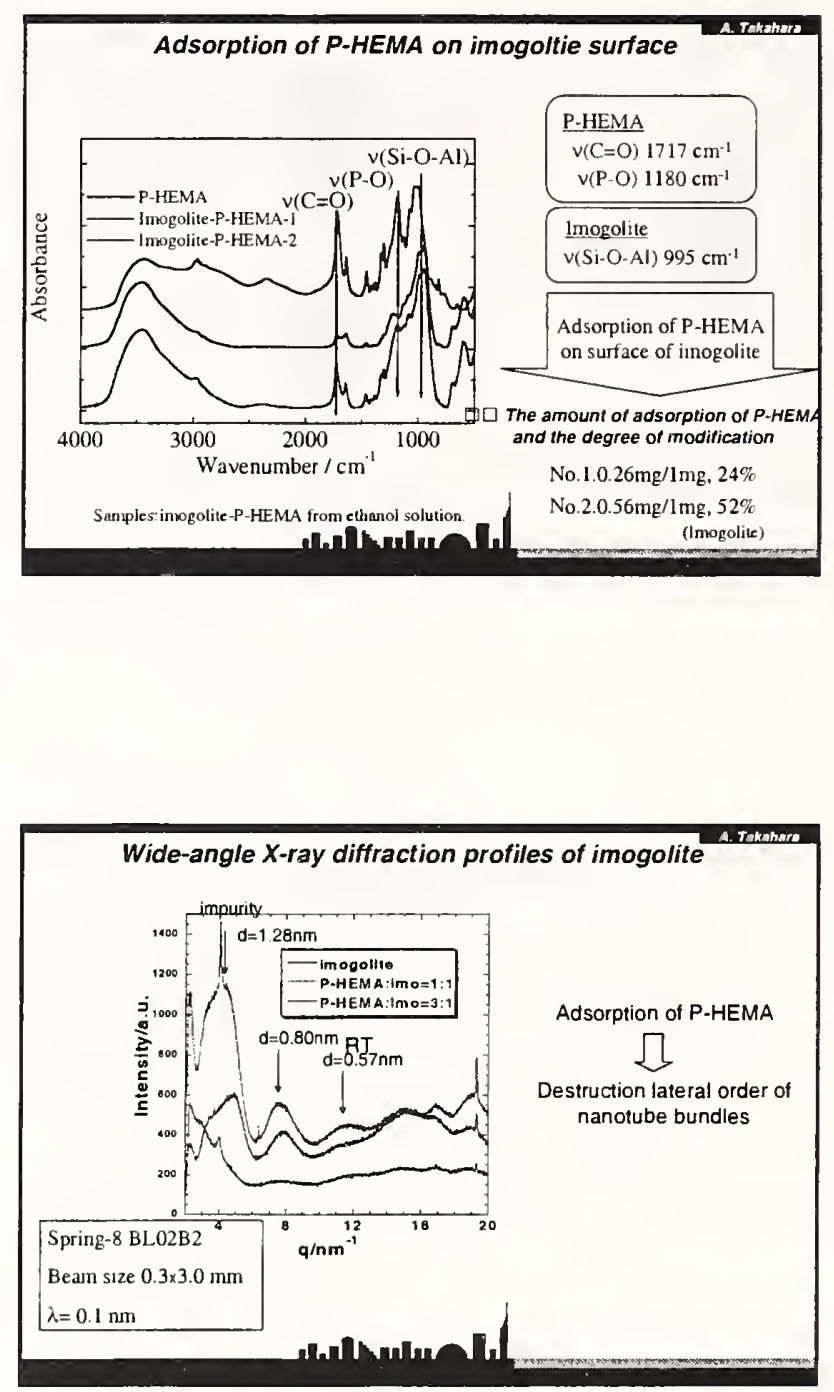


\section{Light transmission through (imogolite/PMMA) $\square$ hybric}

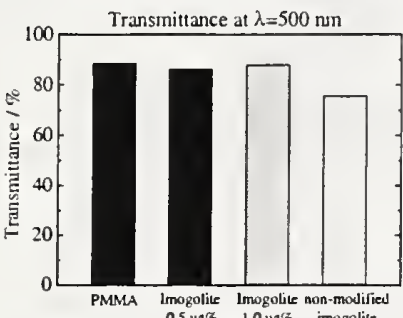
$056 \mathrm{mg} / \mathrm{lmg}$

\section{Modified imogolite/PMMA}

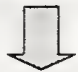

Transınittance through PMMA film revealed that the dispersion of modified-innogolile did no sacrifice the transparency of PMMA film

Monomer : Initiator $=50: 1$

polymerization condition $343 \mathrm{~K} .6 \mathrm{~h}$

\section{miviluent}

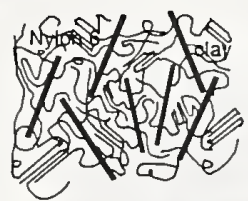

Application of $\mathrm{NCH}$

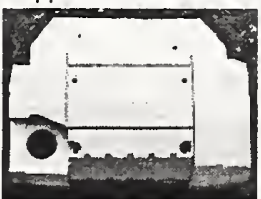

butp //www.unitiks co.jp/plastics/nylon/nylon6/nanohone_n hit
Nylon Clay Hybrid

In spite of low clay content

- Good mechanical properties

- High heat distortion temperature

- Low gas permeability

- Fatigue?

- Atutomotive timing belt covers (Toyota)

- Engine cover(Mitsubishi)

- Barrier filim

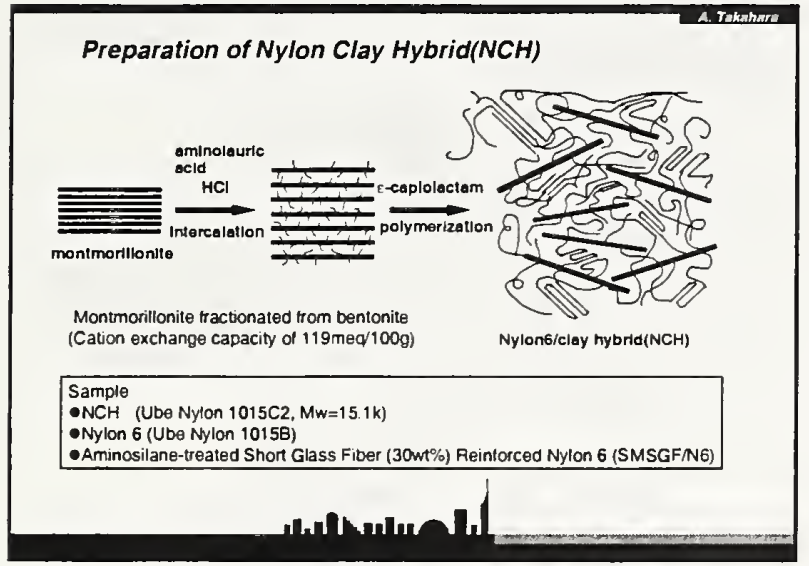

\begin{tabular}{|c|c|c|c|}
\hline \multicolumn{4}{|c|}{ Characterization of $\mathrm{NCH}$-Tensile test } \\
\hline Sample & $\begin{array}{l}\text { Tensile } \\
\text { modulus/GPa }\end{array}$ & $\begin{array}{l}\text { Tensile } \\
\text { strength/MPa }\end{array}$ & $\begin{array}{l}\text { Elongation } \\
\text { at breakk\% }\end{array}$ \\
\hline $\begin{array}{l}\text { Nylon } 6 \\
\text { (1015B) }\end{array}$ & 2.00 & 70.9 & 350 \\
\hline $\mathrm{NCH} 2$ & 2.33 & 81.1 & 330 \\
\hline SMSGFNG $=30 / 70$ & 4.64 & 101.8 & 6.5 \\
\hline
\end{tabular}

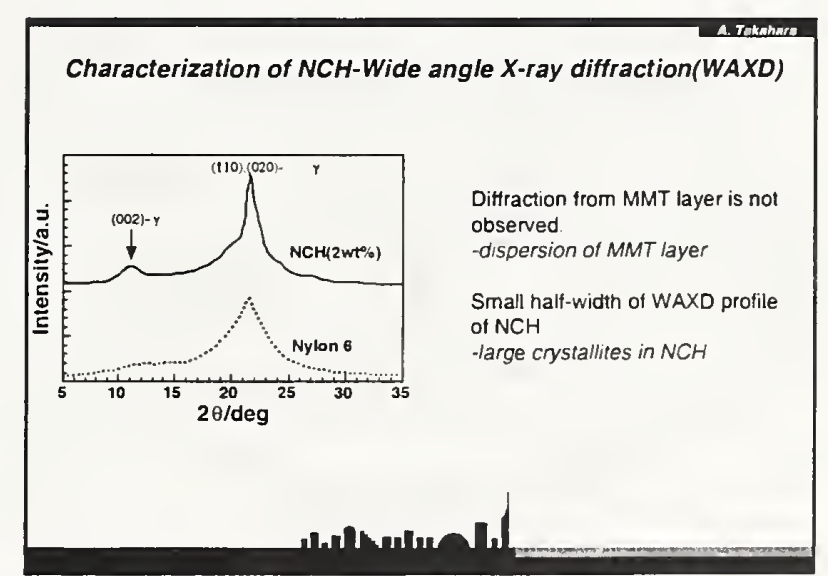

Characterization of $\mathrm{NCH}$-Temperature dependence of dynamic viscoelasticity

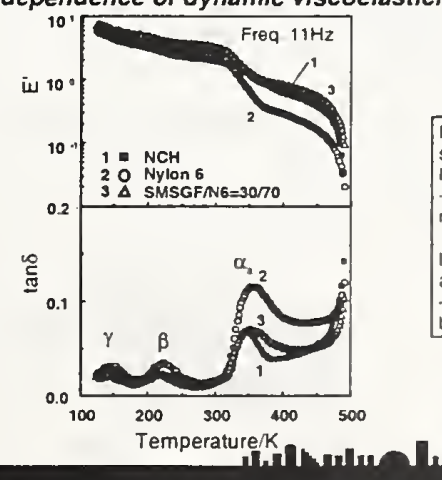



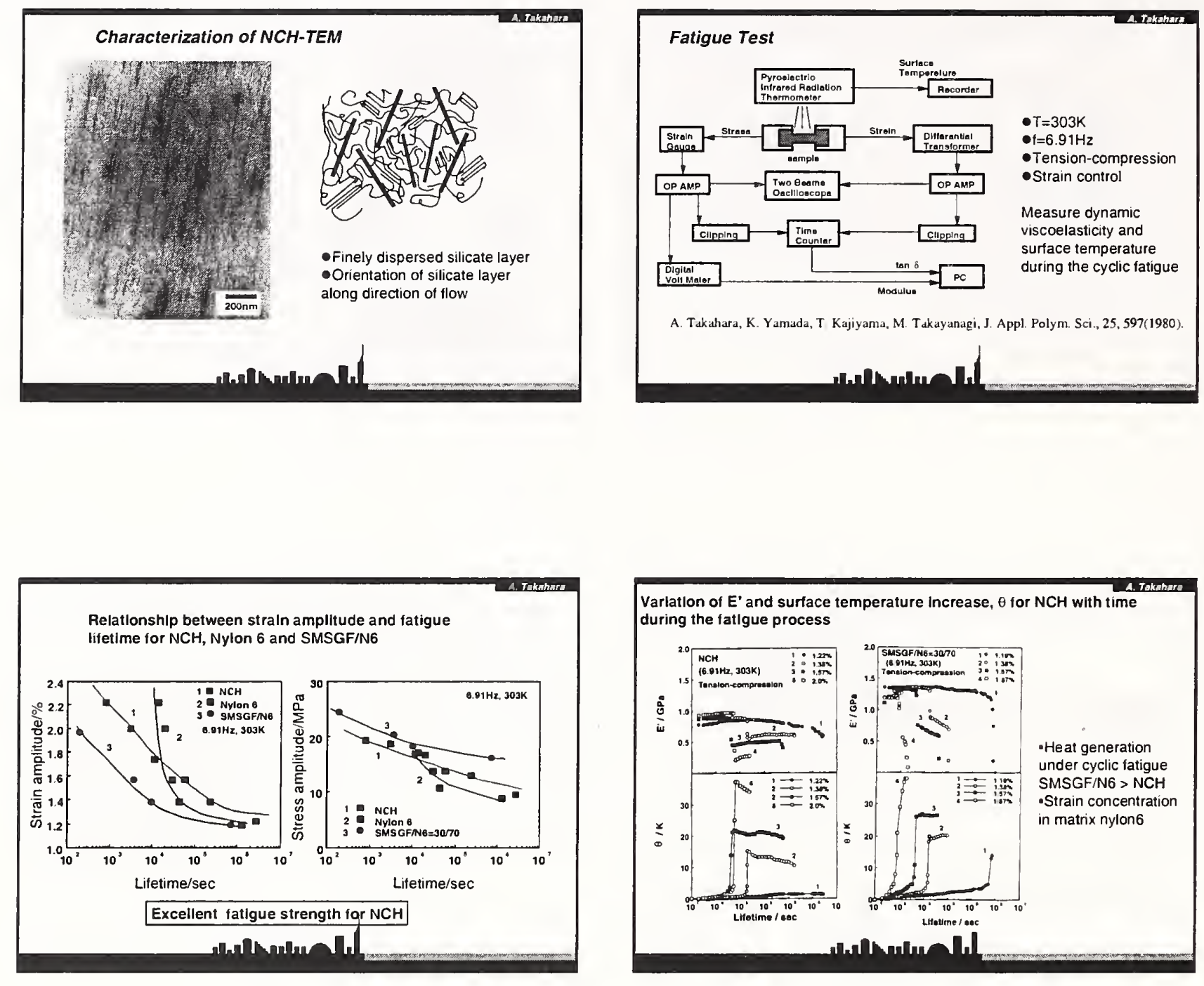

Fatigue Criterion based on Viscoelastic Energy Loss

Surface temperature increase is smaller than that expected from the viscoelastic energy loss. Some part of the viscoelastic energy did not appear as heat but consumed for irreversible structural change.

$$
\begin{gathered}
H=\chi H+(1-\chi) H \\
\frac{d T_{s}}{d t}=\frac{1}{\rho c}\left[\chi \pi f \varepsilon_{d}^{2} E "-\kappa\left(T_{t}-T_{0}\right)\right]
\end{gathered}
$$

Evaluation of heat transfer coefficient, $\kappa$

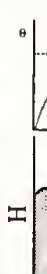

$\left(H_{s, a v}-H_{0}\right) t_{f}=C$ Stop tatigue tasl $\frac{d \theta}{d t}=\frac{1}{p c}(-\kappa \theta)$
Fatigue failure criterion

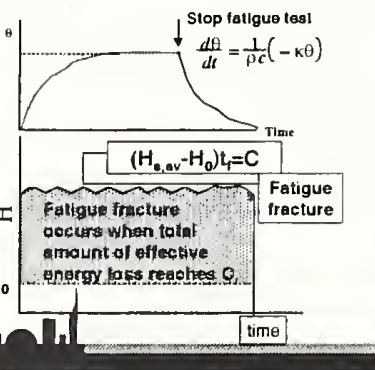

Relationship between $\mathrm{H}_{\mathrm{ar}}$ and lifetime for $\mathrm{NCH}$, Nylon 6 and SMSGF/N6 composite.

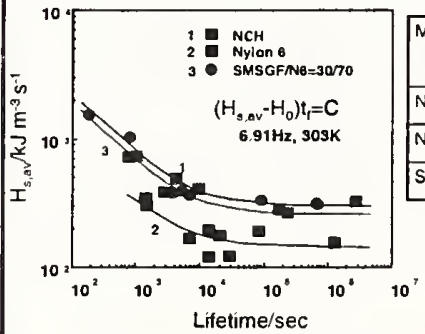

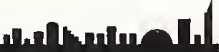

\begin{tabular}{|l|c|c|c|}
\hline Matenal & $\begin{array}{l}\text { Density } \\
/ 10^{3} \mathrm{~kg} \mathrm{~m}^{-3}\end{array}$ & $\begin{array}{l}\text { Tensile } \\
\text { strength/ } \\
\mathrm{MPa}\end{array}$ & $\begin{array}{l}\mathrm{C} \\
/ 10^{2} \mathrm{M} / \mathrm{m}^{3}\end{array}$ \\
\hline $\mathrm{NCH}$ & 1.15 & 81 & 6.5 \\
\hline Nylon 6 & 1.14 & 71 & 4.1 \\
\hline SMSFG/N6 & 1.36 & 102 & 3.6 \\
\hline
\end{tabular}

$\mathrm{NCH}$ showed fatigue strength being superior to nylon 6 and glass-fiber reinforced nylon 6 -no macroscopic interface 


\section{Conclusions}

- Surface of imogolite was successfully modified by organic molecule with phosphonic acid. Modified imogolite was successfully dispersed in organic solvent.

- Novel-Green nanohybrid was prepared from imogolite (natural inorganic nanofiber) and environmentally benign poly (vinyl alcohol) (PVA).

- (Imogolite/PMMA) nanohybrid was successfully prepared through surface modification of imogolite with P-HEMA.

- NCH showed excellent fatigue performance compared with conventional short glass-fiber reinforced nylon 6 .

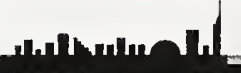


7) R. A. Vaia, "Impact and control of Ultrastructure (Meso) in Polymer Nanocomposites" [PowerPoint] [PDF]

Dr. Vaia emphasized the balance between cost and added value in filled materials that drive the development of these materials at the Air Force Research Laboratory and elsewhere. After giving a valuable summary of opportunity areas for development of nanocomposites in aerospace and the challenges for understanding structure-property relationships in these systems, he summarized some experience of filled systems in relation to self-passivation and erosion in aggressive environments. Tools found helpful in characterizing these systems are summarized (SAXS, WAXS). Challenges in understanding filled rubbers and parallels of the filled systems to complex liquids were also considered. It was suggested that many useful properties of these nanocoposites could be obtained by exploiting the high particle anisotropy and field structuring and preliminary work on this topic (e.g., orientation of clay particles with an E-field). 


Impact and Control of
Ultrastructure (Meso)
in
Polymer Nanocomposites
R. A. Vaia, H. Koerner, R. Reuter, G. Price
Air Force Research Laboratory, Polymer Branch
WPAFB, OH, 45433-7750
Alf Fores Offlce of Sclentife Resesrch
AFRL Moterials ond Manutecturing Directorate

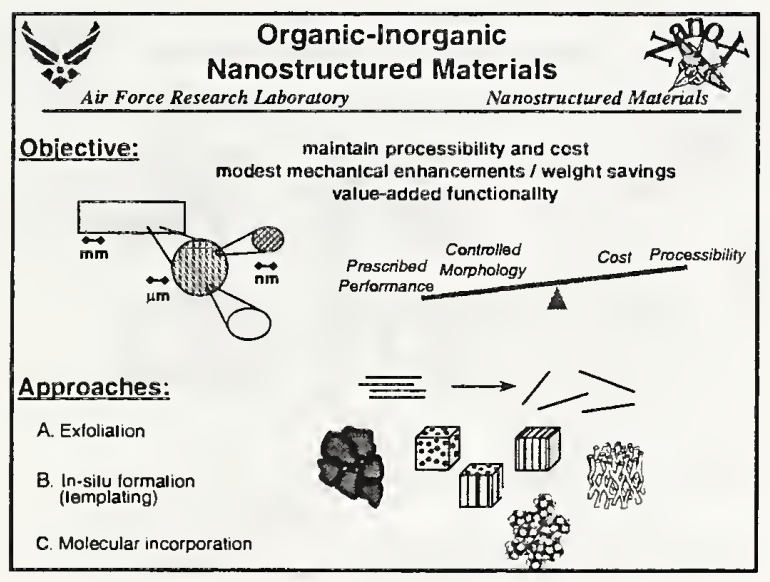

Fundamental Challenge:
Structure-Property-Processing Relationships
Air Force Research Laboratory
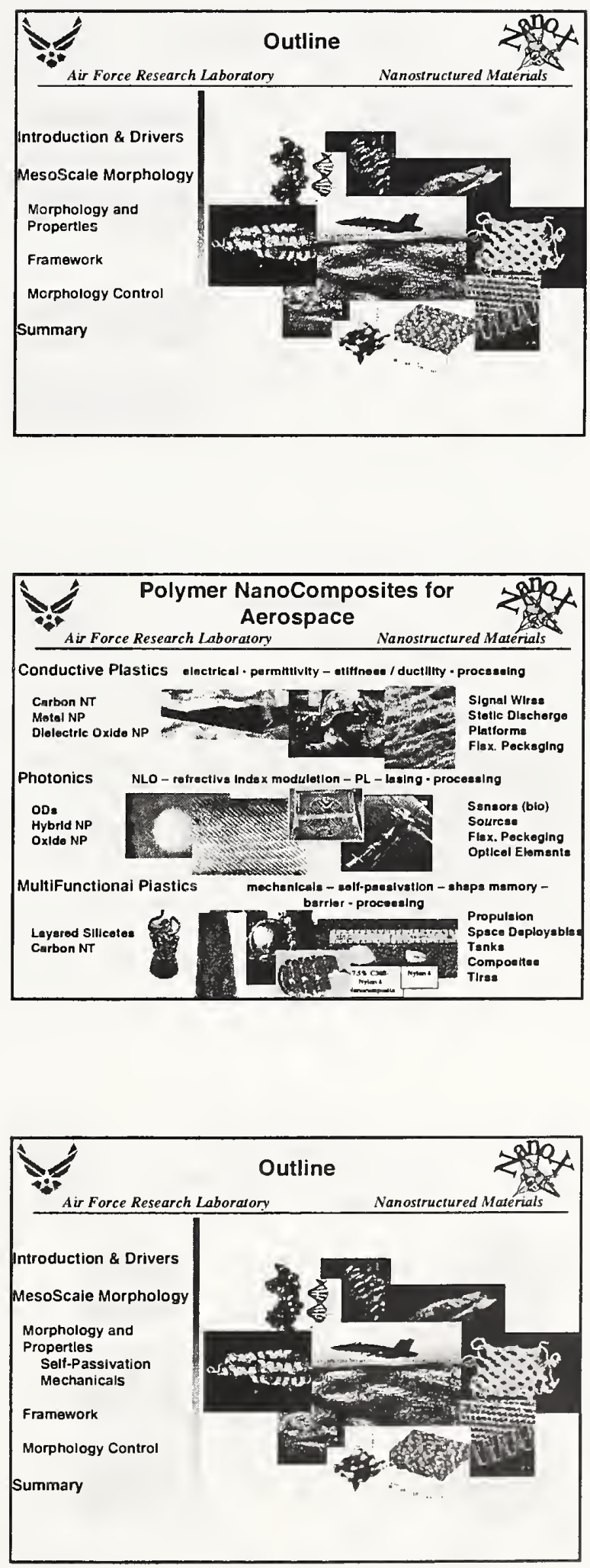

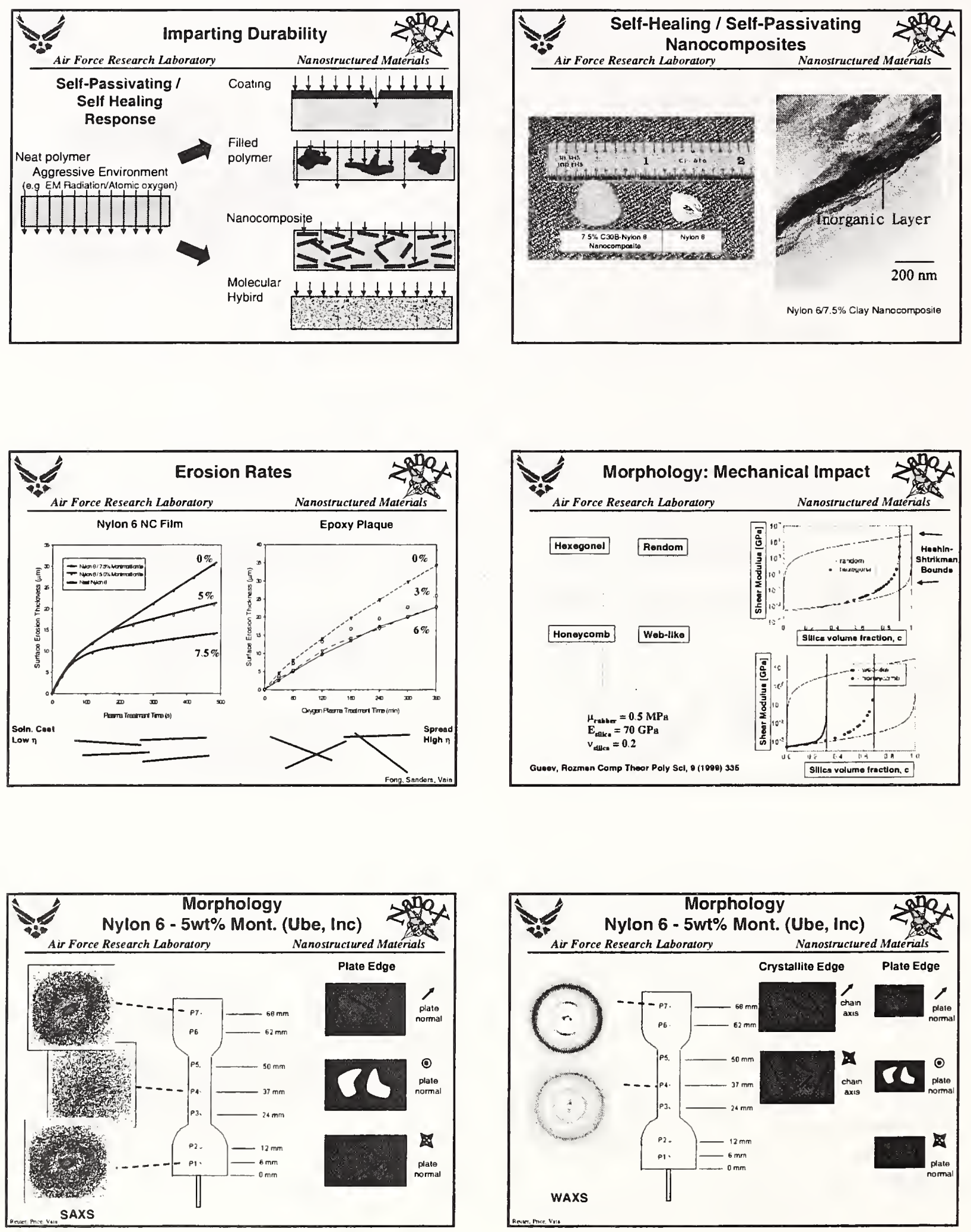

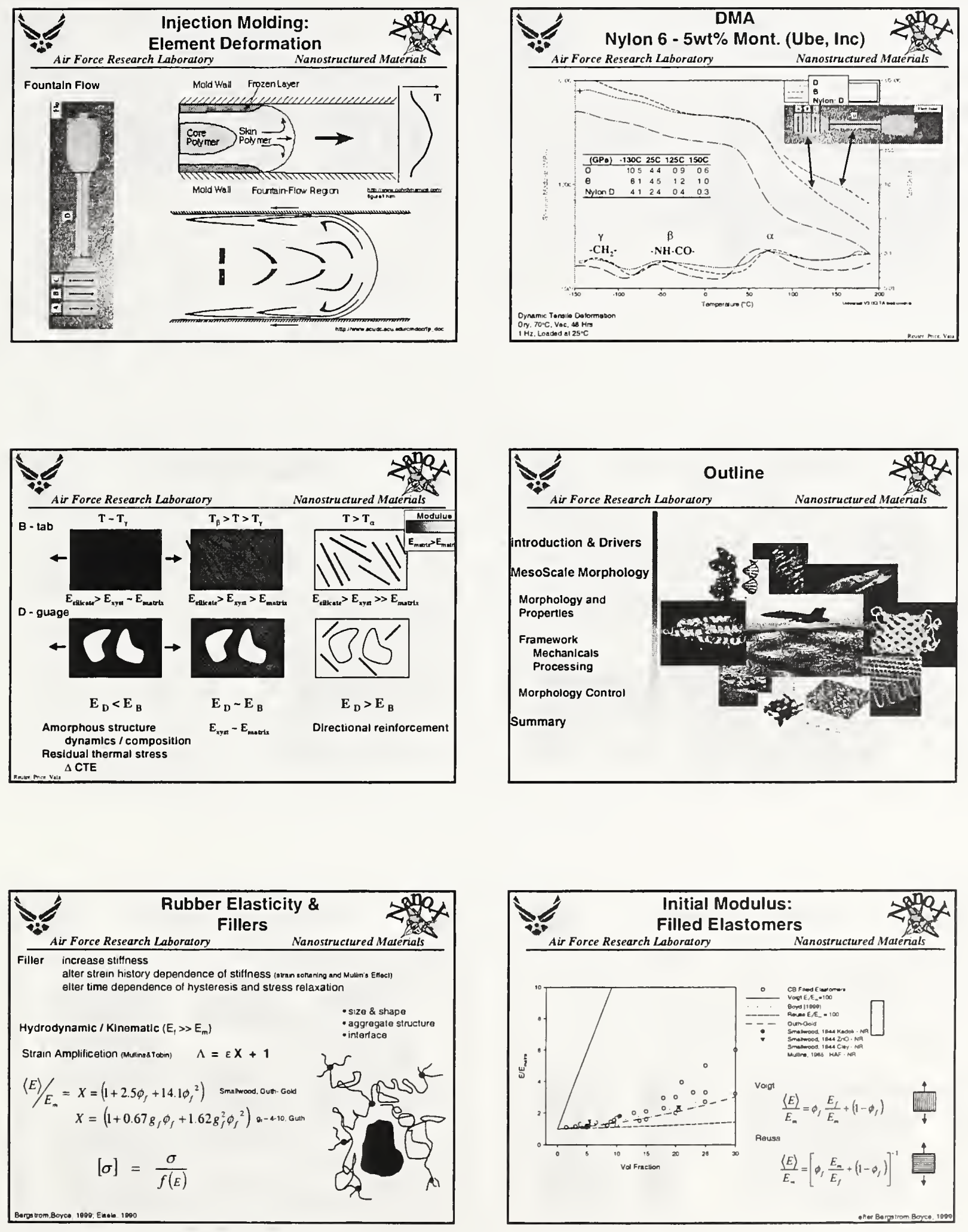

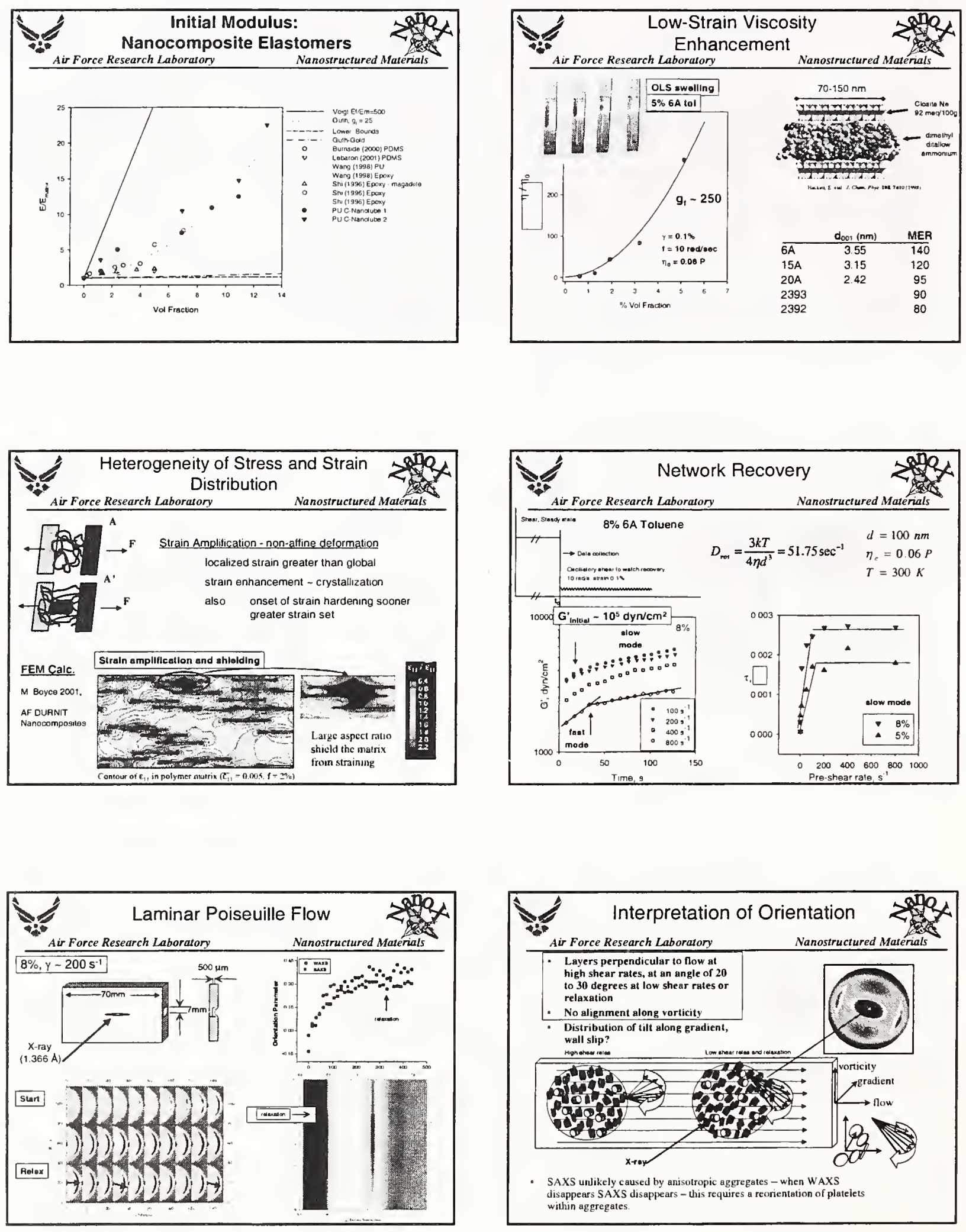

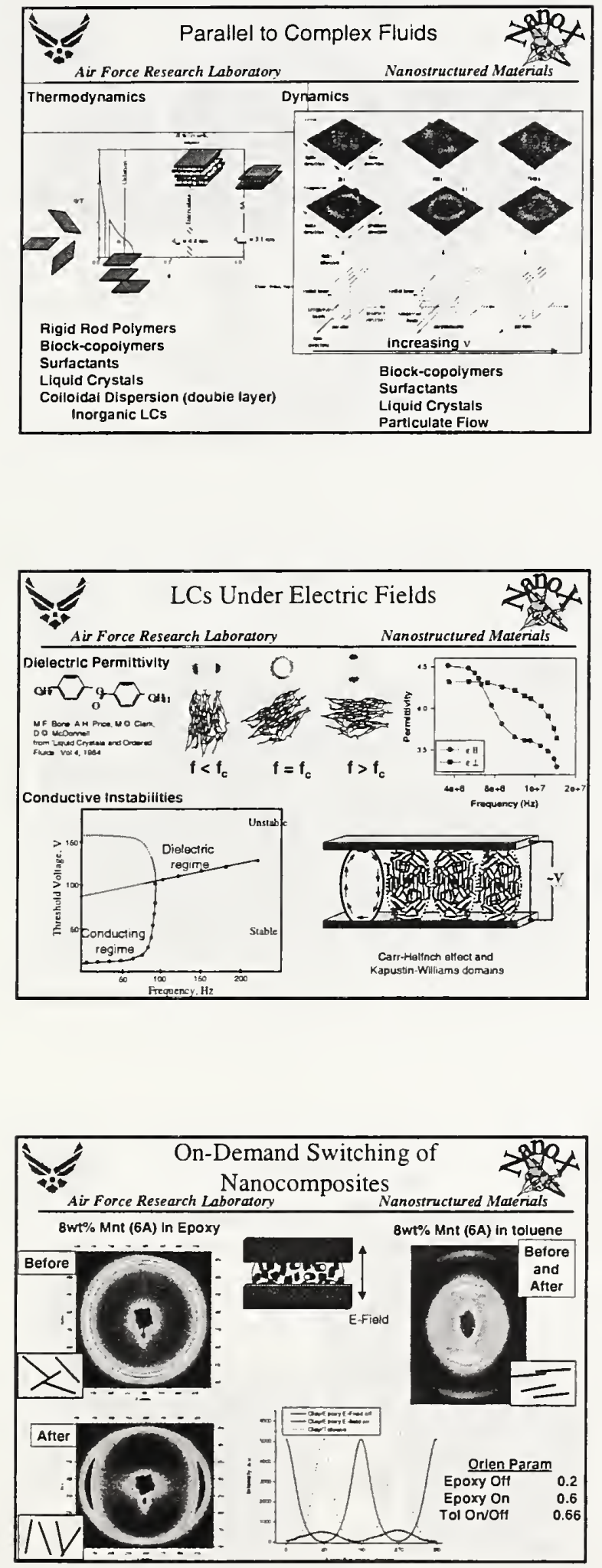
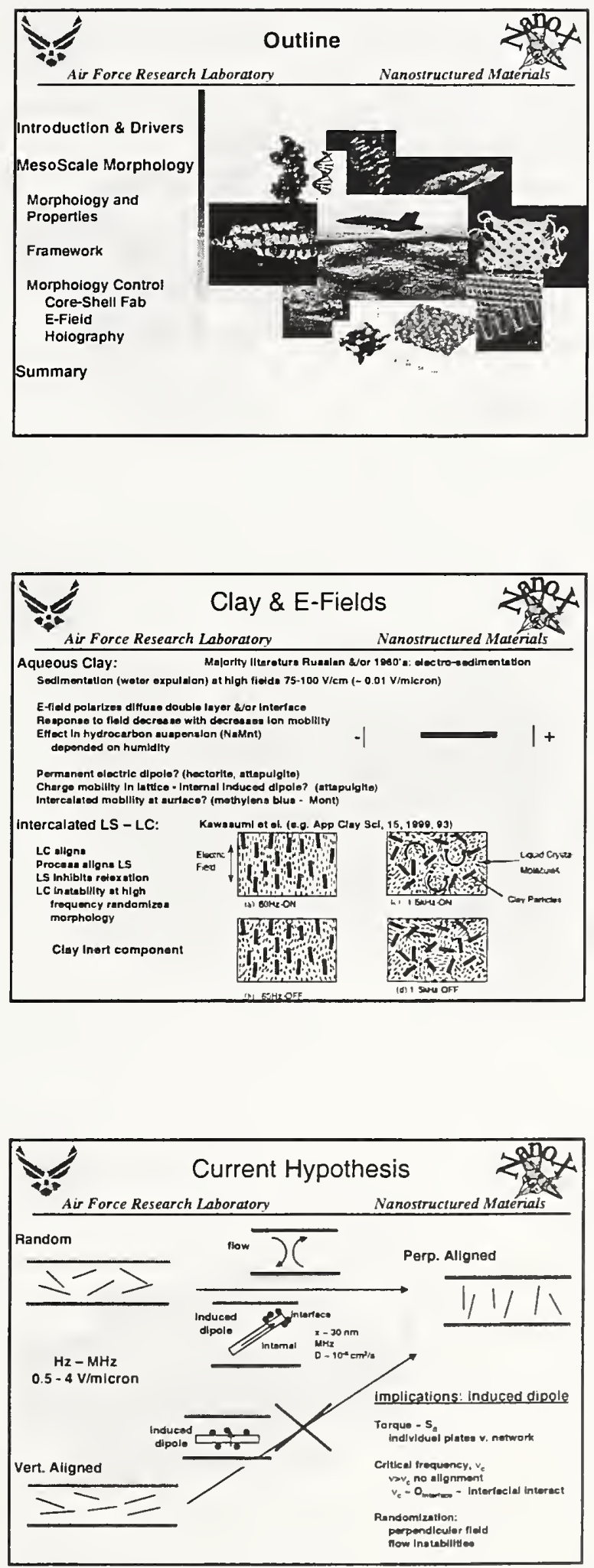


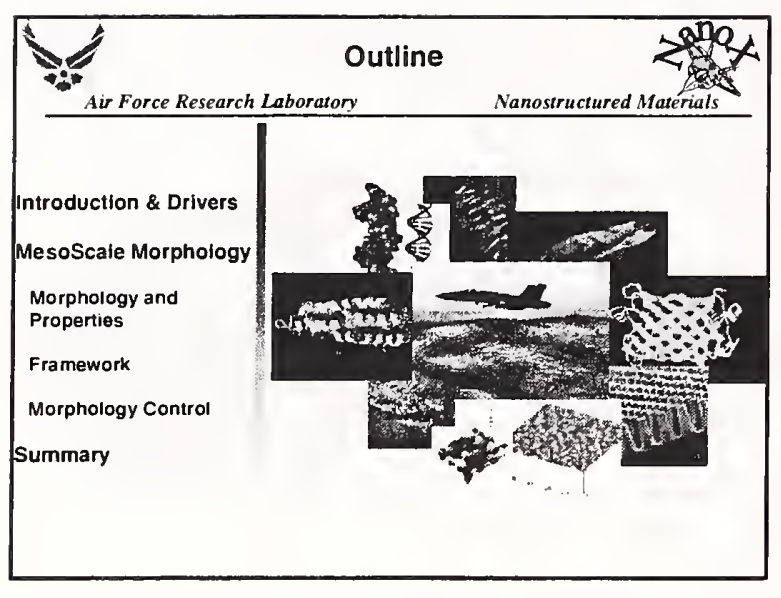

\begin{tabular}{|c|c|c|}
\hline \multicolumn{2}{|c|}{ Potential } & ostructured Materials \\
\hline $\begin{array}{l}\text { Precision } \\
\text { Morphology }\end{array}$ & $\begin{array}{l}\text { Predictive } \\
\text { Relationships }\end{array}$ & $\begin{array}{l}\text { Cost Elfective } \\
\text { Manufacturing }\end{array}$ \\
\hline 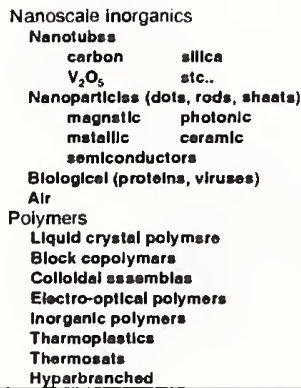 & $\begin{array}{l}\text { Objectives } \\
\text { Multifur } \\
\text { EMI } \\
\text { Smar } \\
\text { Embe } \\
\text { Chan } \\
\text { Activs } \\
\text { Actuato } \\
\text { Sensor } \\
\text { Obsecur } \\
\text { Dlaloctr } \\
\text { Nonline } \\
\text { Fusl col }\end{array}$ & $\begin{array}{l}\text { isi materials } \\
\text { Ing } \\
\text { Icas } \\
\text { lantannas } \\
\text { mambranes } \\
\text { nic crystals } \\
\text { cilion } \\
\text { tleal materiale } \\
\text { nbrana }\end{array}$ \\
\hline
\end{tabular}

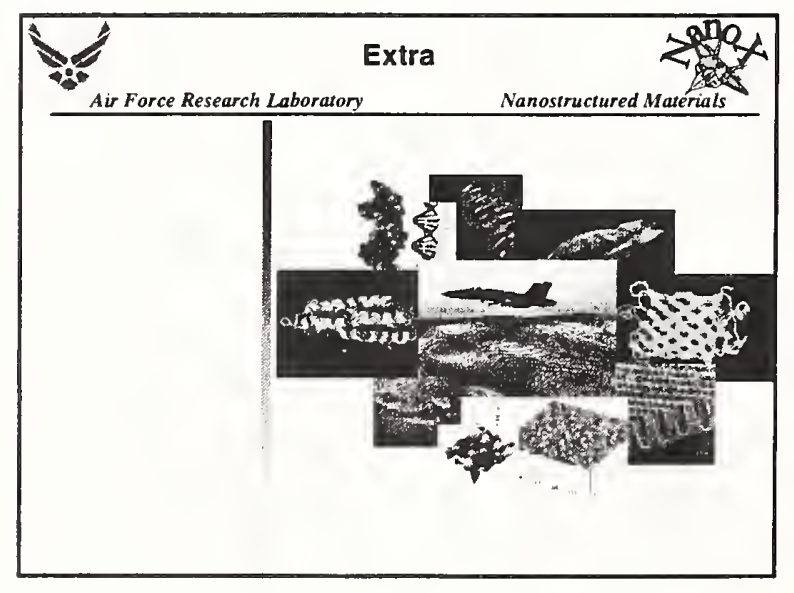

Conclusions
Air Force Research Laboratory
- Inltiai Frameworks exist to develop SPP Reiations hips
Not sufficient to treat as isotropic systems
Preferential reinforcement, self-passivation, CTE, etc..
Heterogeneity of local stress/strain distribution
- Network history (not just individuai particle key)
Anisotropic percolation and recovery
Aspect ratio - persistence length
- Techniques for Hierarchlcal Morphology Control Necessity
Experimentai data for SPP theory
Unique nanocomposite applications:
Electronlc packaging, optics, polyelectrolytes

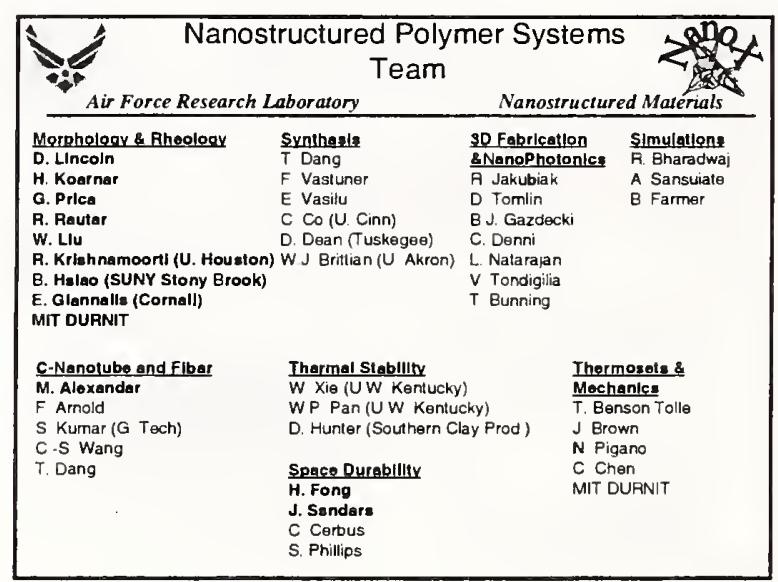

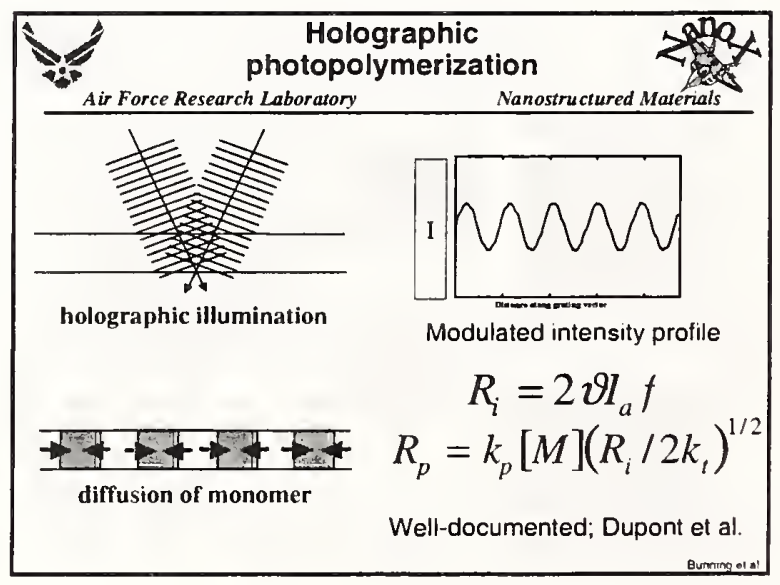



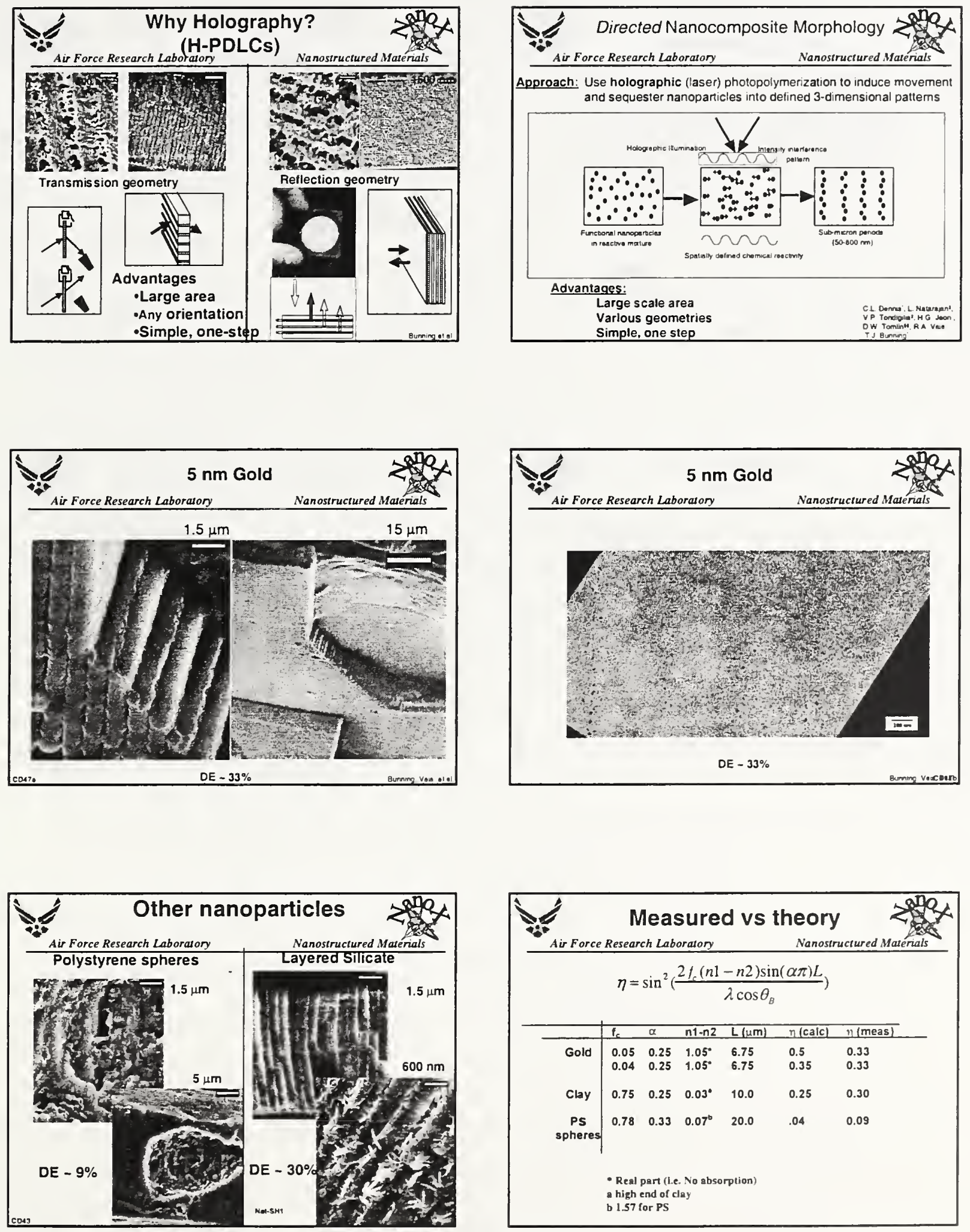

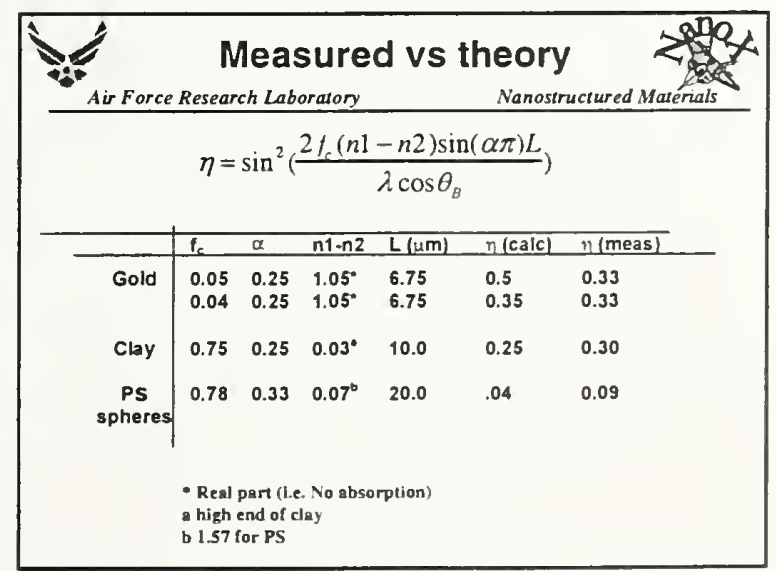



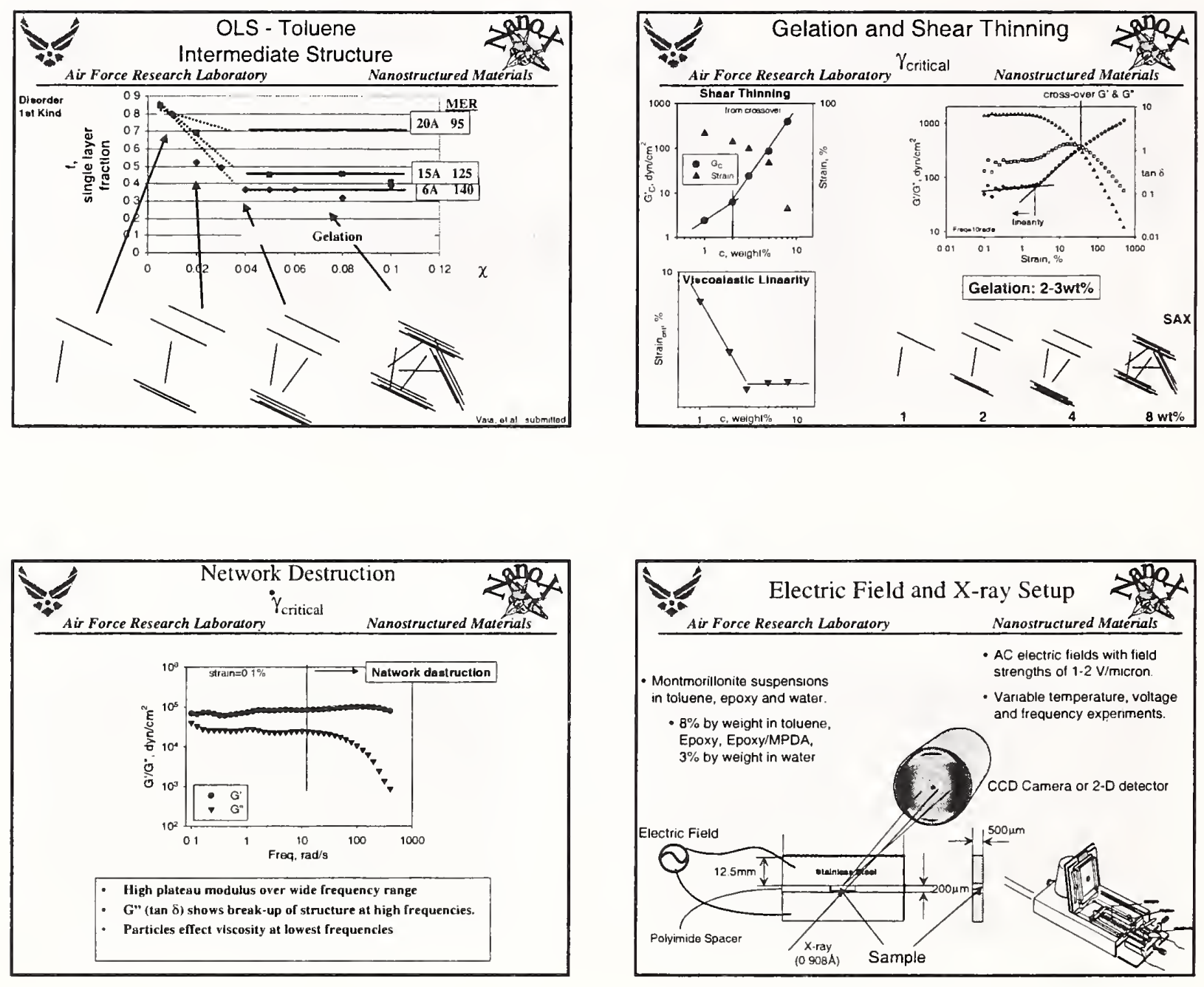
8) Francis W. Starr, 'Probing Nanocomposite Structure and properties using Computer Simulations" [PowerPoint] [마 $]$

Dr. Starr emphasized the need to study nanofilled systems using idealized models with the intention of identifying general properties. First, he summarized recent molecular dynamics work by himself and coworkers showing that the glass transition $\mathrm{T}_{\mathrm{g}}$ of filled systems can be shifted to higher or lower temperature depending on the polymer particle interaction. This effect was compared to similar results, supported both by experiment and theory, for shifts of $\mathrm{T}_{\mathrm{g}}$ in thin polymer films with variable polymer surface interactions at the boundaries. Preliminary results were then shown for simple simulation models of clay sheets and compact nanoparticles. Not surprisingly, the compact nanoparticles aggregated when the polymerparticle interaction was weak. This effect was quantified through the phase diagrams' governing the clustering state of the particles in the plane of temperature and polymer-particle interaction and the plane of the concentration of particles versus polymer-particle interaction. The clustering transition was identified through a maximum in the specific that accompanies the particle clustering transition. These observations are consistent with an equilibrium clustering transition that requires further investigation. Useful criteria for identifying this clustering from scattering measurements were then summarized. Finally, the influence of shear on the clustering of model clay particles in a polymer matrix was investigated by molecular dynamics and the thermodynamic clustering line was found to shift under shear. Finally, the importance of developing hierarchical multiscale modeling approaches was emphasized in order to model nanoparticle systems under more realistic processing conditions. 
Probing Nanocomposite Structure and Properties using Computer Simulations

Francis W. Starr

Polymers Division, Center for Theoretical and

Computational Matenals Science

Jack Douglas, NIST

Sharon Glotzer, NIST \& Michigan

Thomas Schroder, NIST \& Roskilde

Barry Farmer, AFRL

Anuchai Sinsuiate, AFRL

Richard Vaja, AFRL

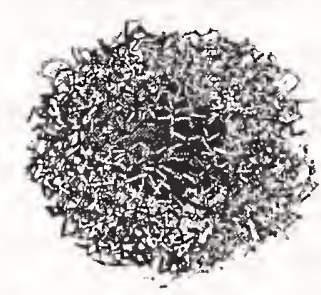

NIST

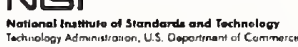

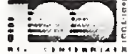

Filled Polymers and Nanocomposites

- Improve mechanical, rheological, dielectric, optical and other properties

- Low tech: tires, bumpers, paints and coatings

- High tech: micro- and nano-electronic devices

- Nanofillers

- Tailor size and interactions to make specific property

modifications

- Custom designed materials!

Molecular level mechanisms poorly understood!

- Philosophy of this work: Start with simple systems, and work towards complexity
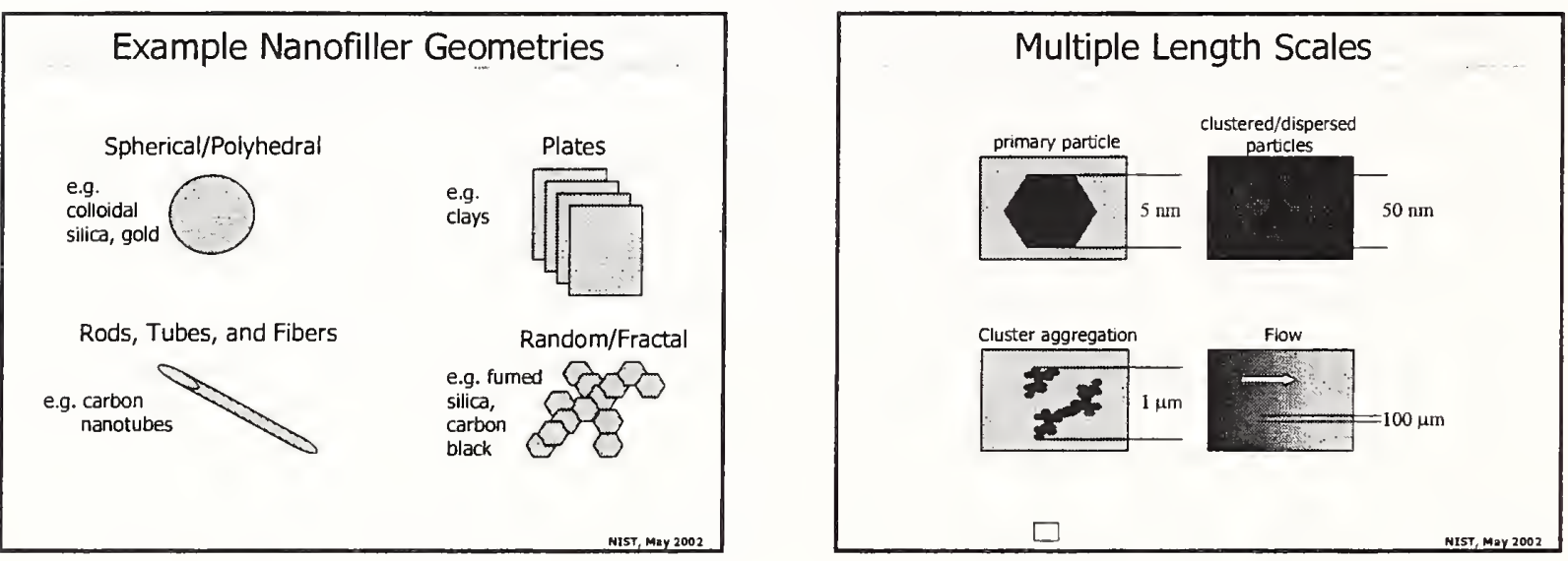

\section{Outline}

- Single, Symmetric Nanoparticle in a Dense Melt; consider effect of interactions on:

- Chain Structure and Dynamics near interface

- Relation to thin films (geometry implications)

- Nanocomposite: Symmetric nanoparticles in a meit

- Aggregation and dispersion

- Response to shear/relation to structure

- Clay-like Nanocomposite:

- Response to shear (preliminary!) 

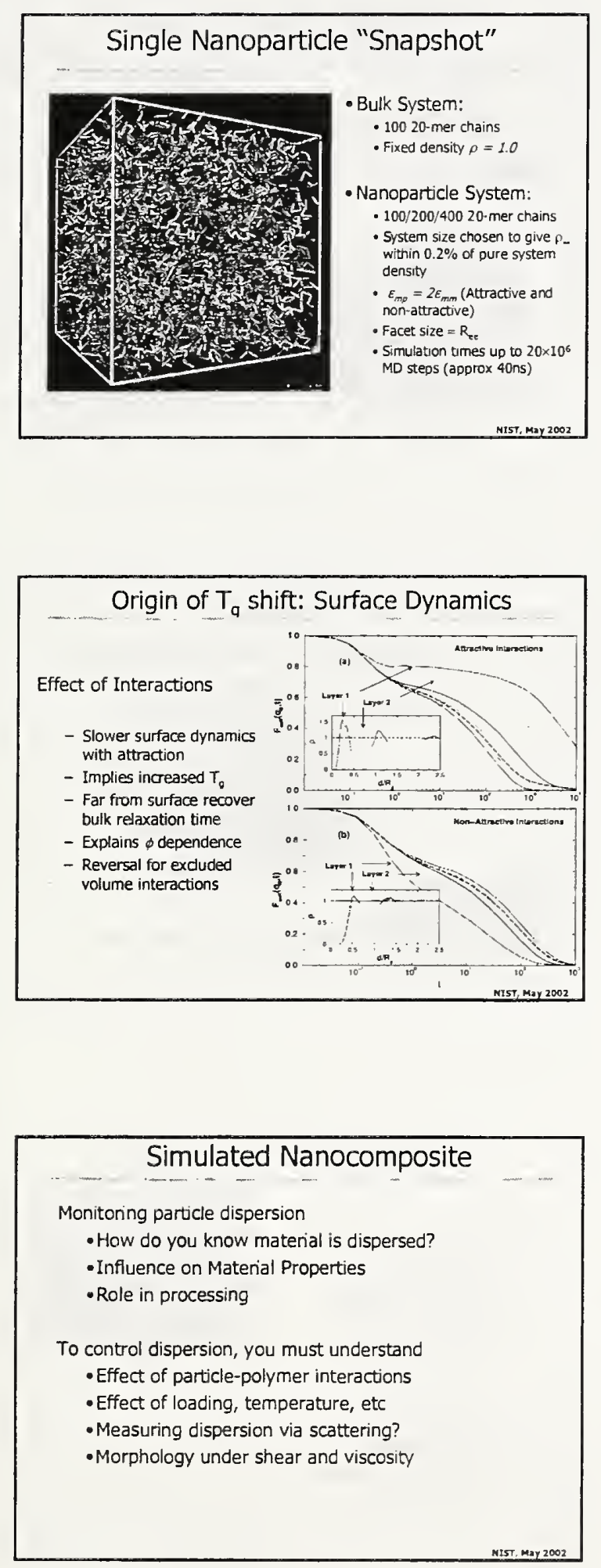
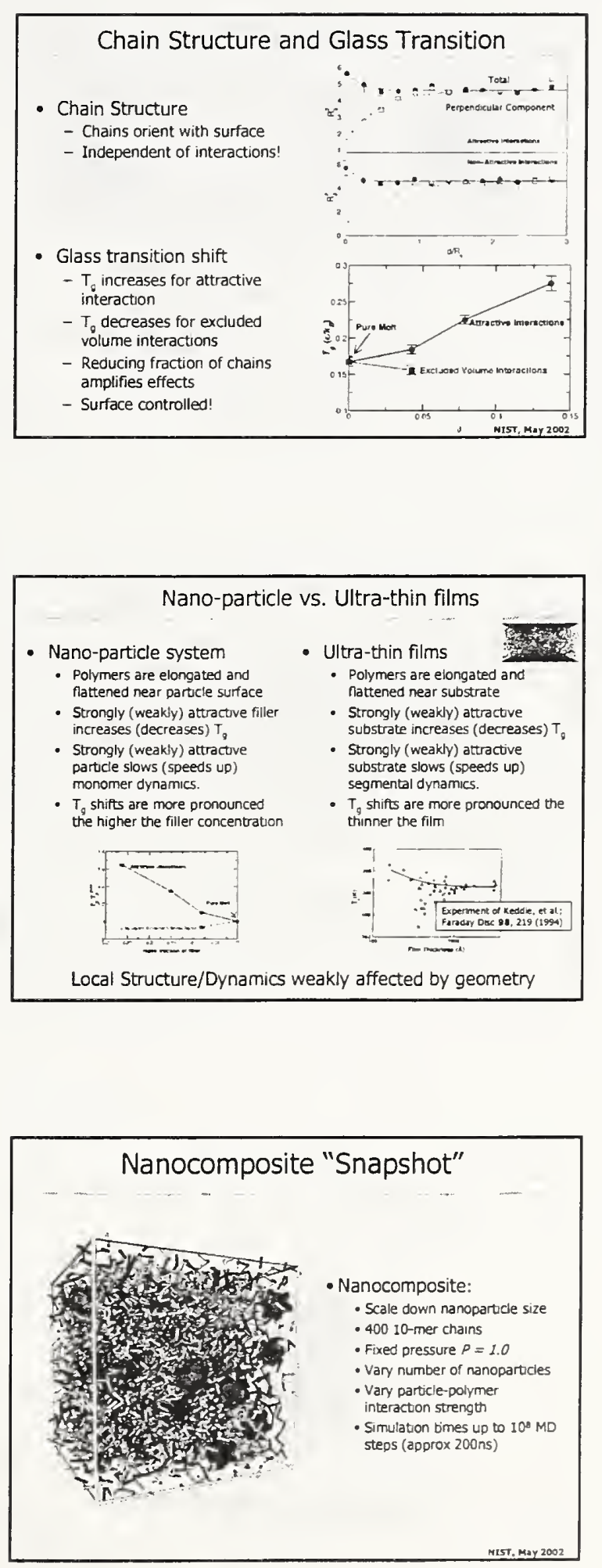

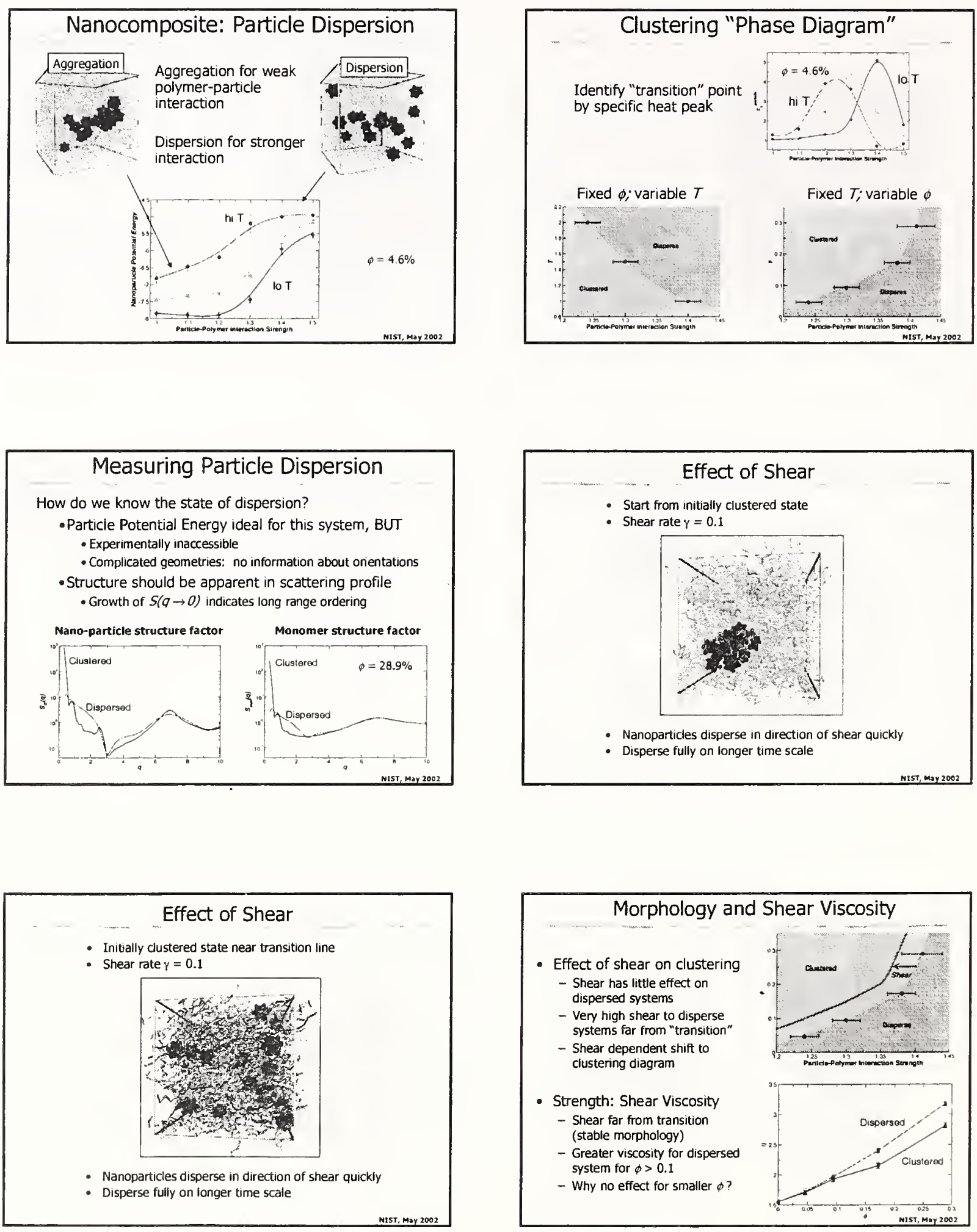


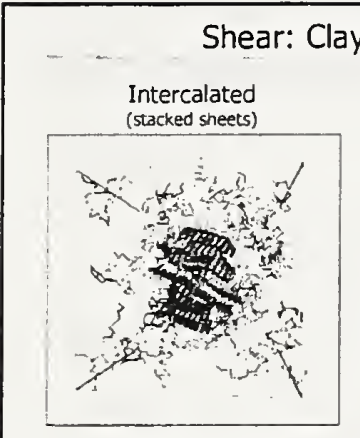

Shear: Clay-like sheets

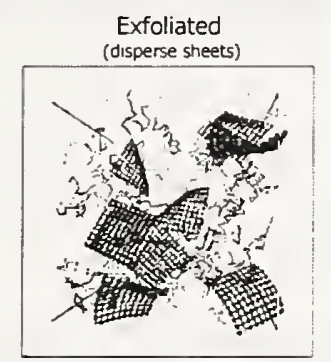

- Loading: $\phi=0.057$

- Viscosity disparity equivalent to $\phi=0.2$ for nanoparticles

\section{Conclusions}

- Surface Effects

- Chains align with filler surface

- Chain conformation insensitive to interaction

- Interactions dominate surface dynamics and $T_{g}$

- Clustering and Dispersion

- Dispersion dominated by particle-polymer interaction

- Dispersion measurable via scattering (impractical)

- Response to shear

- Shear favors disorder here

- Greater viscosity when dispersed

- Geometry important for improving properties

\section{What next?}

- Filler Geometry and Interactions

- Expand sheet studies

- More complex interactions (electrostatic?)

- Keep models simple

- New Approaches?

- Larger length scales impractical for MD/MC approach

- Mesoscopic methods

- Lattice Boltzmann/Lattice Gas

- Dissipative particle dynamics

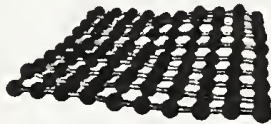

\section{Acknowledgments}

Eric Amis

Charles Han

Eric Hobbie

Alamgir Karim

Alan Nakatani

Andrew Roosen

Wen-li Wu

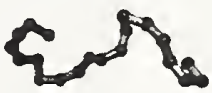


9) Juan J. de Pablo, "Molecular Simulation and Characterization of Ultrathin Films and Nanoscopic Polymeric Structures: Departures from Bulk Behavior" (talk presented by Kevin Van Workum) [PowerPoint] [PDF]

Dr. De Pablo's approach to modeling polymer thin films and nanoparticle filled polymer materials stresses the need for molecular modeling (molecular dynamics and Monte Carlo), continuum theory and measurement. As in the talk of Dr. Francis Starr, this contribution emphasizes simple model systems capable of inferring behavior of qualitative importance for process applications. First, recent experimental and simulation studies of the glass transition in thin films are summarized as an illustration of the value of computational methods in interpreting measurement. This is followed by the challenge of understanding finite size effects in polymer lithography applications where the scale of the patterns becomes below the scale of convenient measurement and where continuum theory can no longer be trusted. Simulations provide insight into what might be expected in this nanoscale regime. The Young's modulus of the etched lines depends on the line width and elastic constants become anisotropic. Nanoparticle fillers are shown to offer some promise in improving the properties and stability of these nanoscopic patterns. Further simulation applications explore the alignment of liquid crystal molecules about nanoparticles in connection with the development of sensors based on the binding of biological molecules to liquid crystalline substrates. Segregation of nanoparticles in block copolymer systems was also investigated in connection with the self-assembly of metal nanostructures on diblock copolymer scaffolds. 


"Molecular Simulation and Characterization of
Ultrathin Films and Nanoscopic Polymeric Structures:
Departures from Bulk Behavior"
Kevin Van Workum,
Profs. Juan J. de Pablo and Paul F. Nealey
Department of Chemical Engineering
and the Center for NanoTechnology
University of Wisconsin - Madison

Multiscale Modeling of the Mechanical
Properties of Polymeric Nanoscopic
Structures
3

Introduction
Understanding Structure-Property relationships at nanometer
length scales is becoming increasingly important.
Tiree Distinct Applications:
- Mechanical Properties of Nanostructures and
Nanocomposites
Nanoparticles dispersed in Liquid Crystals
Nanoparticles dispersed in Block Copolymers
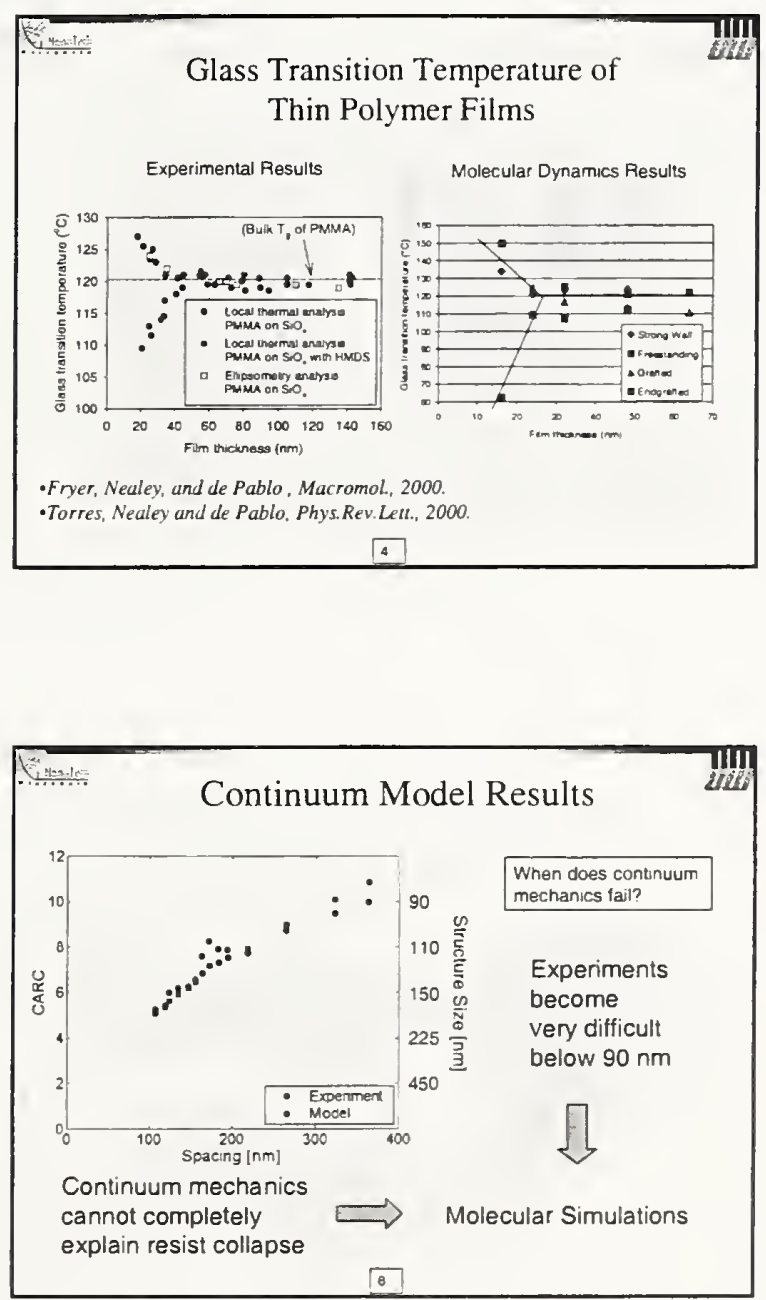

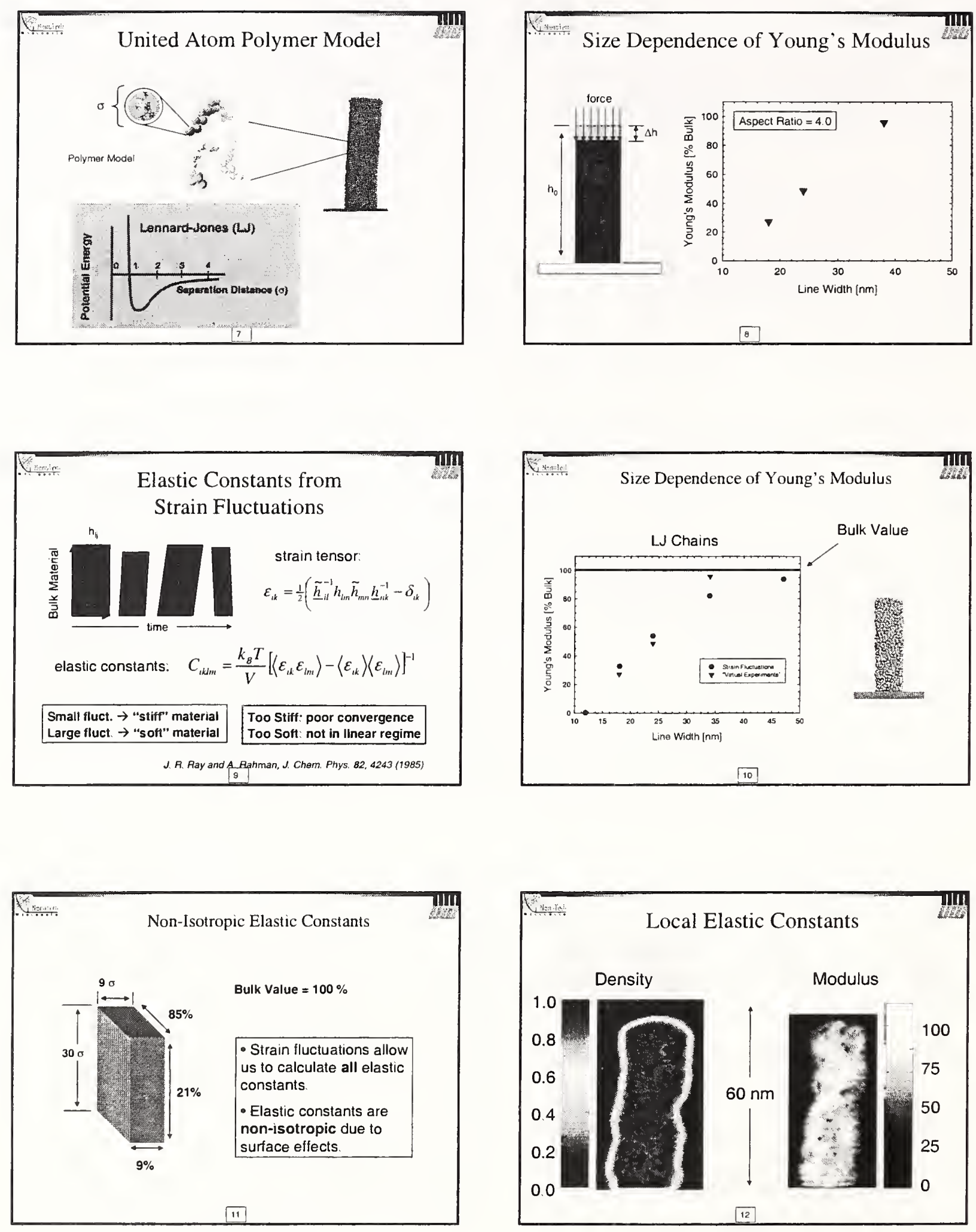

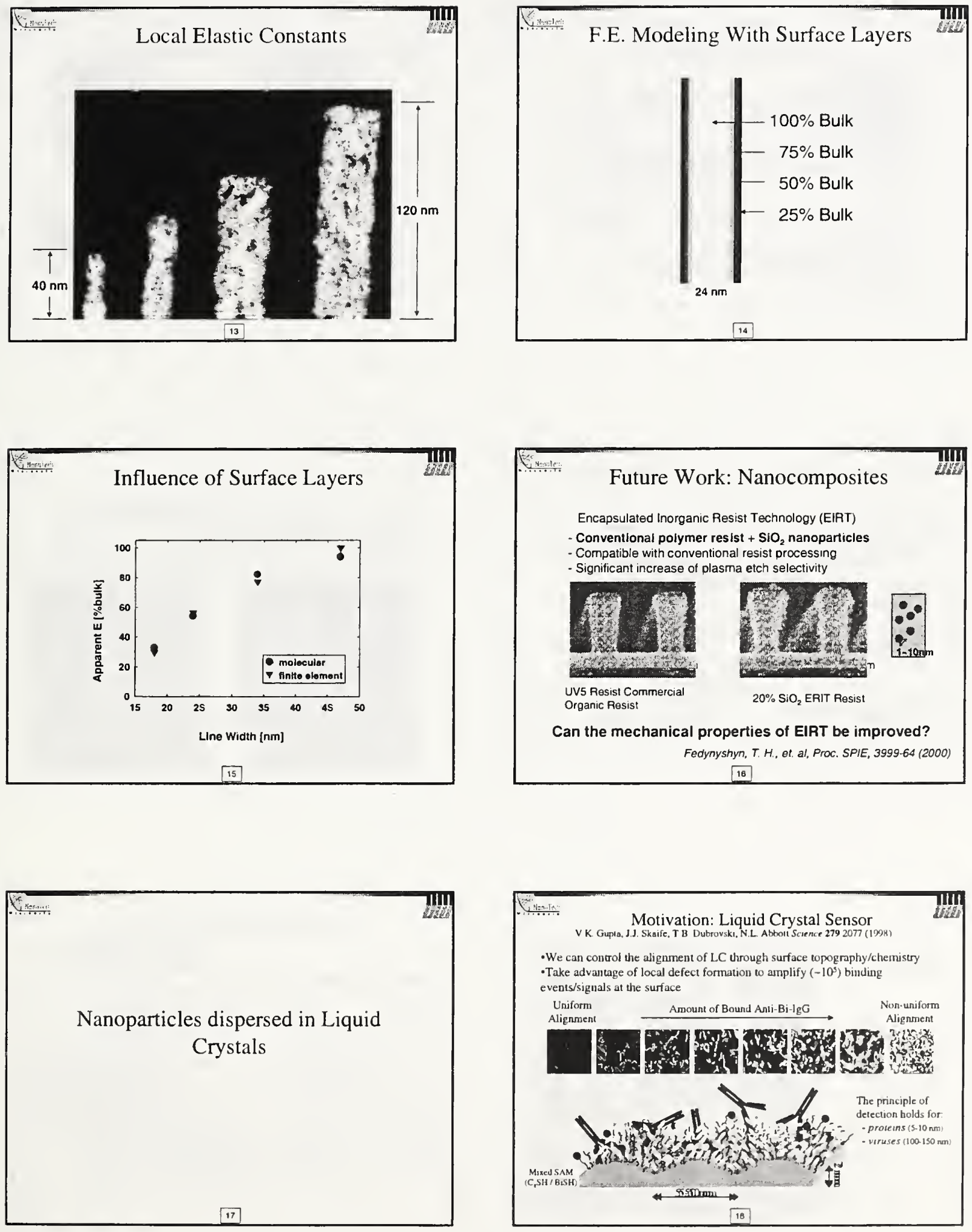


Multi-Scale Modeling
- Can we use models to anticipate which defect structure
arises for specific systems?
- Can we use theory to establish quantitative relations
between bound-particle concentration and shape and defect
structure?
- Can we use these results to design optimal substrates?
- Can we make use of transient or time-dependent
observations to infer additional information?

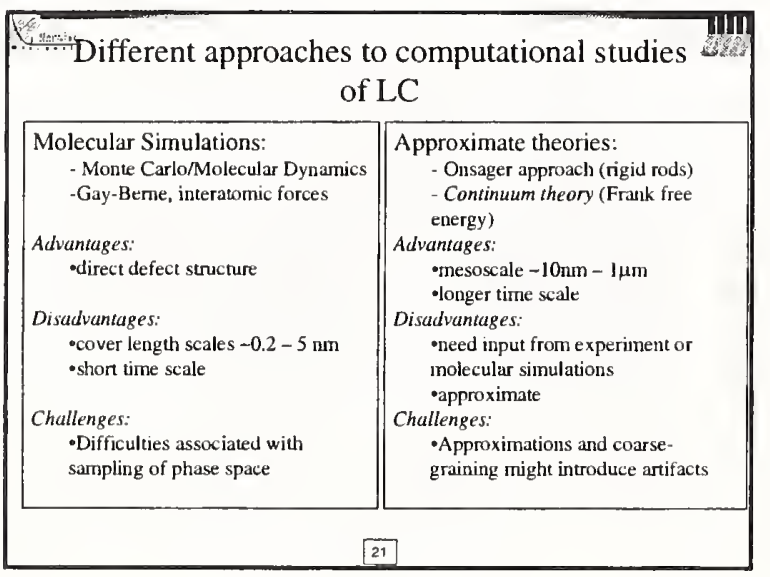

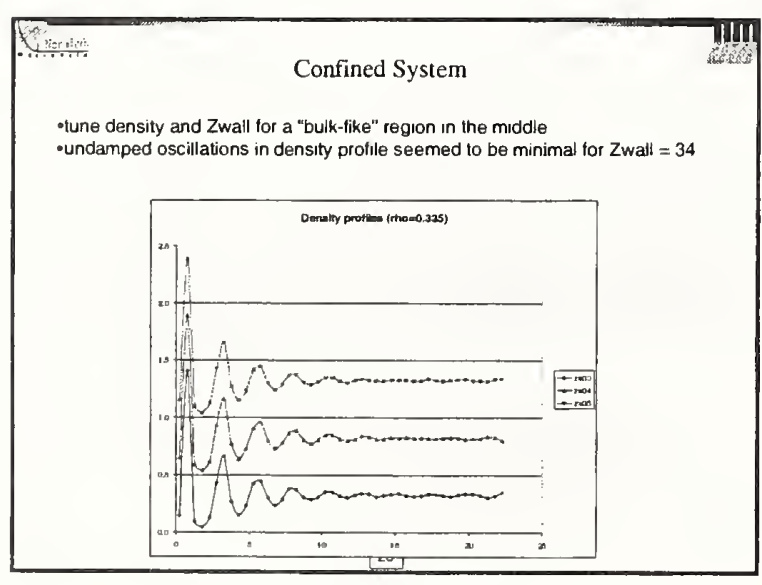

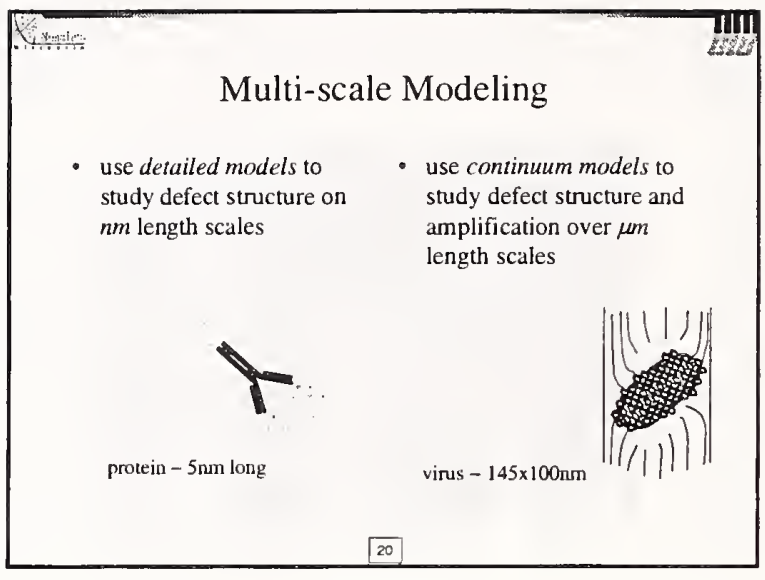
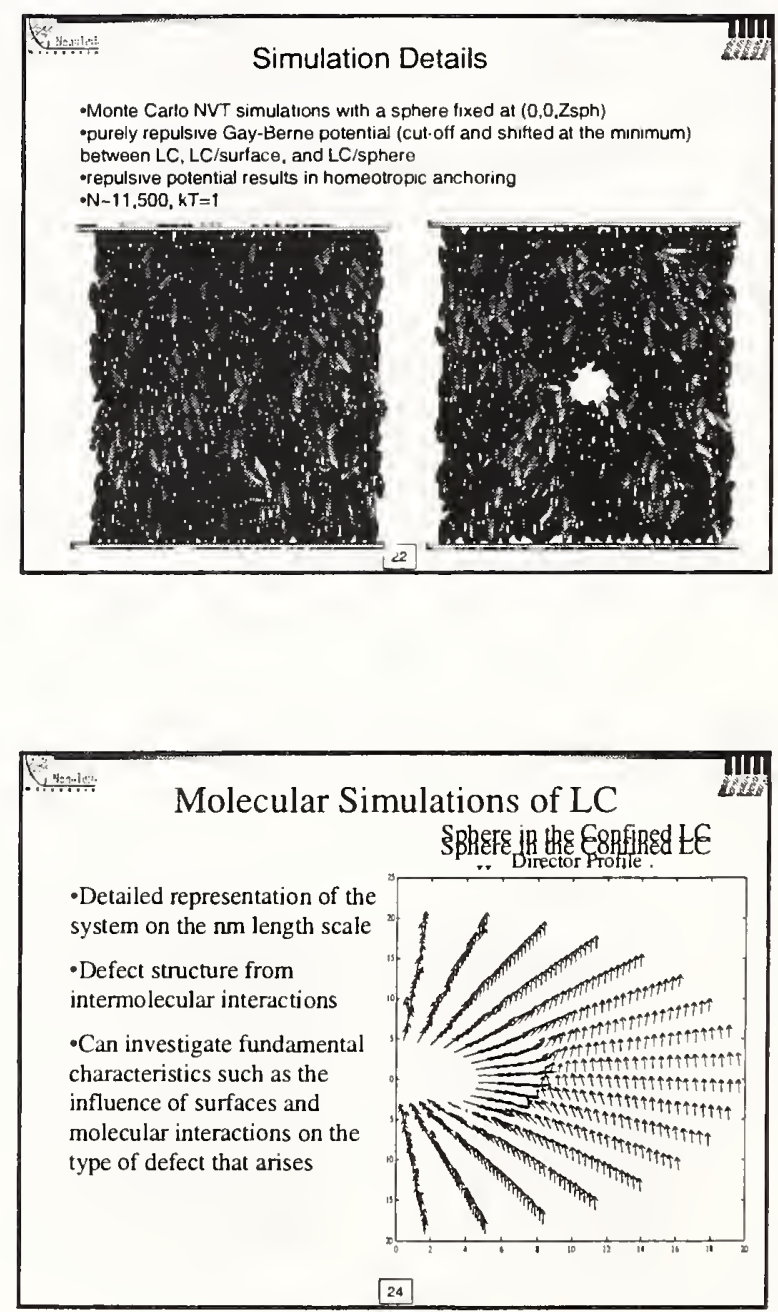

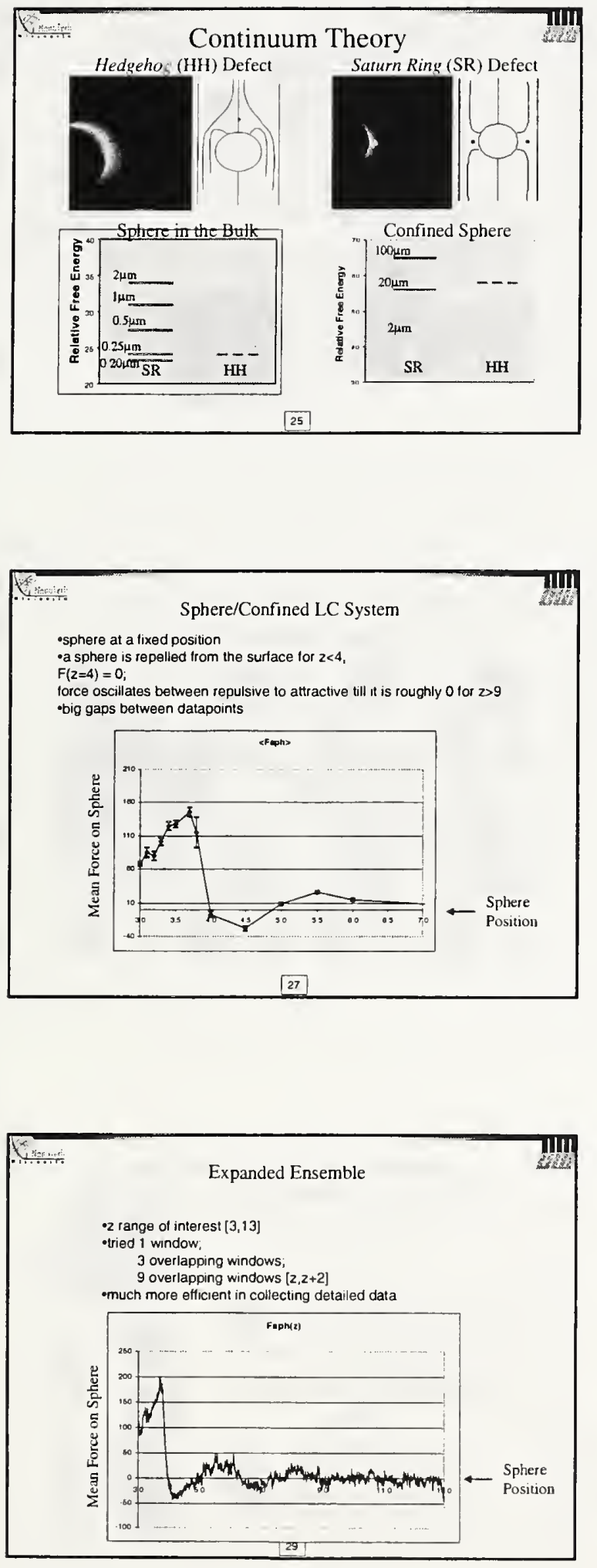
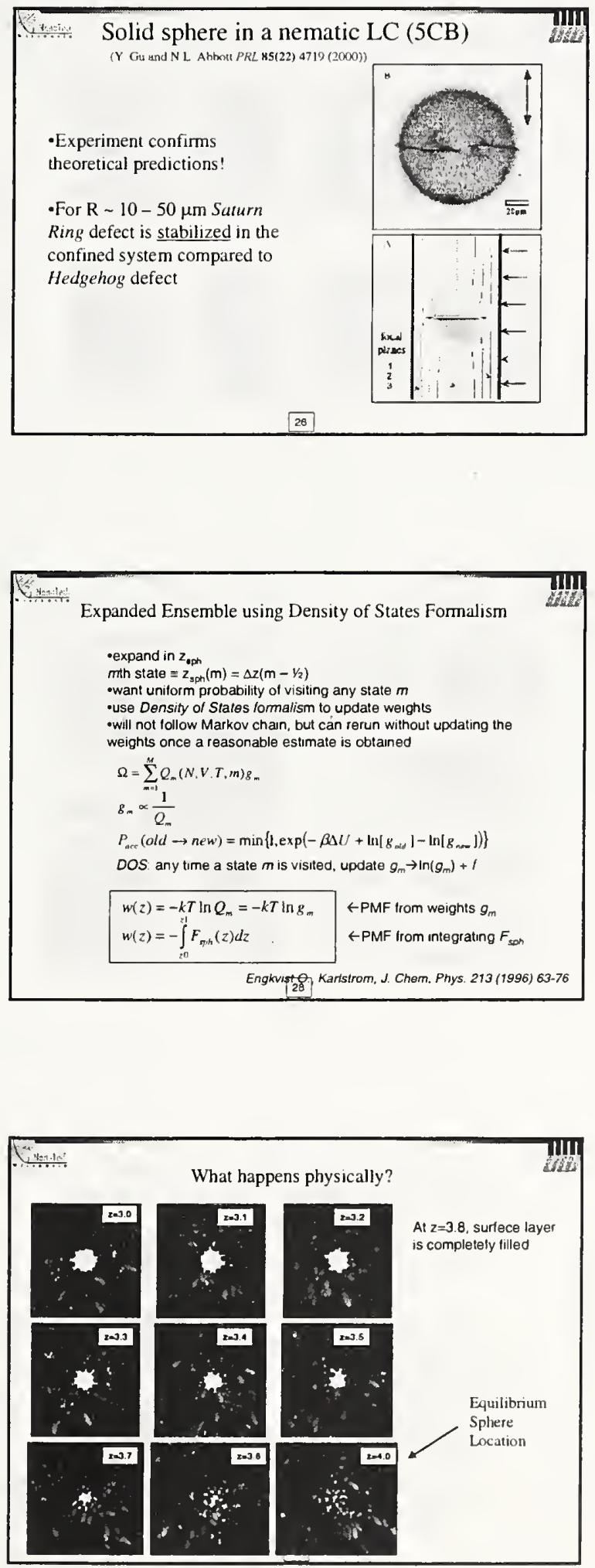

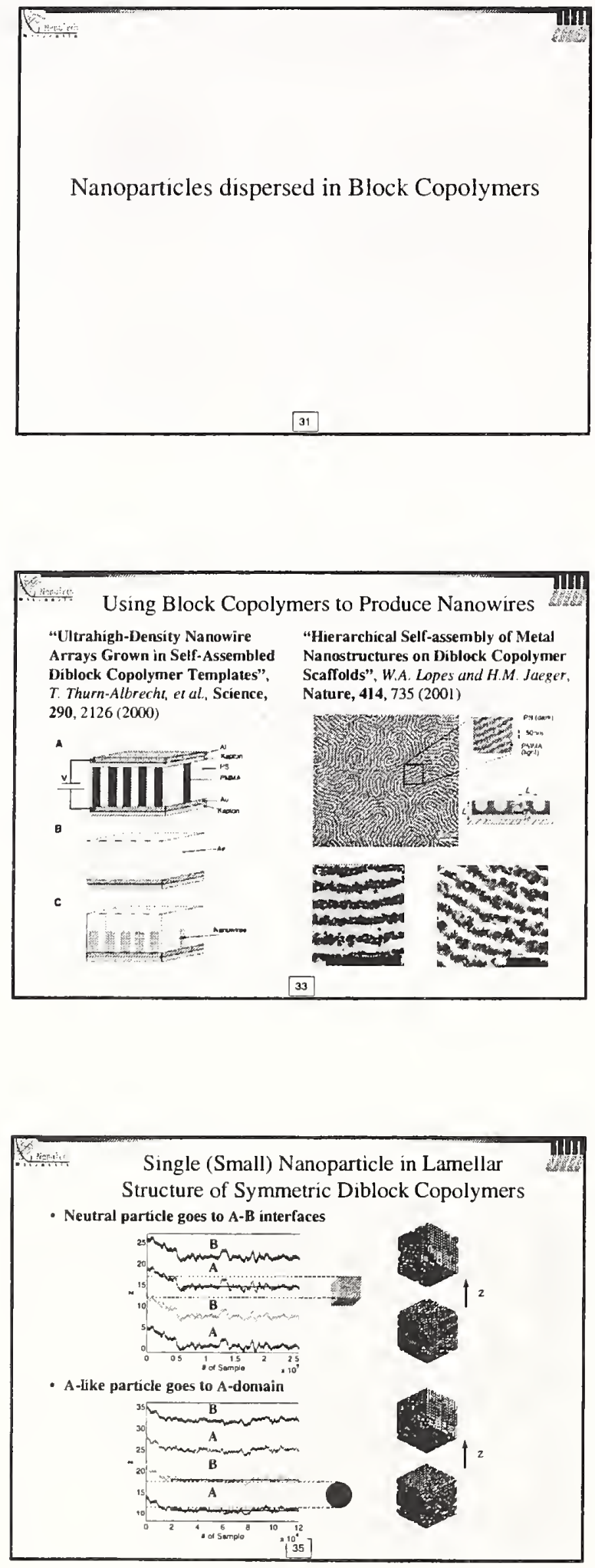

Self-Assembly of Block Copolymers
and Nano-fabrication
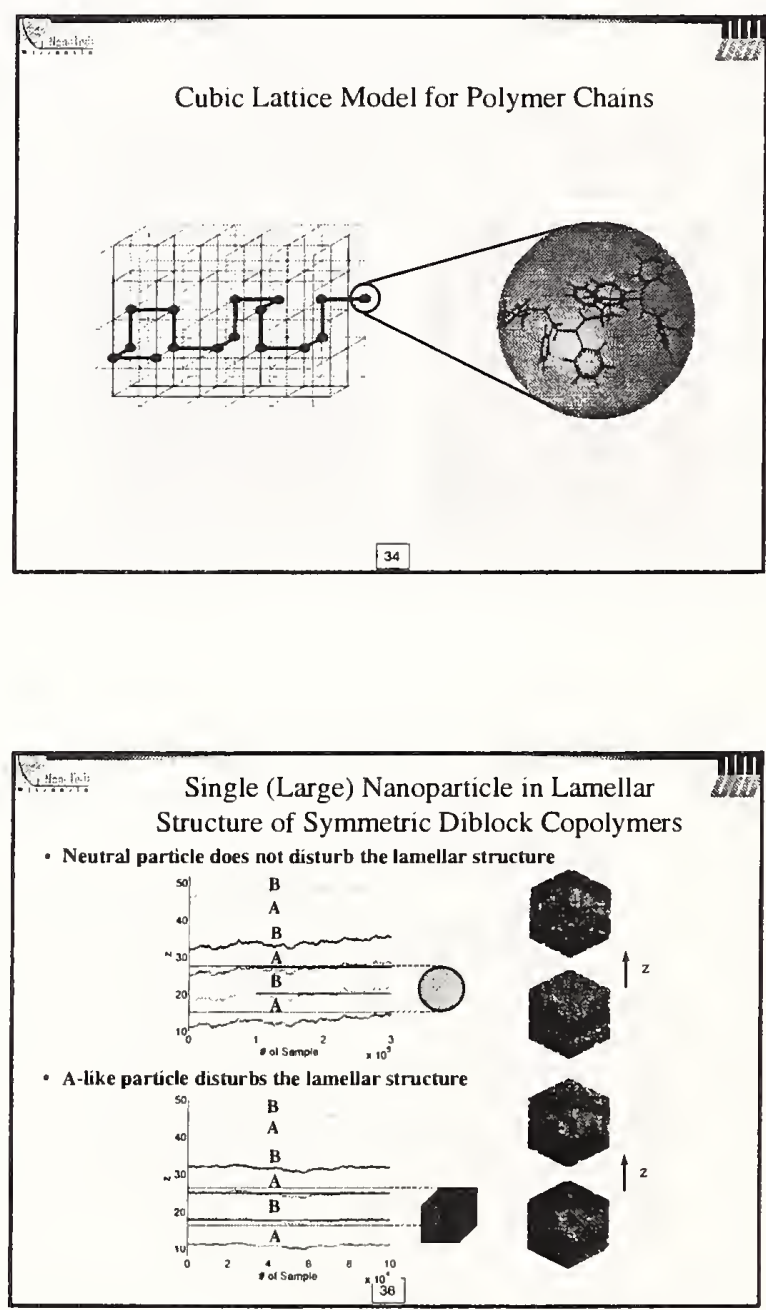

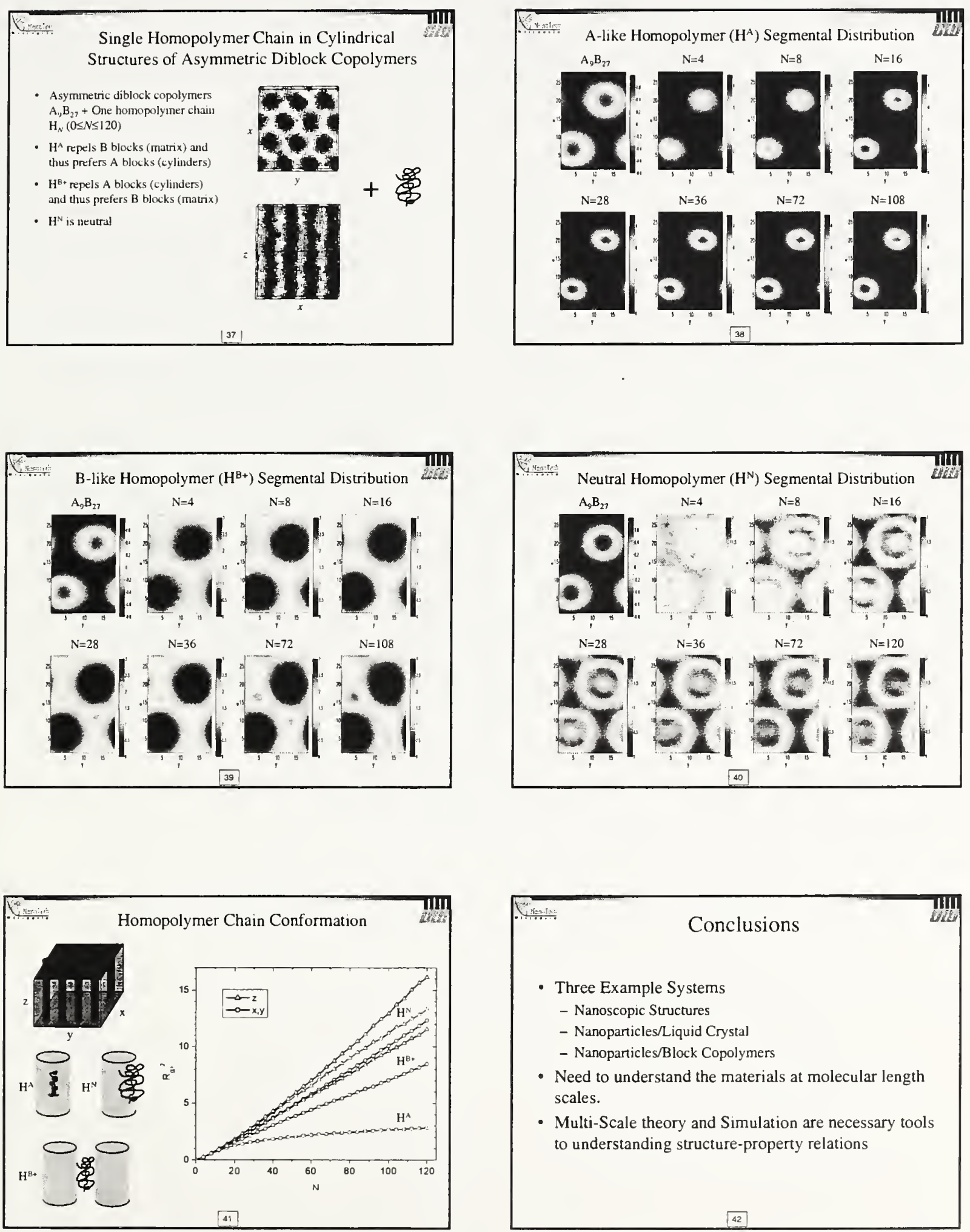

Conclusions
- Three Example Systems
- Nanoscopic Structures
- Nanoparticles/Liquid Crysta]
- Nanoparticles/Block Copolymers
- Need to understand the materials at molecular length
scales.
Multi-Scale theory and Simulation are necessary tools
to understanding structure-property relations




Acknowledgements
Contributors:
- Qang Wang - Diblock Copolymers
- Evelyn Kim - Liquid Crystals
Group Members:
- Roland Faller
- Tushar Jain
Advisors:
- Juan J. de Pablo
- Paul F. Nealey


10) Guoqiang Qian, "Applications of Plastic Nanocomposites" [PowerPoint] [PDF]

The main purpose of this talk was to provide ample evidence of the growing commercial importance of clay-filled polymer materials. Dr. Qian summarized numerous Nanocor products and the desirable property changes achieved by these products in the area of control of gas permeation, food packaging. The promise of these materials in the area of fire suppression and anti-sagging agents for fiberglass processing was also noted. The development of pre-dispersed pellets enlarges the number of users of these products. 


\section{APPLICATIONS OF PLASTIC NANOCOMPOSITES}

Guoqiang Qian and Tie Lan

$\Rightarrow$ Nanocor

\section{OUTLINE}

- NANOCOR PRODUCT INTRODUCTION

- Nano-NYLON 6

- Nano-MXD6: ULTRA-HIGH BARRIER

- Nano-POLYOLEFIN

- Nano-UNSATURATED POLYESTER

- SUMMARY

\section{PRODUCTS}

- NANOMER ${ }^{\circledR}$ POWDERS

1.24TL, 1.34TCN, 1.42TC for Nylons

I.30P, I.44PA for Polyolefins

I.30E, I.28E for Thermoset Epoxy

Rhoespan ${ }^{\otimes}$ AS for UPE

- NANOMER ${ }^{\circledR}$ CONCENTRATES

C.30P, C.44PA, C.30PE, and C.44TPO for

Polyolefins

- IMPERM ${ }^{\mathrm{TM}}$ NANOCOMPOSITES

High Barrier Packaging Applications

Danocor WHW NANOCOR CON

\section{NYLON 6 NANOCOMPOSITES}

- Nanomer I.24 TL

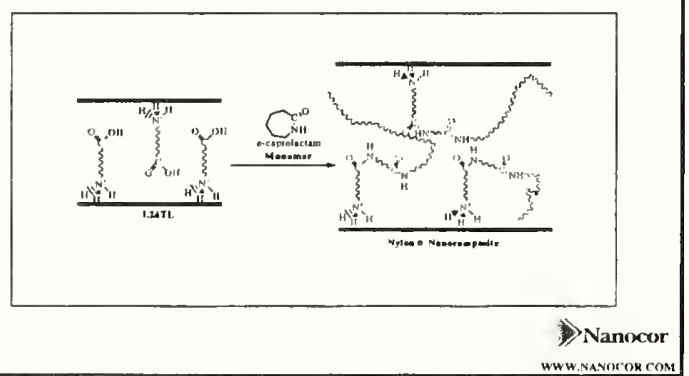

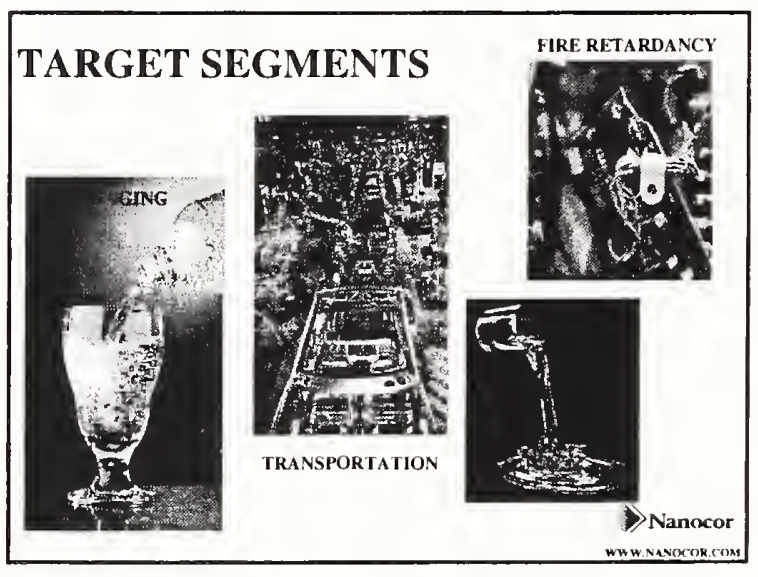

NYLON 6 NANOCOMPOSITES

- COMMERCIAL SOURCES:

Bayer AG and Honeywell Eng. Polymers and Solutions

- COMMERICAL PRODUCTS:

2-4\% Nanomer® loading

- FEATURES:

2-3X improvement in gas barrier

FDA Approval for food direct contact

Enhanced mechanicals

Processes similar to neat nylon 
BARRIER PROPERTIES OF NANO-PA6

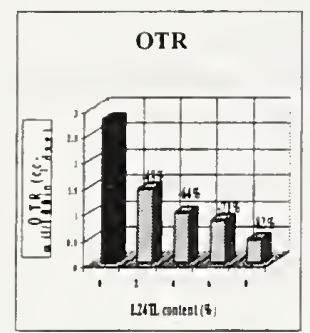

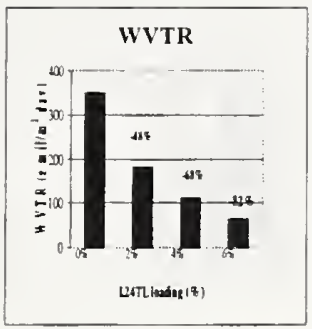

$\Rightarrow$ Nanocor

\section{FILM APPLICATIONS}

- Mono and multilayer

- Thin-wall structures

- Stiffness ideal for stand-up pouches

- Barrier/strength combo permits downgauging

\section{REDUCED SENSITIVITY TO HUMIDITY}

Percent Improvement Nano-PA6 Versus Neat Nylon 6

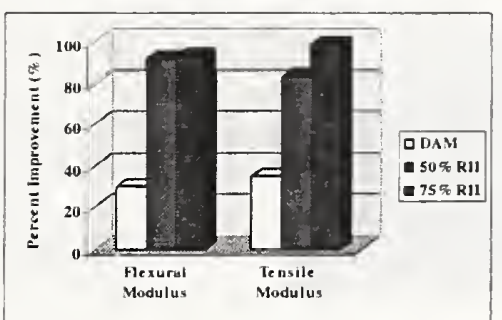

$>$ Nanocor พww vasocoucos

\section{FILM APPLICATIONS}

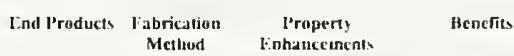

Imperm $^{\text {TM }}$ ULTRA-HIGH BARRIER NANOCOMPOSITES

- Nylon MXD6 based nanocomposite

- Easy processing for multi-layer and blend applications

\section{Imperm $^{\text {TM }}$ ULTRA-HIGH BARRIER NANOCOMPOSITES}

- COMMERCIAL SOURCE:

\author{
Nanocor
}

- FEATURES:

3-5X improvement in oxygen barrier vs MXD6

Low haze

Rigid and flexible packaging

Multi-layer or blends with PET and PA6 

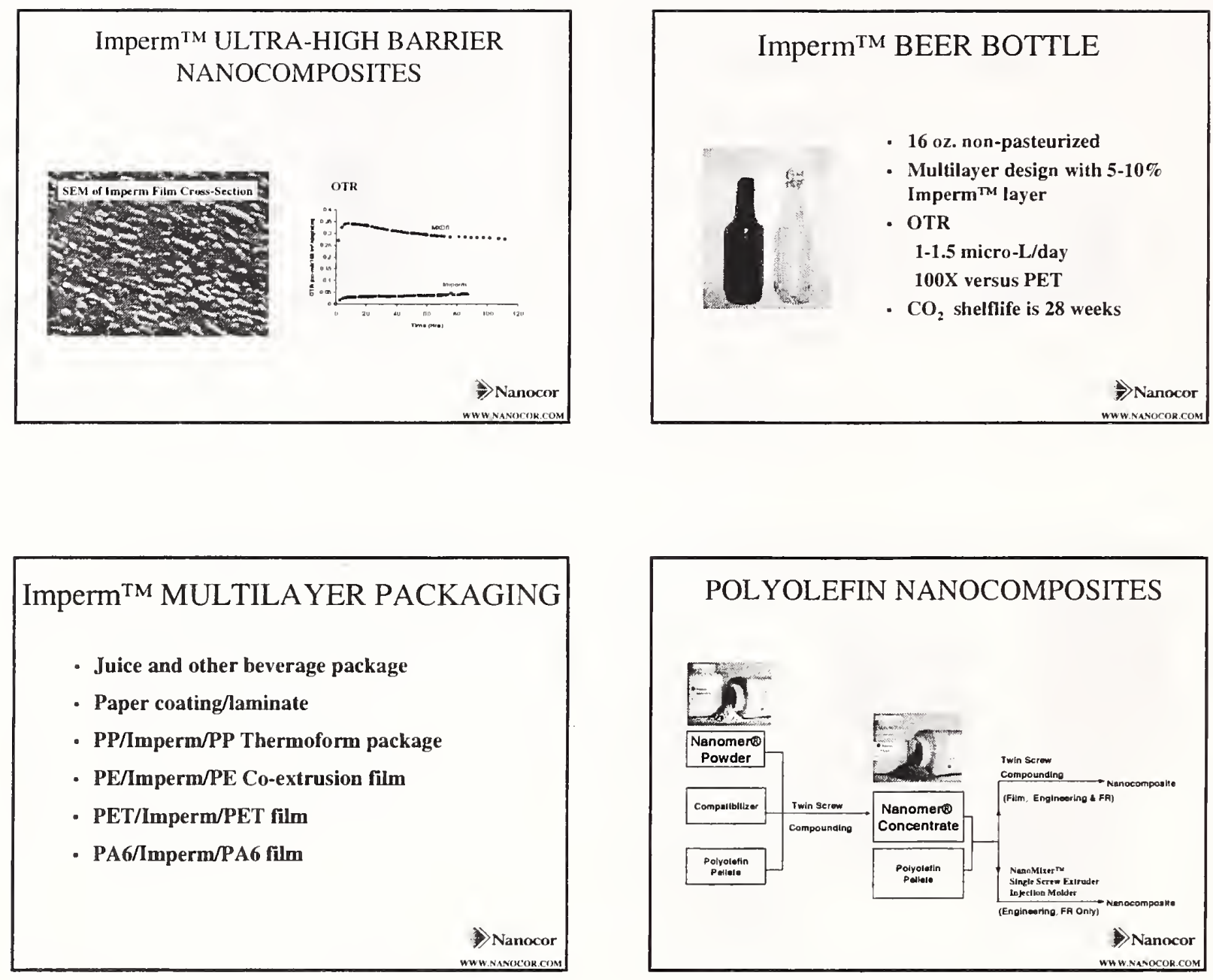

\section{POLYOLEFIN NANOCOMPOSITES}

- COMMERCIAL SOURCES:

Nanocor, PolyOne, and Clariant Corporation

- COMMERCIAL PRODUCTS:

Nanomer, Nanomer Concentrates and Nanocomposites

- FEATURES:

Enhanced mechanicals

Enhanced barrier

Synergy with FRs for flame retardancy

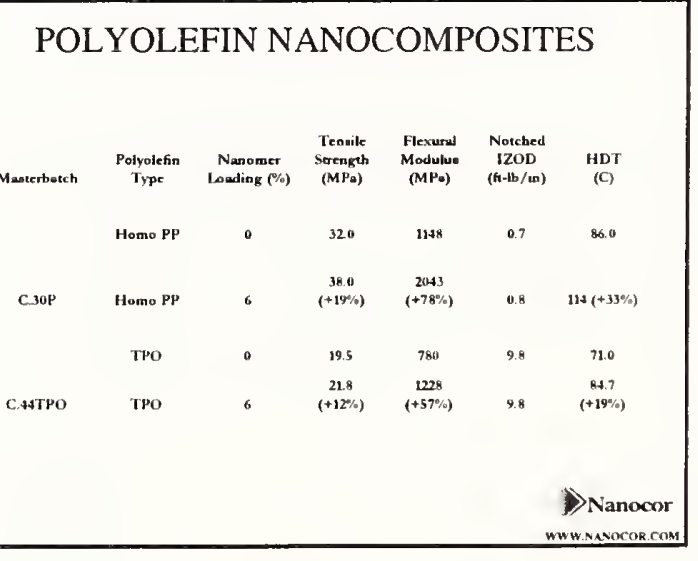


POLYOLEFIN NANOCOMPOSITES

\section{Barrier Properties}

\section{FR APPLICATION OF NANOCOMPOSITE}

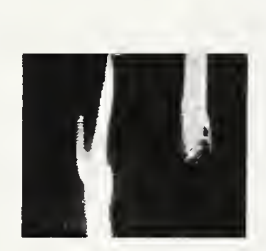

Reduction of Traditional FR Agents

Reduction of Dripping

Anti-Blooming

Good Mechanical Properties

Easy Processing

Regulation Favorable

FR APPLICATION OF NANOCOMPOSITE

Nanomer Synergy with $\mathrm{Mg}(\mathrm{OH})_{2}$

\begin{tabular}{|c|c|c|c|c|}
\hline Components & & & & \\
\hline EVA (wre/s) & 40 & 45 & 42 & 47 \\
\hline $\mathrm{Mg}(\mathrm{OH})_{2}(\mathrm{wr} / \mathrm{l})$ & 60 & 55 & 55 & 50 \\
\hline Nanomer 1.30P (wr\%) & 0 & 0 & 3 & 3 \\
\hline UL-94 rating & $Y-0$ & Fail & $v_{-0}$ & $V_{-1}$ \\
\hline
\end{tabular}

- Nanomer can be added in pow der or concentrate forms

- 3 wt\% Nanomer can replace at least 10 wt\% $\mathrm{Mg}(\mathrm{OH}) 2$

- Easy Processing

FR APPLICATION OF NANOCOMPOSITE

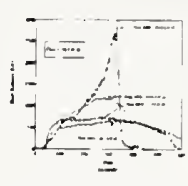

Fundamental Study

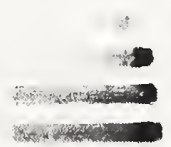

Perfonnance Screenin

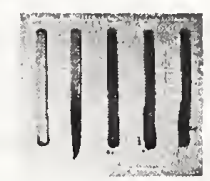

FR-Rating

FR APPLICATION OF NANOCOMPOSITE

Nanomer Synergy with Br-FRs

\begin{tabular}{|c|c|c|c|c|c|c|}
\hline Components & & & & & & \\
\hline Horne-PP ( $(\mathrm{mt} / \mathrm{s})$ & 731 & 80 & $\pi$ & 34 & 74 & 68 \\
\hline DBDPO (Ne\%) & 211 & 15 & 15 & 15 & 15 & is \\
\hline $\mathrm{Sb}_{1} \mathrm{O},(\mathbf{m \%} \%)$ & 6.7 & 5.0 & 5.0 & 5.0 & 5.0 & 5.0 \\
\hline Nanomer 1.44PA ( $\mathrm{x} \%$ ) & o & 0 & 3.0 & 6.0 & (3.0) & (6.0) \\
\hline Nenomer C.4JPA ( $(\mathrm{x} \%)$ & 0 & 0 & 0 & 0 & 6 & 12 \\
\hline ULOS Ruting & $\mathrm{V}-\mathrm{s}$ & Fat? & $v .2$ & $v-0$ & v.2 & $v-0$ \\
\hline
\end{tabular}

- Nanomer can be added in powder or concentrate forms

- $6 \mathrm{wt} \%$ Nanomer can replace at least 6 wt \% Br-FR

Reduction of Blooming
FR APPLICATION OF NANOCOMPOSITE

Mechanical Properties of Nano-FR Formulations

\begin{tabular}{|c|c|c|c|c|}
\hline Propertie" & UL-94 & $\begin{array}{c}\text { Tenaik Modules } \\
\text { (MPa) }\end{array}$ & $\begin{array}{l}\text { Elongation } \\
\text { (a) Brcak }\end{array}$ & $\begin{array}{l}\text { Speciffic } \\
\text { Gravity }\end{array}$ \\
\hline $\begin{array}{c}\text { Regular FR EVA } \\
\mathrm{Mg}_{\mathrm{g}(\mathrm{OH})_{2}}\end{array}$ & v. 0 & 533 & $30-40 \%$ & 1.42 \\
\hline $\begin{array}{c}\text { NanorfF EVA } \\
\mathrm{Mg}_{\mathrm{g}}(\mathrm{OH})_{2}\end{array}$ & $V-0$ & 569 & $30-40 \%$ & 1.34 \\
\hline $\begin{array}{c}\text { Regulat Br.FR PP } \\
\text { DBDPO/ATO }\end{array}$ & v.o & 2018 & $20-30 \%$ & \\
\hline $\begin{array}{l}\text { Nano-Br.FR PP } \\
\text { DBDPO/ATO }\end{array}$ & $v-0$ & 2055 & $20-30 \%$ & \\
\hline
\end{tabular}

Nanocor 
FR APPLICATION OF NANOCOMPOSITE

- Heavy duty PP electrical enclosure

- SG reduction from 1.35 to 1.16

- Flex modulus increased by $25 \%$

- Maintain UL94 V-0 rating

\section{UPE NANOCOMPOSITES}

- Rheospan® AS

Montmorillonite based anti-sag agent

Easy processing and nano benefits
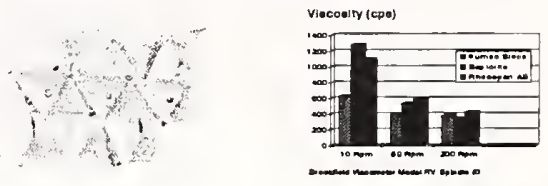

$>$ Nanoco WWW. NANOCOR.COM

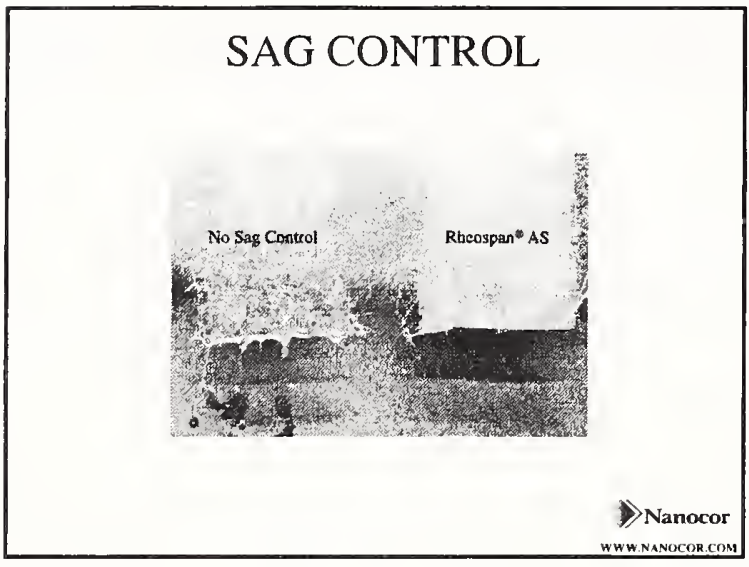

\section{UPE NANOCOMPOSITES}

- COMMERCIAL SOURCE:

Nanocor and Polymeric Supply Inc.

- COMMERCIAL PRODUCTS:

Formulations containing 1-2\% loading

- FEATURES:

Enhanced chemical resistance

Char formation for flame retardancy

Sag control

\section{BOAT ACCESSORIES}

- UPE/fiberglass construction

- Reduced microcracking

- Reduced color fading

- Elimination of fumed silica

\section{SUMMARY}

- Nanocomposite plastics are commercial

- Barrier, reinforcement and flame retardancy drive most applications

- More applications are emerging 


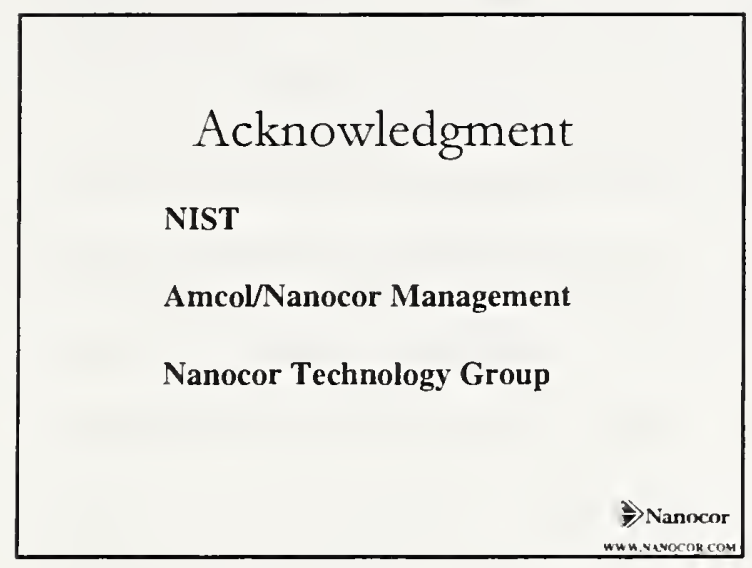




\section{1) Eric A. Grulke, "Production, Dispersion and Applications of}

\section{Multiwalled Carbon Nanotubes" [PowerPoint] [PDF]}

Dr. Grulke provides an overview of the many activities of the Advanced Carbon Materials center at the University of Kentucky, which specializes in the production characterization, and development of applications of multiwalled carbon nanotubes. The first part of the talk provided a contrast between the morphologies of the single and multi-walled nanotubes. It was made clear that these materials exhibit a variety of hierarchal structures, depending on the conditions of their formation and that dispersion is a matter of degree because of these superstructures. The synthesis procedure for the mass production of multi-walled tubes was then discussed along with economic factors relevant to developing these materials. TEM images showed that these tube layers grow as a 'turf' from the substrate on which they are grown where the iron catalyst particles tend to concentrate near the tips of the growing tubes. The mechanism of the tip growth was identified as a fundamental problem in understanding and controlling the structure of these materials. The further essential problem of tube dispersal makes the functionalization of the tubes another essential problem. Progress on functionalization and the characterization of this functionalization was then summarized. Some essential properties of polymer materials filled with multi-walled tubes are considered. The viscosity depends strongly on shear in these non-Newtonian fluids and large changes in the conductive properties are found. Finally, a variety of processing techniques for forming nanotube filled polymers are reviewed and dispersion and property changes resulting from these various methods are characterized. Preliminary observations indicate that the concentration of the tubes has a large impact on the tendency of the particles to cluster and the resulting properties. 
104 


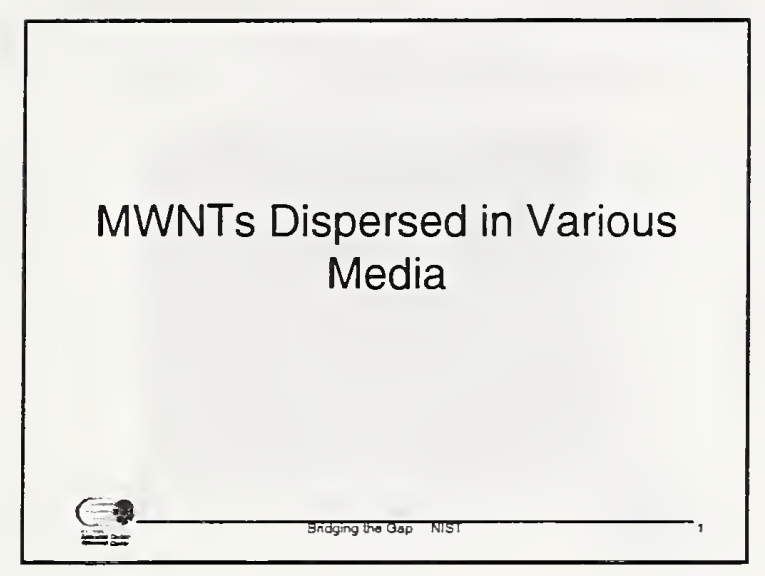

\section{Example of MWNT Dispersion}

Nanolubes quickly

settle without use

of a prope

dispersant; $b$. The

very stable

nanotube nanofluid

produced by this

method is thus
sultable for thermal

sultable for the
conductivity

measurements and

future heat transfer

applications

Poly(alpha-olefin)

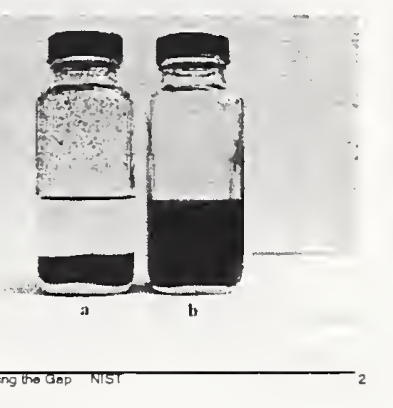

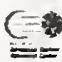

2.5 wt \% MWNTs in Poly( $\alpha$-olefin).

High shear dispersion This sample has high thermal conductivity.

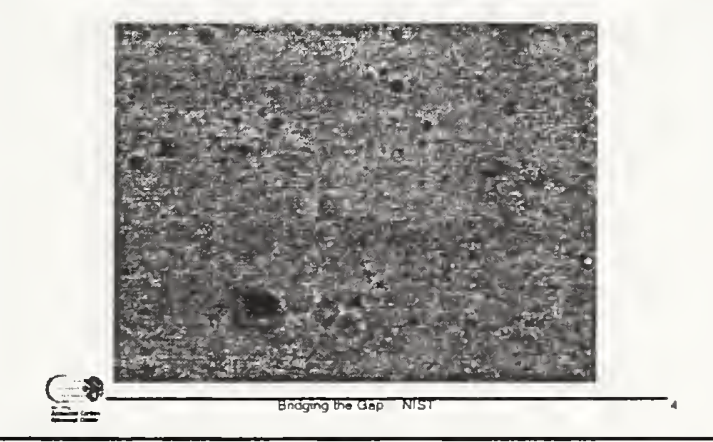

\section{Dispersion during Melt Blending}

- MWNTs in polystyrene

- Haake rheometer, 180 C, Dow 666, 30 min, constant torque @ $30 \mathrm{~min}, 50 \mathrm{rpm}$

- Consistent flow properties, physical properties (tensile, resistivity) in bulk tests

- What is the dispersion quality?

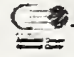

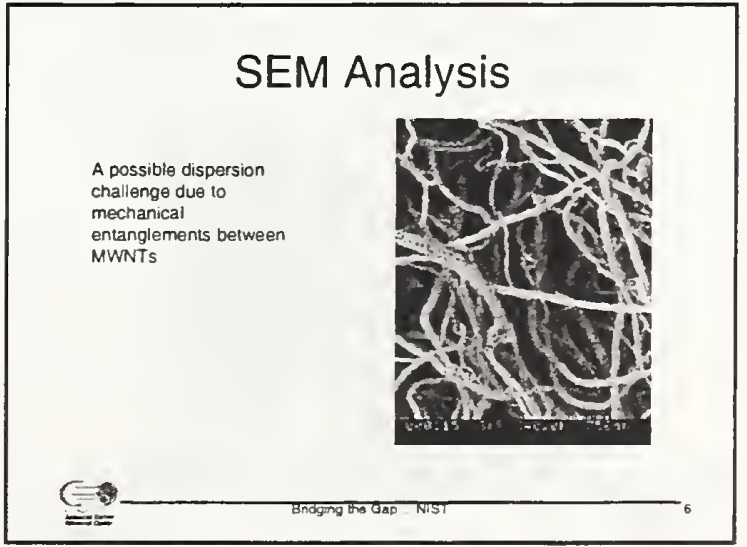



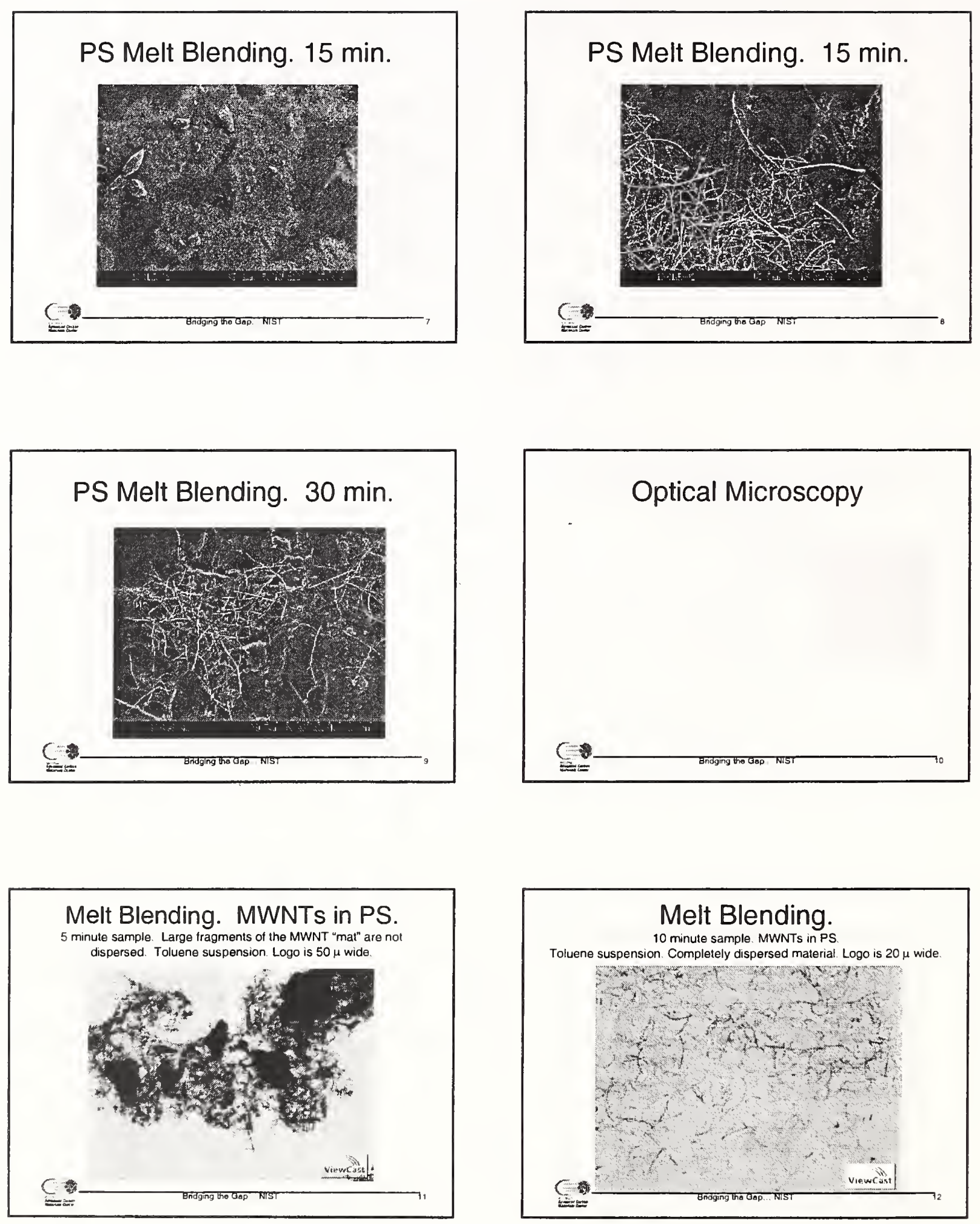

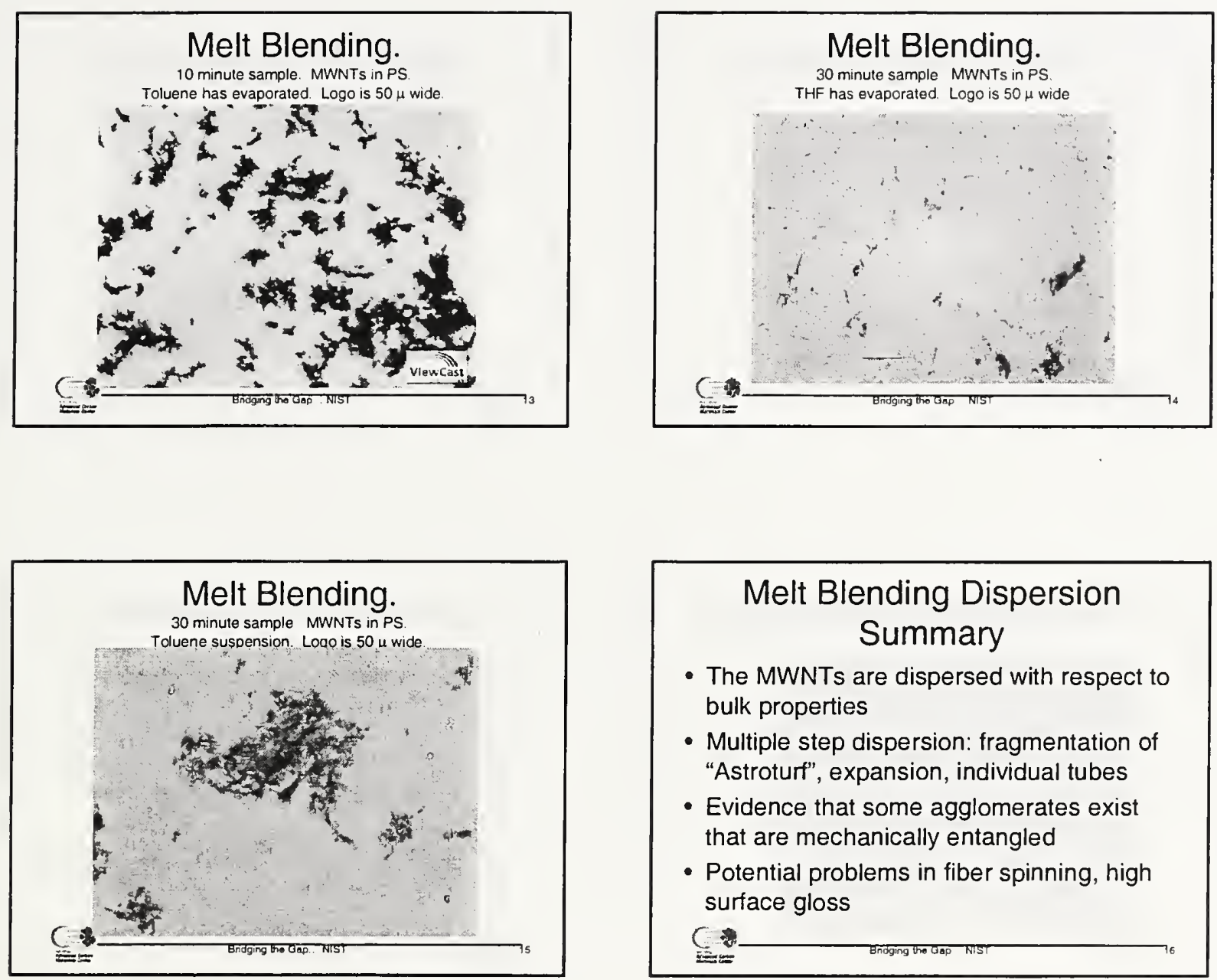

\section{Melt Blending Dispersion Summary}

- The MWNTs are dispersed with respect to bulk properties

- Multiple step dispersion: fragmentation of "Astroturf", expansion, individual tubes

- Evidence that some agglomerates exist that are mechanically entangled

- Potential problems in fiber spinning, high surface gloss

$C$

\section{Surface Chemistry}

- Distinct differences on solvent removal from MWNT solutions

- Drying from toluene gave agglomerates of 25 microns in size, while drying from THF gave much smaller agglomerates

- Surface chemistry (with control by solvent, polymer, surfactants, etc) may be useful in developing aggregate structures

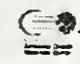
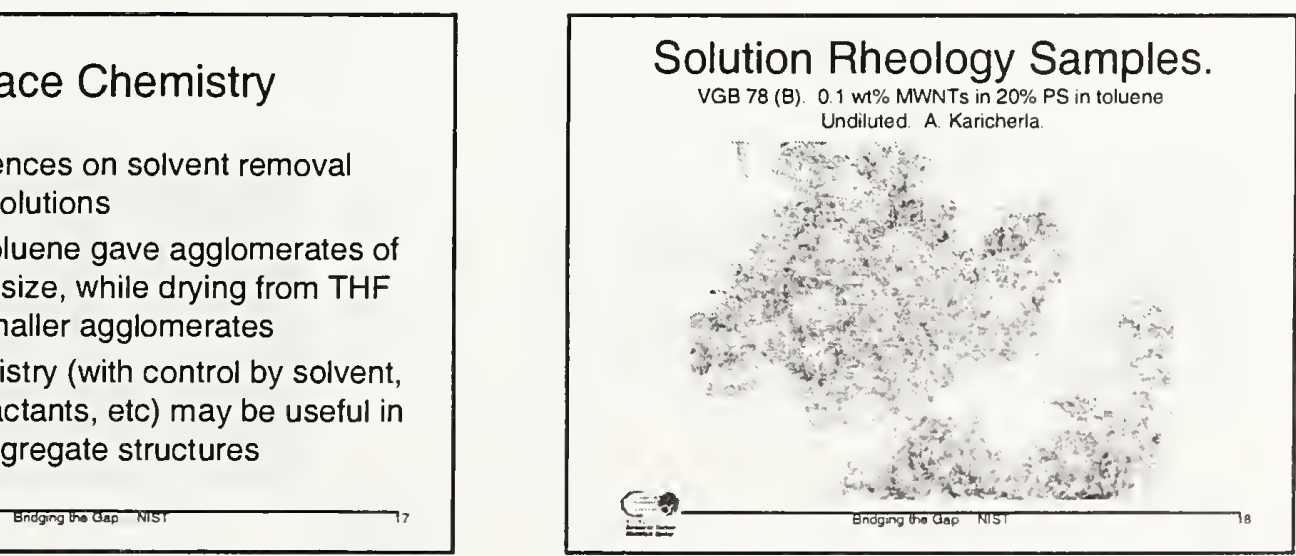

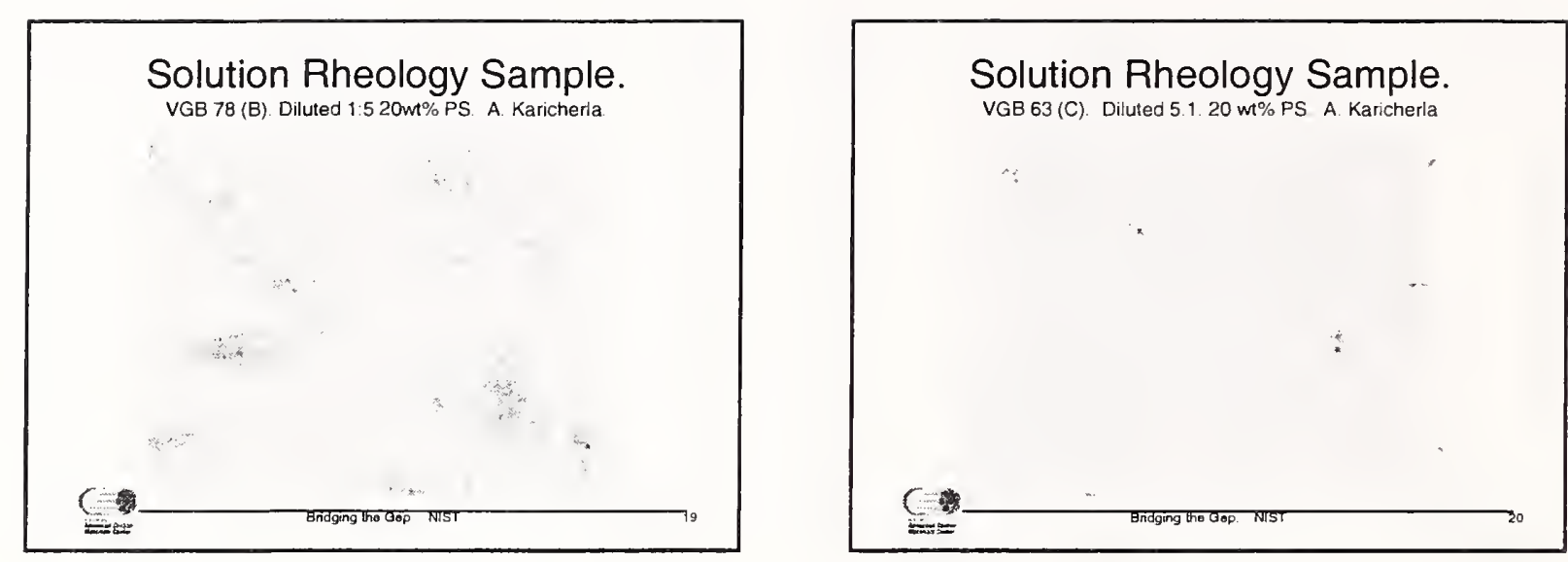

\section{Re-entanglement (Mechanical)}

- Agglomerates that appeared to be physically entangled will redisperse when the MWNT concentration is reduced

- Consistent with statistical approach to percolation, i.e., as the concentration increases, a distribution of particle agglomerates form

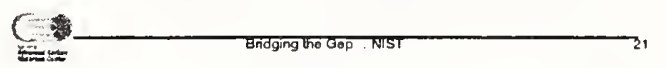

Conclusions. Melt Blending.

- MWNT mat fractures to dense fragments, which then "expand" and can disperse

- 30 min. melt blending samples show few dense fragments, but do have "expanded" structures that are mechanically intact

- There is a MWNT length distribution

- Continuous phase affects particle-particle associations, particularly when an air-fluid interface is present

$c$

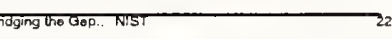

\section{Particle Comminution}

- Distribution of MWNT lengths

- Few expanded structures, but long dispersion times used to attain constant viscosities

- Dilutions show that most of the MWNTs can be individually separated

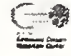

- Ultrasonics

- Melt blending

- High shear mixing

- High shear nozzle

- mechanical 

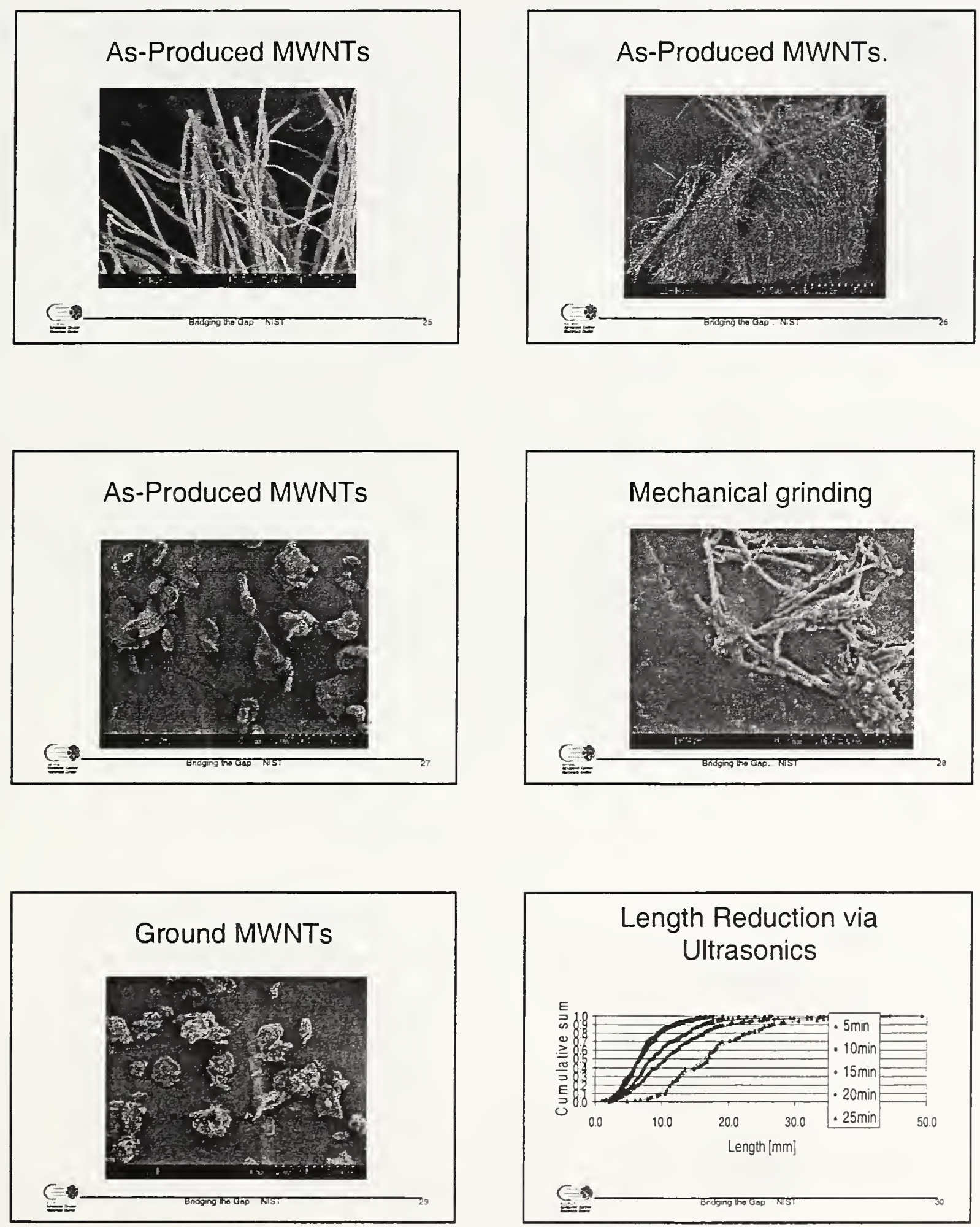


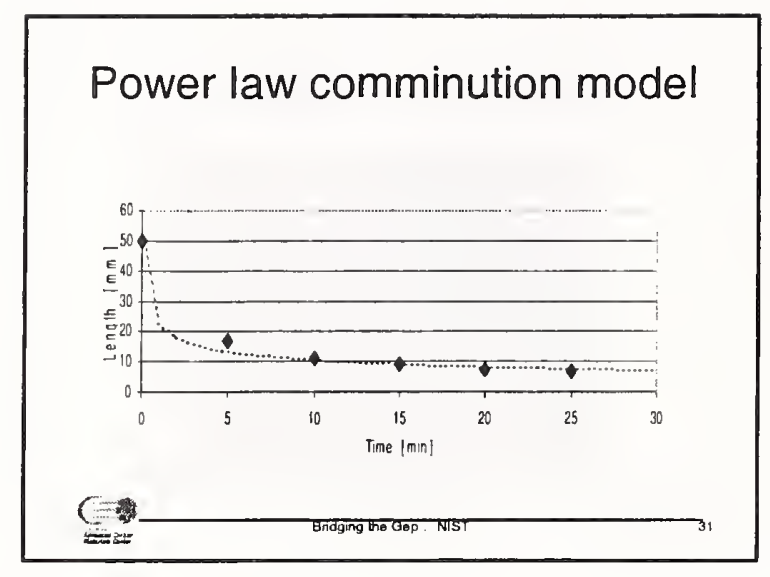

\section{Conclusions. High Shear Dispersions.}

- Very efficient dispersion, but lengths are < 10 microns

- Still achieve "percolation" limits, but these should be based on different lengths from the starting material
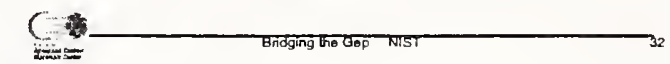

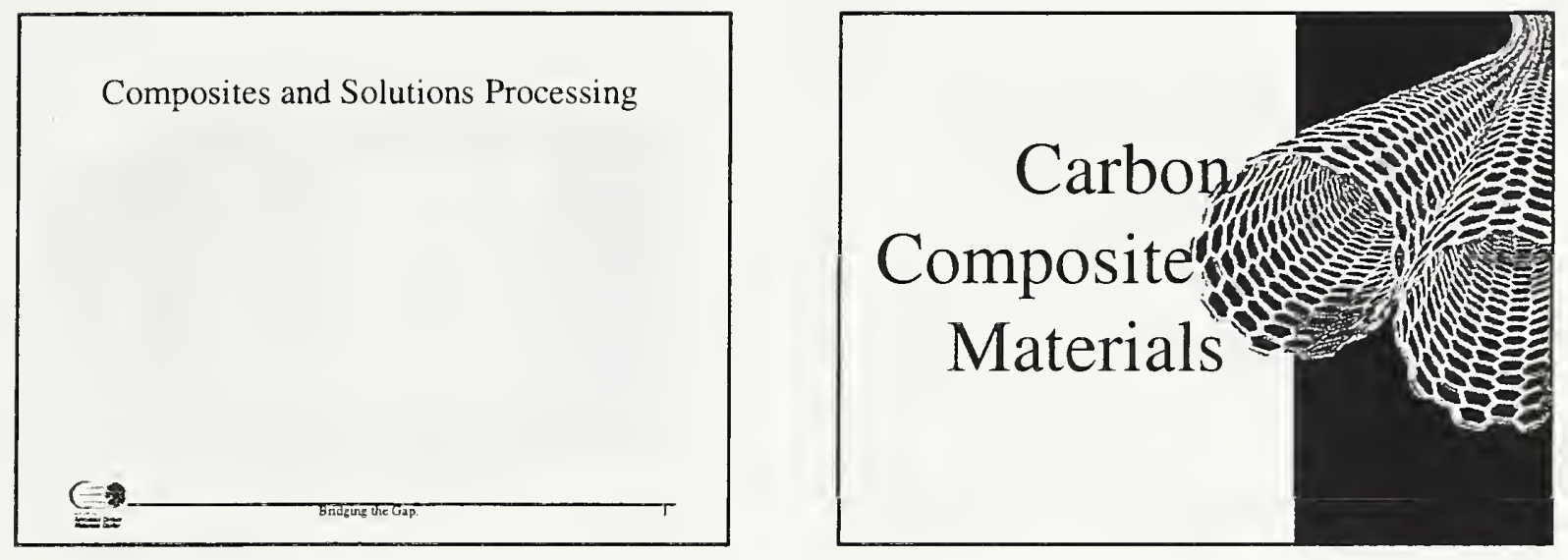

\section{Composites with Nanotube}

Typical composite materiats tssuess

Fatigue, high temperature, chemical

resistance, weathering

Typical composite materials failure mechanisms: Fiber pullout, stress concentration at fiber ends

Typical composite processing issues:

Dispersion, orientation, conventional processing

Commercial Forming Methods for

\begin{tabular}{l} 
Nanotube \\
\hline - Pultrusion: \\
- Filament winding: \\
- Compression molding: \\
- Hand lay-up: \\
- Hand spray-up: \\
- Reactive RIM:
\end{tabular}

- Reactive RIM:

$0=$ science fiction, $2=$ demonstrated, $4=$ ready for market applicable for yarns

MWNT-containing fibers (2)

extrusion and pelletizing (3)

thin films fabricated (2)

spray coatings ( 3 )

suspending agents (2)

$$
E
$$$$
\text { Bतगg, he Gap }
$$

\section{Accomplishments}

- Dispersion via ultrasonics and polymer melt processing techniques

- Orientation in shear fields, leading to 2-D, 3-D structures

- Adhesion between matrix and MWNTs is an issue: functionalization should help

$C$ 7

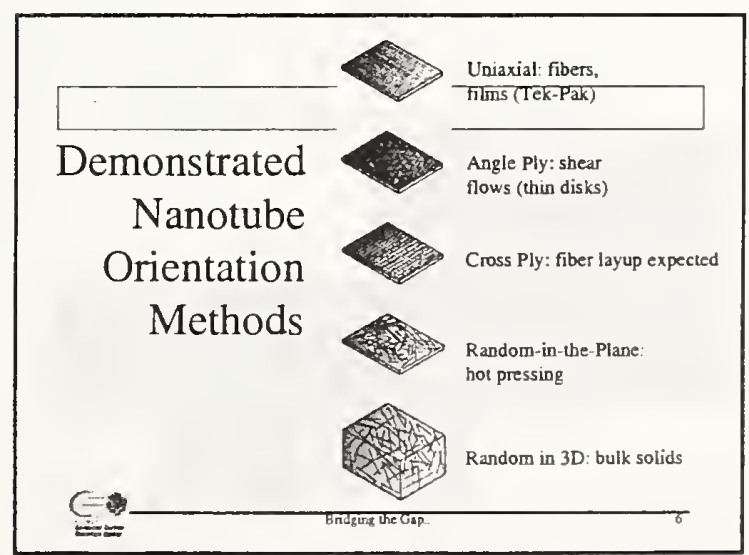




\section{Composites: New Work}

- Functionalization: improved dispersion in liquids, tethered chains for improved interfacial adhesion, in situ end group functionalization

- Mechanical testing of improved nanotube composites

- Engineering science models of processing methods

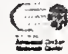
Bतd ing the Gar

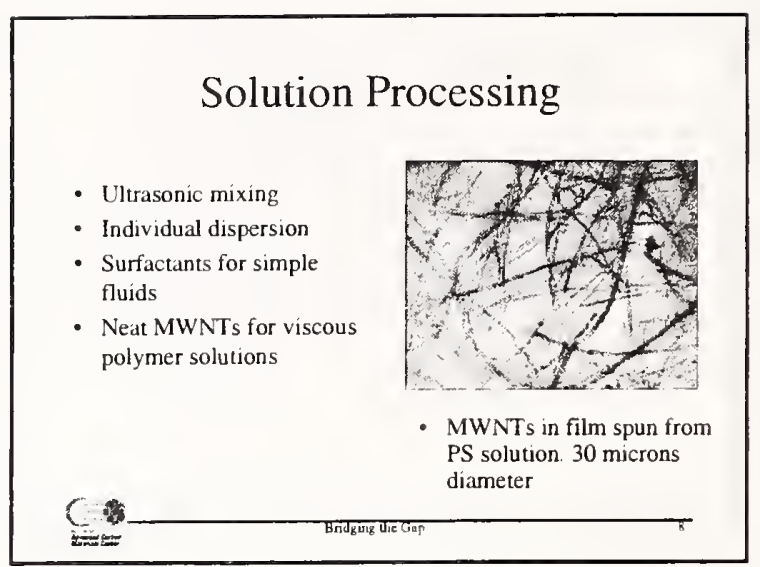

\section{Melt Processing}

- Mixing and dispersion into pitch and polymer melts

- Polystyrene, High Impact PS, Polypropylene, ABS

- Petroleum Pitch, Coal-denved Pitch

- Furfural Resins

- Thin polymer film and fiber formation

- Nanotube alignment in shear field

- Use of traditional polymer processing equipment

- Industrially viable processing techniques

$C$
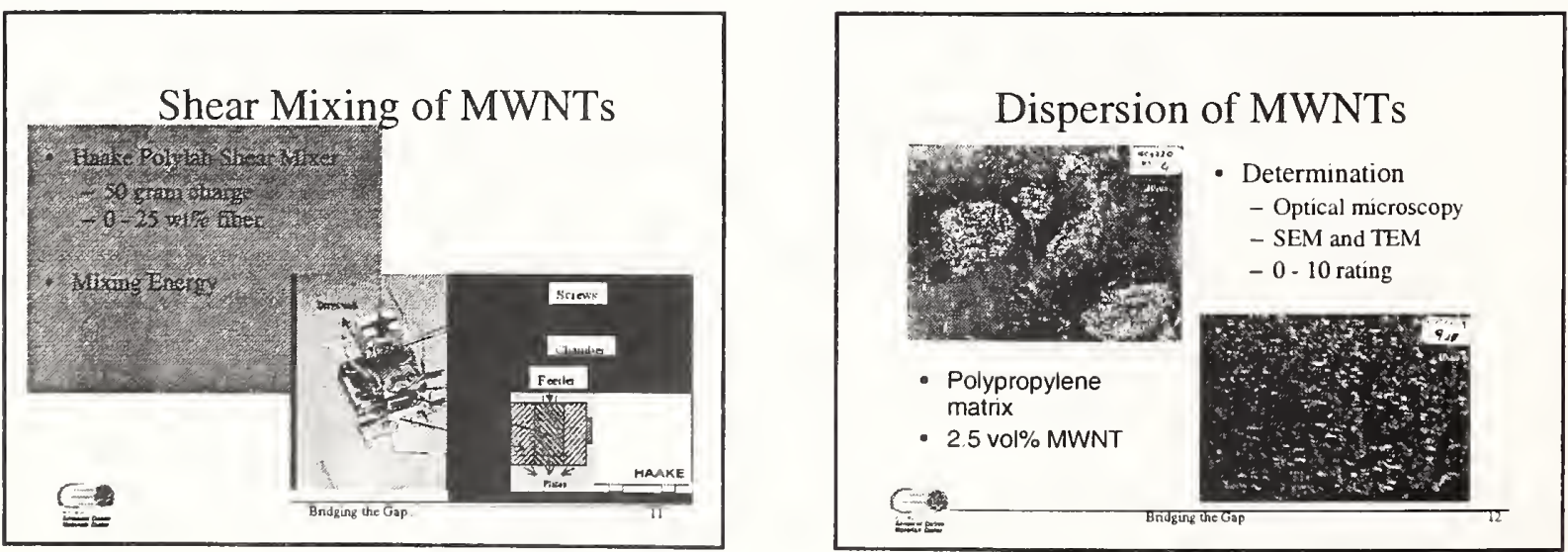

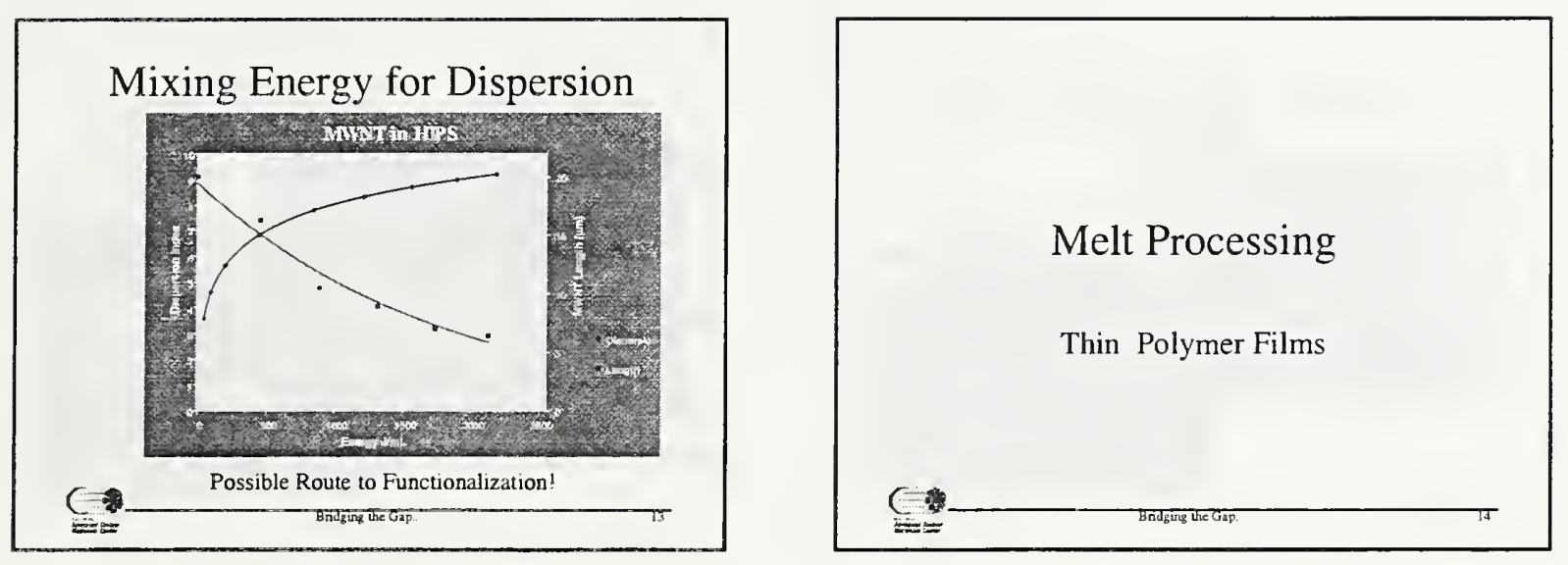

Tensile Properties of Films. PP

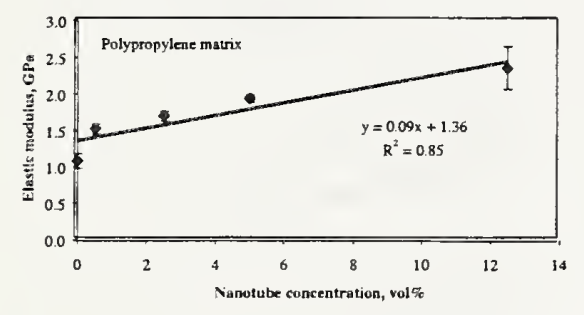

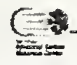

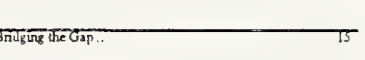

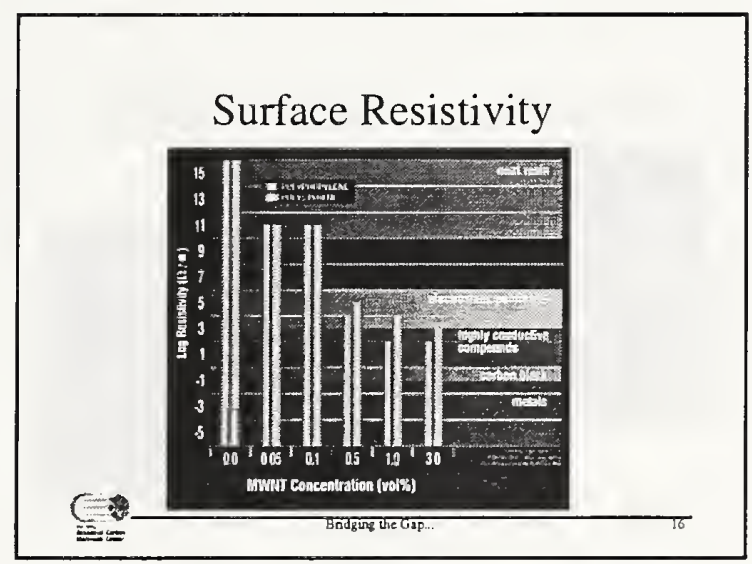
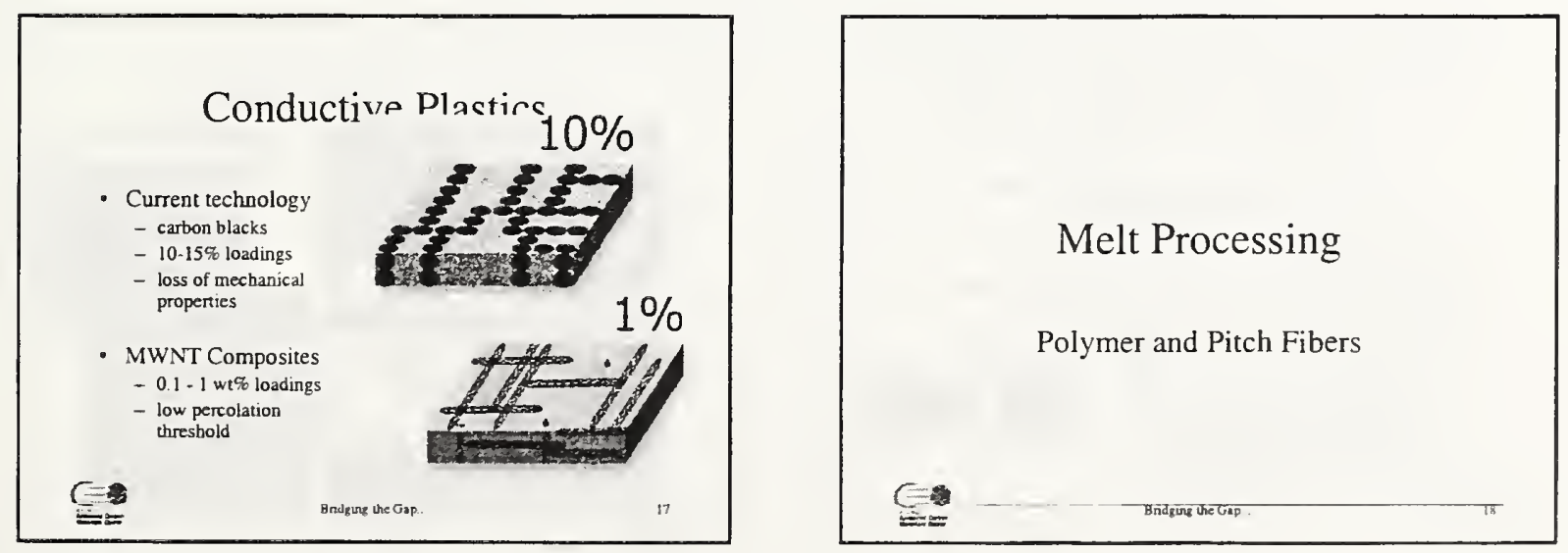

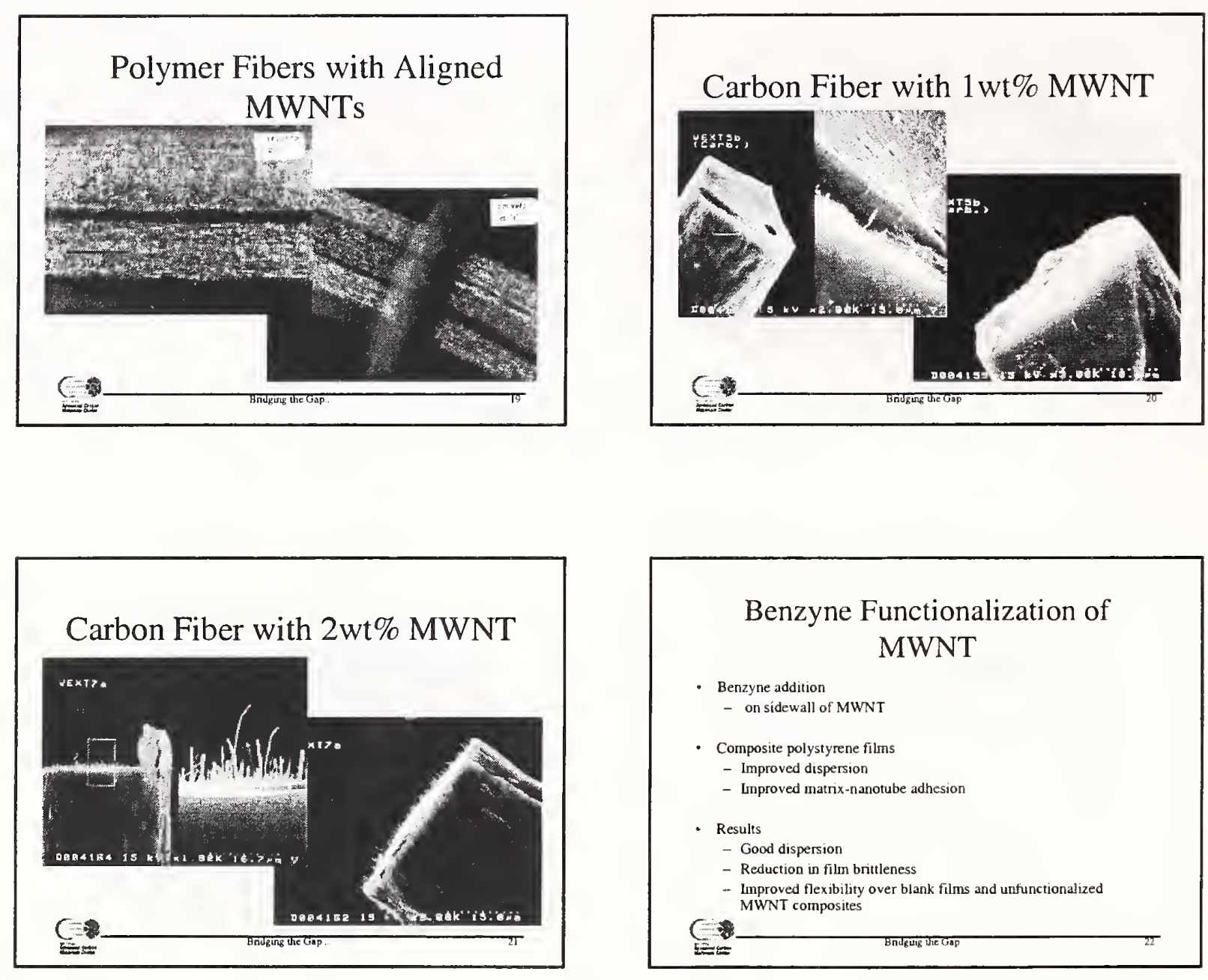

Computational Studies of the Mechanical and Tribological Properties of Carbon Nanotubes. (Sinnott)

- Results for indentation of multi-walled nanotubes on surfaces - Mechanism is the same as for the síngle-walled nanotubes

- MWNTs are stiffer than comparably sized SWNTs

- Shearing of Carbon Nanotube Buodles Between Slíding Surfaces - Movemenl of the nanotubes is slidíng; no rolling is predicted

- Horizontal bundles of single-walled nanotubes

- little change in frictional forces with slíding

- forces do not vary with changes in pressure

- Vertical bundles of single-walled oanotubes.

- Strong dependence of frictional forces on plied pressure for capped nanotubes

$c=$ little dependence for attached nanotubes

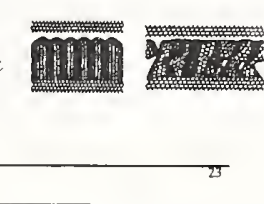

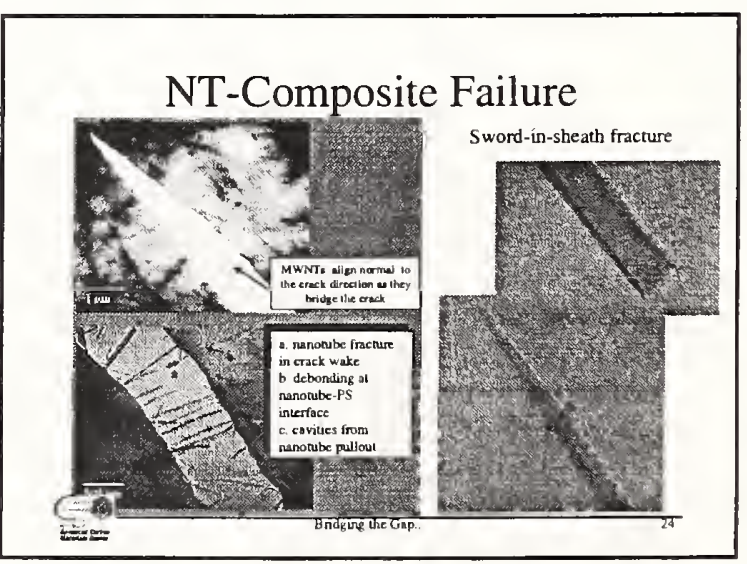




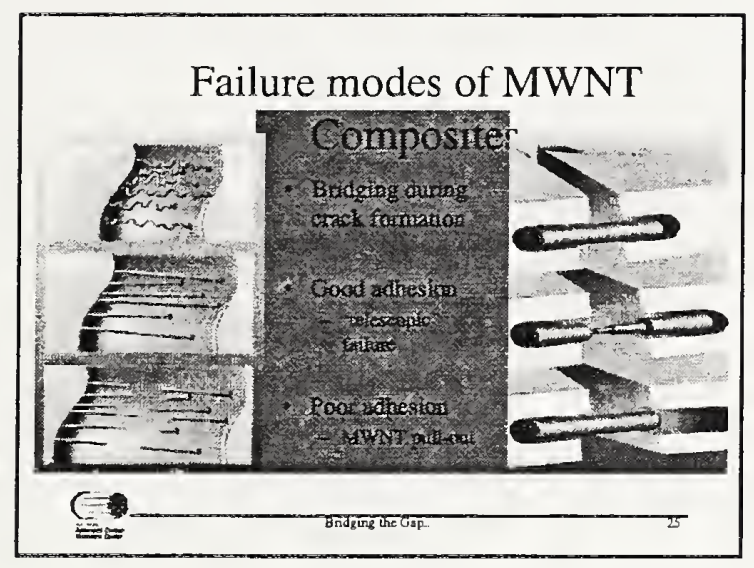

\section{Sizing}

- Commercial graphite fibers having sizings that improve fiber/matrix adhesion

- We have been developing sizings for MWNTs in various commodity polymers

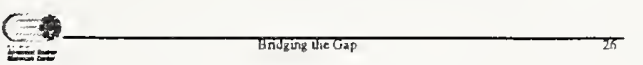


Production, Dispersion and Applications of Multiwalled

Carbon Nanotubes

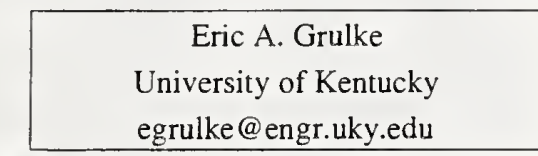

$C$

$=0.5 / 302002$

Bndgung the Gup , NIST

\begin{tabular}{|l|l|}
\hline \multicolumn{2}{|c|}{ NSF MRSEC } \\
Advanced Carbon Materials \\
- Eric Grulke & Center \\
- Mark Meier & - Janet Lumpp \\
- Robert Haddon & - Marit Jagtoyen \\
- Rodney Andrews & - Susan Sinnott, U of Fl \\
- John Anthony & - Kozo Saito \\
- Jack Selegue & - Bruce Hinds \\
- Madhu Menon & - Leonidas Bachas \\
\hline & \\
\hline
\end{tabular}

\section{Outline}

- Synthesis of ordered carbons: emphasis on MWNTs

- Functionalization of MWNTs

- MWNTs applications in polymer systems and fluids develop different morphologies

- Manipulate dispersion, orientation and interphase region

$C$

Bndzres the Gap.. NIST 3

\section{Synthesis of Ordered Carbons}

1. What can we make?

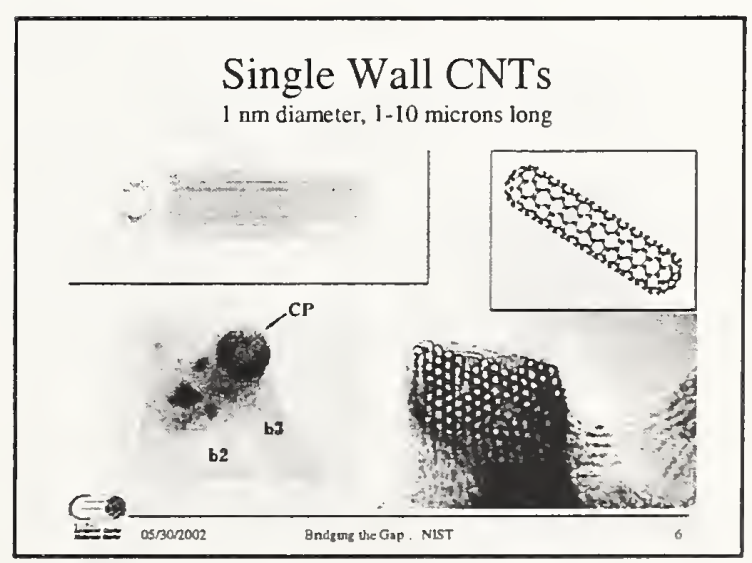



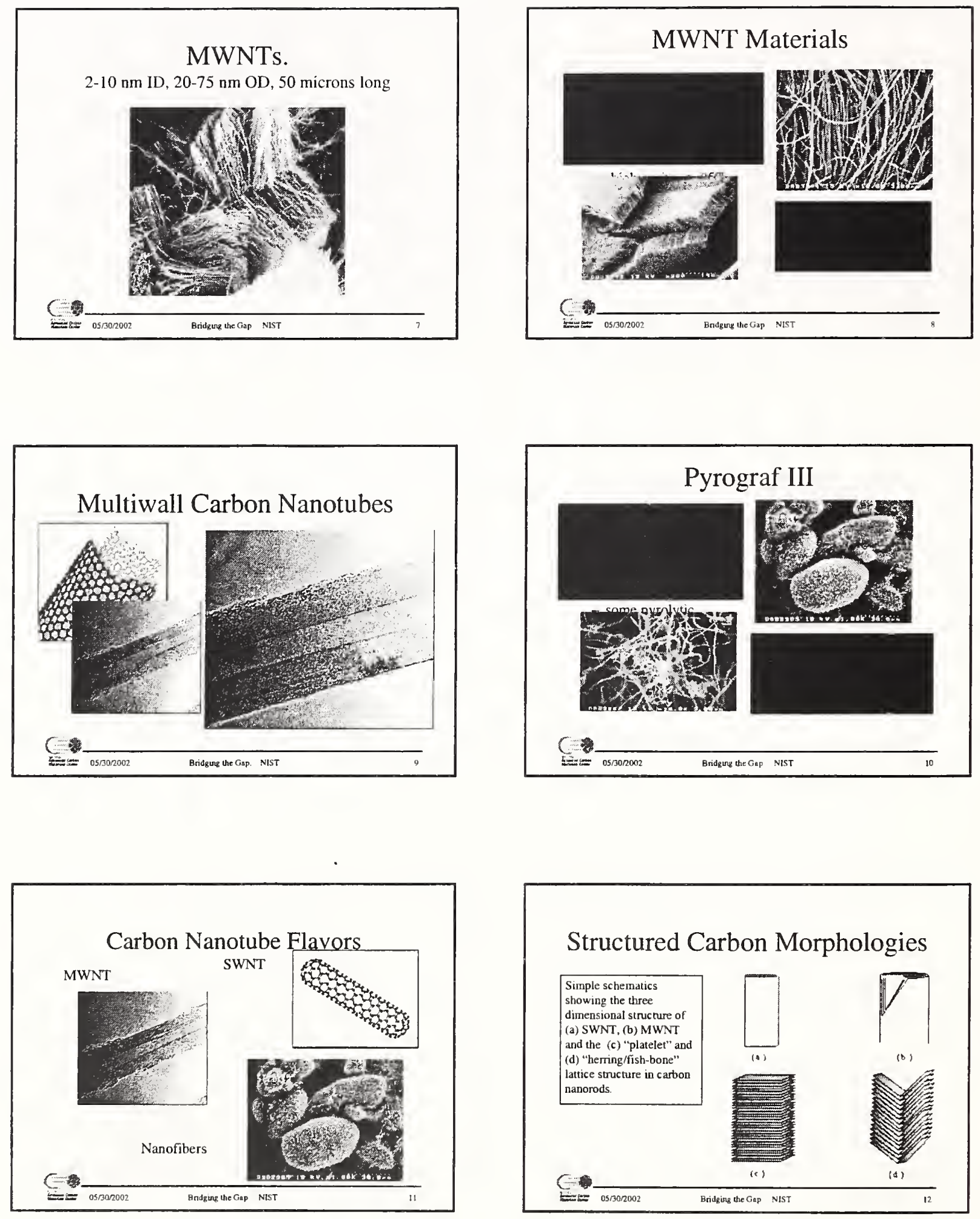

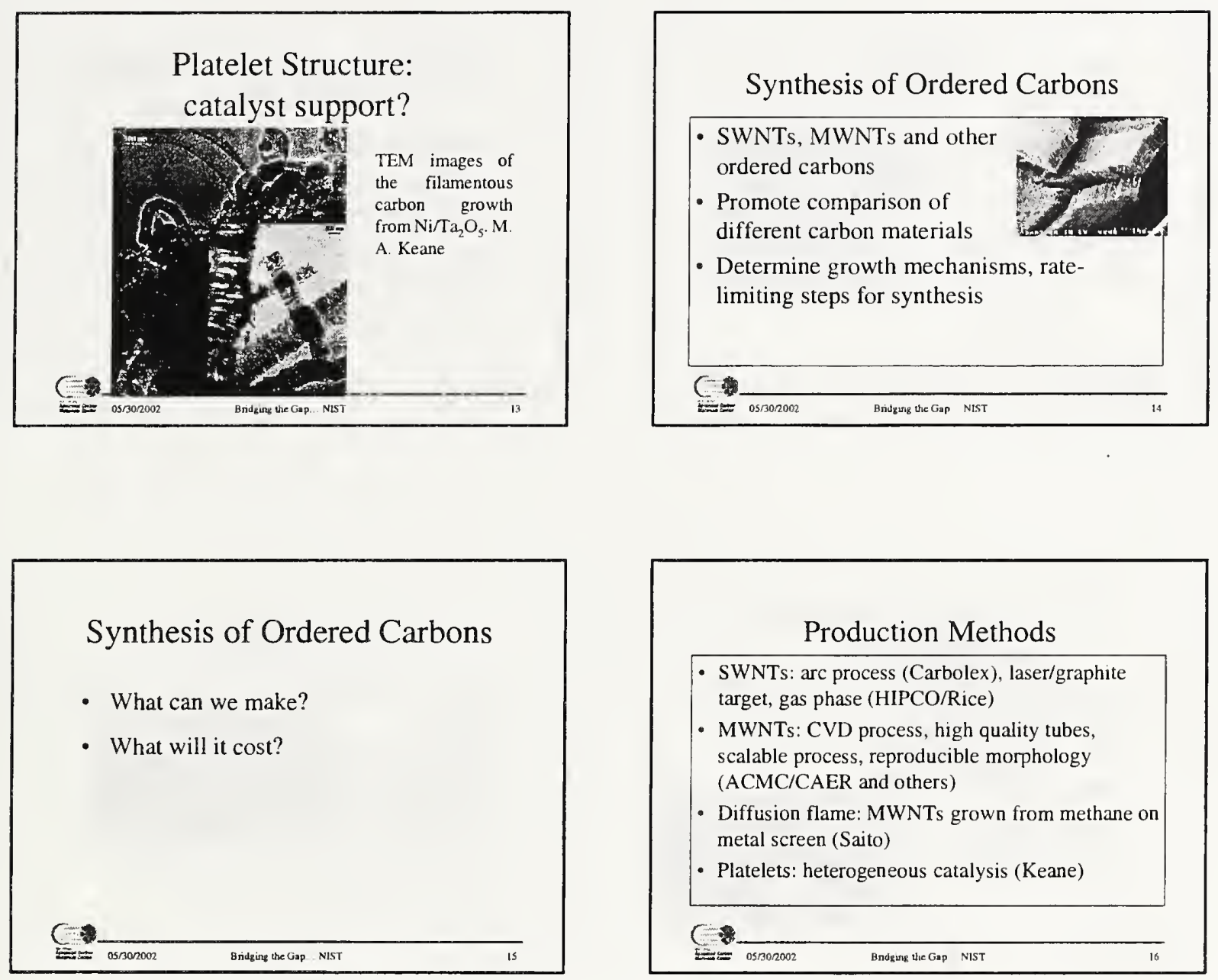

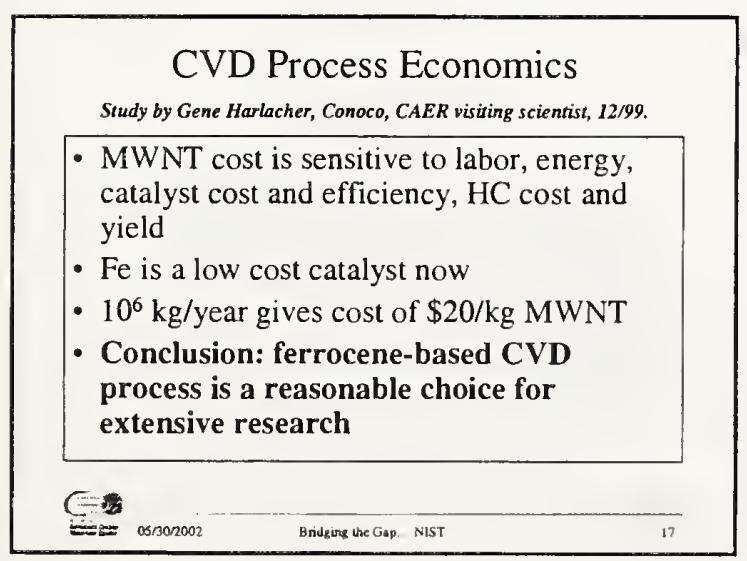

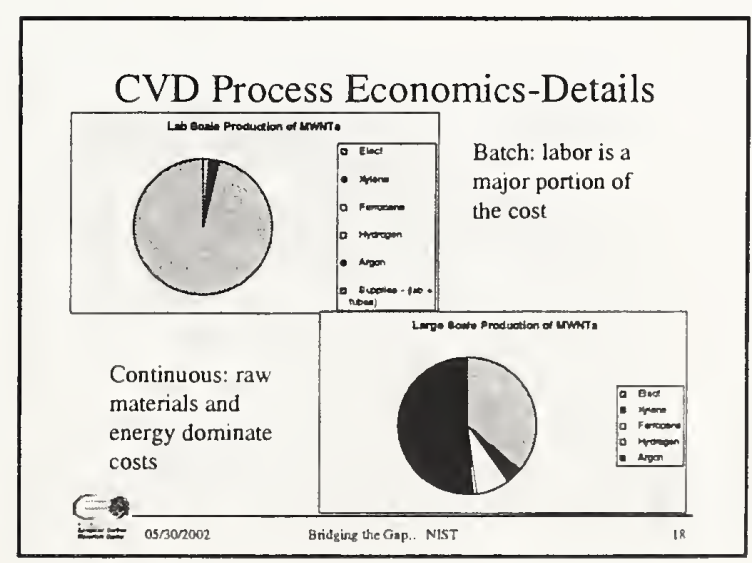




\section{Synthesis of Ordered Carbons}

- What can we make?

- What will it cost?

- How do we make more?

\section{$C$}

Bndgug the Gap. NIST

\section{Scale-up of Carbon Nanotube Production Systems}

- Quantity \& Quality

- Bench scale, pilot plant, commercial plant

- Morphology control

- Recycle of gases, conversion and yield, choice of carbon source, catalyst recycle, solids recovery, solids post processing

C

051302002 Bridging lue Gasp .. NIST

\section{Two Step Synthesis}

- Transition metals and their alloys: $\mathrm{Fe}, \mathrm{Co}, \mathrm{Ni}$

- Prepared nanoscale metal oxide particles $\mathrm{Fe}_{2} \mathrm{O}_{3}, \mathrm{NiO}-\mathrm{CoO}$ on supports

- Catalyst thin films on silica Floating catalyst organometallic precursors form metal nanoparticles in situ

\section{CVD Methods for Nanotube} Synthesis

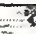

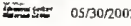

Bndgrng the Gap ... NIST

\section{Two-Step Synthesis Reactor}
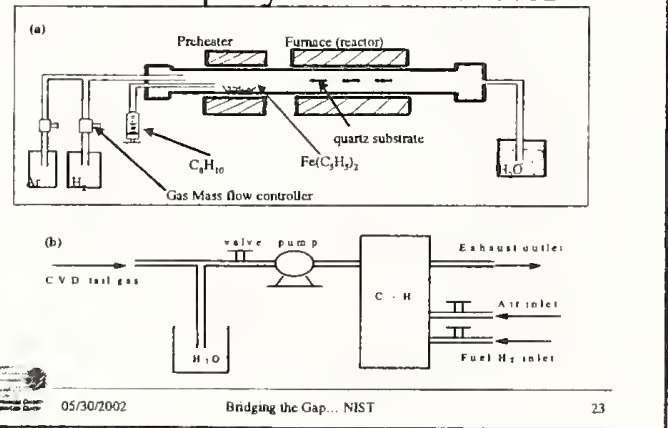

- Gas flow into quartz tube: carbon source, $\mathrm{H}_{2}$, Ar

- Sublime ferrocene into reaction zone and prepare in situ catalyst on reactor surfaces

- Xylene feedstock decomposes over Fe nanoparticles to produce CNTs

- Vary T, C:H ratio to evaluate effect of MWNT growth over rxn. time

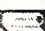
Exis $05 / 302002$ Bridging the Gap. NIST 

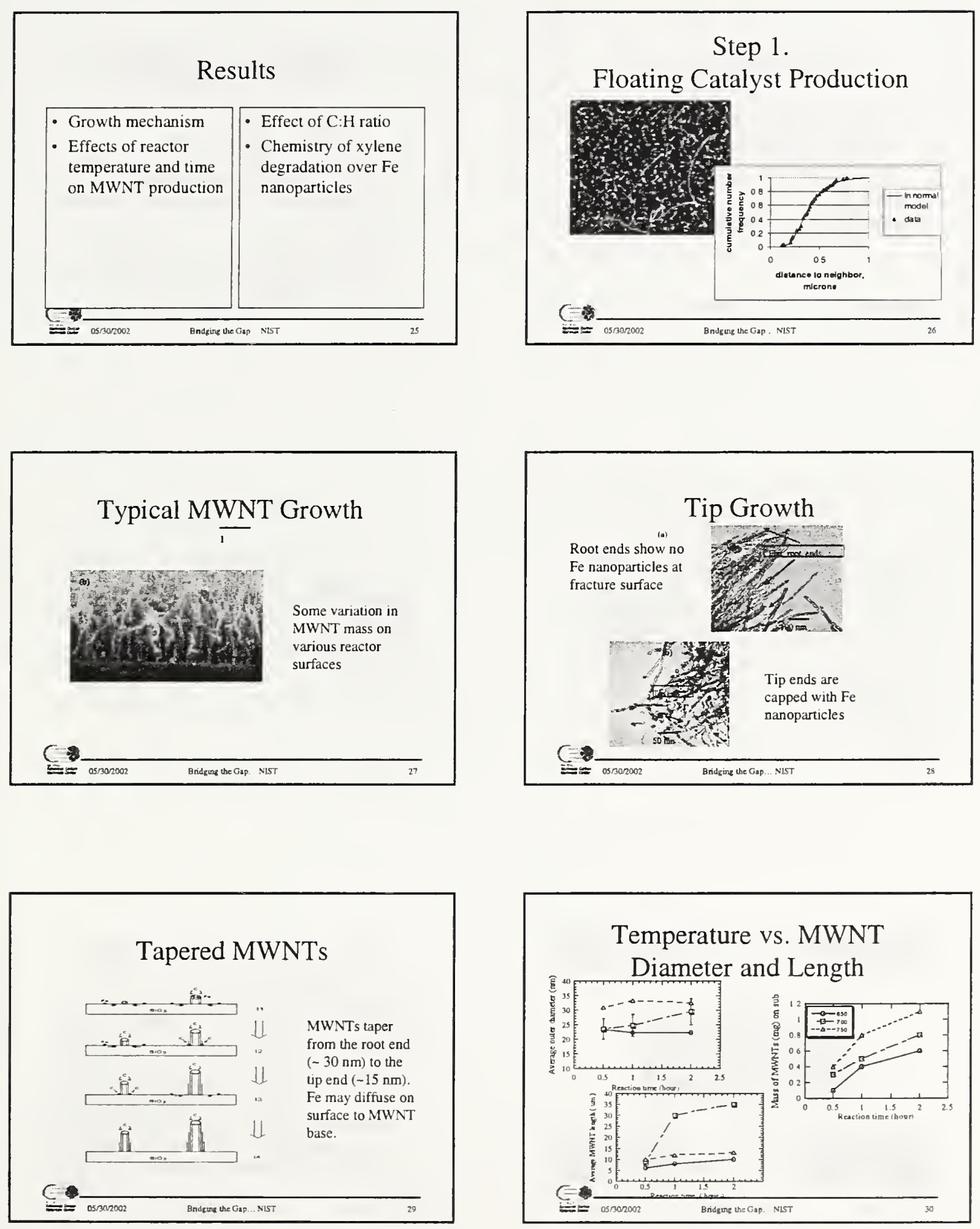


\section{Effects of Temperature}

- Tube coarsening is occurring increasing with time at $700 \mathrm{C}$, while $650 \mathrm{C}, 750 \mathrm{C}$ samples have nearly constant tube diameters

- MWNT mass increases with temperature

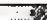

0 Bridgur the Gap NIST

\section{Effects of C:H Ratio}

- Decreasing the C:H ratio results in

- Higher purity MWNTs

- Lower external diameters, and

- Lower standard deviations of the diameter distributions

- $\mathrm{H}_{2}$ : Ar ratio of $0.25: 1$ gives $8 \%$ of MWNTs with $\mathrm{D}<10 \mathrm{~nm}$, and some double wall tubes

\section{Effect of C:H Ratio}

\begin{tabular}{|c|c|c|c|c|}
\hline $\begin{array}{c}\text { Gas } \\
\text { mixture }\end{array}$ & $\begin{array}{c}\text { C:H } \\
\text { ratio }\end{array}$ & $\begin{array}{c}\text { Length } \\
(\mu \mathrm{m})\end{array}$ & $\begin{array}{c}\text { Average } \\
\text { OD (nm) }\end{array}$ & Purity \\
\hline $\begin{array}{c}0 \% \mathrm{H}_{2}- \\
\mathrm{Ar}\end{array}$ & $1: 1.25$ & 2 & $\begin{array}{c}18.2 \\
(12.3)\end{array}$ & $\begin{array}{c}<50 \% \\
\mathrm{NT}\end{array}$ \\
\hline $\begin{array}{c}5 \% \mathrm{H}_{2}- \\
\mathrm{Ar}\end{array}$ & $1: 4.3$ & $\begin{array}{c}10 \\
(3.0)\end{array}$ & $\begin{array}{c}14.1 \\
(6.86)\end{array}$ & $\begin{array}{c}\sim 70 \% \\
\mathrm{NT}\end{array}$ \\
\hline $10 \% \mathrm{H}_{2}-$ & $1: 7.4$ & 35 & 24.4 & $\sim 90 \%$ \\
$\mathrm{Ar}$ & & $(31)$ & $(8.83)$ & $\mathrm{NT}$ \\
\hline $25 \% \mathrm{H}_{2}-$ & $1: 16.6$ & 6 & 14.4 & $\sim 95 \%$ \\
$\mathrm{Ar}$ & $(1.8)$ & $(7.09)$ & $\mathrm{NT}$ \\
\hline
\end{tabular}

\section{Xylene Degradation.}

Simplified kinetics, dilute carbon source, no mass transfer limitations

$$
\begin{aligned}
& \mathrm{C}_{8} \mathrm{H}_{10}+\mathrm{H}_{2} \rightarrow \mathrm{C}_{7} \mathrm{H}_{8}+\mathrm{CH}_{4} \\
& \mathrm{C}_{7} \mathrm{H}_{8}+\mathrm{H}_{2} \rightarrow \mathrm{C}_{6} \mathrm{H}_{6}+\mathrm{CH}_{4} \\
& \mathrm{C}_{6} \mathrm{H}_{6} \rightarrow \mathrm{MWNT}+3 \mathrm{H}_{2}
\end{aligned}
$$

Few hydrocarbons with $\mathrm{C}<6$ are observed in the tailgas

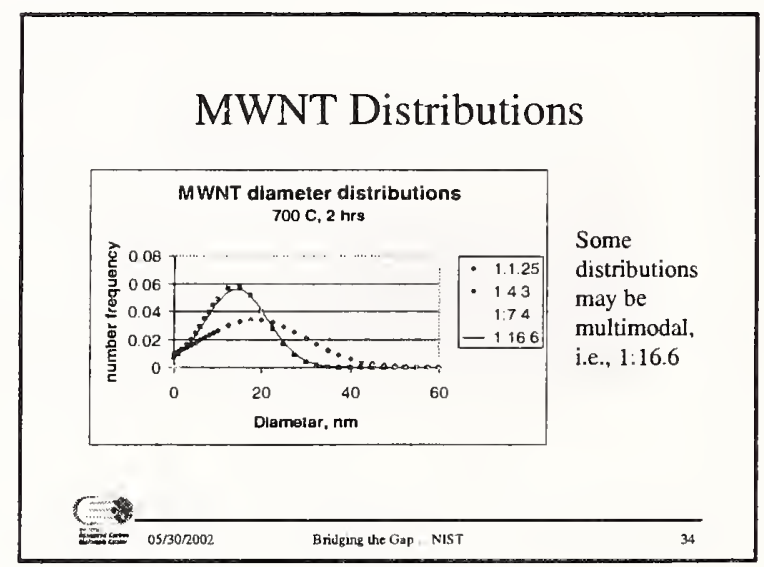

\begin{tabular}{|c|c|c|c|c|c|}
\hline $\begin{array}{l}\mathrm{C}_{n} \mathrm{H}_{\mathrm{n}} \text { Fraction (\%) } \\
\text { (Conoentration } \mathrm{ppm})\end{array}$ & $\mathrm{C}_{1} \mathrm{H}_{0}+\mathrm{C}_{2} \mathrm{H}_{\mathrm{n}}$ & $\mathrm{C}_{3} \mathrm{H}_{n}$ & $\mathrm{C}_{\Delta} \mathrm{H}_{\mathrm{H}}$ & $\mathrm{C}_{7} \mathrm{H}_{4}$ & $\mathrm{C}_{9} \mathrm{H}_{10}$ \\
\hline 5 min & $\begin{array}{c}347 \\
(5 \mathrm{pmn})\end{array}$ & $\begin{array}{l}0.00 \\
(0)\end{array}$ & $\begin{array}{l}0.54 \\
\text { (1) }\end{array}$ & $\begin{array}{l}7.98 \\
(12)\end{array}$ & $\begin{array}{l}8745 \\
(135)\end{array}$ \\
\hline $15 \min$ & $\begin{array}{c}5.38 \\
(11 \mathrm{pom})\end{array}$ & $\begin{array}{l}0.00 \\
(0)\end{array}$ & $\begin{array}{l}0.00 \\
(0)\end{array}$ & $\begin{array}{l}7.99 \\
(17)\end{array}$ & $\begin{array}{l}8607 \\
86.63 \\
(182)\end{array}$ \\
\hline $30 \min$ & $\begin{array}{c}449 \\
(21 \mathrm{pmm})\end{array}$ & $\begin{array}{l}0.20 \\
\text { (1) }\end{array}$ & $\begin{array}{l}0.45 \\
(2)\end{array}$ & $\begin{array}{l}15.28 \\
(73)\end{array}$ & $\begin{array}{l}79.58 \\
(379)\end{array}$ \\
\hline 60 min & $\begin{array}{c}293 \\
(29 \mathrm{mmm})\end{array}$ & $\begin{array}{l}0.09 \\
(1)\end{array}$ & $\begin{array}{l}0.29 \\
(2)\end{array}$ & $\begin{array}{l}1253 \\
(99) \\
\end{array}$ & $\begin{array}{l}83.39 \\
(657)\end{array}$ \\
\hline $90 \mathrm{mn}$ & $\begin{array}{c}2.00 \\
(42 \mathrm{pom})\end{array}$ & $\begin{array}{l}0.07 \\
(1)\end{array}$ & $\begin{array}{l}0.27 \\
(4)\end{array}$ & $\begin{array}{l}1113 \\
1161)\end{array}$ & $\begin{array}{r}85.63 \\
(1240)\end{array}$ \\
\hline $120 \mathrm{mn}$ & $\begin{array}{l}259 \\
(38 \mathrm{mpm})\end{array}$ & $\begin{array}{l}0.08 \\
\text { (1) }\end{array}$ & $\begin{array}{l}0.26 \\
\text { (4) }\end{array}$ & $\begin{array}{l}1188 \\
(172)\end{array}$ & $\begin{array}{l}85.02 \\
(1234)\end{array}$ \\
\hline
\end{tabular}

\section{Hydrocarbons in the Tailgas}

Feed has $3750 \mathrm{ppm}$ xylene, $0.1 \mathrm{H} 2: \mathrm{Ar}, 700 \mathrm{C}$ 


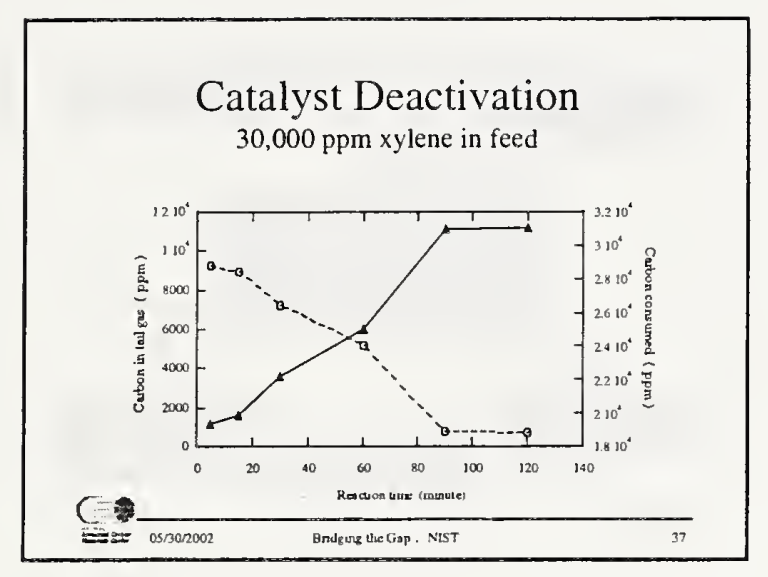

Computational Fluid Dynamics

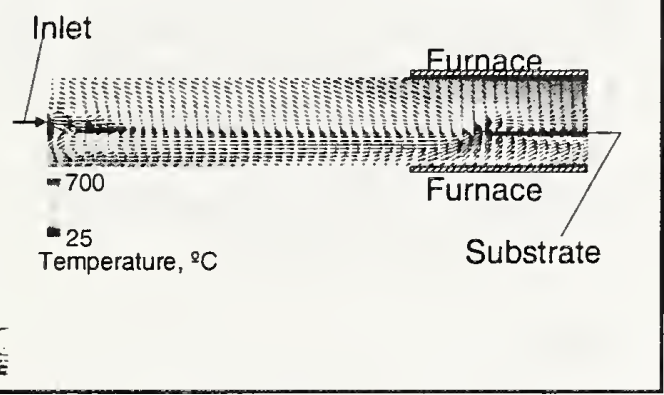

\section{CVD Process Summary}

- Practical experience: scaled from $1 \mathrm{~cm}$ to $10 \mathrm{~cm}$ tube in 2 steps; from 2 to $6 \mathrm{~g} / 2 \mathrm{hr}$ run over one year

- Computational fluid mechanics: gas flows and concentrations

- Overall and component balances: conversion, yield, mechanism(s)

- Catalyst particle model: NT growth, limiting rates

- Needs/Directions: multiple scale model, metal nanoparticle detection/control, "morphology" C pater

$=05302002$

Bnidging the Gap NIST

\section{Conclusions}

- Tip growth is critical mechanism

- Temperature is important for catalyst coarsening, deactivation

- Xylene, toluene conversions may be ratelimiting; benzene and smaller molecules are present in low mass fractions

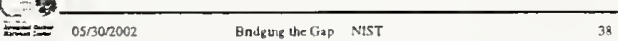

\section{Mass Transfer of $\mathrm{C}$ through $\mathrm{Fe}$} Nanoparticle

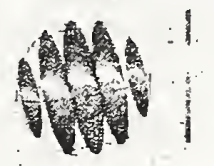

Left: Concentration levels of $C$.

Right: Flux of $\mathrm{C}$ on nanosphere surface.

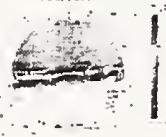

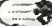

ED OSROR002 Brugngy the Gap. NIST

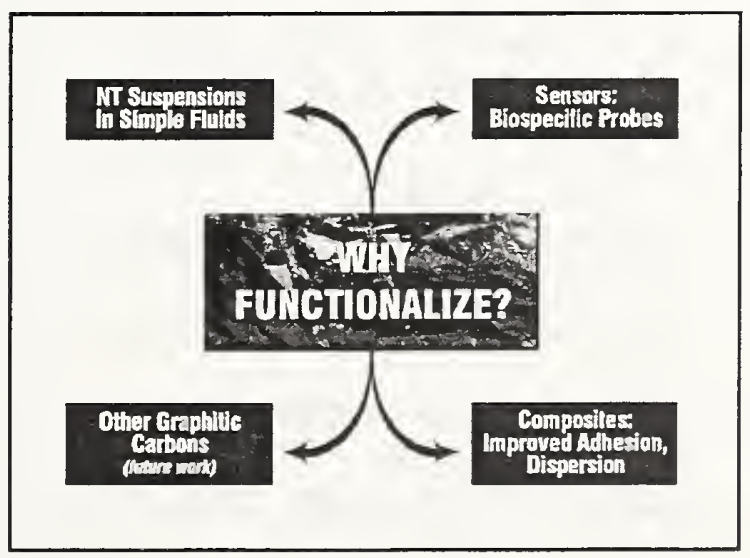



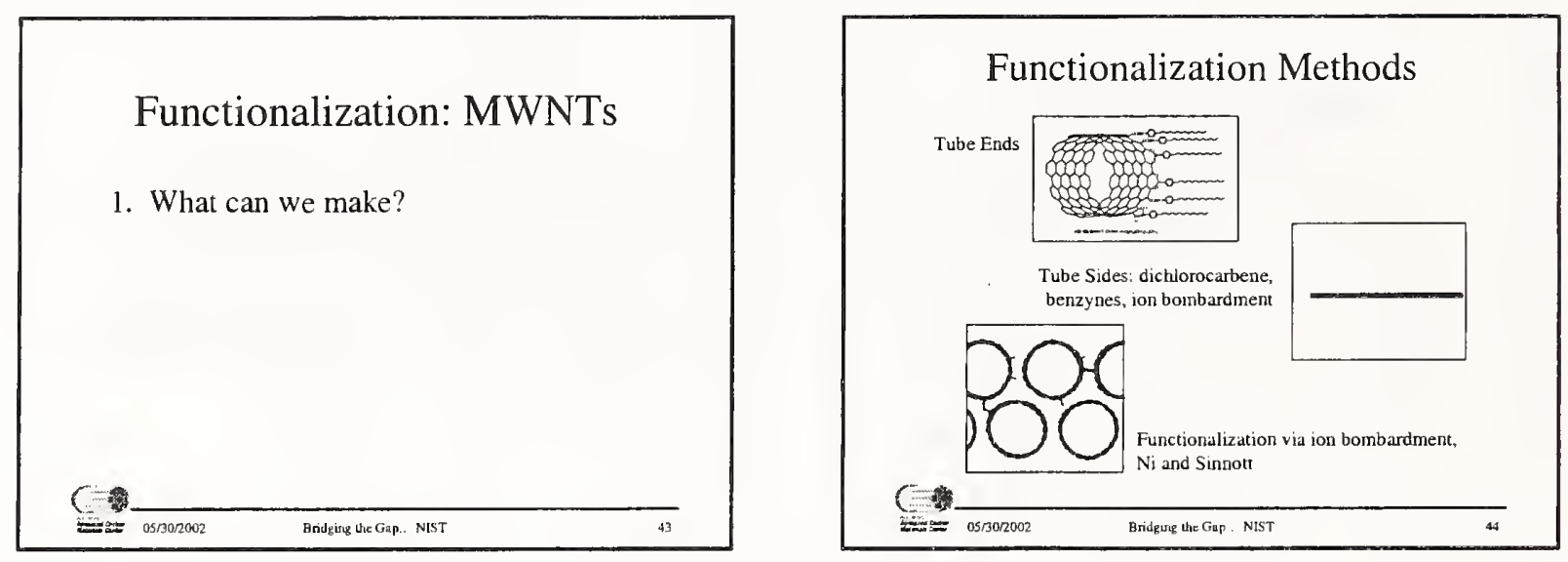

Functionalization: New Work

\section{Haddon, Meier, Anthony}

- Transfer dichlorocarbene method from SWNTs to MWNTs; benzyne method from fullerenes to MWNTs

- Attach oligomer and polymer chains to MWNTs

- Attach conductive links and ion-specific sites

C.

$=05,300002$ Bridgurg the Gap , NIST

\section{Current Research Directions}

Functionalized Carbon Materials

- Additions: halogenation,

halomethylation,cycloaddition, Grignard

- Cleaning: $\mathrm{CO}_{2}$, steam, graphitization

- Novel Carbons: fulleroids, baskets and test tubes

- Functionalized Soluble Graphenes

- Characterization: FFF

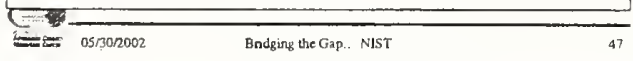

\section{Functionalization}

- Fullerene work shows that "defect sites" are more reactive to functionalization

- Feedstocks used in CVD synthesis control defects

- MWNTs have been functionalized and incorporated into composites

$=0=\frac{}{05 / 30 / 2002}$ Bndging the Gap. NIST

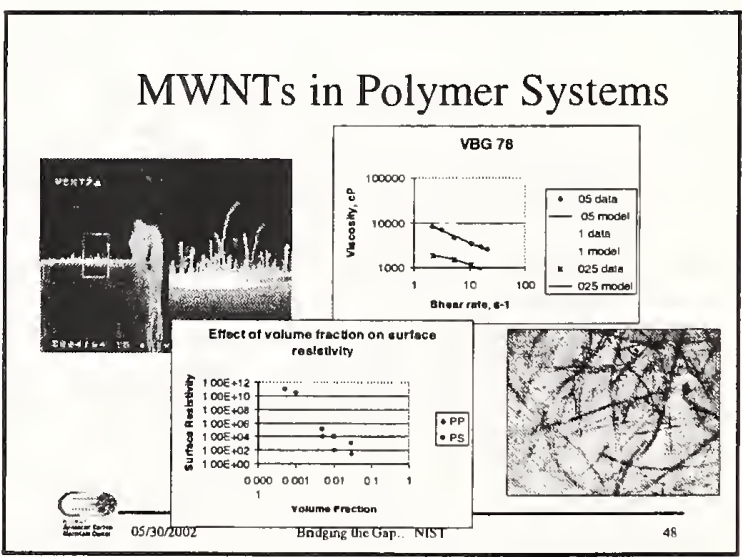




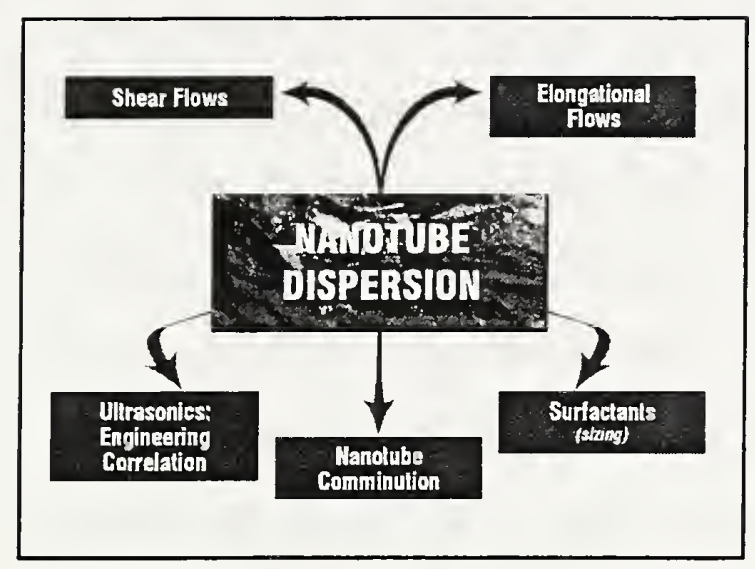


12) Ken McElrath and Tom Tiano, "Achieving Conductive Polycarbonate with Single Wall Carbon Nanotubes" [McElrath Powerpoint] [McElrath PDF] [Tiano PowerPoint] [Tiano PDF]

Dr. McElrath and Dr. Tiano give an emphasis on the single-walled carbon nanotubes that is complementary to the presentation of Dr. Grulke that emphasized the multi-walled tubes. The single wall materials should have remarkable strength, electrical conductivity and electrical conductivity and are characterized by a rather precise molecular structure. The realization of this potential is limited by the tendency to form rope like structures and thus there is a great need to improve the dispensability to fully realize the potential of this type of material. Progress on the development of single wall tubes as commercial materials were summarized along with the intense scientific interest generated in the course of the development of this exceptional material.

After the introductory material, the presenters focused specifically on the problem of nanotube dispersal and which solvents were favorable for this. The importance of ultrasonic processing in effective dispersion was also emphasized. The most dramatic success in dispersion was found and characterized for single wall tubes dispersed in polycarbonate. Substantial improvements in electrical and thermal conductivity were found for polar polymer matrices where appreciable dispersion of the tubes was possible. The presentation was concluded with a summary of the many areas where single walled nanotubes have promising commercial applications. 

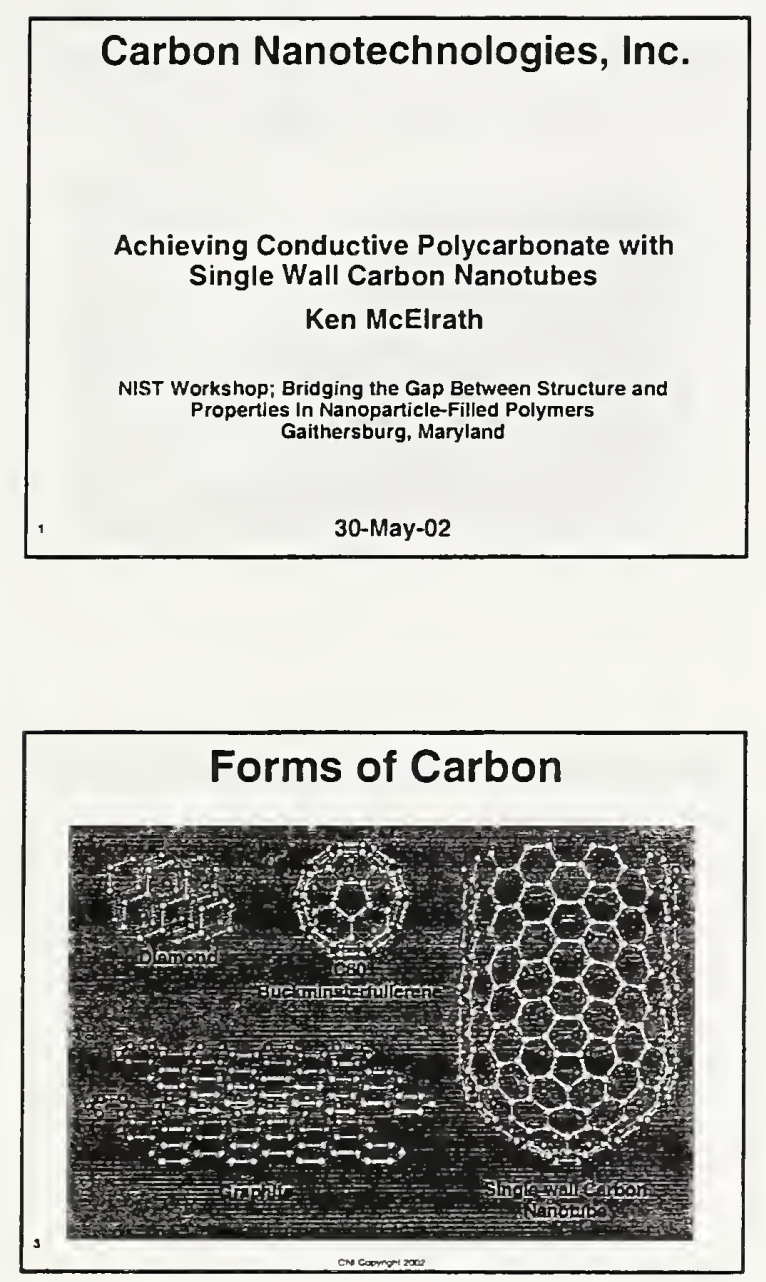

SWNTs have Tremendous Accessible Surface Area

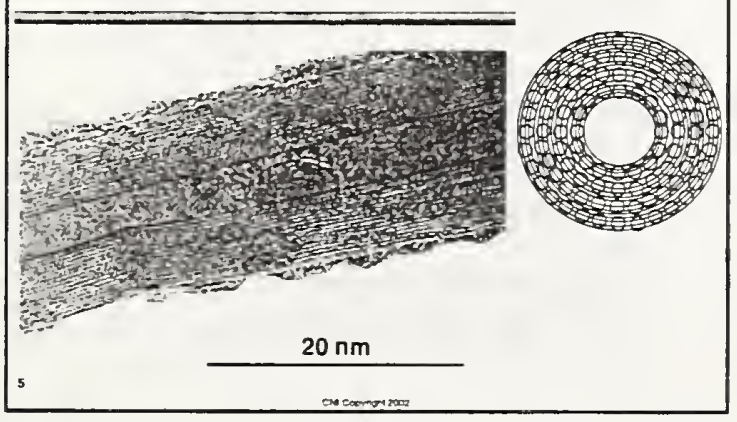

\section{Agenda}

- What are single wall carbon nanotubes?

- Why are they useful?

- CNI plans for SWNT commercialization

- Presentation by Tom Tiano, Research Partner with Foster-Miller

\section{Types of Nanotubes}

- Defined by the number of walls they are made of Single-wall (SWNT)

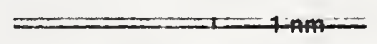

Multi-wall (MWNT)

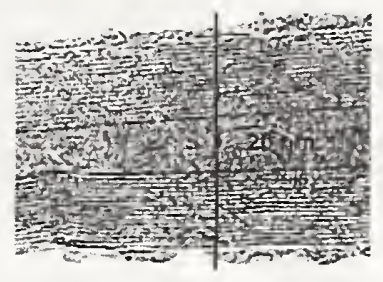

\section{SWNTs: The Perfect Material}

- Single-wall Carbon Nanotubes (SWNTs) are unique: - Fullerene molecules

- Perfect structures

- Polymers ol pure carbon

SWNTs have extraordinary properties:

- Strength (- 100x oteal)

- Electrical conductlvity (-Copper)

- Thermal conductivity ( $-3 \times$ Diamond)

- Combination of the abovo

$-1 \mathrm{~nm}$

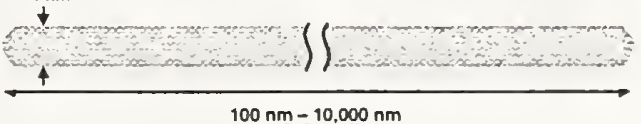



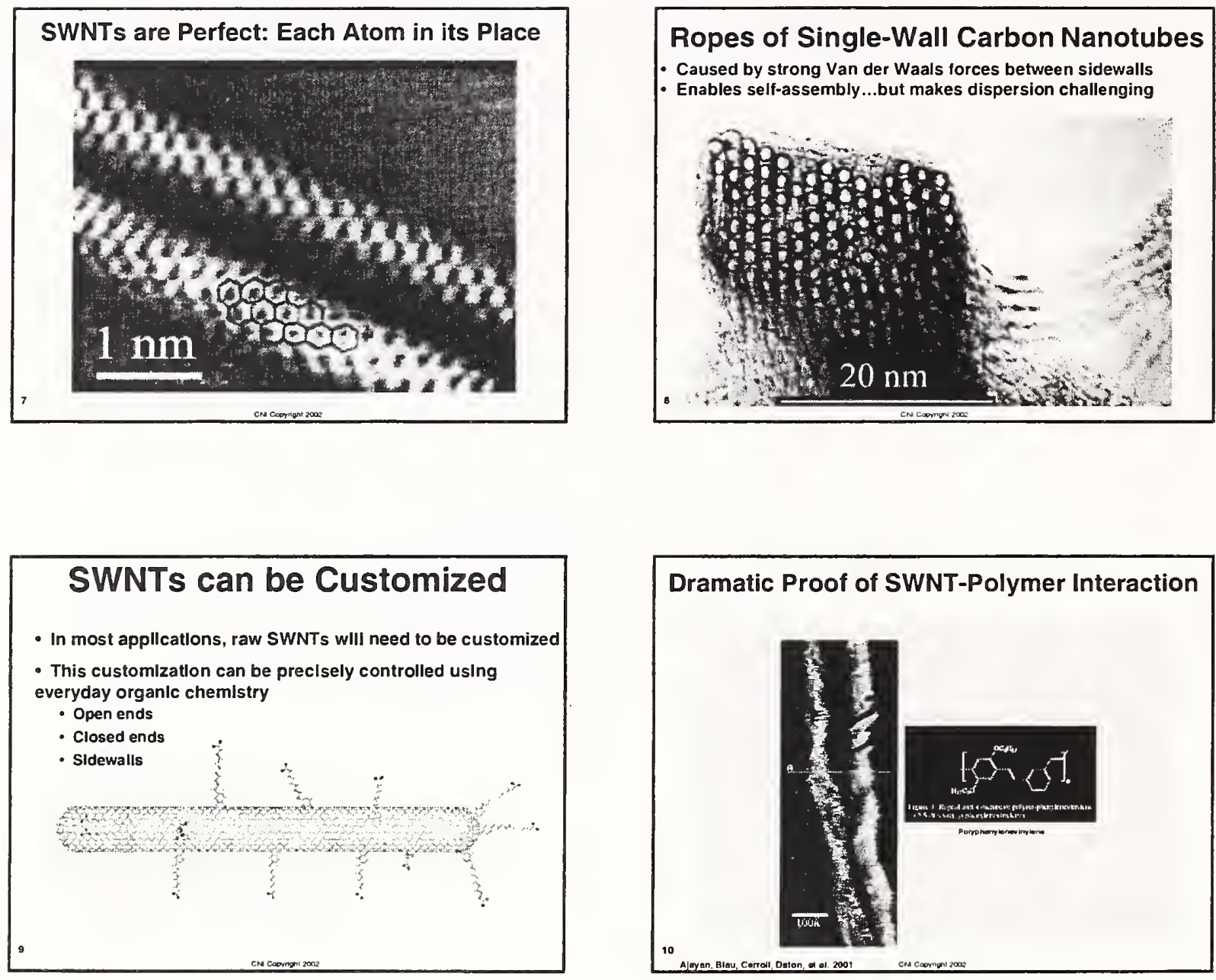

\section{Conductive Polymer Applications}

- ABS, PVC, PC, PE, PP, etc. loaded with conductlve fillers and Inherently conductive polymers

- Total market for conductive polymers is $\$ 3.6$ blillon/year and growing

- A broad range of appllcatlons:

- Electrostatic diealpation (ESO)

- Electromegnetic ahielding (EMI)

- A broad range of potentlal beneflts

- Lightar

- Easler to manutacture

- Choaper

- Nanotubes should enable new appllcatlons that carbon

black, carbon fiber, graphlte and metal flliers cannot

en cosmint 2000

\section{Fast Track to Commercialization}

- Scaling up from milligrams to kilotonnes

- Bench unit - $g$

- Pilot plant - kg

- Commercial unit - kt

- Creating commercial products

- Joint development

- End-use alliances

- Exploding IP portfolio

- CNI research

- Joint research with corporations

- Ongoing relationship with Rice

- Research support at other universities 

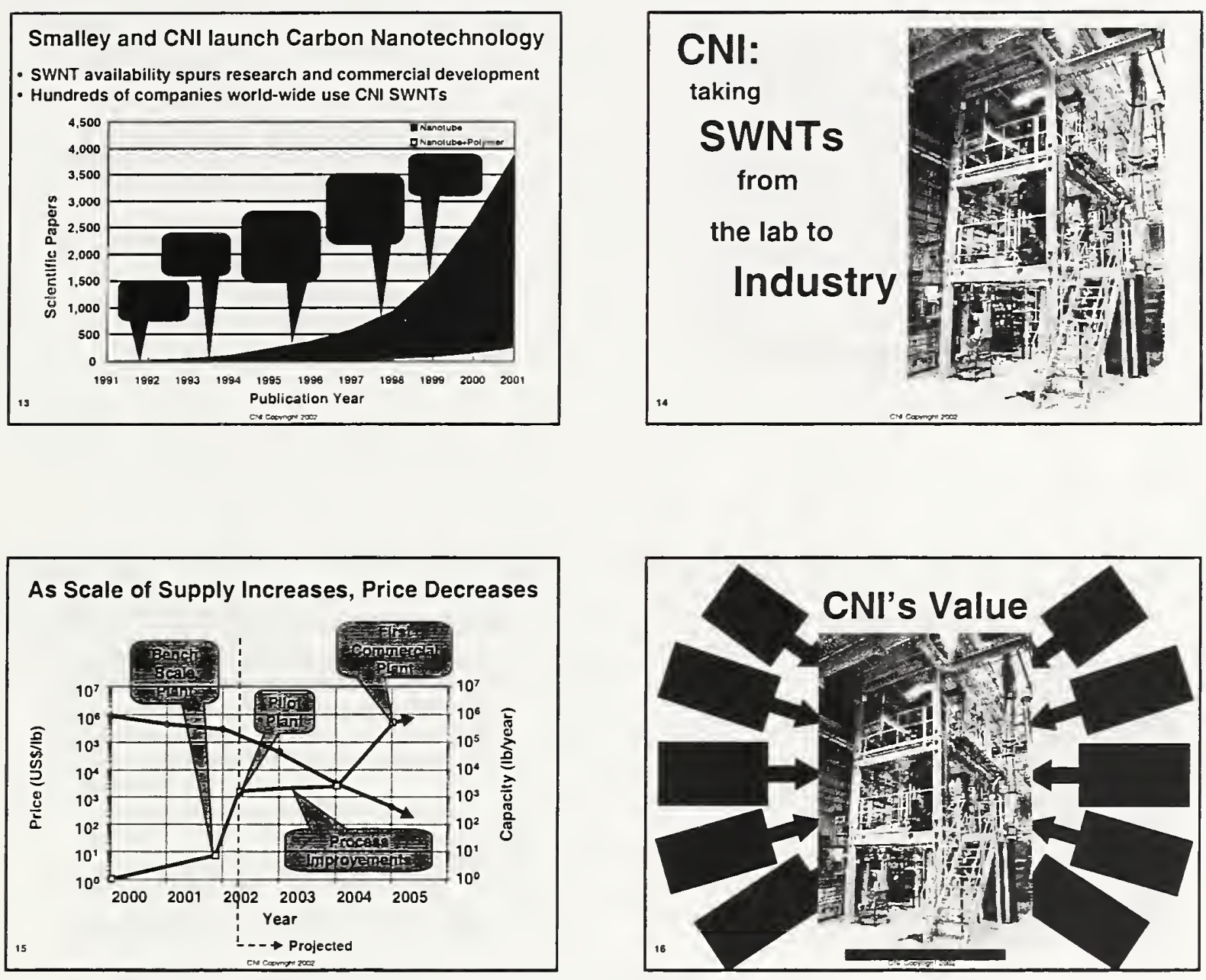
Div rouser-mitle

Dispersing Single-Wall Carbon Nanotubes in Polycarbonate to Achieve Electrical Conductivity

Thomas Tiano - Foster-Miller, Inc.

Ken McElrath and Ken Smith - Carbon Nanotechnologies, Inc.

Presented to

National Institute of Standards and Technology

May $29 \& 30,2002$ ii. Footer- bitlec

Single Wall Nanotubes Properties

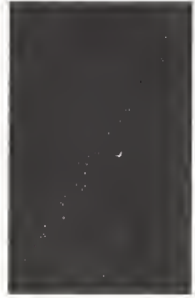

$\begin{array}{ll}\text { Aspect Ratio } & 1000: 1 \\ \text { Specific Gravity } & 1.3 \\ \text { Electrical Res. } & 10^{-4} \Omega \cdot \mathrm{cm} \\ \text { Therm. Cond. } & 1750-5800 \mathrm{~W} / \mathrm{m} \cdot \mathrm{K} \\ \text { Young's Modulus } & 650 \mathrm{GPa}-1 \mathrm{TPa} \\ \text { Tensile Strength } & 65-300 \mathrm{GPa} \\ \text { Tensile Elong. } & 20 \%\end{array}$

Adequate dispersion is required to take advantage of these properties in multi-phase systems.
(111) roetrom-killer

Objective

$\therefore$ Develop processes for preparing single wall carbon nanotube (SWNT) composites in which the SWNTs are highly dispersed in the polymer matrix.

$\therefore$ Assess electrical and thermal conductivity and mechanical properties.

$\because$ Target applications in the electronics industry. in roser bitlo

Electrical Critical Composition

$\therefore$ Critical composition is the filler volume loading at which a conductive network is created (see schematic).

$\therefore$ Critical composition is highly dependent on aspect ratio (see schematic).
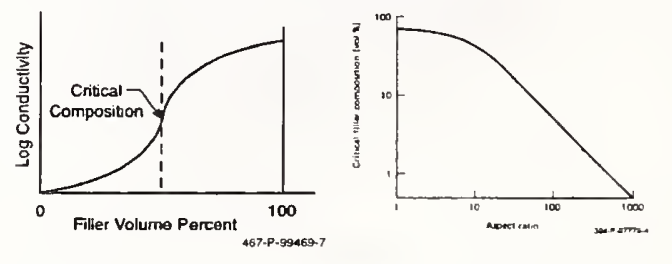

rooser-meres

Impediments to Dispersion of SWNTs in Nanotube Composites

$\because$ Strong Van der Waals interactions

- SWNTs form ropes (bundles of tubes) ranging from 10 to $100 \mathrm{~nm}$ in diameter

- Ropes are very difficult to de-bundle

$\because$ Low surface energy

- Low affinity for organic solvents and matrices

- Extremely high critical length
1. rosur-biter

\section{Processing Steps}

* Disperse SWNT into polar polymer (assisted by polar solvent)

$\therefore$ Remove and recover solvent

$\therefore$ Process composite into parts and specimens

$\because$ Perform electrical, thermal and mechanical assessment

$\therefore$ Perform "let-down" studies for processability 


\begin{tabular}{|c|}
\hline SWNT Dispersion \\
Polymer and Solvent Selection \\
$\therefore$ Solvent Requirements \\
- Good dispersant for SWNTs \\
- Good solvent for polycarbonate \\
- Low boiling point \\
$\therefore$ Polycarbonate grades \\
- Lexan 101-112 (multi-purpose) \\
Lexan HF1110 (high-flow)
\end{tabular}

ratar vitar

SWNT Dispersion

Ultrasonic Processing

$\therefore$ Dissolve polymer into solvent

$\therefore$ Add SWNT to solvent and insonify for 30 minutes

$\therefore$ High amplitude insonification induces cavitation

$\because$ Cavitation bubbles nucleate on nanotube clusters

$\therefore$ De-agglomeration occurs when cavitation bubbles collapse on SWNT bundles

$\therefore$ Implosion of voids is driven by reversal of pressure in the sound wave
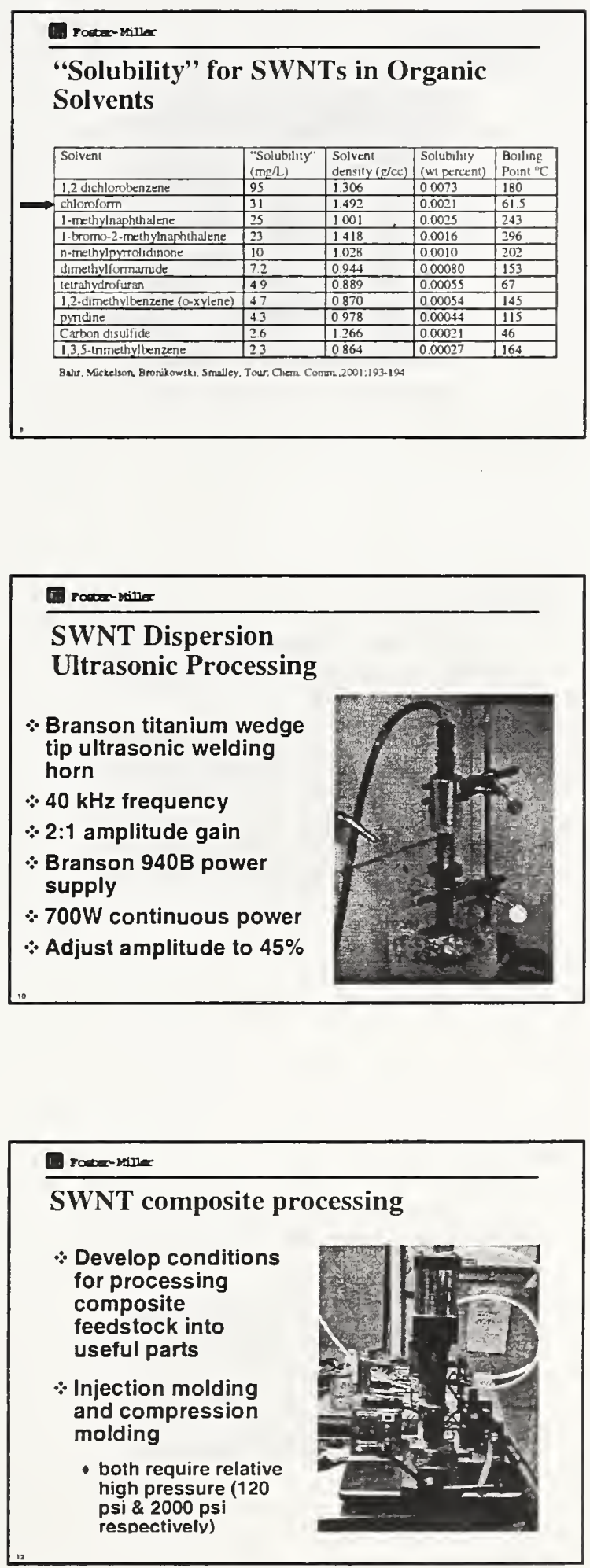

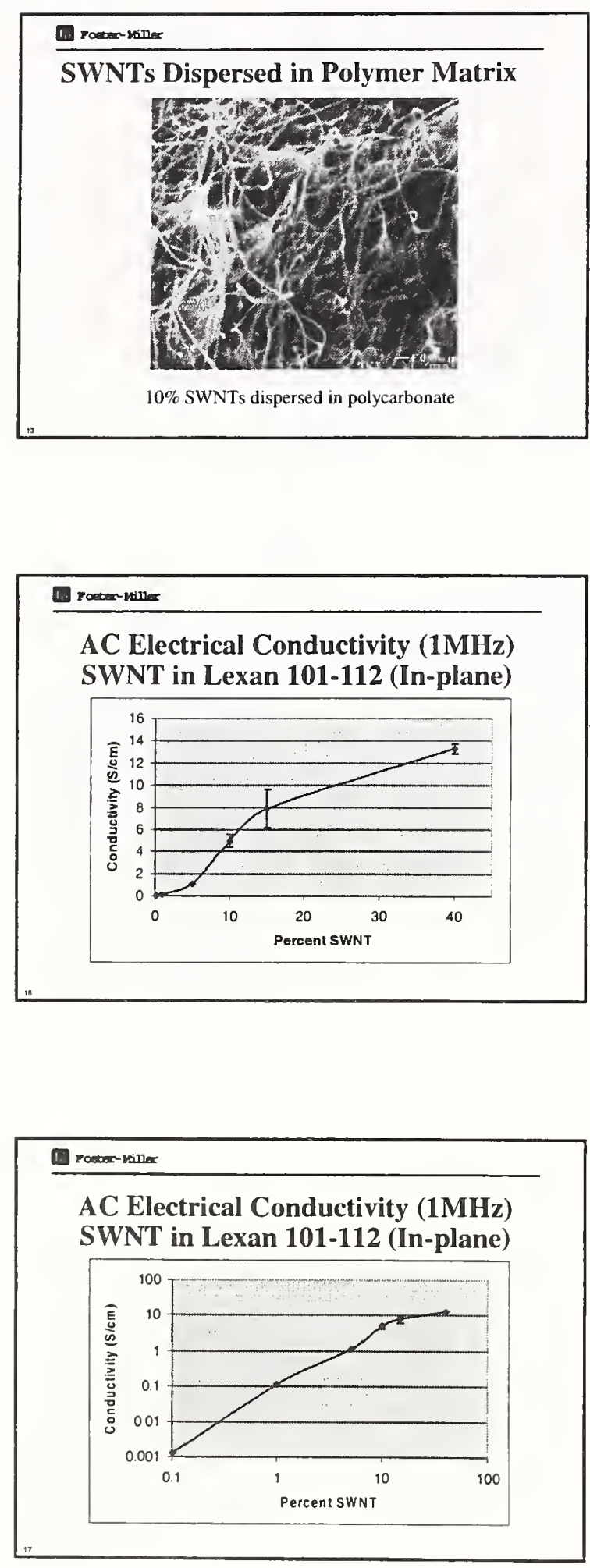

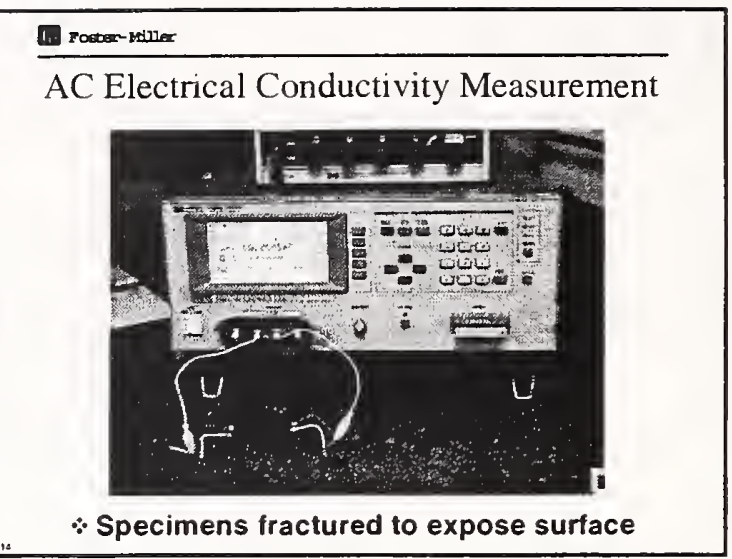

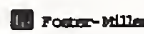

AC Electrical Conductivity (1MHz) SWNT in Lexan 101-112 (In-plane)

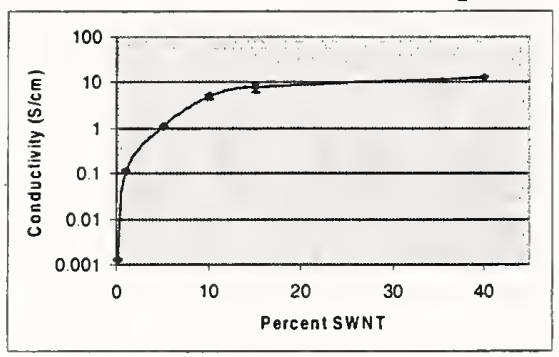

1. Toaber-binger

Thermal Conductivity Measurements

$\therefore$ Samples mounted in vacuum chamber with diffusion pump ( $10^{-7}$ torr).

$\therefore$ Thermocouples mounted to side of sample.

$\therefore$ Radiation shield placed over sample.

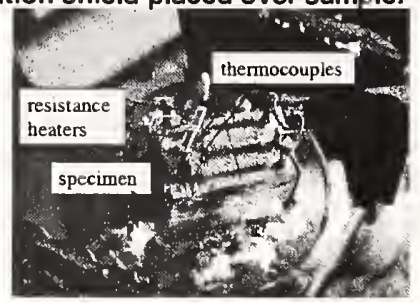


1. Fourer-winer

Room Temp. Thermal Conductivity SWNT in Lexan 101-112 (In-Plane)

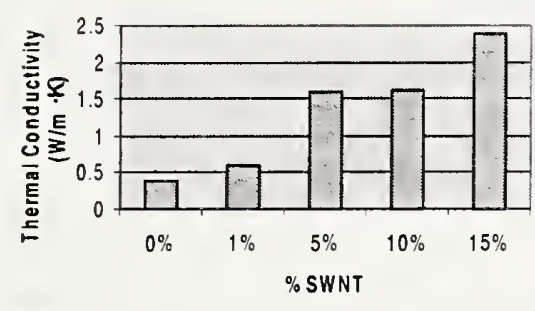

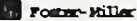

Proprsetary

Further Research in Thermoplastics

$\therefore$ Continue to investigate SWNT dispersion techniques to increase conductivity

$\because$ Obtain more data for electrical and thermal conductivity and mechanical properties

$\therefore$ Further develop composite processing techniques

$\therefore$ Investigate polymer "let-down" procedures

$\because$ Investigate different thermoplastic polymers

Orosen noine

Potential Applications of SWNT-Filled Thermoplastics

$\because$ Electromagnetic interference protection

$\therefore$ Electrostatic discharge materials

$\therefore$ Electrostatic paint substrates

$\therefore$ Lightweight thermal management materials

$\therefore$ Thermoplastic die attach 


\title{
FinalParticipants' List
}

\section{Bridging the Gap between Structure \& Properties in Nanoparticle-Filled Polymers}

\author{
May 29-30, 2002 \\ National Institute of Standards and Technology (NIST), Gaithersburg, MD
}

Fred Allen

Engelhard Corp.

101 Wood Ave.

Iselin, NJ 08550 USA

Telephone: $732 / 205-6042$

Fax: 732/205-5300

Email: fred.allen@engelhard.com

Eric Amis

NIST

100 Bureau Dr., Mail Stop 8540

Gaithersburg, MD 20899-8540 USA

Telephone: 301/975-6681

Email: eric.amis@nist.gov

Larry Anderson

PPG Industries

4325 Rossanna Dr.

Allison Park, PA 15101 USA

Telephone: 412/492-5210

Email: lyanderson@ppg.com

Tony Andrady

Research Triangle Institute

3040 Cornwallis Rd.

Durham, NC 27709 USA

Telephone: 919/541-6713

Email: andrady@rti.org

Joe Antonucci

NIST

100 Bureau Dr., Mail Stop 8545

Gaithersburg, MD 20899-8545 USA

Telephone: 301/975-6794

Email: joe.antonucci@nist.gov
George Baran

Temple Univ.

1947 N. 12th St.

Philadelphia, PA 19122 USA

Telephone: $215 / 204-8824$

Fax: 215/204-4956

Email: grbaran@astro.templ.edu

Gary Beall

Southwest Texas State Univ.

601 University Dr.

San Marcos, TX 78666 USA

Telephone: 512/245-8796

Fax: 512/245-2374

Email: gb11@swt.edu

Charles Beatty

Univ. of Florida

Dept. of Ma'tl. Sci. \& Eng.

Gainesville, FL 32611 USA

Telephone: 352/846-3786

Fax: 352/846-3355

Email: cbeat@mse.ufl.edu

Phillip Britt

Oak Ridge National Laboratory

P.O. Box 2008

Bldg 4500N, C-26, MS

Oak Ridge, TN 37922 USA

Telephone: 865/574-5029

Fax: 865/576-7956

Email: brittpf@ornl.gov

Geoff Broadhurst

GWB Consultants LLC

26 Cottontail Lane

Irvington, NY 10533 USA

Telephone: 914/591-7356

Fax: 914/591-4630

Email: g.broadhurst@worldnet.att.net 
Tony Bur

NIST

100 Bureau Dr., Mail Stop 8544

Gaithersburg, MD 20899 USA

Telephone: 301/975-6748

Email: abur@nist.gov

Anthony Carignano

ITC Minerals \& Chemicals

6 North Park Dr., Ste. 105

Hunt Valley, MD 21030 USA

Telephone: 410/512-4108

Fax: 815/333-2997

Email: awcarignano@itcglobal.com

John Coulter

Lehigh Univ.

19 Memorial Dr. West

Bethlehem, PA 18015 USA

Telephone: $610 / 758-5148$

Fax: 610/758-5623

Email: john.coulter@lehigh.edu

Mark Dadmun

Univ. of Tennessee

321 Buehler Hall

Knoxville, TN 37996 USA

Telephone: 865/974-6582

Fax: 865/974-3454

Email: Dad@utk.edu

Vinay Dayal

Iowa State Univ.

2271 Howe Hall

AEEM Dept., Rm. 1200

Ames, IA 50011 USA

Telephone: 515/294-0720

Fax: 515/294-3262

Email: vdayal@iastate.edu

Hugh De Long

Air Force Ofc. of Scie. Research

801 N. Randolph St., Rm. 732

Arlington, VA 22203 USA

Telephone: 703/696-7722

Fax: 703/696-8449

Email: hugh.delong@afosr.af.mil
Jack Douglas

NIST

100 Bureau Dr., Mail Stop 8542

Gaithersburg, MD 20899-8542 USA

Telephone: 301/975-6779

Email: jack.douglas@nist.gov

Fangming Du

M.S.E. of UPenn

3231 Walnut St., Rm. 324

Philadelphia, PA 19104 USA

Telephone: 215/898-2700

Email: fangming@seas.upenn.edu

Peter Ferraro

Specialty Minerals, Inc.

640 Noth 13th St.

Easton, PA 18042 USA

Telephone: 610/250-3202

Fax: 610/258-1203

Email: peter.ferraro@mineralstech.com

William Finch

Rohm \& Haas Co.

727 Norristown Rd.

P.O. Box 904

Spring House, PA 19477 USA

Telephone: 215/619-1547

Fax: 215/619-1648

Email:WFinch@rohmhaas.com

Jeffrey Gilman

NIST

100 Bureau Dr., Mail Stop 8665

Gaithersburg, MD 20899-8665 USA

Telephone: 301/975-6573

Email: jeffrey.gilman@nist.gov

Harris Goldberg

InMat LLC

216 Route 206, Ste. 7

Hillsborough, NJ 08844 USA

Telephone: 908/874-7788

Fax: 908/874-7672

Email: hagoldberg@inmat.com

Caiguo Gong

ExxonMobil Chemical

5200 Bayway Dr.

Baytown, TX 77520 USA

Telephone: 281/834-1326

Fax: 281/834-2480

Email: caiguo.gong@exxonmobil.com 
Eric Grulke

Univ. of Kentucky

Chemical \& Materials Engineering

Lexington, KY 40506 USA

Telephone: 859/257-2300

Fax: 859/323-1929

Email: egrulke@engr.uky.edu

Reto Haggenmueller

Univ. of Pennsylvania

3231 Walnut St.

LRSM

Philadelphia, PA 19104 USA

Telephone: $215 / 898-2700$

Fax: 215/573-2128

Email: retohagg@seas.upenn.edu

Charles Han

NIST

100 Bureau Dr., Mail Stop 8543

Gaithersburg, MD 20899-8543 USA

Telephone: 301/975-6772

Email: charles.han@nist.gov

Christopher Harrison

NIST

100 Bureau Dr., Mail Stop 8542

Gaithersburg, MD 20899-8542 USA

Telephone: 301/975-3586

Email: christopher.harrison@nist.gov

Erik Hobbie

NIST

100 Bureau Dr., Mail Stop 8543

Gaithersburg, MD 20899-8543 USA

Telephone: 301/975-6774

Fax: 301/975-4977

Email: erik.hobbie@nist.gov

Douglas Hunter

Southern Clay Products

Tadahiro Ishii

Tokyo University of Science

1-3 Kaguraska

Shinjuku-ku

Tokyo 162-8601, JAPAN

Telephone: $81 / 352288257$

Fax: 81/3 32352214

Email: taishii@ch.kagu.sat.ac.jp
Jack Johnson

ExxonMobil Research \& Engineering

1545 Route 22 East

Annandale, NJ 08801 USA

Telephone: 908/730-2895

Fax: 908/730-3198

Email: jack.w.johnson@exxonmobil.com

Karl Kamena

Omni Tech. International

2715 Ashman St.

Midland, MI 48640 USA

Telephone: 989/631-3377

Fax: 989/631-7360

Email: kkamena@omnitechintl.com

Alamgir Karim

NIST

100 Bureau Dr., Mail Stop 8542

Gaithersburg, MD 20899-8542 USA

Telephone: 301/975-6588

Email: karim@nist.gov

Takashi Kashiwagi

NIST

100 Bureau Dr., Mail Stop 8665

Gaithersburg, MD 20899-8665 USA

Telephone: 301/975-6699

Email: takashi.kashiwagi@nist.gov

Hubert King

ExxonMobil Research \& Engineering

1546 Route 22 East

Annandale, NJ 08822 USA

Telephone: 908/730-2888

Fax: 908/730-2536

Email: hubert.e.king@exxonmobil.com

Satish Kumar

Georgia Institute of Technology

School of Textile \& Fiber Eng.

Atlanta, GA 30332-0295 USA

Telephone: 404/894-7550

Fax: 404/894-8780

Email: satish.kumar@textiles.gatech.edu

Steve Lawrence

Naval Research Lab

Code 6134

Washington, DC 20375 USA

Telephone: 202/767-3310

Fax: 202/767-4642

Email: Steven.Lawrence@nrl.navy.mil 
Marshall Ledbetter

Mitsubishi Polyester Film

P.O. Box 1400

2001 Hood Rd.

Greer, SC 29652 USA

Telephone: 864/879-5352

Fax: 864/879-5940

Charles Lee

AFOSR/NL

801 N. Randolph St., Ste. 732

Arlington, VA 22203 USA

Telephone: 703/696-7779

Email: charles.lee@afosr.af.mil

Andre Lee

Michigan State Univ.

Dept. of Chemical Eng. \& Mat'l. Scie.

East Lansing, MI 48824 USA

Telephone: 517/355-5112

Fax: 517/432-1105

Email: leea@msu.edu

Wendy Lin

GE Global Research

1 Research Circle

K-1 4B5

Niskayuna, NY 12309 USA

Telephone: 518/387-4081

Fax: 518/387-7403

Email: Wendy.Lin@crd.ge.com

Eric Lundquist

Rohm \& Haas Co.

727 Norristown Rd.

Spring House, PA 19477 USA

Telephone: 215/619-5335

Email: wlundquist@rohmhaas.com

Michael Mackay

Michigan State Univ.

Dept. Chem. Eng. Mat. Sci.

East Lansing, MI 48824 USA

Telephone: 517/432-4495

Fax: 517/432-1105

Email: mackay@msu.edu
Michael McBrearty

Chemical ElectroPhysics Co., Inc.

705 Yorklyn Rd.

Hockessin, DE 19707 USA

Telephone: 302/234-8206

Fax: 302/239-4677

Email: cep@cep-corp.com

Kenneth McElrath

Carbon Nanotechnologies, Inc.

16200 Park Row

Houston, TX 77084 USA

Telephone: $281 / 492-5883$

Fax: 281/492-5810

Email: kmcelrath@cnanotech.com

Alexander Morgan

Dow Chemical Company

1776 Bldg, Door A

Midland, MI 48674 USA

Telephone: 989/638-1774

Fax: 989/638-9716

Email: abmorgan@dow.com

Tinh Nguyen

NIST

100 Bureau Dr., Mail Stop 8621

Gaithersburg, MD 20899-8621 USA

Telephone: 301/975-6718

Email: tinh.nguyen.nist.gov

Marc Nyden

NIST

100 Bureau Dr., Mail Stop 8665

Gaithersburg, MD 20899-8665 USA

Telephone: 301/975-6692

Email: marc.nyden@nist.gov

Byoungkyeu Park

Cornell Univ.

Bard Hall

Ithaca, NY 14853 USA

Telephone: $607 / 255-4557$

Fax: 607/255-2365

Email: bkp@cornell.edu

Ray Pearson

Lehigh Univ.

5 East Packer Ave.

Bethlehem, PA 18015 USA

Telephone: 610/758-3857

Fax: 610/758-4244

Email: rp02@lehigh.edu 
Giampaolo Pellegatti

Basell USA, Inc.

912 Appleton Rd.

Elkton, MD 21921 USA

Telephone: 410/996-1677

Fax: 410/996-1811

Email: giampaolo.pellegatti@basell.com

Louis Pilato

Pilato Consulting

598 Watchung Rd.

Bound Brook, NJ 08805 USA

Telephone: 732/469-4057

Fax: 732/764-9747

Email: pilato-consulting@worldnet.att.ne

Srinivasa Raghavan

Univ. of Maryland

Dept. of Chem Engineering, Bldg. 090

College Park, MD 20742 USA

Telephone: 301/405-8164

Email: sraghava@eng.umd.edu

Asif Rasheed

Univ. of Tennessee

Dept. of Chemistry

Knoxville, TN 37996 USA

Telephone: 865/974-6596

Email: arasheed@utk.edu

Kim Rasmussen

Los Alamos National Laboratory

Theoretical Div.

MS-B262

Los Alamos, NM 87545 USA

Telephone: 505/665-3851

Fax: 505/665-4063

Email: kor@lanl.gov

Robert Reitz

Dupont Co.

Experimental Station, Bldg. 310

Wilmington, DE 19880 USA

Telephone: 302/695-2182

Fax: 302/675-1513

Email: robert.r.reitz@usa.dupont.com
Paul Rice

NIST

325 Broadway

Boulder, CO 80305-3328 USA

Telephone: 303/497-7601

Fax: 303/497-5030

Email: paulrice@boulder.nist.gov

Stephanie Scierka

NIST

100 Bureau Dr., Mail Stop 8621

Gaithersburg, MD 20899-8621 USA

Telephone: 301/975-6448

Fax: 301/990-6891

Email: stephanie.scierka@nist.gov

John Shost

Congoleum Corp.

861 Sloan Ave.

P.O. Box 3127

Trenton, NJ 08619 USA

Telephone: 609/584-3347

Fax: 609/584-3333

Email: jshost@congoleum.com

Andrew Slifka

NIST

325 Broadway

Boulder, CO 80305 USA

Telephone: 303/497-3744

Fax: 303/497-5030

Email: slifka@boulder.nist.gov

James Smith

Univ. of Utah

12 S. Central Campu,. MSE Dept.

EMRO 304

Salt Lake City, UT 84112 USA

Telephone: $801 / 585-6131$

Fax: 801/581-4816

Email: jsmith@bede.coe.utah.edu

Chad Snyder

NIST

100 Bureau Dr., Mail Stop 8541

Gaithersburg, MD 20899-8541 USA

Telephone: $301 / 975-4526$

Fax $301 / 975-3928$

Email: chad.snyder@nist.gov 
Francis Starr

NIST

100 Bureau Dr., Mail Stop 8540

Gaithersburg, MD 20899-8540 USA

Telephone: 301/975-8359

Email: francis.starr@nist.gov

Li-Piin Sung

NIST

100 Bureau Dr., Mail Stop 8621

Gaithersburg, MD 20899-8621 USA

Telephone: 301/975-6737

Fax: 301/990-6891

Email: lipiin@nist.gov

Atsushi Takahara

Kyushu University

Hokozaki, Higashikm

Fukuoka, 812-8581 JAPAN

Telephone: 81/92 6422721

Fax: 81/92 6422715

Email: takahara@cstf.kyushu-u.ac.jp

Russell Thompson

Los Alamos National Laboratory

Theoretical Div.

MS B262

Los Alamos, NM 87545 USA

Telephone: 505/665-9283

Fax: 505/665-4063

Email: rthompson@lanl.gov

Richard Vaia

Air Force Research Laboratory

2941 P St.

AFRL/MLBP

WPAFB, OH 45433 USA

Telephone: 937/255-9184

Fax: 937/255-9158

Email: richard.vaia@wpafb.af.mil

Kevin Van Workum

Univ. of Wisconsin

Mark VanLandingham

NIST

100 Bureau Dr., Mail Stop 8621

Gaithersburg, MD 20899-8621 USA

Telephone: 301/975-4686

Fax: 301/990-6891

Email: mack.vanlandingham@nist.gov
Noel Vanier

PPG Industries, Inc.

4325 Rosanna Dr.

Allison Park, PA 15101 USA

Telephone: $412 / 492-5640$

Fax: 412/492-5522

Email: vanier@ppg.com

Vedagiri Velpari

PPG Ind., Inc.

Guys Run Rd.

Pittsburgh, PA 15238 USA

Telephone: 412/820-4946

Fax: 412/820-4952

Email: velpari@ppg.com

Daike Wang

Milliken Research Corp.

920 Milliken Rd.

Spartanburg, SC 29334 USA

Telephone: 864/503-2793

Fax: 864/503-2793

Email: daike.wang@millliken.com

Howard Wang

NIST

100 Bureau Dr., Mail Stop 8543

Gaithersburg, MD 20899-8543 USA

Telephone: 301/975-6781

Email: wangh@nist.gov

J.B. Wright

U.S. Army SBCCOM

Kansas St.

Natick, MA 01760 USA

Telephone: 508/233-6313

Fax: 508/233-5521

Email: jeffery.wright@natick.army.mil

Jusong Xia

Milliken Chemical

920 Milliken Rd., M-401

Spartanburg, SC 29304 USA

Telephone: 864/503-6055

Fax: 864/503-1365

Email: jusong.xia@milliken.com 
Langqiu $\mathrm{Xu}$

PPG Industries, Inc.

Glass Technology Ctr.

P.O. Box 2844

Pittsburgh, PA 15230-2844 USA

Telephone: 412/820-4953

Fax: 412/820-4952

Email: lqxu@ppg.com

Xiaoping Yang

Goodyear Tire \& Rubber Co.

142 Goodyear Blvd.

Akron, OH 44305 USA

Telephone: 330/796-1325

Fax: 330/796-7060

Email: Xiaoping_Yang@goodyear.com

William Znidarsic

Univ. of Pennsylvania

4045 Baltimore Ave.

Apt C-1

Philadelphia, PA 19104 USA

Telephone: $215 / 662-7523$

Email:williamz@seas.upenn.edu 



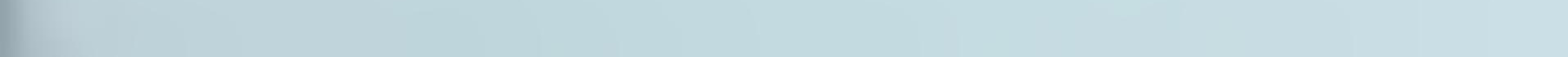


